


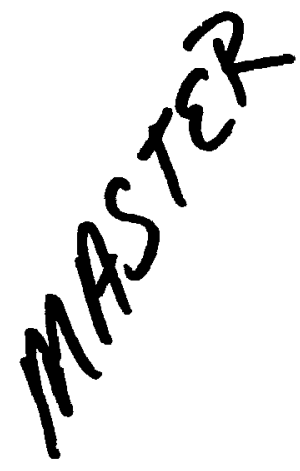

ORNL-5672

Distribution

Category UC-25

Contract No. $W-7405-e n g-26$

METALS AND CERAMICS DIIISION

METALS AND CERAMICS DIVISION MATEI:IALS SCIENCE PROCRAiI ANNUAL PROGRESS REPORT

FOR PERIOD ENDINC JUNE 30,1980

Compiled by

C. J. Mchargue, Manager, iaterials Sclence Program

Edited by

Sigfred Peterson

Date Published: October 1980

\footnotetext{
OAK RIDGE NATIONAL LABORATORY

Oak RIdge, Tennessee $\mathbf{3 7 8 3 0}$

operated by

UNION CARBIDE CORPORATIDN

for the

DEPARTMENT OF ENERGY
} 
CONTENTS

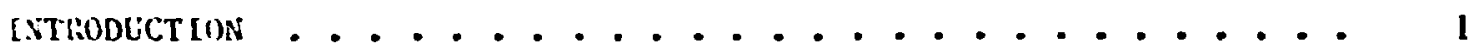

1. STRuCtuke of Metals - . . . . . . . . . . . . . . . . . . . 3

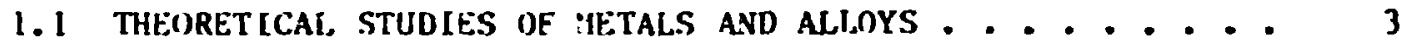

1.1.1 Alloy Theory . . . . . . . . . . . . . . . 4

l. l. l. Calculating Pruperties with the Coherent-Potential Approximation . . . . 7

1.1.1.2 First-Principles Band Theory for Random Metallic Alloys . . . . . . . 8

1.1.1.3 Aspects of the Numerical Solution of the KKR-CPA Equations......... 9

1.1.1.4 New Formulas for Calculating Proferties with the KKR-CPA: Algebraical ...... 10

1.1.1.5 Hew Formulas for Calculating Properties with the KKR-CPA: Vumerical . . . . . 10

1.1.1.6 Moment:um Distribution of Flectrons in Random Alloys: The Fermi Surface of $\mathrm{Ag}_{c} \mathrm{Pd}(1-c)$. N loys . . . . . . . . .

1.1.1.7 Total and Component Densities of states in the KKR-CPA and Average t-Matrix Approximation . . . . . . . .

1.1.1.8 Residuzl Resistivity of AgPd Mlloys . . . . . . . . . . . . . .

1.1.1.9 Soft $X$-Ray Emission trom Li-Mg and $I, i-A l$ Alloys and Comparisons with KKR-CPA Calculations . . . . . . 12

1.1.2 Fiectron-phonon Interactlons . . . . . . . . 13

1.1.2.I Upper Critical Field of Pure Niobiun: Calculated Temperature Dependence and Anisotropy ........

1.1.2.2 Filectronle Structure and the Electron-Phonon Interaction . . . . .

$\therefore 1.2 .3$ Solutions tu the Boltzmann Fquation for Flectrons in a Metal: Fnergy Dependence . . . . . . . . . . . . .

1.1.2.4 Calculation of the Anisotr.DIc Flectron-Phonon Mass Finhancement In Copper and Niobium . . . . . . .

1.1.2.5 Calculation of the low-Fteld thil Coefficlent in Copper ar.d Ninbium . . . 
1.1.2.6 Ideal Themal Conductivity of

Palladium and Niobium ........ 17

1.1.2.7 Exotic Pairing In Metals: Formalism

and Application to Niobium and

Palladiun ............... 17

1.1 .3 Surface Theory ................. 17

1.1.3.1 Localized Muffin-Tin Orbital Basis

for Atomic Cluster Calculations

Within the Local Density Formalism . . . 19

1.1.3.2 Calculation of the Multipole Potential

from an Arbitrary Localized Charge

Distribution ............ 20

1.2 i-RAY SCATTERING RESEARCH ............... 20

1.2.1 Polymer Research ................ 21

1.2.1.1 Temperature-Dependent Smal1-

Angle X-Ray Scattering From

Poly(Vinylidene Fluoride) ....... 21

1.2.1.2 Saall-Angle X-Ray Scattering From

Polybutene-1 Films Crystallized

from a Highly Extended Melt ....... 21

1.2.1.3 Annealing of Polypropylene Films

Crystallized From a Highily

Extended Melt ........... 22

1.2.1.4 The Kinetics of Defect Clustering in

Fibrillar Polypropylene Crystals .... 23

1.?.2 Irradiation Ef fects in Metals .......... 23

1.2.2.1 The Use of Small-Angle X-Ray and

Neutron Scattering for Characterizing

Voids in Neutron-Irradiatec Metals

and Alloys................. 23

1.2.2.2 A Small-Angle X-Ray Study of NeutronIrradiation Ef fects in Molybdenum and Molybdenum Alloys ........ 24

1.2.3 Facflity Development ............ 25

1.2.3.1 An Intelligent CAMAC I/O Module Based

on The Signetics $8 \times 300$ Microcontroller . . 25

1.2.3.2 The LASL-ORNL Fast Digital Data

Acquistion System ......... 25

1.2.3.3 A CAMAC Modular Programmable

Funct Ion Generator ......... 26

1.3 SYNTHESIS AND CHARACTERIZATION OF

STRUCTURAL CERAMICS ................. 
1.3.1 Barides and Other Hard Ceramics .........

1.3.1.1 Synthests, Characterization, and Properties of Diboride Ceranics . . . . 27

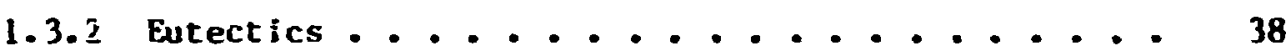

1.3.2. I Mathematical Modeing of Internal Zone Growth (IZG) and Electrical Conductivity

Tailoring of Compacts ........ 38

1.3.2.2 Oxygen Partial Pressure and Regular

Solution Model for Plase Equiltbrium

in Oxide-Metal Eutectic Systems .....

1.3.2.3 Chemical and Structural Considerations for Design of High-Strength Toughened Eutectics ........ 41

1.3.3 Growtt. of Single Crystals ............ 42

1.3.3.1 Czochralski Growth of Single-Crystal Fayalite $\left(\mathrm{Se}_{2} \mathrm{SiO}_{4}\right)$..........

1.3.3.2 Czochralski Growth of Single-Crystal Cehlenite $\left(\mathrm{Ca}_{2} \mathrm{Al}_{2} \mathrm{SiO}_{7}\right) \ldots . . . .$.

1.3.3.3 Flux Growth of $\mathrm{LaPO}_{4}$ (Monazite) Crystals Containing $\mathrm{Pu}, \mathrm{Np}, \mathrm{Am}$, and $\mathrm{Cm} \ldots 44$

1.3.3.4 Hydrothermal Growth of Quartz and other Phases ......... 44

1.4 ST sLICTURE OF COAL ................. 45

1.4.1 Techniques Based on Optical Microscopy ...... 45

1.4.1.1 Transmitted Infrared Light Microscopy: An Improved Method for Viewing Coal Thin Sections..........

1. 1.2 A Study of Elemental and Maceral Distribution in Crals of Difterent Paleoenvi ronments .........

1.4.1.: A Review of Advanced Coal Petrographic Methods in Characterizi. 18 and Assessing Coals for Utilization .....

J.4.2 Electrin .13tallography ............

1.4.2.1 High-Temperature Transmission Electron Microscope Studies of Coal ...... 47

1.4.2.2 TEM Characterization of Coals ..... 47

1.4.2.3 A New Improved st andard for Electron Probe Determination of Organic Sulfur in Fossil Fuels ........... 
1.5 TRANSFIJRMATIONS AND SHAPF MFMORY IFFEC.T

IN URANI'J alioYs . . . . . . . . . . . . . . . . . 48

1.5.1 A Phenomenolngical Study of the Shape Menory Effect (Sile) in Polycrystalline Uraniun-Niobium N Inys . . . . . . . . . . . . 49

1.6 X-RAY RESFARCH WITH SYNChROTRON RADLTTLON SOURCES . . . 50

1.6.l $X$-Raj Optics for Focusing and lonochrumatisation

of Synchrotron Radiation . . . . . . . . . . 53

1.6.1.1 X-Ray Yonochronator Ceometry for Focuslng Synchrotron Radiation Above $20 \mathrm{keV}$... . . . . . . . . 54

1.6.1.2 Some Things About $x$-Ray Optics for Synchrotron Radiation . . . . . . 54

1.6.1.3 Cenical Section Curved Crystals for Focusting Synchrotron Radiation... . . 55

1.6.2 Research Topics

1.6.2.1 Resonant X-Ray Auger Measurements . . . 55

1.6.2.2 Determination of the Cation SiteOccupation Parameter iru a Cobalt

Ferrite From Synchrotron-Radiation Deffraction Data . . . . . . . . . . 56

1.6.2.3 Atomic Distributions in Iron-Chromium Sigma Phases Quenched From Several

Temperatures . . . . . . . . . . 57

1.7 ANALYTICAL AND HIGH-VOLTAGE, F.LECTRON MICROSCOPY • • . . . 58

1.7.1 DefEraction .................... 59

1.7.1.1 Three-Dimenstonal Strain-Field Information in Convergent-Beam Elestron Diffraction Patterns............... 59

1.7.1.2. Microdiffraclion from Crystals Containing Defects.......... 60

1.7.2 Imagfng . . . . . . . . . . . . . . . . . 41

1.7.2.1 The Observation of "Dumbbell" tine Structure in $\langle 110\rangle$ Structure Images of Silicon ....... . . . . . . .

1.7.2.2 Achromatic Interference Effects in Lattice Images Pormed by UsIng High-Coherence Covergent-Beam Il Iumination . . . . . 63

1.7.2.3 Advantages of a Field Fmisston Gun for a Combined Analytical and High-Resolution Transinission Flectron Microscope . . . . 68

1.7.3 Electron Energy Los: Spectroscopy . . . . . . . 70 
1.7.j.l The Influence of Disfracting Conditions on Quantitative Electron Energy

Loss Spactrocopy ........... $7_{1}$

1.7.4 Mictochemical Analysis ........... 73

1.7.4.1 On the Limitations of X-Ray Microanalysis of Heterogeneous Specimens Using Analytical Electron Microscopy ........ 73

1.7.5 Applifcations ............. 73

1.7.5.1 Phase Identification Investigation in Silicon Nitride Ceranic Structural

Alloys ...............

1.7.5.2 The Intergranular Phase in Hot-Pressed Sflicon Nitride Alloys. I. Elewental Contosition ........... $8 \mathrm{i}$

1.7.5.3 The Intergranular Phase in Hot-Pres::ed Silicon Nitride Alloys. II. Evidence For Phase Separation and Crystallization ...........

1.7.5.4 Observations of Cas Bubhles in an Austenitic Stainless Steel Charged with ${ }^{3}$........... 82

1.7.5.5 Creep Microstructure of Ferritic $9 \mathrm{Cr}-1$ Mo Steel ........... 84

1.7.6 High-Voltage Etection Microscopy ........ 87

1.7.6.1 Image Recording System for High-Voltage Electrun Microscope Dynamic Studies . . 87

1.7.6.2 In Situ Deformation of Aluminum Alloys ..............

1.7.6.3 Low-Pressure In Situ Oxidation of Vanadium and $\mathrm{V}-20 \mathrm{Ti}$. . . . 89

1.7.6.4 HVEM In Situ Hydriding of Hydrogen Storage Materials .......,... 91

1.7.6.5 The Effect of Stacking Fault Energy on Sliding Wear Behavior of CopperAluminum Al loys ...........

1.7.6.6 Metal Surface Mnformation and Subsurface Defect Structure: A Microscopy Correlation Study . . . . . . . .

1.7.6.7 Catalog of Computer-Siaulated TRM Images of Small PCC and BCC Dislucation Lops 
2. Deforhation AND hechanical PROPERTIES . . . . . . . . 95

2.1 INTt.RGRANULAR FRACTURE . . . . . . . . . . . 96

2.1.1 Trace Element Ef fects in Creep Cavitation ..... 96

2.1.1.1 Studies on Nickel ........... 96

2.1.1.2 Studies on Type 304 Stainless Steel . . 99

2.1.2 Trace Element Ef fects on Vacancy Clustering

and Heterogenesus Kucleation of Micro'ivi's

During Various Therwomechanical Treatments .... 102

2.1.3 Creep Cavity Observation in

Nickel Alloys................. 104

2.1.4 Micrucavitfes and Their Ef fects on Ele:ated-

Temperature Hechanical Properties of

Austent:ic Stainless Steel .......... 107

2.1.5 Fracture luitiation at Grain Boundary.

Inclusions - Internal Stress Effects . . . . . 109

2.1.6 Low-Temperature Grafn Boundary Fracture ...... 111

2.1.6.1 Fracture Energy Measurements

in Fe-32 Si Bicrystals ......... 112

2.1.6.2 Grain Boundary Segregation and Intergranular Faflure ........ 112

2.1.6.3 Boron Segregation to Grain Boundaries and Improved Ductility in Pt-30 wt $\%$

$\mathrm{Rh}-8$ wt $z \mathrm{~W} \ldots . . . . . . . .113$

2.1.6.4 A Study of Graln Bounaary Enbrittlement in Cu-3F Al-1Z Si Using AES ...... 113

2.2 DEFORMATION MEChANTSMS . . . . . . . . . . 114

2.2.1 Anelastic Creep Recovery in Nickel ........ 114

2.2.2 Radius Dependence of the Sink Strength

of a Dislocation Lonp ............. 116

2.2.3 The Rolling and Recrystallization of (110)[11io]

Tantalum Single Crystals ........... 118

2.3 HYDROGEN IN METALS .................. liy

2.4 FACILITY DEJELOPMENT ................. 120

2.4.1 High Spatial Resolution AES ........... 120

2.4.2 High-Temperature Mechanical Testing Pacjlity . . 121

3. PHYSICAL PROPERTIES AND TRANSPJRT PHENOMENA . . . . . . . . 123

3.1 MeCHANISMS OF SURFACE AND SOLID-STATR REACTIONS . . . . 123

3.1.1 Sulfidation Studies ............. 124

3.1.1.1 Evolution of Scale Microstructure and

the Pressure Dependence of the

Sulfidation Rate of Iron........ 124 
3.1.1.2 Iron and Vacancy Diffusion

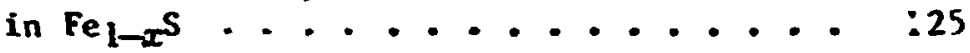

3.1 .2 Diffusion theory ............... 127

3.1.2.1 Diffusion in a Pure, High-Vacancy-

Content Crystal ........... 127

3.1.2.2 Thermodynamics and kinetics of Interstitial Diffusion in a Two-

Component System ........... 127

3.1.2.3 Site Blocking and Correlated Defect

Motion in Tracer and Chenical

Iffusion ............ 128

3.1.3 Alloy Oxidacion at Elevated Temperatures .... 129

3.1.3.1 The Oxidation of Zirconium

from 1098 to $1416^{\circ} \mathrm{C} \ldots \ldots 129$

3.1.3.2 Oxygen Diffusion and Dif fusion

Modeling in the Zirconfun-Oxygen

System ............... 130

3.1.3.3 Effects of Finite Specimen Geometry

on the Oxidation Kinetics of

Zircaloy $-4 \ldots . . . . . . . . . \mid 131$

3.1.3.4 Some Experiments and Calculations

Regarding the Ef fect of Specimen

Dimensions and Oxygen Solubility

on Oxidation Kinetics ........ 132

3.1.3.5 The Oxidation Kinetics or Zirconium

at $1000^{\circ} \mathrm{C} \ldots . . . . . . . . . .132$

3.1.3.6 Effects of the $M$ Toclinic-Tetragonal

Transformation on Oxidation Kinetics

of Zirconium .............

3.1.3.7 Oxidation of Zirconium in Oxygen and

Oxygen-Steam Mixtures ........ 134

3.1.3.8 A Comparison of the High-Temperature Oxidation Behavior 21rcaloy-4 and

Pure Zirconium . . . . . . . . 134

3.1.3.9 The Interaction of Stress and Mechanical

Property Ef

Tantalum-Base Alloys ......... 135

3.3.3.10 The Influence of Alloying Elements

on Oxygen Diffusion in Tantalum-

Base Nlloys ............ 136

3.1 .4 Diffusion in oxides ............. 136 
3.2 PHYSICAL PROPERTIES RESEARCH . . . . . . . . . . 137

3.2.1 Transport in Hetals ............... 137

3.2.1.1 Experimental Determination of the Phonon and Electron Components of the Theraal Conduct ivity of bec Iron ........ 137

3.2.1.2 Therwal Transport Properties of Niobium and Some Nioblum-Base Alloys from 80 to $1600 \mathrm{~K} \ldots . . . . . . . . .138$

3.2.i.3 Phonon Conductivity of IHobium ...... 138

3.2.1.4 The Theral Conductivity, Electrical Resistivity, and Seebeck Coeffictent of Skat-735 ............. 141

3.2.1.5 The Electrical Reststivity and Theraal Conduct ivity of Mobium-Titaniun Alloys at Low Tenperaturès ......... 142

3.2.1.6 Tantaium .............. 142

3.2.1.7 Measurements on A15 Compounds . . . . 142

3.2.1.8 Deviations from Matthiessen's Rule .... 143

3.2.2 Equipwent Developwent ............. 144

3.2.2.1 Anaiysis of Apparatus with Radial Symetry for Steady-State Measurements of Theraal Conductivity ....... 144

3.2.2.2 Multeproperty Apparatus ........ 144

3.2.2.3 The Themal Conductivity of Powders of Microspheres .......... 145

3.3 metastable materials . . . . . . . . . . . . 146

3.3.1 Summary of Completed Superconductivity

Experiments .............. 146

3.3.1.1 Evidence for Microstructural Effects Under Strain in Bronze Process Nb3Sn ... 146

3.3.1.2 Superconducting and Mechanical Properties of $\mathrm{Mh}_{3} \mathrm{Sn}$ Conductors Under Tensile Stress .......... 148

3.3.1.3 Plux PInning by Sall Perturbations In the Superconducting Order Parameter In Iype II Superconductors ........ 148

3.3.2 Equipment Development .............. 149

3.3.2.1 Arc-Hammer - Quenching Prom the Llquid State ............. 149

3.3.2.2 Melt Spinning Apparatus - Quenching Frow the liquid State ......... 
3.3.2.3 Vapor Deposition Apparatus:

Quenching From the Vapor State ..... 151

3.3.3 Qunching Rate Studies in the Arc-llaner

Apparatus ................ 152

3.3.4 Stability and Physical Properties of $\mathrm{T}_{5} \mathrm{~T}_{9}$ Amorphous Alloys ........... 157

3.3.5 Amorphous Superconductors ........... 157

3.3.5.1 Supercorductivity in Amrphous " ${ }^{-} \mathrm{T}_{5}-\mathrm{T}_{9}$ " Transiticn ifetal Alloys ....... 15

3.3.5.2 The Effects of Cold Roling on Fluxoid Pinning in a Superconducting ierallic

Glass ............ 159

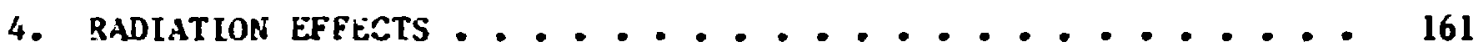

4. NeUtron Radiation EFfEctS ............... 162

4.1.1 Defect Structures in Neutron-Irradiation Iron ... 162

4.1.2 Microstructure and Tensile Properties of Heavily irradiated 5052-0 Aluminum Alloy .... 165

4.1.3 Grain Boundary Segregation and Radiation Effects ............ 167

4.2 Charged Particle radiation Effects ........... 169

4.2.1 Depth Profiles of Swelling in Ion-Boabarded ilickel .................... 169

4.2.2 Experimental Observations of Effects of Inert Gas on Cavity Formation During Irradiation ..................

4.2 .3 Comparing Simultaneous vs Preimplantation of Helfun in Rarlation Damage Simulation ...... 173

4.2 .4 Growth of Interstitial Loops in ElectronIrradiated Nickel .............. 178

4.2 .3 Precipitation of $\mathrm{Mo}_{2} \mathrm{C}$ in Nickel-:iolybdenum Alloys During High-Temperature Ion Irradiation Experiments ........... 181

4.2.6 Heavy-Ion Damage Structure in Ordered $\left(\mathrm{C}_{0.18} \mathrm{Fe}_{0.22}\right)_{3} \mathrm{~V}$ Alloy $\ldots . . . . . . .183$

4.2.7 Irradiation Creep Using Li',nt Ions ........ 197

4.3 THEORY AND MODELING ............................ 191

4.3.1 Effective Diffusion Coefficients of Point Defects in Impure Materials .......... 191

4.3.2 Applications of the Thaory of Cavity Growth to Dual-ion Swelling Experiments ....... 
xii

4.3.3 The Dependence on Cascade Size of Point Defect Fluctuations Calculated by Using the Cascate Diffusion Theory ......... 197

4.4 FACILITY DEVELOPIENT ANT NUCLEAR MLCROANALYSIS . . . . 200

4. . I Nuclear Microanalysts as a Probe of Inpurity-Defect Inceractions ......... 200

4.4.2 An Ion-Beas Technique for the Measurement of Deuteriem Diffusiur Coefficients .............. 201

4.4.3 Carbon Migration and Contanination Studies .... 202

4.4.4 Bean Shutters and Computer Automation of Target Chamber ileasurements ........ 203

5. ERGINEering Materials ................. 205

5.1 EROSION AND MEAR OF CERAMIES .............. 205

5.1.1 High-Strain-Rate Detcrantion ........ 206

5.1.1.1 Explosive Compartion and Microstructural Analysis of AlN, Amorphous $\mathrm{Si}_{3} \mathrm{~N}_{4}$, Boron, and $\mathrm{Al}_{2} \mathrm{O}_{3}$ Ceramics .......... 206

5.1.1.2 Observation of Dislocations and Twins in Explosively Compacted Alumina .... 206

5. .2 Erosion of Alumina ............ 207

5.2 FUNDAMENTALS OF WELDING AND JOINING ......... 207

5.2.I A Study of Ferrite iorphology in Austenitic Stainless steel Helds ........... ?09

5.2.2 Ferrite Content Variations in Austenitic Stainless Steel Multipass Helds . . . . . . 209

5.2.3 Structure of Austenftic Stainless Steel Laser Welds ................ 211

5.3 STUdiES IN NONDESTRUCTIVE EVALUATION .......... 212

6. THE HIGH TEMPERATURE MATERIALS LABORHTORY .......... 215

7. USERS GROUPS ........................ 217

7.1 SHARED RESEARCH EQUIPMENT PROGRAM (SHaRE) ........ 217

i.2 SMall-ANGle ScatTERING RESearch . . . . . . . . 219

7.3 ORNL-ORAII SYNCHROTRON LIGHT SOURCE USERS GROUP . . . . . 220 APPENDIX ....................... 223 ORGANIZATION CHART ......................... 257 


\section{INTRODLCTION}

The prog-iss and current status of the Materials Sciences Program (Office of Basic Energy Sciences! conductad in the Metals and Ceramics Division are reporced herein. These activities represent between onefifth and one- surth of the researcl: and development racried nut ia that division. An overview of the Division's program and 'ie role of thi? Materials Sciences Program in it are given in th? Metals and Cerwics Division Annual Progress -Report for the Period Ending June 30, 1980, ORNL-5670.

The shift 1r: emphasis from support of nuclear technologies to nonnuclear energy systems has cont nued. Because the Oak Ridge National Laboratory has emerged $z=$ a lead nat:onal laboratory in the fossil energy area, we have reoriented or initlated a nuber of tasks to a.dress the long-range problems assoct-ied with this energy source.

Two major changes have occurred in the Materials Sclence Program during this reporting period. Ihe stidies on oxidation of zirconium and refractory metals, diffusion in metals, and citium diffusion in oxides were replaced by research on the attack ot netals by sulfur. The level of effort on solidification of eutectics containing metals and metai oxides was decreased and a structural ceramics program was inteiated. The intial emphasts of the latter program is on the processing, structure, and properties of hard ceramics. Consideration of the supply of strategic matertals and the neads of energy systems determine the specific systems chosen for study.

Interactions with universities and other laboratories have continued to be an Important function of this program. Progress in establishing users groups and collaborative research programs 18 described in Cilaf. 7.

A section has been included on the progress made toward establishing a HIgh Temperature Materials Program at ORNL. This orogram is conducted In several divisions and Includes applied as well os basic activities. 


\section{STRUCTURE OF IEETALS}

1.l THEORETICAL STUdies OF HETALS AND ALloys - J. S. Faulkner

The unffying feature of this program is a mutual interest in certain theoretical techniques for studying the electronic states in condensed matter and in relating the properties of solids and surfaces to the electronic states. Techniques that have been invented by this group or that we have played a leading role in deve.oping are multiple-scattering thenry, constant-energy-search KKR band theory, discrete-variationalwethoa band thoory, theories of disordered solids, coherent potential approximation for substitutional alloys, cluster calculations, and layer calculations for surfaces. We are also involved heavily in investigating the applicability of the local density approach in one-electron calculations of total energies as well as other properties.

These and other techniques are used tu investigate certain phenomenological areas that are sufficiently diverse that it is useful to describe them separately. The ones that we are presently looking at follow.

Electron-Phonon Interacticns - Our studies in this area are based on our constant-energy-search KKR band theory techntques and also the rigldmuffin-tin approximation that was proposed by one of our collaborators. They lead to specific predictions that are used to explain and organize experimental measurements in the areas of superconductivity, hightemperature electical and thermal conductivity, and neutron diffraction.

Alloy Theory - We have been contrlbuting to the theory of disordered solids since the inception of thu theory group. Mucn of th:e theoretical data on the electronic states in real alloy systems that ts presently avallable to the scientific community is generated here. This work is used to explain the rasults of photoemission, soft $x$-ray, and positron annihilation experiments.

Surface Theory - This program is direrted to the theoretical study of the interaction of gases with metal surfaces. The goal is understanding the mechanisms operative in such surface phenomena as corrosion and catalysis on the basis of the underlying electronic structure. A thin-film energy band approach allows us to investigate the effects of clectron 
delocalization in the surface plane. Cluster programs of various levels of sophistication give us the capability of studying the interactions between surface and gas atoms for a wide range of configurations.

Band Theory - This group has been known for many years for its work on the multiple-scattering theory approach to band theory known as the KKR method. A recent trend in band theory is the development of linearized methods, which speed up the computational proress enough to significantly alter the kind of properties for whic.l calculations are feasible. Most of these linearized band theories are based on a hybrid multiple-scatteringvariational approach, but we have shown that even more useful equations can be obtained from a pure multipla scattering approach. We are presently investigating the possibility that a quadraticized band theory would have significant advantuges over a linearized one.

Our progress in these phenomenological are ss is described in wore detall below.

\subsubsection{Alloy Theory - G. M. Stocks and J. S. Faulkner}

The major theoretical advance of this reporting period is a new method. for calculating the properties of random alloys from the solutions of the KXR-CPA equations. The method is based on newly derived formulas for the average Green's function and was proved to be necessary by the discovery of unphysical behavfor in a Bloch spectral density function, which was calculated according to the formula currently available. The new method provides the necessary theoretical framework for calculating many observables that had previously been zapossible to deal with. We are presently calculating the momentum dinsity $N(\bar{p})$, which is used to Interpret position annihilation studies of the Fermi surfaces of random alloys. The new method provides the basis for a critical review of existing formulas for calculating total and component densities of states in the muffin-tin version of the average $t$-matrix approximation, and they have all turned out to be incorrect.

We calculated the concentration depeidence of the residual resistvity of $A_{g} c^{P d}(1-c)$ alloys entirely from first principles (Fig. 1.1). The calculations reproduce the large asymetry in the experimertal data and 


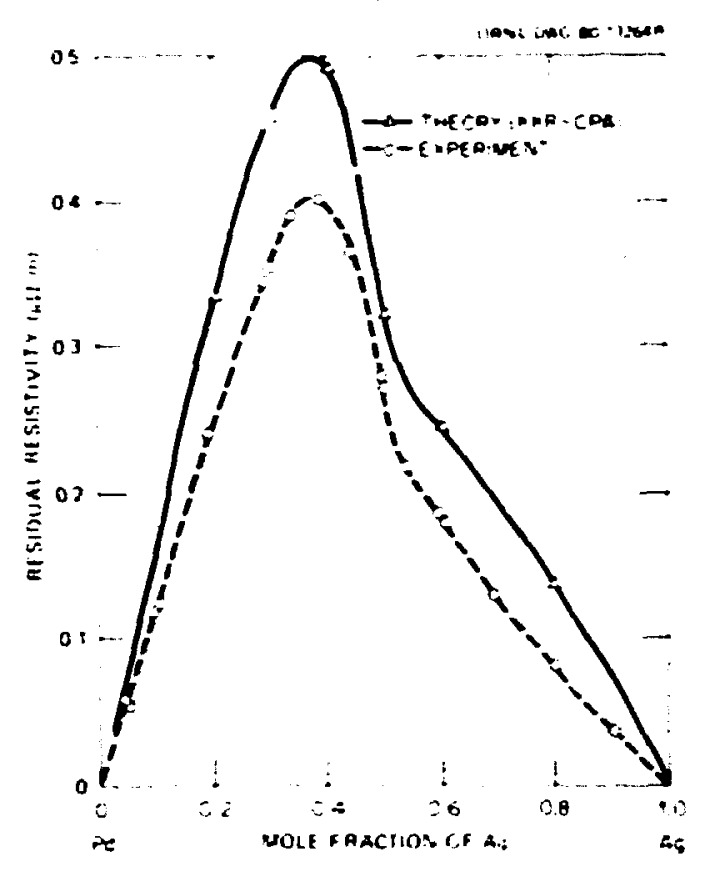

F1g. 1.1. Residual Resistivity of $A c_{c} c^{\mathrm{Pd}}(1-c)$ Alloys. The experimental results were taken variously from $B$. R. Coles and J. C. Taylor, Proc. R. Soc. London Ser. A 267: 139 (1962); W.R.C. Kemp et al., Proc. R. Soc. London Ser. A 233: 480 (1956); and R. Fletcher and D. Greig, Philos. Mag. 17: 21 (1968).

are off by only about $30 \%$ for the magnitude. The concentrations dependence of the residual resistivity in $\mathrm{AB}_{c} \mathrm{Pd}(1-c)$ alloys was one of the cornerstones on which Mott's "rizid band" model of electronic states in random alloys and his "sd" model of electrical transport in random alloys were buflt. Both these models have had enormous influence on the thinking of metallurgists and solid state physicists over the last 45 years. Our calculations show "rigid band" modt . and the "sd" model to be invalid even for the system for which they were first developed.

Although both lithtum and magnesium belong to the class of "simple" metals, the effects of alloying on the densities of states, as monitored by soft $x$-ray studies, are quite dramatic. The magnesium $L$ emission suggests 1 that as the conceniration of magnesium is reduced the density $c$. states on the magnesium sites is increasingly peaked at low energies. We

1J. A. Tagle, E. T. Arkawa, and T. A. Calcott, Physical Review (In pressi. 
have calculated the densities of states shown in Fig. 1.2 ising the KKR-CPA wethod and find that the total density of states in the alloy is rather free-electron-1ike. However, the f-density of states on the sium sites (which is being prob d in the magnesium $L$ spectrum) is peaked at the bottom of the lithium band. This low-energy peaking results from an incipient o-wave resonance in the magnesium muffin-tin potential. In Fig. 1.3 we compare our calculated $L I K$ and $\mathrm{Mg}$ I soft $x$-ray spectra with experiment. This good agreenent could never have been outalned with psoudopizential theory, which has hitherto been suggested as the best way to treat simple met.als.

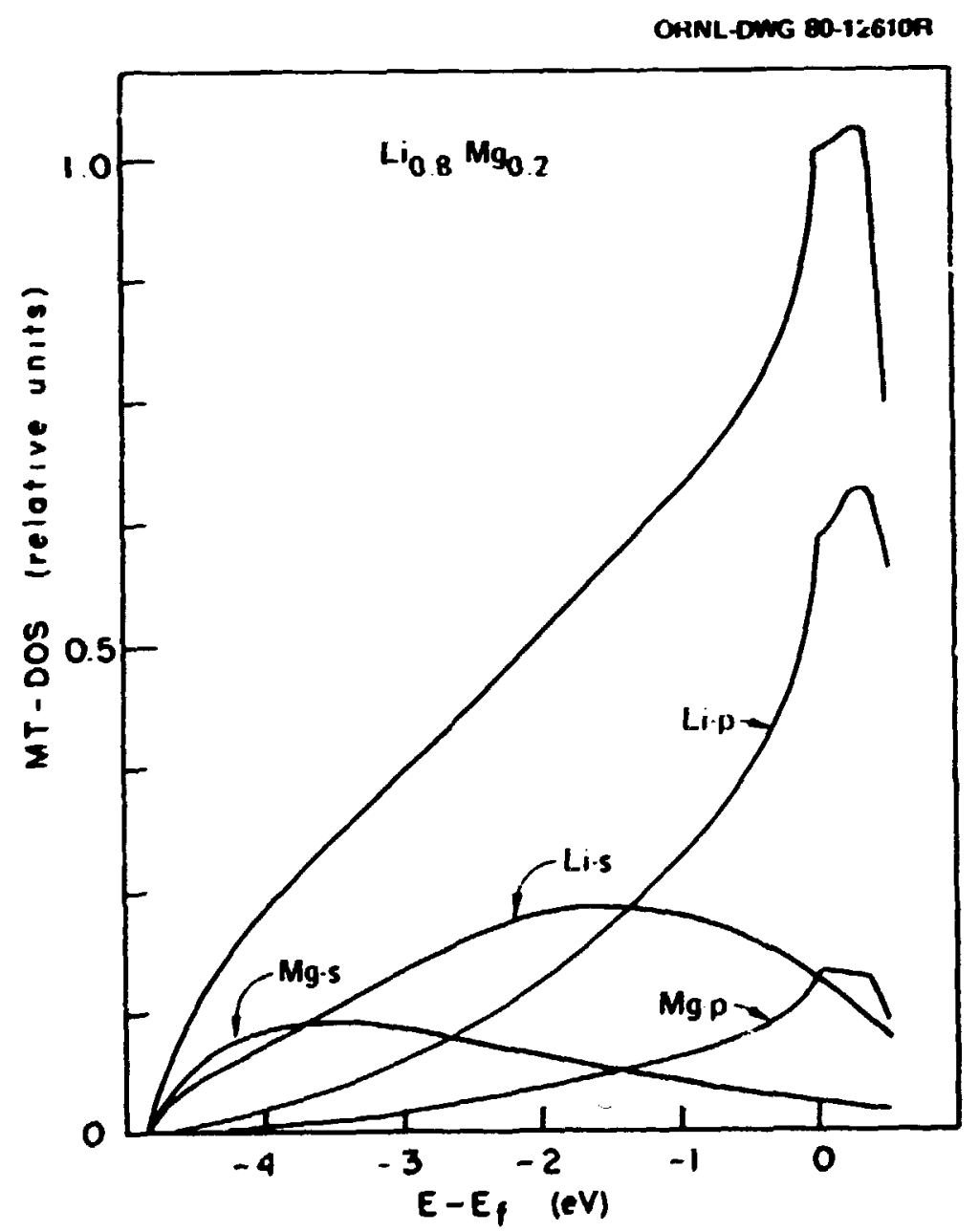

918. $: .2$. Total and Component Densities of States of an $\mathrm{LI}_{0.8} \mathrm{M}_{\mathrm{B}} \mathrm{O.2}$ Alloy. The outer curve gives the total density of states; the varlous specles and symetry decomposed densities of states are marked in a selfexplanatory notation. 


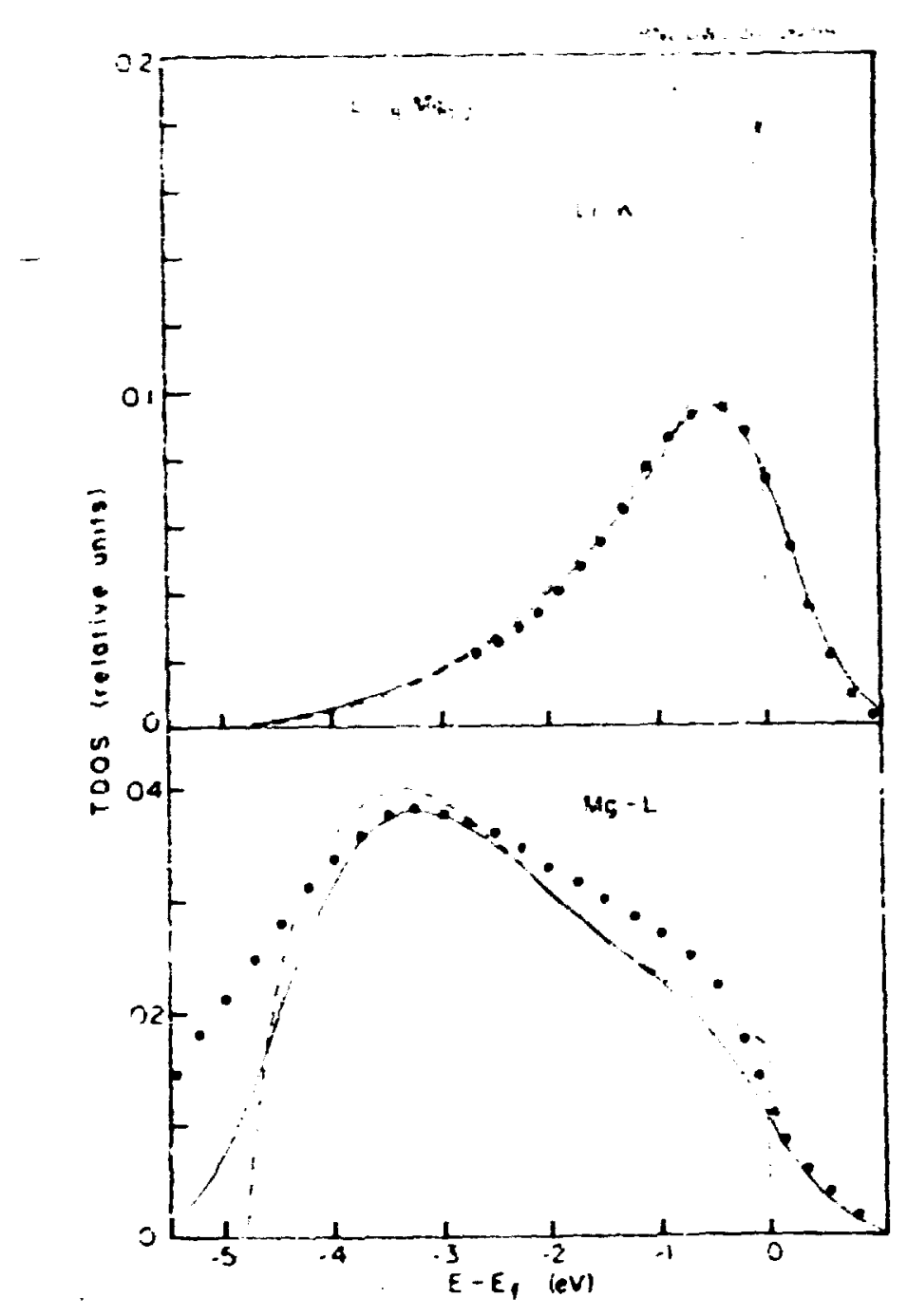

Fig. I.3 ra! iulated and ileasured Soft X-kay Spectra of an Li, $i_{1} .8: \lg _{0} .2$ Allny. The solid line gives the theoretical prediction, the dots give the measured spectra. The dash line gives the theoretical curve before broadening with a $0.5-\mathrm{eV}$ Caussian to account for core hole lifetimes.

1.1.1.1 Calculating Properties with the Coherent-Potencial Approximation 2 - J. S. Faulkner and G. M. Stocks

It is demongtrated that the expression that has hitherto been used for calculating the Bloch spectral-density function $A^{B}(B, \vec{k})$ in the Korringa-Kohn-Rostoker coherent-potent Lal-approximatirn theory of alloys

2Abstract of paper published in Phys. Rev. B 21: 3222-44 (Apt11 1980). 
ieads to manifesily unphysical results. No manipulation of the expression can elimirate this behavior. We develop an averaged Green's-function formulation and from it derive a new expression for $A^{B}(E, \vec{k})$, which does not contain unphysical fealures. The earlier expression for $A^{B}(E, \vec{k})$ was suggested as plausible on the basis that it is a spectral decomposizion of the Lloyd formula. Expressions for many other properties of alloys have been obtained by manipulations of the Lloyd formula, and it is now clear that all such expressions mist be consideref suspect. It is shown by numerical and algetraic comparisois that some of the expressions obtained in this way are equivalent to the ones ubiained from a Green's function, while others are not. In addition to studying these questions, the averaged creen's function formulation developed in this paper is shown to furnish an interesting niw way to approach many problems in alloy theory. The methoi is described in such a way that the aspects of the formulation that arise from the single-site approximation can be distinguished from those that depend on a specific cholce for the effective scatterer.

1.1.1.2 First-Principles Band Theory for Random Metallic Alloys ${ }^{3}-$ D I.. Gyorffy a:d G. M. Stocks

We desaribe and idrocate is first-principles approach to the problem of calcuiating islectronic states in random substitutional alloys. He begin by reviewing wie three major elements in the band-theory program for pure metals and alloys; that is, specification of the one-electron potential function, solution of the Schrödinger equation, and calculation of observablcs. The coherent-potential approximation (CPA) as a method for dealing with Hamiliconians having random potentials is motivated through the analogous problem of the conductivity of an inhomogeneous conductor. We then give a detalled description of the CPA for the case of interest,

\footnotetext{
${ }^{3}$ Prologue to lecture notes published in Electrons in Disomdered Metals and at Metallic Surfaces, P. Phariseau, B. L. Gyorffy, and L. Schelre, eds., Plenum Yress, New York and London, 1979, PP. 89-192. 4University of Bristol, Bristol, U.K.
} 
namely, the calculation of the electronic states of randons substitutio:al alloys for a weffin-tin model of the crystzl potential function. For this so-called KKR-CPA (Korringa-Kohn-Rostoker-CPA) we describe che specification of the uffin-tin potential functions appropriate to the alloyinb spectes, the evol-ition of the mothods used to solve the KKR-CPA equations, the nature of che solutions, and the calculation of certain observables. Results for che $\mathrm{Cu} \mathrm{C}^{\mathrm{NI}}(1-\mathrm{d})$ alloy systen illustrate the physical content of the theory. Using the gloch spectral density, we show how the effects of alloying manifest thenselves in the band structure of the alloy. Again using the Bloch spectral density function, the evolution of the alloy Fermi surface as a function of concentration is followed. In order to illustrate the detalled contact that can be made between the ab-initio KKR-CPA alloy theory and experiment, we focus on soft $x$-ray spectroscopy. The one-electron theory of soft $x$-ray emisition and absorption in a randow ailoy is presented. Calculations of the $L_{23}$ emission spectra for Cu $\mathrm{CiI}_{1-C}$ are compared with the recent experiwenta: zesults of Durham et al. 5 In conclusion, some possible future developments are speculated upon, including the implementation of charge self-consistency, development of a spin polarized theory, calculation of total energles, and calculation of electron-phonon coupling.

1.1.1.3 Aspect; or the Numerical Solution of the XKR-CPA Equations ${ }^{6}-$ C. H. Stocks, H. M. Temerman, 4 and B. L. Gyor f $f y^{4}$

We review sone of the difficulties encountered in the solution of the KKR-CPA equations and the numerical techniques developed to overcome them. We begin by setting out the KXR-CPA and briefly reviewing the band theory prograx for tandod alloys. The naturs of the difficulties encountered in solving the KKR-CPA equations is detalled. The numerical techniques

SP. J. Durhan, D. Chaleb, B. L. Cyorffy, C. F. Hague, J-M. Martor, C. M. Stoiks, and W. M. Temerman, "Soft $X$ Ray Eaission and the Local Densities of States in Cu-N1 Alloys," J. Phys. F. 9(8): 1719-30 (Auguse 1979).

6 Abstract from lecture notes published in Electrons in Disomdered Metals and at Metallic Surfaces, P. Phariteau, B. L. Gyorffy, and L. Schelre, eds., Plenum Press, New York and London, 1979, PP. 193-222. 
developed for the efficient evaluation of the KKR structure cunstants requiced ia the caliulation, for petforaing the necessiry brillowia zune integrations, and for iterating the KKK-CPA equation are preserised.

1.1.1.4 Siew formulas for Calculating Properties with the KKR-CPA: Algebraical ${ }^{7}$ - J. S. Faulkner and 6. :l. Stocks

The expression that has hicherto ineen ised for cialculating the Bl.,.!. spectral densicy function $A^{D}(\vec{r}, \vec{k})$ bas been foumi io lead to manifescly unphysical results. He aevelop an averaged Greva's function formulation and from it decive a new expression for $A^{R}(E, \vec{k})$, whiol elininates the unphysical features. The earlier expression for $A^{B}(E, \vec{k})$ was derived hy manipulating the Lloyd formuld. Lany other expressions for properties have been obtained in chis way, and they must be consi:. red suspect. It is show'n algebraically chat the Gyorffy-Stocics formula for the density of states is equivalent (u) che Green's-function formula, but mist other expressions derived from the Lloyd formula are not equivalent. The axpressions obtained from our averaged Green's function are casier co apply for mis purposes.

1.1.1.5 dew formulis for Calculiting Properties with the KKR-CPA: Vure rical ${ }^{7}-$ G. M. Stocks and .I. S. Faulkner

We show that for che $d_{c} P d(1-c)$ allny system, the existing formula for the Bloch spectral density $A^{\beta}(F, \vec{k})$ within the KKH-CPA gives negative values over a range of energles $E$ and wave vectors $\vec{k}$. It is : :hown that this is not a numerlcal convergence problem; rather, it is a general problem associaced wich singularicles of the inverse of the single-gite tmatclces of the consticuent spectes. We show that the new formula for $A^{R}(F, \vec{k})$ of Faulkner and Scocks does not have this unphyslcal behavlor and that 111 che scructures in $A^{R}(E, \vec{k})$ can be understood in terms of states of

${ }^{7}$ Abstract of a paper presented at the March Meeting of the American Physical Soclety, New Yorl:, March 24-28, 1980. 
the disordered alloy. Results for the total densities of stites of $\mathrm{Cu}_{e^{N i}(1-r)}$ alloys are shown, which support our al ine Green's-function formulas and the Gyorffy-Stocks formula are equivalent. He also show component densities of states ba. ed on wur Green's-function forvulas. He beileve this to be the first totally satisfactory KKR-CPA calculation of component densit les of states.

1.1.1.6 Momentur Distribution of Electrons in Random N.loys: The ferai

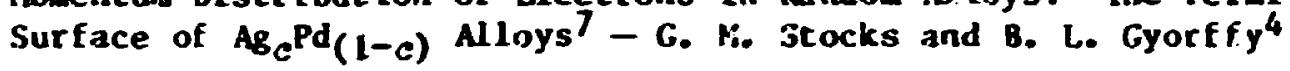

We derive an expression for calculating the wonentum distribution function, $N(\vec{p})$, in randow substitutional alloys within the framework of the first-principles KKR-CPA (Korringa-Kohn-Rostoker Coherent-PotentialApproximation) wethod. The formula is derived iy using the wethods of calculating observables in the KKR-CPA proposed by Faulkner and Stocks (Sect. 1.1.1.1) and tavolves no approximations beyond those inherent in the KKR-CPA. We show calculations of $N(\vec{p})$ for an $\mathbf{B B O}_{0.2} \mathbf{P d}_{0.8}$ random alloy, whlch show structure resulting from a well defined "r-centered" sheet of Fermi surface and from inciplent $X$-centered "ellipses" and a multiply cunnected "jungle-gym." The implications of these results for positron annihilation experiments in random alloys are discussed.

1.1.1.7 Total and Component Densities of States in the KXR-CPA and Average t-Matrix Approxination - A. Conis 8 and G. M. Stocks

We use the one-dimensional muffin-tin Korringa-Kohn-Rostoker wodel of Butler to investigate the equivalence or otherwise of varlous formulas that have been proposed for calculating propertles wthln the KKR-CPA aud within the average $t$-matrix approximation. The previously proposed formulas for component densities of states based on Lloyd formula derfvations and those based on a proper Green's function formulation are not equivalent. For the ATA, all the Lloyd-formula-based equations for calculating densities of states that are currently in use can lead to pathological results, while the corresponding Green's-function-based formulas lead to physically sensible results.

\footnotetext{
${ }^{8}$ Argonne Natlonal Laboratory, Argonne, Illinols.
} 
1.1.1.8 Residual Resistivity of AgPd Mlloys ${ }^{7}-$ G. M. Stock: and H. H. But let

He have calculated the residual resistivities of $\mathrm{AB}_{\mathrm{C}} \mathrm{Pd}_{(1-c)}$ alloys for $0<c<1$ from first principles using no adjustable parameters. In these alloys, the $\mathrm{r}$-centered sheet of the ferm surface aintains its integrity throughoit the concentration range. Since this sheet provides the dominant contribution to the curtent, the residual resistivity is determined by the impurity lifetises and the velocities of the electrons on this sheet. He have calculated these lifetimes and velocities using the $a b$-initio KKR-CPA band theory method for random alloys. Results for $\mathrm{ABg}_{0.8} \mathrm{Pd}_{0.2}$ and $\mathrm{AB}_{0.2^{\mathrm{Pd}}} 0.8$ agree with experiment.

1.1.1.9 Soft X-Ray Enission frow Li-ilg and Li-Al Alloys and Comparisons with KKR-CPA Calculations ${ }^{9}-$ T. A. Callcott, 10,11 J. A. Tagle 10,12 E. T. Arakawa ${ }^{10}$ and G. M. Stocks

The $K$-emission band of $L I$ and the $L_{23}$ enission bands of $M g$ and $A 1$ have been measured for $\mathrm{LI}-\mathrm{Mg}$ and $\mathrm{Li}-\mathrm{Al}$ prepared in a range of concentrations by either coevaporation or by evaporating thin films of $L I$ on $\mathrm{Mg}(\mathrm{Al})$ substrates or $\mathrm{Mg}(\mathrm{Al})$ on $\mathrm{LI}$ substrates. The LI $K$ spectrum is nedrly unchanged at all alloy concentrations in the LI-Mg system but broadens and develops a low-energy shoulder for large Al concentrations in the Li-AI system. Both $\mathrm{Mg}$ and $\mathrm{Al} L_{23}$ spectra are narrower and more peaked at low energy in the equilibrium alloys than in the pure metals. The "many-body" threshold peaks on the $\mathrm{Al}$ and $\mathrm{Kg} \mathrm{L}_{23}$ spectra are generally suppressed by alloying wth Li, except for low-temperature coevaporated LI-Al samples, where the peak persists to very Li-rich alloys. Data for a LI-20 at. I Mg alloy are compared with KKR-CPA calculations, and good agreenent is found for both the LI $K$ spectrum and the $M_{B} L$ apectrum.

9 Abstract of invited paper for Sixth International conference on Vacuun Ultraviolet Physics. To be published in Joumal of Applied Physics.

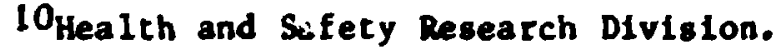

1 Department of Physics, University of Tennessee, Knoxville.

12 Departanento de Pisica Pundamental and Insticuto de Pisica del Estado Solido (SCIC), Universidad Autonoma, Madrid, Spain. 


\subsection{2 Ëlectron-Phonon Interactions - W. H. Butler}

During the past two years, we have ade substantial progress in understanding the electrical and thermai resistivities of transition netals. Extensions of the iheoretical and computational techniques that we earlier applied to superconductivity in the transition metals have enabled us to solve the Boltzann equation (which governs transport) raking full account of the anisotropy of the Fermi surface and of the electron-phonon atrix elements. We obtain good agreement between theory and experiment without having to resort to adjustable parameters, as our results for nioblum and palladium in Fig 1.4 Hlustrace. This agreement gives us added confideace in the techniques that we use to generate the electron-phonon atrix elements, which are central to the calculation of the superconducting transition temperature.

We expect our work to have a significant inpact on the way experimentalists analyze transport data. Typically, a simple wodel of the electronic atructure is used to explain the low-temperature resistivity of transition metals. This model assumes that there are two types of electronic states at the Ferai energy, " 8 " states, which have a high velucity and carry wost of the current, and " $d$ " states, which have a

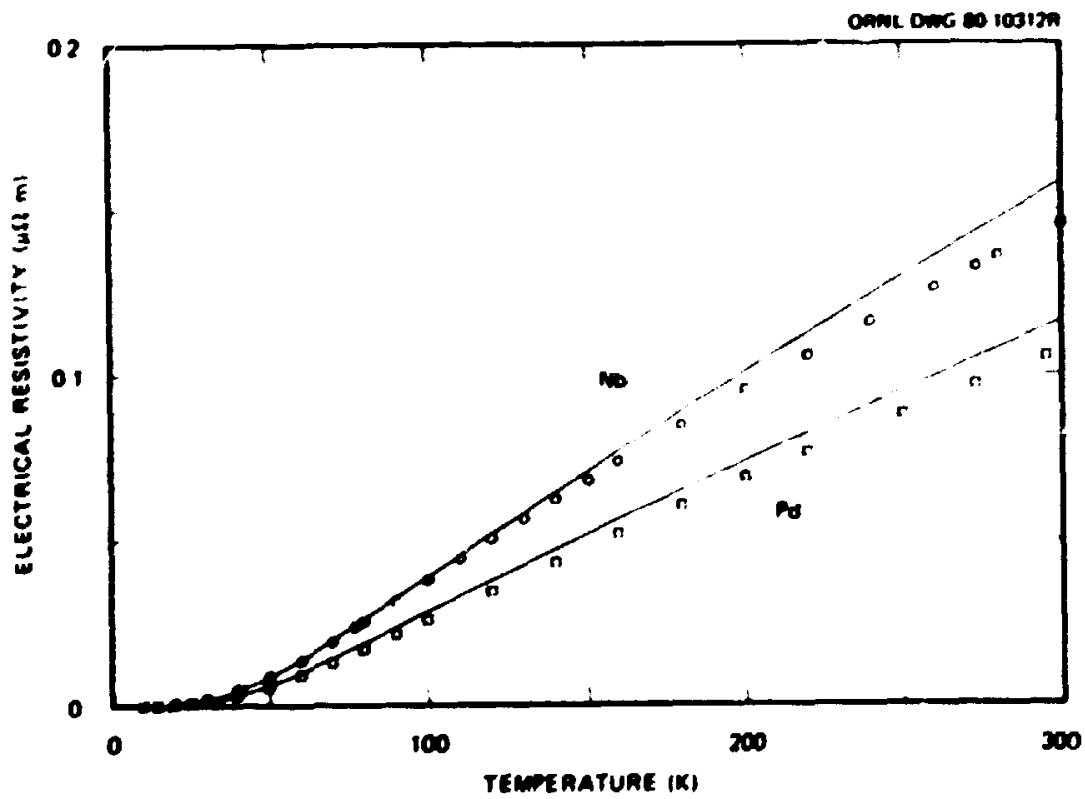

Fig. 1.4. Electrical Resistivity of Nlobium and of Palladiun. The solid lines are results of first-principles calculations using no adjustable paraneters. The circles and squares are experimental values for niobium and palladiun, respectively. 
relatively low velocity. The low-temperature experimental resistivity is fit to an expression of the form $\rho(T)=4+3 T^{2}+C T^{3}+D T^{5}$, where the four terms are assumed to arise from: $A$, impurity scattering; $B T^{2}$, electron-electron scattering; $C T^{3}$, " s to $d$ electron-phonon scattering (where the electron is scattered between an 6 state and a $d$ state; $D T^{5}$, - 6 to $6^{\prime \prime}$ electron-phonon scattering. The particular power law dependences of the various scattering processes result from furthcr assumptions about the nature of the solution to the Boltzmann equation. Our work shows these assumptions to be seriously in error ar che typical analysis of the data to be misleading. The electron-phonon contribution to the resistivity is much wore romplicated than had been supposed. It is, however, anenable to theoretical analysis and provides much useful information if properly analyzed. Our research program has benefitted from interactions with P. B. Allen of the Stale University of New York at Stony Brook and from the assignment to ORNL of F. J. Pinski and T. P. Beaulac of that university. It has also benef tced from interactions with members of several experimental groups, es,ectally R. K. Williams of the Physical Properties group.

\subsubsection{Upper Critical Field of Pure Nioblum: Calculated Temperature Dependence and Anisotropy 7,13 - K. H. Butler}

The upper critical field, $H_{c 2}$, uf niobium was calculated as a function of field direction and temperature caking into account Fermi velocity anisotropy, finite mean free path effects, and strong coupling effects. The calculations use an accurate niobium fermi surfaze and no adjustable parameters. Agreement with experiment is excellent for the magnitude, temperature dependence, and anisotropy of $H_{\mathrm{C} 2}$, and the deviation of its temperature dependence from that calculated by Hohenberg and Werthamer is due primarily to the anisotropy of the Fermi velocity. Anisotropies in $H_{c 2}$ previously ascribed to gap anisotropy are found to result from ferwi velocity anisotropy instead. Strong coupling effects enhance $H_{c z}$ in niobium by a factor that is approximately independent of temperature and is appioximately 1.10. Implications of this work for the $H_{c 2}$ of A-15 materials is briefly discussed.

$13_{A}$ papc - on this subject has been published by W. H. Butier, Phys. Rev. Lett. 44: 1516 (1980). 
1.1.2.2 Electronic Structure and the Electron-Phonon Interdction ${ }^{14}-$ H. H. But ler

The electron-phonon interaction affects the physical properties of metals in many ways. It causes, for example, electrical resistivily, electronic mass enhancement, superconductivity, phonon lifetimes, and phonon frequency shifts. Part I of this article relates all these piasical effects to the hasic elevtron-phonon interaction and emphasizes their intertelationships. Part II of the article discusses the theory of the electron-phonon matrix element for simple metals, cransition metals, ani transition metal compounds. The large variation in the electron-phonon irteraction between different materials is expiatned qualitatively.

\subsubsection{Solutions to the Boltzmann Equation for Electrons in a itetal: Energy Dependence 15 - F. J. Pinski ${ }^{16}$}

The solution to the Boltzmann equation for electrons in a metal is a distribution function that depends on energy and wave vector. This paper solves the energy dependence by expanding the distribution function : 1 sets of orthogonal Eunctions: (1) energy polynomials, (2) Legendre polynomials in $\tanh \left(\varepsilon_{k} / 2 k_{B} T\right)$, or (3) a combination of these two choices. To study only the effects of the energy dependence, the electrical and thermal conductivities were calculated for a class of isotropic models. For one of these models, the electrical resistivity is $37 \%$ Jower than the Bloct-Grueneisen result at a temperature of 0.15 (in units of the Debye cemperature, $\left.\theta_{D}\right)$. For thermal resistivity, this method is consistent with the result of Klemens; that 18 , at very low temperature the correction to the lowest order result is $51 \%$. Corrections are important at tomperatures as high as $0.3 \theta^{D}$. These results show that the standard - that is, simple

14 Abstract of a review article. to be published in Eiectronic Stmucture and Properties, F. Y. Pradin, ed., Academic Press.

15 Abstract of a paper published in Phys. Rev. B 21: 4380-88 (1980).

160n assignment from the Department of Physics, State University of New York, Stony Brook. 
variational - results for the temperature dependence of transport soefficients makc jignificant errurs. However, the methods of this paper can obtain accurat: asu's qu!te easily by computer, not only for simple isotropic mujels but ilso for realiscic metals. Results for transition metals are briefly mentloned; nore complete calculations will te presented el sewhere.

\subsubsection{Calculation of the Anisotropic Electron-Phonon Mass Enhancement} in Copper and Niobium 7 F. J. Pinski 16 and W. H. Butler

We have calculated the electron-phonon mass enliancement $\lambda_{k}$ in copper and niobium. We used accurate KKR wave functions calculated on a dense mesh of points on the Fermi surfaces. Phonon frequenctes and pelarizations were obtained from Born-von Kármán force constait: ifts to neutron data. Electron-phonon mix elements were calculated in the rigidmiffin-tin approximation. For copper we find $\lambda=\left\langle\lambda_{k}\right\rangle=0.11$ with an $\mathrm{ms}$ deviation of $14 \%$. The enhancement is highest near the necks, in qualitative agreement with interpretations of cyclotron-mass data. For niobium we find $\lambda=1.11$ with an ns deviation of $5 \%$. The calculated eninancements for nioblum differ substantially frow those inferred from de Has-van Aphen measurements.

1.1.2.5 Calculation of the 'N-Field Hall Coeffictent in Copper and
Niobium 7 - T. P. Beaulac, 16 P. B. Allen, 17 and F. J. Pinski 16

We have solved the linearized Boltzmann equation for electrons in a metal and in the presence of unfform electric and magnetic fields. In lowest order, the low-fleld Hall coefficient is given as a ratio of quantities that are expressible as averages over the Ferri surface. We used exact KKR wave functions on a dense mesh of aboist 500 wave vectors on the 1.redu:ible $1 / 48$ of the Fermi surface. Results for copper ar = whin $5 \%$ of experimental data at room temperature. Similar results are obtained for nioblum, for example, whthin $8 \%$ of experiment. These calculations afe free of all adjus:able parameters.

17 Department of Physics, State University of New York, Stony Brook. 
1.1.2.6 Ideal Thermal Conductivity of Palladium and Niobium 18 F. J. Pinski, 16 W. H. Eutler, and P. B. Allen 17

We have calculated the electron-phonon contribution to the therwal conductivity of palladium and niobium. The Boltzmann equaticn describes the electronic distribution function ir. the presence of a thr sal gradient. We solved the Boltzmann equation within the rigid-muffintin approximation, using a very dense mesh of first-principles Korringa-Kohn-Rostoker wave vectors on the Ferml surface. Phonon frequencies and polarizations were obtained from born-von kármán force-constant fits of neutron scattering data. The electron-phonon matrix elements were calculated by using the rigid-muffin-tin approximation. Our calculation is free of adjustable parameters. Agreement with experiment is at the $15 \%$ level at room temperature.

1.1.2.7 Exotic Pairing in Metals: Forwalism and Application to Niobfum and Palladium 19 W. H. Butler

In all known superconductors the pair-wave function is a singlet (antisymmetric in the electron spins and spatially symetric). Hore complicated pairing can occur in principle and has been predicted in pailadium. In this paper, a general formalism of $l>0$ pairing is developed, including the influence of impurities. Previous treatmerts of $Z>0$ palring assumed a spierically symmetric Fermi surface, which de find gives large errors in a metal like palladium. Prevlous treatments also overestimated the depression of $T_{c}$ due to impurities. Calculations of the electron-phonon $\Gamma_{15}$ ("p-wave") coupling constants for niobium and palladium suggest that exotic palring will be hard to observe in metals.

\subsubsection{Surface Theory - G. S. Painter}

Our major effort during the year has been to develop refined theoretical techniques for carrying out studles within a cluster framework,

18 Abstract of a paper presented at the International Thermal Conductivity Conference, proceedings to be published.

${ }^{19}$ Extended abstract of a paper presented at the La Jolla Conference on "Superconductivity in $t^{-}$and $f$-Band Metals," June 1980, procaedings to be published by Academic Press. 
which focuses on the local bording within a cluster of atoms. Our capabilities in this area are unique in that our discrete variation method (DVM) cluster techniques are directly related to those of our DVy energy band method so that localization effects can be obtained by correlating results from our energy-band and cluster studies of a given system.

We are continuing our studies of the precursor stages of aluminum oxidation (the molecular dissociation of $0_{2}$ ) in order to determine the basic mechanisms of ji-face-induced dissociation. There is an increasing amount of experimental data ${ }^{20-22}$ on well-characterized single crystal samples (Al 2p-core s'lifts, ExAFS determination of oxygen bond site, etc.), and our program will focus on relating the one-electron features for various bon's sites to experiment in order to assess the capabilities of the surface probe for identifying surface species. In this work an effictent "self-consistent-charge" procedure is used in which selfcorsistency is established in the charge density as determined through a ilullikan population analysis of the occupied states. While full selfconsistency is not attained (as in our localized muffin-tin orbital approach, below), we have a commensurate fincrease in capability to treat larger clusters. Thus, we are using this scheme for problems where higher accuracy is not reyuired.

A major project carried out in collaboration with J. llarris 23 was brought to a successful stage of completion this year. Our localized muffin-tin-orbital cluster approach represents a new level of completeness for carrying out fully self-consistent electronic structure and total energy calculations for atomic clusters. Dur present efforts involve completing calculations for selected dimers, investigating the accuracy of

20L. I. Johansson and J. Stohr, "Bonding of Oxygen on $\mathrm{Al}(111)$ : A Surface Extended X-Ray Absorption Fine-Structure Study." Phys. Rí." Lett. 43: 1882-85 (1979).

$2 I_{W}$. Eberhardt and F. J. HImpsel, "Dispersion and Symmetry of 0xygen-Induced Pands on Al(111)." Phys. Rev. Lett. 42: 1375-78 (i979).

22s. A. Flodström et al., "Ordered Oxygen Overidyer Assoclated with Chemisorption Stace on Al(111)." Phys. Rev. Lett. 40: 907-10 (1978) and references therein.

23Permanent address: Instltut für Festkörperforschung der Kerı.forschungsanlage, Jülich, FRG. 
various exchange-cortelation functionals, and further refining the accuracy of the approach (a paper describling one such refinement is sumaarized i.x Sect. 1.1.3.2). Mur goal in constructing this theoretical technique has been to optimize effictency and accuracy in order to calculate celiably tctal energies. Our future studies will exploit this capability and allow us to ascertain the predictive aspects af the density functional formalism. In another development, carried out in collaboration with F. W. Averill, 24 we have constructed a cluster approach based on Gaussian orbitals. This approach is currently being used to study various density functionals in applications to dimers. He plan to extend our wore elaborate cluster thods to treat the energeticg in our axygen-aluminum chemisorption studies. A. T. Fromold, Jr., 25 is an authority on the theory of meial oxidation, and he has jolned this program with the goal of establishing $a$ better link between quantum thenretical calculations, in which we have expertise, and the phenorsenological oxidation theories used in materials science.

1.1.3.1 Localized ituffin-Tin Orbital Basis for Atomic Cluster Calculations Within the Local Density Formalism 26 J. Harris 23 and G. S. Painter

A new approach for solving the Hohenbery-Kohn-Sham density functional equations for atomic clusters of moderate size and arbicrary symetry is described. A basis set is introduced in the spirit of the LCMTO (linf it combination of muffin-tin orbitals) method of Andersen with a $(\phi, \dot{\phi})$ form inside each atomi $=$ sphere. However, advantageous features of the conventional LCAO method are brought in by introducing only atomic-like orbital cails in the region outside the spheres. The "common- $x$ " approximation and cellular partitioning of the LCMTO approach are ahandoned; with this approach it becomes necessary to carry out some three-dimensional integrations. Techniques are introduced to allow all integrals contributing to the secular matrix and total energy to be evaluated elther

24ORAU Visiting Professor from Judson College, Elgin, Illinois.

${ }^{25}$ NSF Visiting Professor from Physics Department, Auburn University, Auburn, Alabama.

26 Abstract of a paper to be publlshed in Physical Review $B$. 
semianalytically or by the Gaussian integration of swooth functions. Preliminary results tor $\mathrm{H}_{2}$ and $\mathrm{O}_{2}$ dewonstrate the practicality of the scheme.

\subsubsection{Calculation of the itultipole Potential from an Arbitrary Localized Charge Distribution 27 - G. S. Painter}

A thod for solving Poisson's equation as a set of finite-difference equations is described for an arbitrary localized charge distribution expanded in a partial wave representation. The procedure is an extension of the widely used technique developed by Loucks for spherically syametric charge densities. In the present developeent, the higher partial wave components of the density lead to an $Z$-dependence in the boundary condictons and the finite-difference equations. The potential components for $l>0$ can be calculated recursively with the sane degree of accuracy and efficiency as for the $l=0$ case. This procedure requires the additiona' computational step of evaluating a one-dinensional integral of each density component to determine the multipole monent, required by the boundary condition at large $r$. Specific modifications required to adapt the Loucks technique for this more general charge density are described, and 11 lustrative results are given for a model density with components ${ }^{o_{L}}(r)=c_{\imath}{ }^{l} \exp \left(-\alpha_{\ell} r\right)$, wich can also be treated analytically.

\subsection{X-RAY SCATTERING RESEARCH - R. W. Hendricks}

The $x$-ray scattering research task has focused on small-angle $x$-ray scattering (SAXS) studies, During this reporting period a substantial effort was devoted to the $s$ ty of polymers. These studies were carried out in large part by collaboration with guest scientists attached to our group or by visfcors participating in the Users Group of the National Center for Small-Angle Scattering Research.

27 Abstract of a paper submitted to Physical Review B. 


\subsubsection{Polyoer Research}

\subsubsection{Teaperature-Dependent Sall-Argle $X$-Ray Scattering Fron Poly(Vinylidene Fluoride) 28 - J. M. Schultz, 29 J. S, Lin, R. W. Hendricks, R. R. Lagasse, 30 and R. G. Kepler 30}

$X$-ray scattering measurements over the angular range 2 to 30 arad are reported for a uniaxially oriented poly(viaylidene fluoride) film containing the phase I crystal polynorph. Eash intensity profile exhibits at about $10 \mathrm{mrad}$ an interference peak arisin; from quasi-periodic variation in electron density between crystalline and amorphous phases of the polywer. Over the tenperature range 25 to $72^{\circ} \mathrm{C}$, reversible changes of $23 \%$ in peak intensity and $6 z$ in peak position are observed. These reversible changez in $x$-ray scattering are a.lalyzed in teras of a one-dimensional siack of alternating crystalline and anorphous layers. These odel calculations show that the observed changes in the interfetence peak cannot be explained solely by thermal expansion within the two phases. In accordance with previous studies on other semirrystalline polymers, this discrepancy between observed scattering results and the predictions for therwal expansion is taken to be evidence that the crystallinity changes reversibly over the investigated temperature range. This evidence for reversible crystal melting is consistent with a hypothesis proposed by Kepler and Anderson to explain the pyroelectric response of polarized phase I poly(vinylidene fluoride) films.

1.2.1.2 Small-Angle X-Ray Scattering From Polybutene-1 films Crystallized from a Highly Extended Melt 31 - J. Peterman, 32 J. M. Schultz, 29 R. W. Hendrt.cks, and J. S. Lin

In an experimental analog to many industrial processes, very thin $(0.1-0.2 \mu(\mathrm{m})$ polymer films have been produced under elongational strain

${ }^{28}$ Sumary of a paper to be published in Joumal of Applied Physics.

${ }^{29}$ On Assignment to ORNL during a leave from the University of Delaware, Newark.

${ }^{30}$ Sandia Laboratories, Albuquerque, New Mexico.

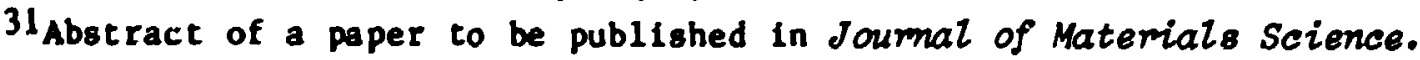
32Universität des Saarlandes, Saarbrücken, PRG. 
$r=$ zes of more than $10^{4} / \mathrm{s}$. The microstructure of these filas is this of considerable technological inportance. As is the case in most aterials science research, it is essential to characterize such filas with a variety of physical terhniques. These films are sufficiently thin to permit transmission electron microscopy, and the results of surh an investigation have been reported previously. In this companion paper, we present results of a swall-angle $x$-ray scattering (SAXS) investigation of the sane files.

\subsubsection{Annealing of Polypropylene Filas Crystallized frow a Highly Extented :ie $1 t^{33}$ - J. M. Schultz 29 J. S. Lin, R. W. Hendricks, J. Petermann, 32 and R. M. Cohil 32}

Thin films of isotactic polypropylene were drawn from the welt at a very high rate of extension. Transmission electron micrographs of this material reveal fibrous crystals lying along the draw direction. The chain axis and $f i b e r$ axis are identical. Dark-field microgro phs show a dark-light modulation along the fiber axis. Annealing at temperatures below $110^{\circ} \mathrm{C}$ produces no qualitative change in the electron afcroscope observations. Annealing between 110 and $150^{\circ} \mathrm{C}$ produces the gradual dominance of lamellar crystals oriented noimal to the draw direction. Data by SAXS exhibit a strong streaking normal to the fiber axis, in broad agreement with the observed fibrosity. A Bragg peak along the draw directions shows that the modulation observed microscopically is a density modulation. The absence of second-order maxima and the dependence of the SAXS peak on treatment temperature strongly suggest that the axial modulation 18 a spinodal decomposition of the material into crystalline and amorphous regions.

33Abstract of a paper to be published in Joumal of Polymer Science Polymer Physics Edition. 
1.2.1.4 The Kinetics of Defect Clustering in Fibrillar Polypropylene Crystals, 34 - J. Peteran, 32 J. Y. Schalex, 29 R. 1. Cohfl, 32 R. H. Hendricks, and J. S. Lin

Polypropy!ere filus wer? prisuced by sulfdification during high-rate $\left(>10^{4} / s\right)$ meli drawt-j. Sall-angle $x$-ray scattering (SAXs) data were collected during intercuptions of the annealing of these filas. Fibrillat crystallization took place during the melt-drawing process. The fibrils exhibli an axtal denstity modulation. Results of SAXS and transmission electron afcroscopy show that anealing increases the anplitude of the density maulation. Detailed exaatmation of the saxs curves shows that the modulation is approximately sinusoidal and that the amplification of the density wodulation occurs with no change in pertodictcy. Comparison of Suls curves taken at different times during annealing suggests a process similar to spinodal decomposition. It is proposed that the aicrostructural change within a fibril cakes place by the axial motion and clustering of chata defects.

\subsubsection{Irradiation Effects in Metals}

1.2.2.l The Use of Sall-Angle X-Ray and Neutron Scatcering for Characterizing Voids in ikutron-Irradiated Metals and Alloys 35 R. W. Hendricks

Saall-angle $x$-ray and neutron sca:tering techniques are powerful analycical tools for investigating long-rar.ge fluctuactons in electron ( $x$-rays) or mgnetic mont (neutron) tinsities in materials. In recent years they have ylelded valuable inforwation about volds, vold size distributions, and swelling in $\mathrm{N}, \mathrm{Al}$ alloys, $\mathrm{Cu}_{1}, \mathrm{Mo}, \mathrm{NI}, \mathrm{Ni}-\mathrm{Al}$ alloys, $\mathrm{Mb}, \mathrm{Mb}$ alloys, stainless steels, graphite, and SiC. In the case of aluminum inforwation concerning the shape o:: the voids and the ratio of

${ }^{34}$ Summary of paper to be suboticted to polymer.

${ }^{35}$ Sumary of a paper to be published In MS-AIME conference Proceedings, Advanced Techniques for the Chamaterization of Microstmucture. Conference held at Las Vegas, Nevada, February 24-28, 1980. 
specific surface energles was obtained. The technique of swall-angle scattering and its applifcation to the study of voids are reviewed in the paper. Emphasis is placed on the conditions that linit the applicability of the technique, the interpretation of the data, and a comparison of the results obtained with companion techniques such as transmisston electron microscopy and bulk density.

\subsubsection{A Srall-Angle X-Ray Scudy of Neutron-Irradiation Effects in Molybdenum and Molybdenum Alloys 35 - J. S. Lin, R. W. Hendricks, J. Bentley, and F. W. Wiften}

Small-angle $x$-ray scattering (SAXS) has been employed to study volds that were created by neutron irradiation in molybdenum and molybdenum alloys. Specimens of unalloyed wolybdenum and TZM (titanium-zirconfummolybdenum alloy) were irradiated tn the EBR-II at temperatures between 425 and $1000^{\circ} \mathrm{C}$ to fluences of $2.5 \times 10^{26}$ neutrons $/ \mathrm{m}^{2}(>0.1 \mathrm{MeV}$ ) or higher in one group, and in another group at temperatures between 600 and $1500^{\circ} \mathrm{C}$ with fluence of about $4.0 \times 10^{25}$ neutrons $/ \mathrm{m}^{2}$. The SAXS studies were performed on the ORNL 10-m camera using Ho Ka radiation. Companion transmission electron microscopy (TEM) was performed on the same specimens. Void sizes in the range from 5 to $20 \mathrm{~nm}$, size distributions, and swelling were determined from both the $x$-ray and TEM data. After correction for the fact that SAXS and TEM measure different moments of the void size distribution, the results from the two techniques were in general agreement; however, in some cases dislocation loops contributed significant $x$-ray scattering, which obscured vold scattering. In two bicrystal samples the diffraction maxima from an ordered vold lattice were observed. The vold lattice parameters (23 and $30.2 \mathrm{~nm}$, respectively) are in good agreement with the values obtained from the small-angle electron scatteriag in an electron microscope. 


\subsubsection{Facility Developoent}

1.2.3.1 An Intelligent CAMAC I/0 Hodule Based on the Signetics $8 \times 300$ Mic rocont roller 36 - G. W. Turner ${ }^{37}$ and R. W. Hendricks

An intelligent CAMAC $1 / 0$ module besed on the Signetics $8 \times 300$ mictocontroller has bzen developed. Sixteen 3-bit I/O ports have been utilized; efight are dedicated to data cransfers with excernal devices and/or processes and eight are dedicated to communication with the CAMAC dataway. Separate status and data registers are provided. The input status port (SIN) can receive up to seven individual signals from external devices or the host computer, while the output status port (SOUT) can be used to provide up to seven internally graded LAMs, and one bit can be used to generate a $Q$-response for termination of block transfers. Diagnostic sofiware has been developed to operate on the host computer and fully tests all implemented instructions. In our application the device is used in a high-speed memory mapping scheme for data acquisition with a two-dimensional position-sensitive detector syster.

1.2.3.2 The LASL-ORNL Fast Digital Data Acquisition System ${ }^{38}$ R. W. Hendricks, P. A. Seeger, ${ }^{39}$ J. W. Scheer, 39 and S. Suehiro 40

A data acquisition system for recording multiparameter digital data Into a large memory array at $1 \mathrm{MHz}$ is described. The system consists of a MOSTEK MK8600 2048K $\times$ 24-bit memory systew, I/O ports to various external devices including the CAMAC dataway, a memory incrementer, and a daisy chain of experiment-specific modules that calculate the memory address that is to be incremented. The design of the daisy chain permits multiple modules and provides for easy modification as experimental needs change. Several specific examples are described.

36Abstract of Nucl. Instmum. Methods 169: 373-80 (1980).

37 Instrumentation and Controls Division.

38 ALstract of ORNL/TM-7325 and LASL-8260-MS.

${ }^{39}$ Los Alamos Scientific Laboratory, New Mexico.

40polymer Research Institute, University of Massachusetts, Amherst, and on assignment to ORNL. Permanent address: Department of Polymer Chemistry, Paculty of Englneerlng, Kyoto University, Kyoto 606, Japan. 
1.2.3.3 A CAHAC Modular Programable Function Cenerator 41 - G. W. Turner, 37 S. Suehiro, 40 and R. W. Hendricks

A CAMAC wdular programable function generator has been developed. The device contains a 1024-word by 12-bit mory, a 12-bit digital-toanalog converter with a 600-ns settling time, an 18-bit programable frequency register, and two programable trigger output registers. The trigger registers can produce programed output logic transitions at various (binary) points in the output function cirve and are used to synchronize various other data acquisteton devires with the function curve.

1.3 SYNTHESIS AND CHARACTERITATION OF STRUCTURAI. CERAMICS - v. J. Tennety

A major part of this year's effort has been devoted to the prepara$t$ ion and characterization of hard ceramics based on $\mathrm{TiB}_{2}$ or $\mathrm{TiB}_{2}-\mathrm{CrB}_{2}$ solid solutions as model systems. This work has included fabrication studies in which nickel powder is blended with the diboride and hot-pressed at temperatures near its melting point to accomplish liquid-phase sintering. Reactions between the nickel and the boride result in a hard, erosion-resistant material. Particulate and coal slurry erosion cest daca on our first samples, obtained by the Albany Research Center (ARC) and tree Batcelle Columbus Laboratories (BCL), indicate that under certain conditions some of our experimental compositions have an erosion resistance comparable to or better than cobalt-bonded tungsten carbide. Additionally, specimens of these materials have been prepared as experimental cutting tools for use on steels and special alloys.

In anocher area, work has been done on the directional solidification of oxide-metal eutectics in the system $\mathrm{ZrO}_{2}\left(\mathrm{Y}_{3} \mathrm{O}_{3}\right)-\mathrm{Al}_{2} \mathrm{O}_{3}\left(\mathrm{Cr}_{2} \mathrm{O}_{3}\right)-\mathrm{Mo}$, and arrangements were completed for evaluation of these materials as abrastue grains for wetal grinding.

Payalite $\left(\mathrm{Pe}_{2} \mathrm{St}_{4}\right.$ ) crystals were grown and distributed to varlous laboratorles for property measurements. Gehlenite $\left(\mathrm{Ca}_{2} \mathrm{Al}_{2} \mathrm{S1O}_{7}\right)$ crystalgrowth work was completed, and flux growth of monazite $\left(\mathrm{LPOO}_{4}\right)$ crystals

41 Abstract of ORNL/ TM-7363. 
containing Np, Pu, An, and Ca was performed as part of an effort to evalwate this crystal as a possible radioactive waste host. Quartz crystals were also grown under a variecy of condittons to deceralne whether crystals of significantly higher electrical $Q$ can be produced.

\subsection{Borides and Otiner Hard Ceranics - V. J. Tennery}

During this period, a signiftcant part of our effort was devoted to the synthesis, fabrication, characterization, and evaluation of hotpressed boride ceraetcs of the worar composition $(1-y)\left(\mathrm{ri}_{1}-a^{C r_{a}} a_{2}\right)+y N i$ with $y=10,0.15$, and 0.20 and $a=0,0.2$, and 0.4 . These aterials constitute a wel system enabling study of the relationshifs between the aicrocomposition and aicrostructure of hard, erosion-resistant ceranic materials in which liquid-phase sintering plays an active role in densiffcation.

1.3.1.1 Synthesis, Characterization, and Properties of Diboride Ceramics - V. J. Tennery, G. H. Clark, C. B. Finch, J. D. Holder, and C. S. Yust

The transition wetal diborides $\mathrm{TiB}_{2}$ and $\mathrm{CrB}_{2}$ are each characterized by a high hatdness and high melling point. Because of thelt refractory nature, it is generally necessary to densify them under pressure at tenperatures near $2000^{\circ} \mathrm{C}$ before a dense, polycrystalline body of potential application is produced. Liquid-phase sintering has previously been shown to permit densification at wuch lower temperatures.

Studies of the densification of $\mathrm{TiB}_{2}$ and $\mathrm{TiB}_{2}-\mathrm{CrB}_{2}$ solid solutions by liquid-phase sintering are employing nickel as the fluidizing nedium. This choice was based on the eutectic temperature of $1180^{\circ} \mathrm{C}$ reported for the IIB 2 -Ni syste and the conclusion that Liquid-phase sintering should be possible at relatively low temperatures. The aicrostructure and properties of compositions from this system are being determined as a function of nickel content up to $20 \mathrm{~mol} x$. Studles were also wade on the hot-pressing paraseters required to achieve high densities, as well as processes for synthesizing solld solutions of $\mathrm{TIB}_{2}$ and $\mathrm{CrB}_{2}$. 
Scanning electron microscope (SEA) data had shown that the commercial TiB $_{2}$ powders contained a significant fraction uf particles large relative to the average particle diameter. This coarse particle fraction results in a wide variation of grain size in the fabricated body and could adve:sely affect the strength and other properties. A study was completed with personnel at the Oak Ridge Gaseous Diffusinn Plant to decerwine the particle-size distributions in the as-recelved $I^{L} B_{2}$ powders and in the $\mathrm{TiB}_{2}$ powder subjecied to several classiflcation regimes. A Vortec $\mathrm{C}-13$ classifier was employed, and optinum operating parameters were deterained for maximizing the fine-fraction yield. The particle-size distributions are shown in Fig. 1.5 for the as-received pc:Aer, the classified fine fraction, and the coarse reject fraction. The mean particle size decreased from 7.2 for the as-received powder to 5.6 im for the fine fraction. The fine-fraction distribution was also considerably narrower after classification, ranging from 0.5 to $13.5 \mathrm{fm}$. Scanning electron micrographs of some of the powders are shown in Figs. 1.6 and 1.7. In Fig. 1.6 it is apparent that the as-received powder contains a coarse particle population having a mean diameter 5 or more times chat of the fines.

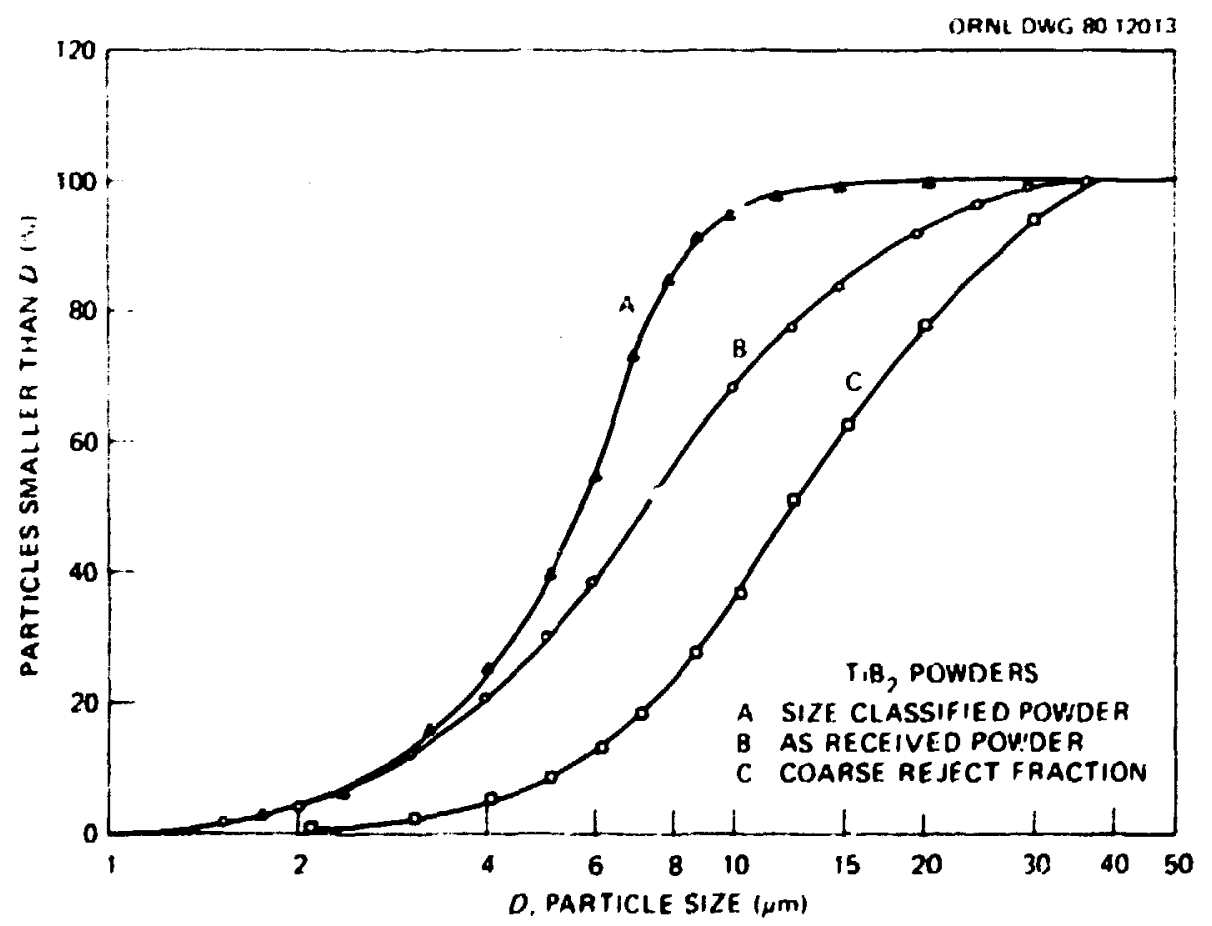

Fig. 1.5. Particle Size Distrihutions of Comercial TiB 2 Powders as Received and After Classiftcation by Vortec Classifier. 

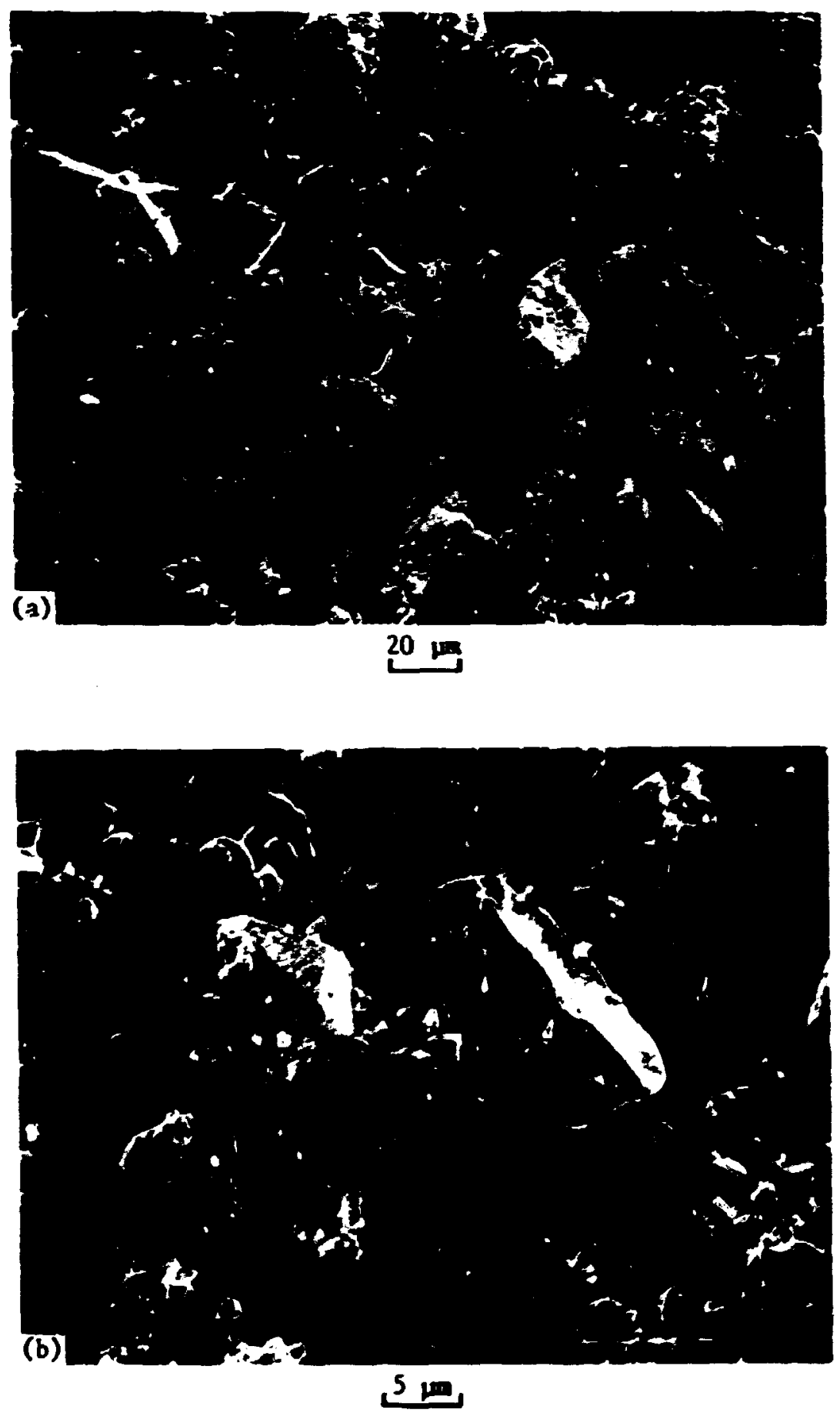

Fig. 1.6. Scanning Electron Micrographs of As-Received Commercial $\mathrm{TIB}_{2}$ Powder. ORGDP photographs. 

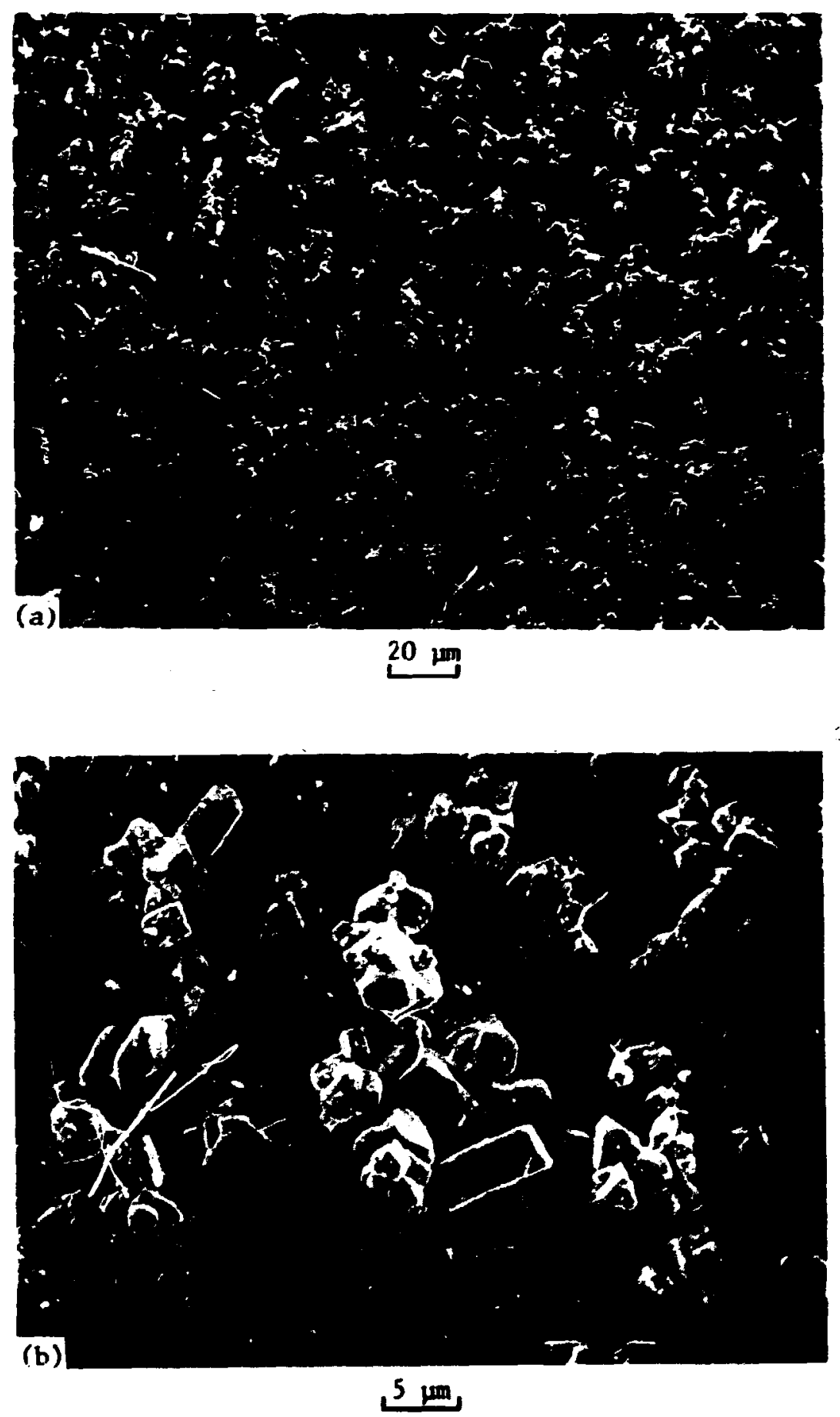

Fig. 1.7. Scanning Electron Micrographs of the Fine Fraction of Classif ted Commerciai TIB 2 Powder. ORCDP pi otographs. 
As shown in Fig. 1.7, the classiffed powder consists of a population devoid of large particles and shows many particles with the sharp angular corners desirable in the microstructure of a cutting tool. Nickel-bonded diboride bodies are belng . -pressed from the size-class:fied pouders, and their properties are compared with bodies fabricated from t!e asreceived (nonclassifted) powders.

Previous results had indicated that the substitution of chiomium for titanium (up to about $40 \%$ in $\mathrm{TL}_{2}$ ) culd produce a more fractureresistant material than $\mathrm{TiB}_{2}$ alone. Experiments were conducted to identify a process whereby homogeneous $\mathrm{TiB}_{2}-\mathrm{CrB}_{2}$ solid solutions could be synthesized. Two value. of $\mathrm{Cr} /(\mathrm{Ti}+\mathrm{Cr})$ mole ratio, 0.20 and 0.40 , were selected. Because of the refractory nature of these cumpounds and their sluggish diffusion benavior at moderate temperatures, powdered mixtires of $\mathrm{TiB}_{2}$ and $\mathrm{CrB}_{2}$ i.ave to be annealed at temperatures well above $1800^{\circ} \mathrm{C}$ for prolonged periods $(-24 \mathrm{~h})$ before interdiffusion begins. We explored reactions with $\mathrm{Ti}-\mathrm{Cr}-\mathrm{B}$ mixtures and reactions with $\mathrm{TiO}_{2}, \mathrm{Cr}_{2} \mathrm{O}_{3}, \mathrm{~B}_{4} \mathrm{C}$, and $C$ for synthesizing the $(\mathrm{T} i, \mathrm{Cr}) \mathrm{B}_{2}$ solid solutions. Initial results indicate that reaction of $\mathrm{Ti}, \mathrm{Cr}$, and $\mathrm{B}$ prociuces the best solid-solution product. Fabrication and characterization of materials in the series $(1-y)\left(T_{0.8}^{\circ} \mathrm{Cr}_{0.2^{\mathrm{B}}}\right)+y \mathrm{Ni}$ and $(1-y)\left(\mathrm{Ti}_{0.6^{-}} \mathrm{Cr}_{0.4^{\mathrm{B}}}\right)+y \mathrm{Ni}$ are under way. During this year, a new hot-press facility was obtainer. The unit is capable of temperatures up to $2200^{\circ} \mathrm{C}$ in vacuum or inert gas e.svironments with pressing loads up to $88 \mathrm{kN}$.

$x$-ray diffraction studies of several experimental compositions were completed and many are still under way. Significant amounts of reaction occur between the nickel and the diboride phase at the relailvely low hot-pressing temperature of about $1450^{\circ} \mathrm{C}$. In the compositions having $y=0.10,0.15$, and 0.20 in the serfes $(1-y) \mathrm{T}_{1} B_{2}+y N 1$, the secondary phases (those other than $\mathrm{TIB}_{2}$ ) fresent after fabrication vary in an orderly way with increasing value of $y$. In most cases th.e fabricated body contains at least two secondary phases. Also, crystalline nickel is not present to any extent after hot-pressing, nor are any of tile four reported nickel borides clearly identiflable. Optical microscopy results indicate that significant grain boundary motion occurs during densification; the 
nickel appears to facilitate eutectic formation and liquid-phase sintering anc is finally incorporated on solidification into complex phases whose identities are presently unknown.

observation of the optical microstructure of our $\mathrm{TiB}_{2}$-based specimens has in the past been complicated by the inability to etch chemically the grain boundary regions between the $\mathrm{TiB}_{2}$ grains while simultaneously developing observable structure within the $T \mathrm{~B}_{2}$ phase. We developed a technique using an evaporated tin oxide film on the polished specimen surface. This technique including examination under polarized light overcomes the previous problems. The various phases or different orientations of the same phase are distinguished by means of an optical phase shift at the film-specimen interface. This shift depends upon the optical constants of the film and the underlying compound or phase of interest. This technique has been referred to in the literature as "deposition etch." Using this technique we have determined that standard polished sections of our diboride ceramics of ten appear to exhibit relatively high porosity jecause the optical field consists of the relatively bright TiB 2 phase and smaller dark angular areas, which were previously assumed to be voids. These observations were inconsistent with immersion density measurements, which indicated densities greater hianin $95 \%$ of the expected theoretical density. The deposition etch technique has shown that in most cases the areas previously presumed to be pores were in fact a phase having much lower reflectivity than the primary $\mathrm{TiB}_{2}$ phase. An example of the microstructure of one of these materials is shown in Fig. 1.8. Figure $1.8(d)$ displays a field in a polished specimen TiB $\mathrm{B}^{-10}$ arol \% $\mathrm{Ni}$ under bright-field oil immersion conditions. Figure $1.8(\mathrm{~b})$ shows the same fleld with the tin oxide film, using polarized light and ofl immersion. In Fig. $1.8(b)$, the $\mathrm{TiB}_{2}$ grains are clearly delineated, as are secondary phases that inftially appeared in Fig. $1.8(a)$ to be porosity (cor example, at point $A$ ). In addition, Fig. $1.8(b)$ reveals numerous curved grain boundaries between $\mathrm{THB}_{2}$ grains, as well as several examples of grain triple points with angles near $120^{\circ} \mathrm{C}$. These observations suggest that significant mass transport had occurred during the $1450^{\circ} \mathrm{C}$ hot-pressing.

We also performed hot microhardness measurements on several diboride specimens, and F1g. 1.9 compares the diamond pyramid hardness (DPH) as a 

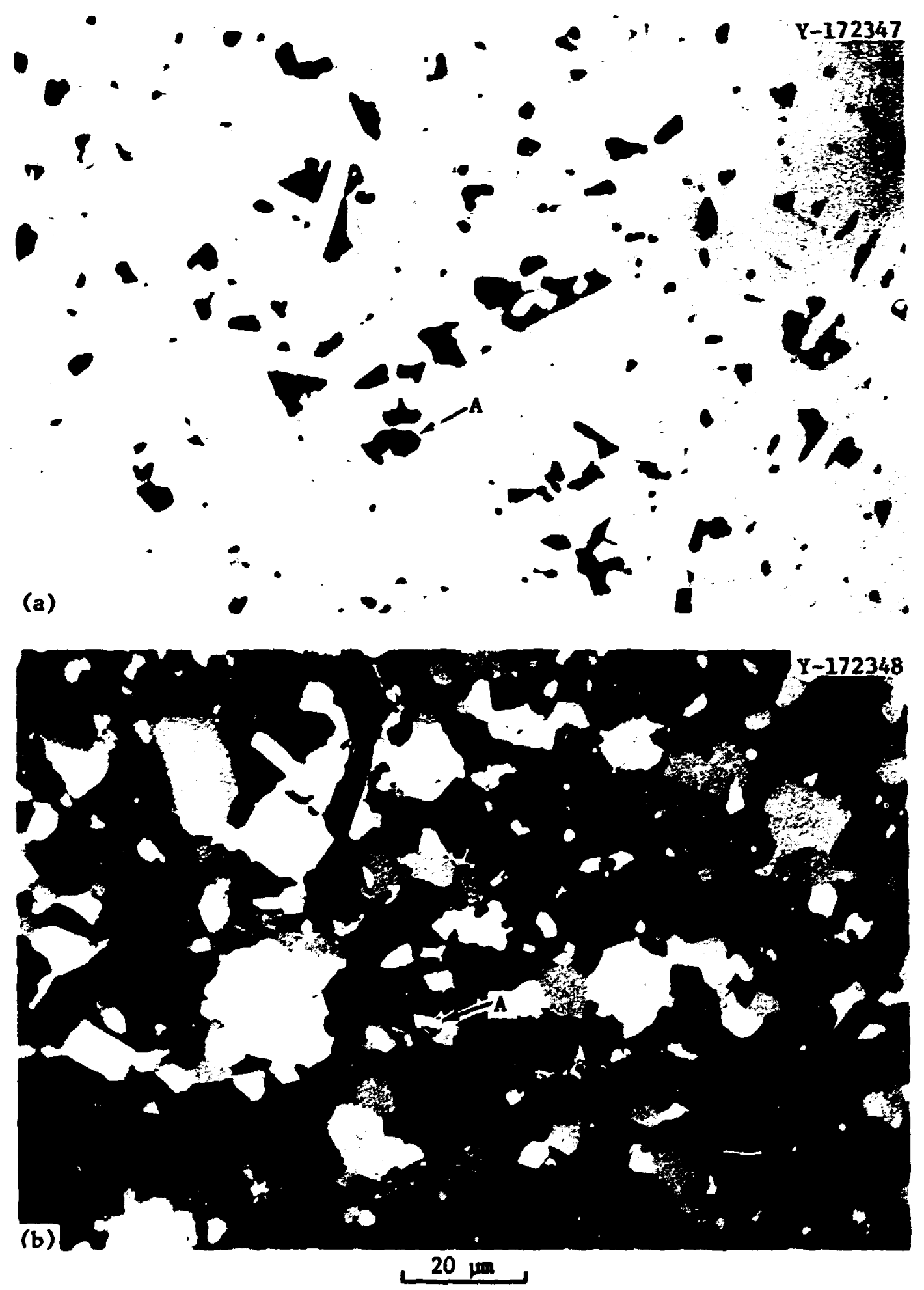

Pig. 1.8. Optical Micrographs of Hot-Pressed Diboride Ceramic Having

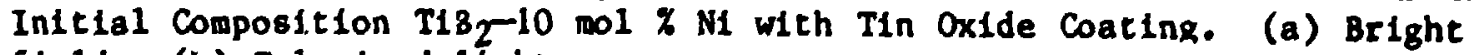
field. (b) Polarized light. 


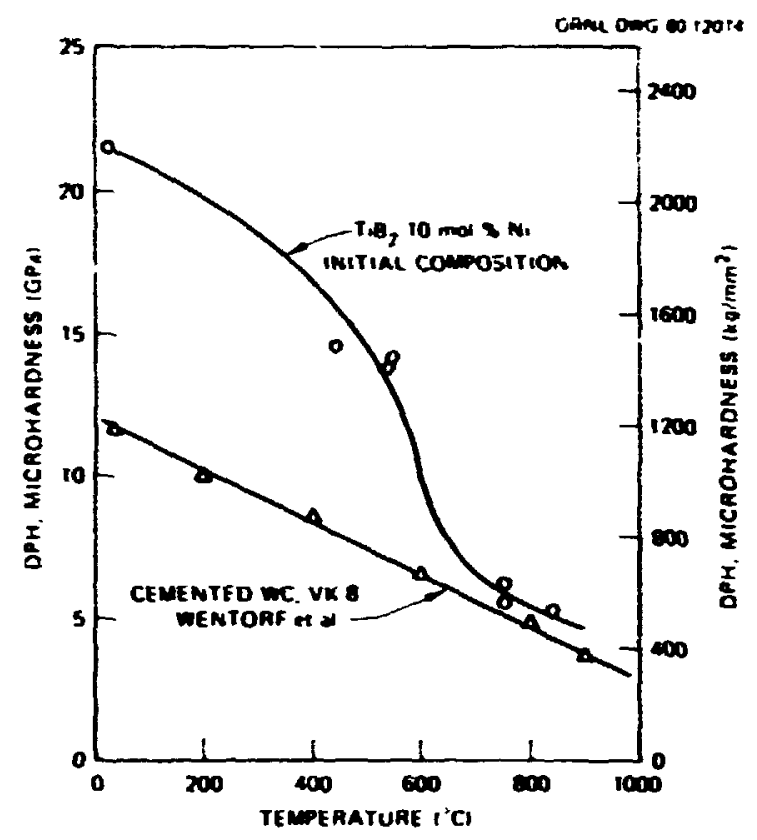

Fig. 1.9. Hot Microhardness of Hot-Pressed Diboride Ceranic Having the Initial Composition $\mathrm{TiB}_{2}-10 \mathrm{~mol} z \mathrm{Ni}$ Compared with Comercial

Cemented Carbide ( $H C-8$ wt $z C_{0}$ ). Tungsten carbide data from R. H. Hentorf, R. C. DeVries, and F. P. Bundy, "Sintered Superhard Materials," Science, 208: 873-80 (May 23, 1980).

function of temperature for a specimen of the initial composition TiBt-10 mol $7 \mathrm{NI}$ with that of a comercial, cobalt-bonded tungsten carbide product. These data indicate that the diborides are quite hard, retaining their hardness to temperatures in the range 500 to $600^{\circ} \mathrm{C}$.

He are also characterizing these materials by transmisston electron microscopy, seeking to determine the grain boundary structure and the identity of the primary and secondary phases. Electron diffraction analyses are anticipated to supplement the x-ray diffraction data and aid in identification of secondary phases. In addition, analytical electron microscopy has just been started with the goal of determining the elemental distributions within the secondary phases. Figure 1.10 illustrates a grain boundary region observed in a specimen of the intial composition $\mathrm{TIB}_{\mathrm{T}^{-1}} \mathrm{~m}$ mol $\% \mathrm{NA}$, revealing a triple point function between three $\mathrm{TiB}_{2}$ grains and a grain boundary in which crystals appear to have grown. 


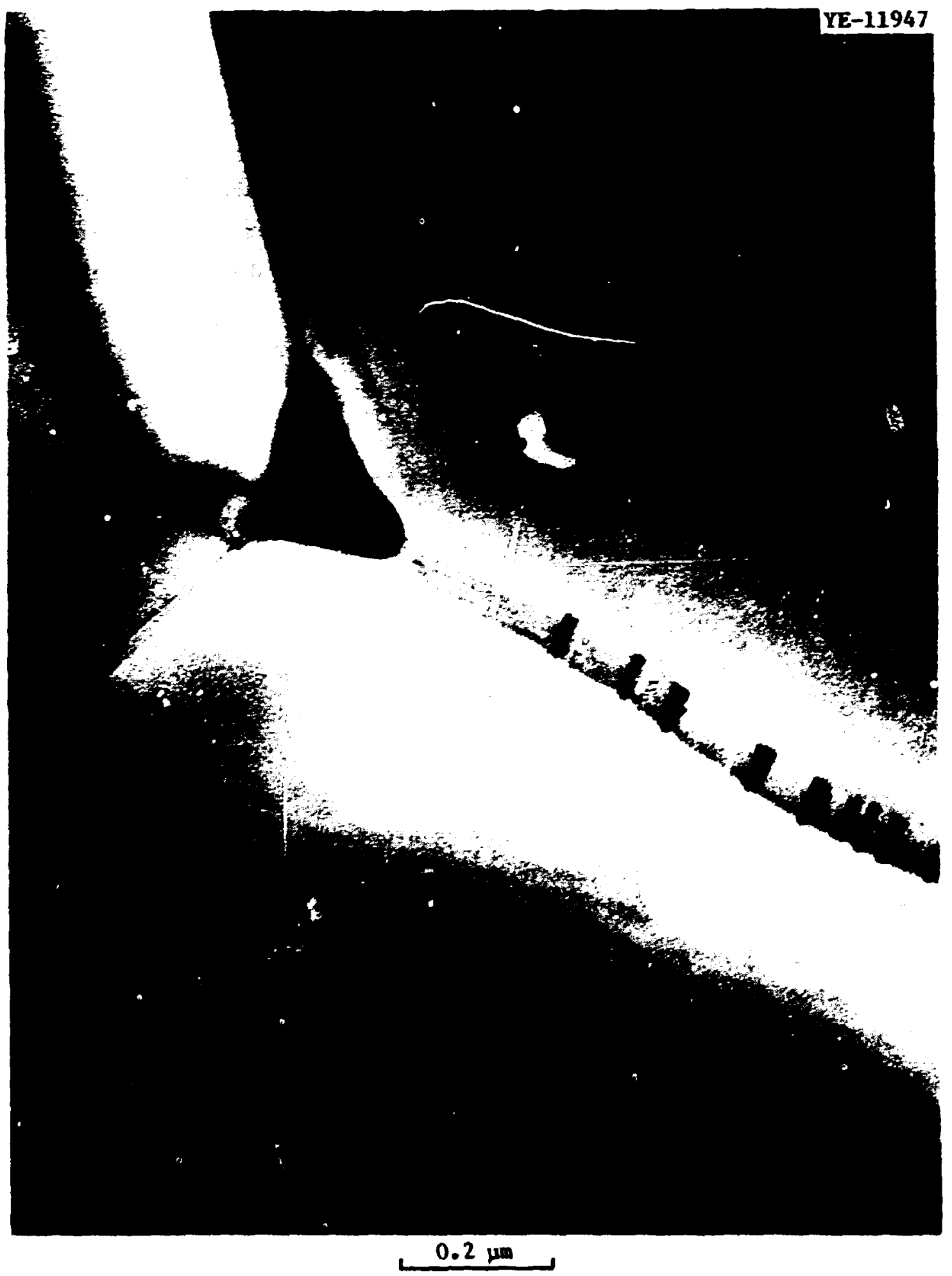

Fig. 1.10. Transmission Electron Micrograph of Hot-Pressed Diboride Ceramic Having Initial Composition $\mathrm{TiB}_{2}-15$ mol $x \mathrm{~N}$. 
During this year, certain propertles of our diboride materials have been deternined by investigators at other laboratories, and artangements have been completed for the performance of other masurements. This work includes particulate erosion tests at the Albany Research Center (ARC), coal-ofl slurry erosion tests at Battelle Columbus Laboratories (BCL), engineering wear tests at Vanderbilt University, flash theralal diffusivity measurements at Virginia Polytechntc Institute and State University, and wachine-cutting-tool tests at the Y-12 facility of Union Carbide, Oak Ridge. Sowe results are availaole from the ARC and BCL test facilities, and these will be briefly reviewed. The ARC test is designed to deteruine the erosion resistance of hard aterials for use as valve components in a highvelocity particulate-laden gas stream, suck as may be experienced in coal gasification systems. The BCL test is designed to evaluate hard materials In a high-velocity jet of anthracene ofl containing dissolved solvent refined coal products (SRC-I). This test simulates the environment of a pressure letdown valve trim in a coal liquefaction plant.

Diboride samples from the compositional series $(1-y) \mathrm{TiB}_{2}+y \mathrm{Ni}$ having $y$ values of $0.10,0.15$, and 0.20 were tested in both the ARC and BCL facilities. The results are given in Tables 1.1 and 1.2 . In the ARC facility materials are classified according to a Relative Erosion Factor (REF) paraneter with Stellite 6B having a defined value of unity. From Table 1.1, it is apparent that our diboride ceramics have a particulate erosion resistance at $25^{\circ} \mathrm{C}$ that is comparable to that of the cemented carbides. This property is valid for both 20 and $90^{\circ}$ impingement angles. The specimen designated as NT-80B had the 1.1ghest erosion resistance. In the BCL facility materials are characterized according to the maximum depth of the erosion pit formed in the material by a jet that impinges the sample at $20^{\circ}$ from the surface. Table 1.2 shows that the boride samples were not quite as erosion resistant as the best cemented carbides. Again the NT-80B specimen exhibited the highest erosion resistance. In this case, the pit depth was 3.9 times that for $\mathrm{K}-701$ cemented tungsten carbide. According to these results, the erosion rate of these materials appears to be sensitive to the inftial composition, that is, the Initial nickel content. The $x$-ray diffraction data show that the specific constitution of the secondary phases in these materials depends strongly upon 
Table 1.1. Erosion prnperties of ORVL boride ceranics (ARC test facility) ${ }^{a}$

\begin{tabular}{|c|c|c|c|c|}
\hline \multirow{2}{*}{$\begin{array}{l}\text { Material } \\
\text { Designation }\end{array}$} & \multirow{2}{*}{$\begin{array}{l}\text { Yajor } \\
\text { Phase }\end{array}$} & \multirow{2}{*}{$\begin{array}{l}\text { Inithal Sickel } \\
\text { Content } \\
\left(\begin{array}{ll}\text { nol } \\
\text { ) }\end{array}\right)\end{array}$} & \multicolumn{2}{|c|}{$\operatorname{REF}^{b}$} \\
\hline & & & $20^{\circ}$ & $90^{\circ}$ \\
\hline NT-80B & $\mathrm{TiB}_{2}$ & 20 & 0.008 & 0.036 \\
\hline$N T-85 B$ & $\operatorname{IIB}_{2}$ & 15 & 0.017 & 0.046 \\
\hline NT-90B & $\mathrm{IIB}_{2}$ & 10 & 0.013 & 0.108 \\
\hline$x-602^{c}$ & WC & & 0.01 & 0.11 \\
\hline$k-701^{c}$ & WC & & 0.02 & 0.25 \\
\hline$K-801^{c}$ & WC & 6 & $d$ & 0.32 \\
\hline
\end{tabular}

atest conditions: $25^{\circ} \mathrm{C}, 27-{ }^{\mu}$-dias $\mathrm{Al}_{2} \mathrm{O}_{3}$ particles, velocity $=170 \mathrm{~d} / \mathrm{s}, 180 \mathrm{~s}$.

bRE calculated by dividing volume loss of sample by volune loss of Stellite $6 B$ tested under identical conditions.

Gennawetal cemented tungsten carbide products shown for comparison.

diot avail lable.

Table 1.2. Erosion characteristics of ORNL boride ceranics (BCL test facility) ${ }^{a}$

\begin{tabular}{|c|c|c|c|}
\hline $\begin{array}{l}\text { Material } \\
\text { Designation }\end{array}$ & $\begin{array}{l}\text { Major } \\
\text { Phase }\end{array}$ & $\begin{array}{l}\text { Inftial Nickel } \\
\text { Content } \\
\left(\begin{array}{ll}\infty & \pi\end{array}\right)\end{array}$ & $\begin{array}{l}\text { Maxinum Depth } \\
\text { of Erosion Pit } \\
\text { (jm) }\end{array}$ \\
\hline NT-80B & $\mathrm{TIB}_{2}$ & 20 & 17.8 \\
\hline$N T-85 B$ & $\mathrm{TIB}_{2}$ & 15 & 35.6 \\
\hline$N T-90 B$ & $\mathrm{TIB}_{2}$ & 10 & 30.5 \\
\hline$k-701^{b}$ & wC & & 4.6 \\
\hline
\end{tabular}

a Test conditions: $343^{\circ} \mathrm{C}$, of 1 jet contalining 24 wt $z$ dissolved SRC-I (Hilsonville product, Run 4b), Iripingewent angle $=20^{\circ}, \mathrm{H}_{2} / \mathrm{Ar}$ carrier gas, $3.6 \mathrm{ks}$.

bennabetal cemented tungsten carbide product - shown for comparison. 
the volume fraction of nickel originally present, the hot-pressing parameters, and probably the boride particle size distribution since this distribution will initially contrul available interfacial contact area between the $\mathrm{TiB}_{2}$ and the nickel phase during densification.

\subsubsection{Euteitics - G. W. Clark}

Studies in the directional solidification of high-temperature eutectic systems by the internal zone growth (IZG) technique have formed the central theme. He continue to devise and improve the methods of directional solidification and crystal growth, to develop an increased understanding of crystal-growth processes and kinetics, and to provide materials needed in research. Tt is satisfying to point out that the mathematical modeling of our IZC technique has been selected by the 1980 Gordon Conference on Crystal Growth for the session entitled "Fundamental Considerations in Crystal Growth." This talk will be presented by R. F. Sekerka, Carnegie-lellon University. J. D. Holder, Structural Ceramics Group, presented an invited review of our work at a symposium sponsored by the Cerman Metallurgical Scciety in Konstanz, Germany, and three seminars in Gerwany and the Netherlands. This program has shifted emphasis towards the design considerations of high-strength, toughened eutectics. The first success was the growth of the eutectic $7, \mathrm{rO}_{2}-\mathrm{ZrB}_{2}$.

\subsubsection{Mathematical Modeling of Internal Jone Growth (IZG) and Electrical Conductivity Tailoring of Compacts - G. W. Clark and J. D. Holder}

The directional solidification of many high-melting eutectics by crucible techniques is severely limited by the lack of compatible crucible materials. Our IZC technique circumvents the problem by balancing the heating effect with large radiant heat losses at the sample surface, producing an unmelted skin, which serves as the crucible. This is proving to be an Important technique for both laboratory studies and technology in general. 
On can devise a mathematical model for the above process by using two partial differential equations, whligh describe the heat $f($ ow and electrical conductivity. However, the variables in these two equatons are interrelated, and the rathematics becones very couplex. We sioght the assistance of R. F. Sekerka (Carnegie-Mellon University). Working with one of his students, R. A. Hartzell, Sekerkid described the growth process theoretically. As a result, Sekerka and Hartzell wera able to predict a terperature instability related to the $r f$ coupling and heat transfer at various frequencies, sample diameters, and sample electrical conductivities. Tre instability had been observed in our own laboratory, although not recognized, during our experiments with the system $\mathrm{Cr}_{2} \mathrm{O}_{3}-\mathrm{Y}_{0}$. often, as we approach.' the melting cemperature the surface cemperature would increcse rapidly, $2: 0$ surfice would melt, and the molten sample would be lost. This work by Sc:orka and Hartzell is one of three topics selected by the 1980 Gordon Conference on Crystal Growth for the session entitled "Fundamental Considerations in Crystal Growth."

In our annual report last year, we based much emphasis on the electrical conductivity tailoring of oxide-metal compacts. This new technique circunvented the occurrence of the above instability during initial sample heat to the melting temperature.

Electrical conductivity tafloring has also been extended to our new investigation of eutectic solidification in metal oxide-meta: boride systems. In this case, the technique appears to work equal .v well. However, the metal oxide-metal boride experiments have only recently been started.

\subsubsection{Oxygen Partial Pressure and Regular Solution Mode' for Phase Equilibrium in Oxide-Metal Eutectic Systems - J. U. Holder and C. W. Clark}

The application of the pinase rule to $M_{2} \mathrm{O}_{4}-\mathrm{H}^{-}\left(M^{-} \neq M\right)$ oxide-metal eutectic systems shows that in an atmosphere bufiered to maintain a constant oxygen pressure only pseudobinary (1.e., two-phase, three-component) eutectir. composites can be grown. The thermodynamic regular solution model has been used to calculate the variation 
of activity coefficient with oxygen pressure in oxide alts produced froo a mixture of $\mathrm{Cr}_{2} \mathrm{O}_{3}$ and ib. The calculations indicate that the aetallic phase would be $\mathbf{a}$ : $0-\mathrm{Cr}$ alloy and that the $\mathrm{Cr}$ content should increase as the oxyyen pressure is reduced.

Composite growth experiments by IZG and cold-cructble skull weiting cechniques were performed to test the predictions; Fig. 1.11 gives the results. The melting techniques did not perait reaching equilibrius in gas alxtuces with $\ln \boldsymbol{\infty}_{2}$ contents. However, as the melt was held for longer times, the chrorium content of the molybdenum-chromiun fiber approached the predicted composition.

The regular solution wodel has been shown to be an adequate treatwent to predict the pseudobinary composition of high-temperature oxide-aetal eutectic composites. Also, it has been demonstrated that oxygen pressure and starting composition (i.e., oxide-metal mixture) are the critical parameters in controlling the oxide-metal eutectic composite composition.

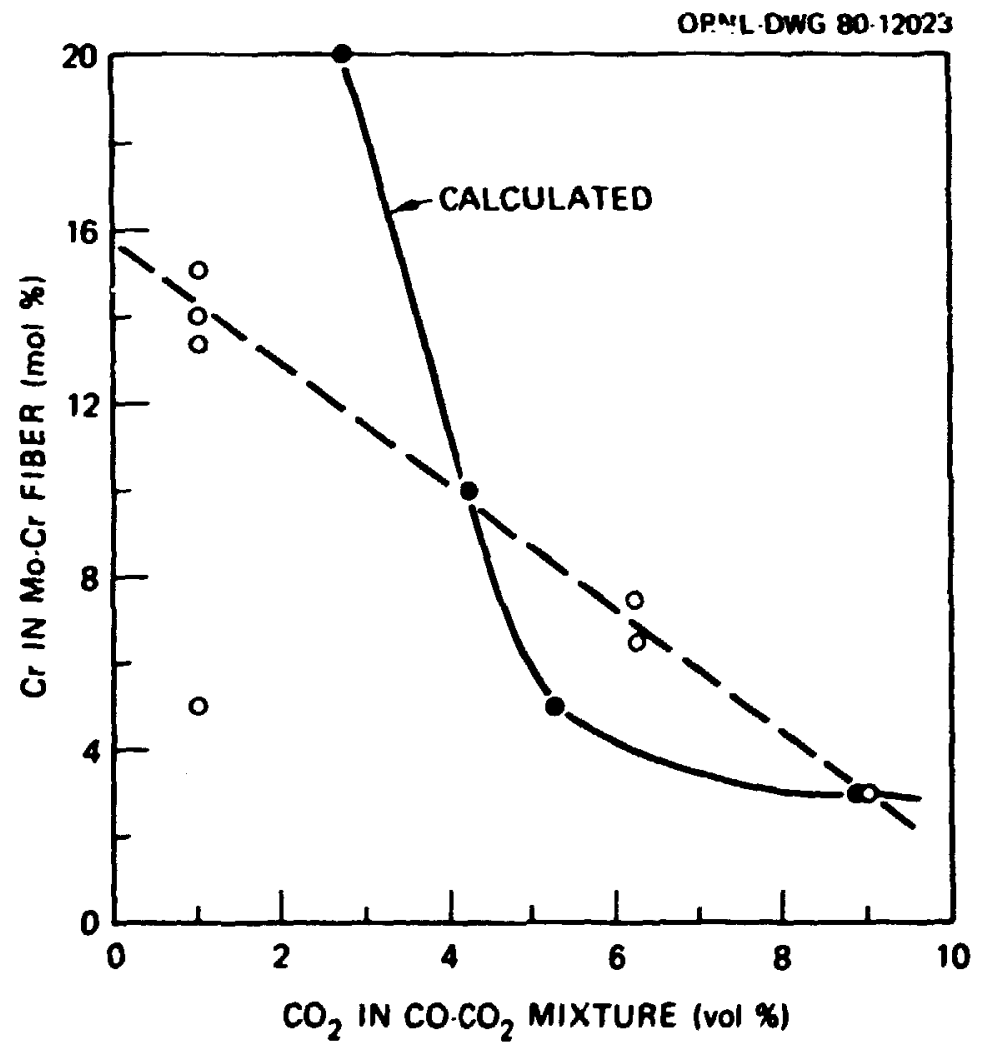

Fig. 1.11. Dependence of Chromium Content in Mo-Cr Fibers in a $\mathrm{Cr}_{2} \mathrm{O}_{3}$-Mo Eutectic upon $\mathrm{CO}_{2}$ Concentration in the Growth Atmosphere. "Calculated" curve is fitted to calculated closed points. Dashed ine Is fitted to experimental open points. 
1.3.2.3 Chemical and Structural Considerations for Design of High-Strength Toughened Eutectics - G. W. Clark and J. D. Holder

Refractory metal oxide-metal eutectics are a relaitrely new class of high-temperacure materials that wiscovered soon after developing the IZG technique for directional solldification. Recent reports on these azerials show that their yield point stress, work-of-fracture, and Charpy inpact strength are 2.5 to 10 times those of similar primary-plase materials. These data encourage us to believe that carefully cisigned refractory eutectics could have important structural applicatio.s. Thus, we are exploring the use of eutectic aterials for the mufacture of high-strength, tough cutting tools or hard, corrusion-resistant valve trim. This interest has been intensified by the recent shortages of minerals containing cobalt, cantalum, and tungsten, as well as by the recent severe price increases for these critical materials. It is significant that our conventional machine-cutting tool technology is largely based on tungsten and cobalt, both of which are now in increasingly short supply.

In mid-1979 a major supplier of abrasive materials announced its plans for producing a new grinding grit based on a eutectic in the $\mathrm{ZrO}_{2}-\mathrm{Al}_{2} \mathrm{O}_{3}$ system. Wi had had previous research experience with the eutectic behavior of these oxides in ternary systems containing molybdenum and iungsten. Arrangements have been made with this U.S. manufaccurer to evaluate our experimental eutectic materials as grinding grain. Cold-crucible meiting and solidification of the pseudobinary eutectic, $2 \mathrm{rO}_{2}\left(\mathrm{Y}_{2} \mathrm{O}_{3}\right)-\mathrm{Al}_{2} \mathrm{O}_{3}$ with Mo and $\mathrm{Cr}_{2} \mathrm{O}_{3}$ additions, were accomplished relatively easily. Soon thereafter, a ternary eutectic in this system was directionally solidified in our IZG equipment. A 63-mm-dlam bar about $70 \mathrm{~mm}$ long was then fabricated by hot-pressing selected powders of $2 \mathrm{ZO}_{2}, \mathrm{Al}_{2} \mathrm{O}_{3}$, $\mathrm{Y}_{2} \mathrm{O}_{3}$, and $\mathrm{Ho}$ to about $90 \%$ of theoretical density before the eutectic growth experiment. The particle size and composition of the powder were tallored such that the aggregate electrical conductivity was in the correct range for the bar to couple directly to a $500-\mathrm{kHz}$ field. The hotpressed bar was then directionally solidified in our IZG equipment, 
resulting in a melt cegion $55 \mathrm{~mm}$ in diameter by $30 \mathrm{~mm}$ high. This pseuduternary eutectic $3 . \mathrm{OO}_{2}\left(\mathrm{Y}_{2} \mathrm{O}_{3}\right)-\mathrm{Al}_{2} \mathrm{O}_{3}-$ to ingot is now ready for crushing and testing as an abcasive grain. We believe that the l-jm ib eutectic fiters may produce a significantly tougher grit for use in betal grinding.

In an effort to prodice superior cutcing cool and valve trim materials, we have expanded our investigations to iaclude boride, carbide, and nitcide phases in conplex entectics with oxides and metals. The fir:i cold-crucible melts of $7 \mathrm{rO}_{2}-\mathrm{ZrB}_{2}$ were the most successful. The 7.rB 2 formed I-jn-thick lamella showing strong erystallogriptic coupling to the 7.rO $\mathrm{r}_{2}$ This is a good example of a material having a hard matrix phase $\left(\mathrm{ZrO}_{2}\right)$ and a layered structure of micrometer-sized sheets of the even harder $\mathrm{ZrB}_{2}$. The systers $\left.\mathrm{Y}_{2}\right)_{3}-\mathrm{ZrB} 2$ and $\mathrm{Al}_{2} \mathrm{O}_{3}-\mathrm{ZrB} \mathrm{B}_{2}$ were also explored. For these, our first impression is that th- eutectic composition is less than a few percent 7.rB2. We shall now work with chenical additives to try to increase the rolume concentration of $\mathrm{ZrB}_{2}$. As these and similar materials are synthesized, they will be evaluated in our machine-tonl, wear test, and abrasive grain programs.

Frum the chemical point of view we have started with some of the more stable borides and oxides. However, there is much yet to be answered in the chemical thermodynamic area. We also ione that the britcle fracture characteristics of these hard phases can be reduced by ifinding appropriate solid solution members that can effectively increase the fracture energy.

\subsubsection{Growth of Single Crystals - C. B. Finch}

Large single-crystal samples are necessary in determining the intriasic anisotronfe properties of material in relat tue absence of grainboundary ef 1 . is. We continued our work on the improvement of existing crystal-growth techniques and on the growth of additional crystals.

In the realm of Czochralski growth, we completed our experiments to optimize the growth conditions for single crystals of $\mathrm{Fe}_{2} \mathrm{SiO}_{4}$ (fayalite) and $\mathrm{Ca}_{2} \mathrm{Al}_{2} \mathrm{SIO}_{7}$ (gehlenite). We continued our experiments on the hydrothermal gr, th of quartz and collaborated to grow several actinidedoped $\mathrm{LaPO}_{4}$ (monazite) crystals for radioactive waste studies. 
The direction of our sizgle-crystal work is shifting to the gruwth of buride-, nitr.de-, or carbide-based phases. He zxpect imediate delivery of a new high-pressure Czochrilski crystal gruwth system, which should acilitate this task.

1.3.3.1 Czochraiski Growth of Single-Cryatal Fayalite $\left(\mathrm{Fe}_{2} \mathrm{SiO}_{4}\right)$ C. B. Filch, G. W. Glark, and O. C. Kopp 42

We completed our work on the growth and characterization of singlecrystal fayalite 43 and distributed boules to researchers throughout the United states, including a sample to the Sinihsonian Institution mineral collection. The low-temperature specific heat $r$ our crysicals was measured by R. A. Robie of the U.S. Seological Survey. In addition, detailed Mössbauer studies by D. Virgo of the Carnegie Institution geophysical laboratory cunfirmed the original parasagnetic resonance results of M. if. Abraham (ORNL) that our best Crochralski- zo'vn material appears to be essentially $\mathrm{Fe}^{3+}$-free. It would thus seem likely that the dark color of melt-grown fayalit: is not associated with the presence of $\mathrm{Fe}^{3+}$.

1.3.3.2 Czochralski Growth of Sirgle-Crystal Gehlenite $\left(\mathrm{Ca}_{2} \mathrm{Al}_{2} \mathrm{SiO}_{7}\right)^{44}-$ C. B. Finch, F. L. Ball, 45 and J. B. Bates 46

Single-crystal boules of gehlente $\left(\mathrm{Ca}_{2} \mathrm{Al}_{2} \mathrm{Sil}_{7}\right)$ were grown from evenand off-stoichiometry melts under differing conditions of oxygen fugacity $\left(\mathrm{fO}_{2}\right)$. Growth was acromplished by the Czochralski method at about $1600^{\circ} \mathrm{C}$ and $0.1 \mathrm{MPa}$ ( $1 \mathrm{~atm}$ ) total pressure, using inductively heated Ir or Pt-20\% Rh crucibles. The supra melt gas ambients included air $\left(f_{\mathrm{O}_{2}}=20 \mathrm{kPa}\right)$, Ar (10 ra), Ar-50\% $\mathrm{CO}_{2}-2 \% \mathrm{H}_{2}(10 \mathrm{mPa})$, and $\mathrm{Ar}-4 \% \mathrm{H}_{2}-1.5 \% \mathrm{H}_{2} \mathrm{O}(0.1 \mathrm{mPa})$.

42Department of Geological si:ences, University of Tennessee, Knoxville and Metals and Ceramtcs Division, ORNL. (1980).

${ }^{43}$ C. B. Finch, G. W. Clark, and 0. C. Kopp, Am. Mineral. 65: 381-89

${ }^{44}$ Abstract of paper submitted to Proceedings of International Conference on Crystal Growth VI, Moscow, September 10-16, 1980.

45 Analytical Chemistry Division.

${ }^{46}$ Solid State Division. 

Several crystals of adequate size and perfection will be grown for fabricating oscillators for auelastic loss determinations. We anticipate that this program will be terminated after these crystals have been obtained.

Crystals of $\mathrm{Cu}_{2} \mathrm{Se}$, produced in earlier uydrothermal experiments, 48 have been analyzed by $x$-ray diffraction. 49 The crystals appear to be orthorhombic (or possibly monoclinic with a o-angle near $90^{\circ}$ ) with cell dimensions: $a=1.41029, b=2.04024$, and $c=0.41332 \mathrm{um}$, comparable to material prepared by solid-state equilibration of $\mathrm{Cu}_{2} \mathrm{Se}$ with $\mathrm{Cu}$. The compound $\mathrm{Cu}_{2} \mathrm{Se}$ is an important material in photovoltaic devices.

\subsection{STRUCTURE OF COAL - L. A. Harris and C. S. Yust}

Physical attributes of coal such as porosity, mineral content, and microstructure are believed important in the utilization of coal in conversion processes. We are using a varfety of optical and electron microscopical techniques to identfy the above features as well as to determine their distributions in a given coal. In addition, the acquisition of a specimen heating stage and ervironmental cell for use in the high-voltage electron microscope (HVEM) has enabled us to perform high-temperature (up to $1000^{\circ} \mathrm{C}$ ) in situ TEM experiments ${ }^{\circ} \mathrm{O}$ on ccal. Such experiments can aid us in our understanding of the reactions taking place in coal conversion systems.

\section{4.' Techniques Based on Optical Microscopy - L. A. Harris}

1.4.1.1 Transmitted Infraced Light Microscopy: An Improved Method for vlewing Coal Thin Sections 51 - L. A. Harris and C. S. Yust

The use of transmitted infrared (700-1200 nm) microscopy for the study of chin sections of coal is discussed. This optical technique is

480. C. Kopp and G. W. Clark, "Hydrothermal Growth of Quartz and other Phases," Metals and Ceramics Div. Mater. Sci. Program Amu. Prog. Rep. Jume 30, 1879, ORNL-5589, p. 41.

${ }^{49} \mathrm{X}$-ray diffraction measurements by 0. B. Cavin.

50 Experiments performed in which the specimen is observed by transmissiun electron microscopy while exposed lo conditions that could alter the stiucture.

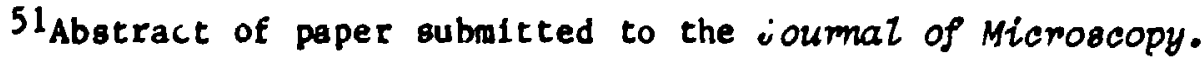


shown to have the capability of transmitting infrared light through many norally opaque organic constituents of coal in typical thin sections (5-10 $\mathrm{mm}$ thick). The relationship between near-infrared transmission, specimen thickness, and maceral type is explored.

\subsubsection{A Study of Elemental and Maceral Distribution in Coals of Different Paleoenvironments 52 - H. E. Barrett, 42 o. C. Kopp, 42 and L. A. Harris}

A comparison of the vertical distribution of major and minor elements and naceral contents in two high-volatile bituminous coals of Eastern Tennessee has been completed. The coals studied are the Pee Wee, deposited in a fresh water environgent, and the Upper Grassy Spring, influenced by a late inzursion of marine water.

$X$-ray fluorescent and coal petrographic analy;es were performed on a continuous series of specimens obtained from face channel samples répresenting the entire thickness $c$. each seam. Offcuts from the petrographic samples were analyzed with an EG\&G 6110 fluorescent analyzer. Element standards were employed and matrix corrections applied. Correlation coefficients $(r)$ for all element pairs were computed in order to reveal any significant relationships.

The Upper Grassy Spring contained over 3 times the weight of tot 1 elements found in the Pee Wee. Comparison of iron and sulfur within these seams shows a near uniform distribution for the Pee Hee, whereas the Upper Grassy Spring shows a continuous increase of both elements from bottom to top. High positive correlations $(r)$ were observed for element pairs normally associated with clay minerals. Equally good correlations were observed for ( $S i, T i$ ) and ( $A I, T 1$ ), suggesting that titanfum is associated with clay in both coals. Negative correlation between $(\mathrm{Ca}, \mathrm{Mg})$ is consistent with the absence of dolomite in both coals. A major difference in correlation was found for $(S r, P)$, which showed a high positive $r$ factor in the Upper Grassy Spring but no correlation in the Pee Wee. Other Important correlations indicated differences in element accumulitions in different paleoenvironments and maceral associations.

52 Abstract of talk presented at the meeting of the ceological Soclety of America, San Diego, California, Nov. 5-8, 1979. 
1.4.1.3 A Review of Advanced Coal Petrographic Methods in Charactertzing and Assessing Coals for Uthlization 53 - L. A. Harris and C. S. Yust

The application of coal petrography ia the characcertzation and assessment of coals for conversion to metalluryical coke is well established. These same methods lave been used in cnal liquefaction studies but with less obvious success. However, recent developments of new petrographic methods, such as ultraviolet fluorescence and near-infrared transmission microscopy, promise to supply additional pertinent data. Specifically, the ultraviolet fluorescence method detects the more hydrogen-rich macerals, whereas the infrared technique appears to identify the less carbonized inert macerals.

\subsubsection{Electron Metallography}

1.4.2.1 High-Temperature Tränsmission Electral Microscope Studies of Coal - L. A. Harris, C. S. Yust, and E. A. Kenik

In situ heating experiments have been performed on several samples of a high-volatile bituminous coal (Elkhorn No. 3) using the specimen heating stage in the high-voltage electron microscope (HVEM). Softening of the exinftic constituents in the ultrathin regions of the coal foll resulted in a corrugated appearance for these constituents. In contrast, the exinites in the thicker region of the foil many have actually melted, forcing delamination of the coal. This was especially true in those coal sections that consisted of interbedded exinites and vitrintes. Also observed in these experiments was the profusion of spherical particles (nonmetallic) reminfscent of carbon blacks on both surfaces of the foll. Electron difiraction analysis of these particles revealed some unusual diffraction aspects.

1.4.2.2 TEM Cinaracterization of Coals S4 $^{54}$ L. A. Harrts and C. S. Yust

Transmission electron microscope (TEM) techniques are applied to coals ranging in rank from subbituminuous to anthracte, with emphasis on

53 Abstract of talk presented at the 109 th Annual Meeting of AIME, Feb. 24-28, 1980, Las Vegas.

54 Abstract of talk pitven it 1979 Annual Meeting of the Materials Research Soclety, Boston, Novem ser 26-30. 
the higher rank coals. The distribution of porosity and aneral content within each coal type as revealed by $\mathrm{TIX}$ and $\mathrm{AEH}$ and the varlations of chese features anong the several coal types studied are discussed. Selected area diffraction (SAD) experiments and dark field aicroscopy are also shown to be invaluable in studies of inerals and macerals. Observations of an anthracite by these cethods reveal a sharper, core distinct set of diffraction rings with a concomitant inprovement in the resolution of domains in the vitrinite, as-revealed by dark field techniques. The use of $\mathrm{WM}$ and associated techniques is shown to be important for the complete characterizatior of coals.

\subsubsection{A Nes Improved Standard for Electron Probe Deternination of Organic Sulfur in Possil Puels 55 L. A. Haríts, R. Raymond, 56 and R. Cooley 56}

Electron-probe aicroanalysis (EPH) has important advantages over conventional wethods of analysis for organic sulfur in coal: analysis by EPH is done directly, avoiding problens associated with calculating organic sulfur content by difference; organic sulfur contents of individual macerals can be measured in situ in a saple. A major problea with this technique has been finding a sultable sulfur standard. We recently obtained a petroleun coke and found it to be a sultable standard.

\subsection{TRANSFORMATIONS AND SHAPE MEMORY EFFECT IN URANIUM ALIOYS - R. A. Vandermeer}

The manufacture and deployment of parts made from uranium alloys demand a high degree of dimensional stability of alloys. Shape change due to swall thermal excursions must be minimized. Solid-stace phase transformations of ten are associated with the difficulties encountered in maintaining dimensional stability. Unfortunately, uranium-base alloys exhibit an enormous diversity of phase transforwation behavior, and certain transforwation states are much less desirable than others. Our main objective

55To be published in the proceedinge of the BMSA-Mas Joint Meeting, San Francisco, Auguet 3-8, 1980.

56reosciences Division of Los Alamos Scientific Laboratory. 
is to unravel the mechanistic details of the complex transformation patterns, especially the metastable states. We explore how composition, temperature, stress, and icrostructure influence transformation behavior.

1.5.1 A Phenomenological Study of the Shape Henory Effect (SME) in Polycrystalline Uranium-Niobiun Alloys 57 - R. A. Vanderacer, J. C. Ogle, and H. G. Northcutt, Jr. 58

Polycrystalline uraniun-niobiu alloys spanning the composition range 13.9 to 17.8 at. $Z \mathrm{Nb}$ were prepared. Decomposition of the elevatedtemperature bcc phase to the displacively formed transition phases during continuous cooling to roon temperature was studied by dilatometry. With the help of $x$-ray diffraction, a mastable phase diagran was determined. At room temperatuce alloys containing less than 15.2 at. $Z$ Nb were $a^{-"}$ (monoclinic), while those with more than 16.0 at $z \mathrm{Nb}$ were $\gamma^{\circ}$ (tetragonal). Reverse transforwation behavior during heating was also surveyed.

The stress-strain characteristics of the atherwally produced $a^{-\infty}$ and $\gamma^{\bullet}$ martensitic phases were measured in uniarial tension at room temperature. Phenomological parameters (macroscopic) associated with the mechanically reversible deformation modes were defined and their niobium composition and structural state dependencles delineated. The SME reversible strain linit, $\varepsilon_{L}$, was identified with a difuse maximum in the stress versus strain plots. The $\varepsilon_{L}$ varied inversely and continuously with composition from a value of $7.2 \%$ in the 13.9 at. $Z \mathrm{Nb} a^{-2}$ alloy to $4.4 \%$ in the 17.8 at. $Z \mathrm{Nb} Y^{\circ}$ alloy.

All the deformed alloys, whether initially in the $a^{\prime \prime}$ or $\gamma^{\circ}$ state, exhibited SME, but the extent of SME depended on composition and structural scate. The $a^{-\prime}$ alloy showed a much larger effect than did the $r^{2}$ alloy. Heat-activated recovery strains ranged from $5 \%\left(\alpha^{\prime \prime}\right)$ down to $1.7 \%$ $\left(r^{\circ}\right)$ as the niobium content increased from 13.9 to 17.8 at. 7. For all the alloys the heat-activated strain recovery occurred in two stages during reversior to the $Y$ phase. Transformation temperatures during shape recovery were higher than expected. This and other peculfaritles in shape recovery behavior were attributed to the influence of rapid aging (solute segregation) processes.

57 Summary of Paper Submitted to Metallungical Transactions A. 58 Development Division, Y-12 Plant, Oak Ridge. 
The plastic yield strength was approximately constant over the composition range studied, with the measured value being 693 : $1 \mathrm{~Pa}$.

1.6 X-RAY RESEARCH HITH SYNCHROTRON RADIATIOR: SOURCES - C. J. Sparks, Jr., and H. L. Yake l

Our decision to use the powerful $x$-ray generator under construction at Brookhaven National Laboratory is involving us in a jor way in the design and engineering construction of the necessary instrumentation. We will apply the $x$ radiation from the National Synchrotron Light Source (NSLS) to probe the structure of materials. We have identffied several materials science programs at ORNL that will benefit from the unique properties of this radiation source. Among these is the study of local atomic arrangements in iron-base alloys containing $\mathrm{Ni}, \mathrm{Cr}, \mathrm{Co}_{0} \mathrm{~V}$, and $\mathrm{TI}$, where our present $x$-ray sources are unable to distinguish between these atoms. However, the tunable $x$-ray energy from synchrotron suurces will allow us to ctetermine the atomic arrangement of these alloys and better understand iseir physical and chemical properties. Another area of research is the study of liquids and amorphous materials. When two or more kinds of atoms are present, two or more measurements with radiations for which the scattering cross sections of the atoms differ are necessary to unravel the pair-wise currelations that characterize their structure. our use of synchrotron radiation will greatly facilitate these determinations. A host of interesting metal phases are formed in ironbase alloys for which we have insufficient structural information. We ate currently conducting research at the Stanford Synchrotron Radiation Laboratory to determine the site occupancies for Fe-Co spinel and an Ie-Cr sigma phase. This promising research will be continued with our equipment at the NSLS. Another area of our restarch program for which synchrotron radiation will provide major improvements is in the study of defects in materials. Radiation danage, mechanical deformation, and impurity alom defects can now be studied at concentrations levels one-hundredth as much as before. In addition, new structural information on corrosion products and surface films can be obtained. 
These research areas involve personnel from the Cheaistry, Solid State, Metals and Ceranics, and Analytical Chemistry Divisions. Through organizational meetings held at the Oak Ridge Associaced Universities in 1979, we formed a consortiun with university and industrial research people wich sinilar research interests in materials science. This collaboration is under the direction of an interí steering comittee consisting of R. DeAngelis, Departwent of Materials Science, University of Rentucky; S. C. Hoss, Departeent of Physics, University of Houston, Texas; C. 3. Sparks, ORNL; and R. Young. Eng neering Experiment Station, Georgia Institute of Technology. Several consortiumbers are presently engaged in software development for our recently acquired PDP $11 / 34$ computer, which will be used to control experibental equipsent, collect data, and provide for data reductiun. DeAngel is' stay at ORNL this sumer produced any worthuhile contributions to our software developsent in association with A. Habenschuss, who is supported by DOE funding through ORAU to manae our computer system and to do research on liquid and anorphous materials.

A schematic drawing of the experimental apparatus to be installed at the NSLS by October 1981 is show in Fig. 1.12. Both tive computer system and the five-axis diffractoneter are on hand and are being interfaced. A fast data acquistition system capable of registering and addressing $10^{6}$ photons per second is under development in cooperation with the Los Alawos Scientific Laboralcry. (See Sect. 1.2.3.2, this report.) This systee has been dewonstrated by $R$. H. Hendricks of ORNL, and little difficulty is expected in reaching fully operational status. This syster will ensure that we can take full advantage of the intense synchrotion radiation avallable to our experiments. As the front end of our beas line (to the left of the concrete shield of Fig. 1.12) is under construction at BNL, our major remaining task is the design and construction of the $x$-ray optics. He have developed computer tracing prograns to examine the many possible $x$-ray optical configurations. Those with the most desirable properties are being evaluated; ore or more will be constructed and tested at ORNL before Implementation at the NSLS. 


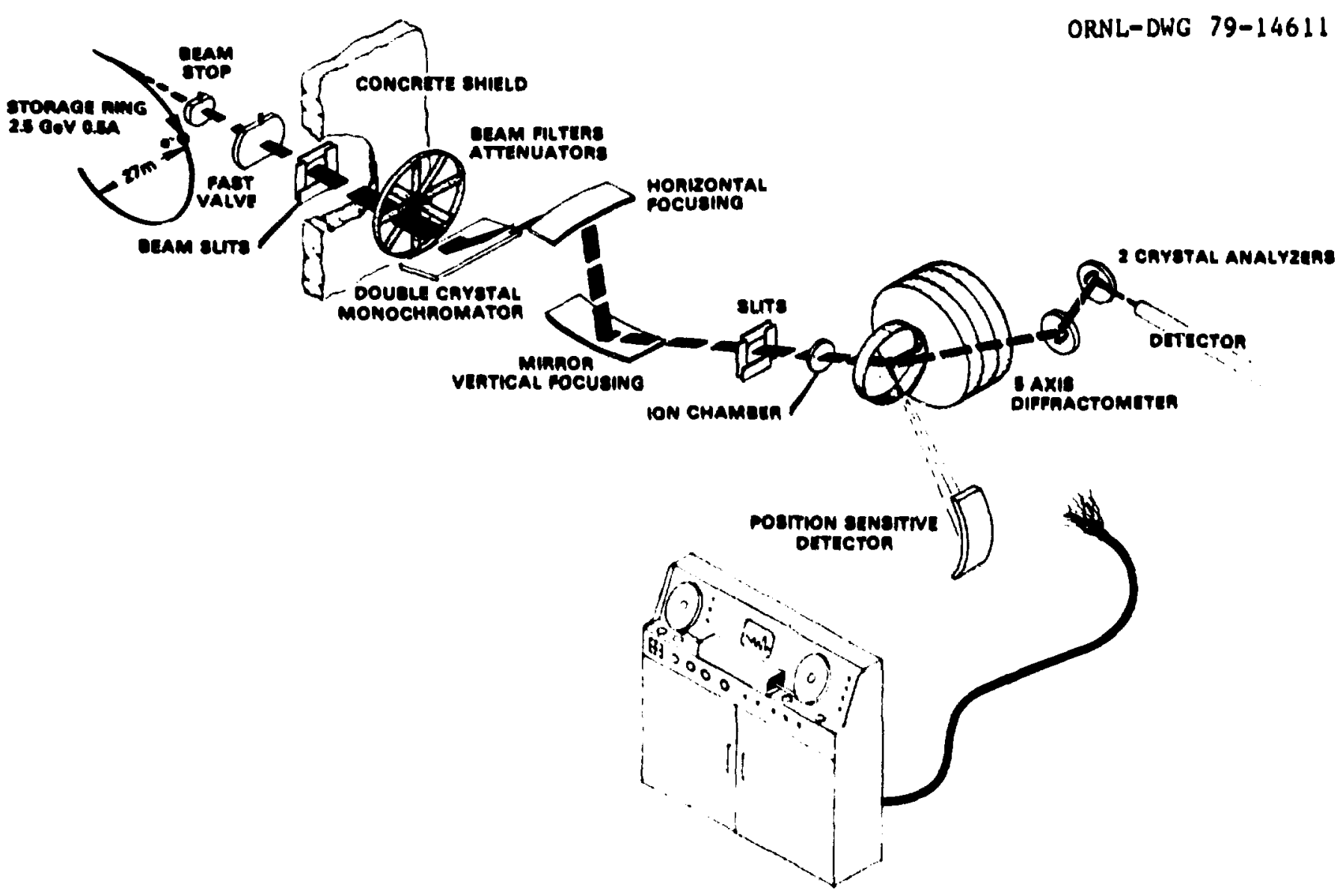

F1g. 1.12. Schematic Representation of the ORNL Synchrotcon Radiation Beam Line. 
1.6.I X-Ray Optics for Focusing and Monochronatization of Synchrotron Radiation - C. J. Sparks, Jr, G. E. Ice, and B. S. Borie

The large distances between the syncintotron radiation source and the experiant require condensing optics to confine the beam to a reasonable size at the sample and to collect as ach of the radiation as possible. The cadiation is sptead over $2 \pi$ in the plane of orbit but i: cunfined to small openiag angles in a plane perpendicular to the plane of the storage ring. This angle ts approxiately given by the rest mass enf $r_{b y}$ of the electron divided by che snergy of the circulating electron, $m_{0} c^{2} / F_{0}$, and is about 0.2 arad for electro energies of $2.5 \mathrm{GeV}$. In the rlane of orbit, the radiation spread from typical bending magnets is from 20 to 50 mrad. Higher intensities and smaller vean areas are produced at th: sample by collerting and focusing this large horizontal divergence.

Two methods for focusing photons are specular teflection from mitror surfaces and diffraction from crystallographic planes. Typical glancing angles for cricical refiection of photons from mirtor surfaces are about $1 / 20$ of that for diffraction from crystallographic planes. For photon energies exceeding $10 \mathrm{keV}$ the small reflection angles require that mirrors be large if they are to intercept che divergence of che source. In addition, sagittal focusing (perpendicular to the plane of scattering) with airrors requires very small be ing radil and conenguently only small divergences may be intercepted.

As crystals are the more desirasle optical element, since they both focus and monochromatize the radiation, we have investigated theoretically the possible geometries to determine those that permit the highest $x$-ray throughput and provide the best energy resolution. To eliminate the complexity of doubly curved shapes required for ideal focusing, we have found that simple cyclindrical and confcal shapes are satisfactory optical elements for synchrotion radiation.

We have derived geometries that show that the radius of cyclindrically and confically curved crystals can be chosen to el lminate the $\Delta \theta$ error introduced by the external shape of tine crystals. This provides for both monochromatization and focusing from a single optical element. 
1.6.1.I X-Ray :tonochronator Geogetry for Focusing Synchrolron Radiation Above $20 \mathrm{kev}^{59}$ - C. J. Sparks, Jr., B. S. Borie, and J. B. Hast ings 60

The relative merits of crystals versus mirrors for focusing synchrotron radiation at energles above $10 \mathrm{keV}$ are explored. As mirror; have critical aingles of reflection typically 1/20 of the Bragg scatrering angles for crystals, large airror surface areas are required. Sagittal focusing is weak for mircors and limits the anount of radiation intercepted. We show that crystals bent tn a simple cylindrical curvature sill accept large divergences of radiation for sagittal focusing. At a magnification near $1 / 3$, the cylindrically curved crystals are shown to make the proper Bragg angle for energies above $5 \mathrm{keV}$ and for divergences larger than 10 mrad and to produce $x$-ray beams that are approximately focused.

1.6.1.2 iome Things About X-Ray Optics for Synchrotron Radiation6I C. J. Sparks, Jr.

Rating factors for choosing $x$-ray optics for synchrotron radiation are defined. The ideal doubly curved crystals produce the maximum intensity and best energy resolution but require a bending mechanism that would be difficult to build, if at all possible, to change the radii to select different energies. The DeWolff logarithmic spiral geometry is found not to be useful for focusing synchrotron radiation. Singly curved surfaces are shown to be the best candidates for feasible application to the focusing of synchrotron radiation. Thermal distortions are likely to be as large as the radius required for focusing the vertical divergence. Crystal combinations are listed for achleving maxisum intensity and energy resolution. Focusing properties are discussed as a function of the radius of curvature and for curved crystals that are ground flat. It is shown that horizontally focusing mirrors mix the large horizontal divergences of synchrotron radiation into the small vertical divergences. Such mirrors

59 Abstracted from a paper in press in Nuclear Instmuments and Methods. 60 Physics Department, Brookhaven National Laboratory.

61 Summary of a report prepared during an August 1979 Research Collaborator's appointment to the National Synchrotron Light Source at Brookhaven National Laboratory. Report BNL-26740 (August 1979). 
placed upstrean of the monochrosatizing erystals deyrade the energy resolution of the optical syster. Horizontal focusing sf synchrotron r.tdiation should be done by crystal optics for x-ray energies above 10 keV and with aircors downstream of the crystal optics for x-ray energies less than If keV.

\subsubsection{Conical Section Curved Crystals for Focusing Synchrotron} Radiation $62-G$. E. Ice

Excellent focus of the horizontal divergence from synchrotron radiation sources can be achieved at magnifications near 1 by using crystals bent to conical curvature. The Bragg planes of a conically curved crystal mimic in orientacton the Bragg planes of a nearly ideal doubly curved "bartel" monochromator for a fan of horizontally divergent radiation. Furtheraore, the crystal acts as a flat crystal to the vertical bean divergence. It is therefore possible to focus simultaneously a horizontal fan of radiation and match the Bragg angles of rays reflected by a flat crystal upstream. This double crystal geometry keeps the diffracted bean fixed in space as energy is changed. The deviation froin a cylindrical bend is small, and the horizontal divergence focused by this crystal can be 20 times that focused by a mirror for $x$-ray energies above $30 \mathrm{keV}$.

\subsubsection{Research Topics}

\subsubsection{Resonant X-Ray Auger Measurements - G. E. Ice}

An atom with an electron removed from an inner shell is in an excited state. This is an unstable situation, and the atom relaxes quickly $\left(\sim 10^{-15}\right.$ s) b; filling the hole with an electron frora a higher shell. Excess energy is enitted by efther a photon (fluorescence decay) or an electron (radiationless decay). The radiationless transition, or Auger effect, is of fundamental importance because it is more sensitive to the detalled nature of atomic wavefunctions than many other observables. Furthermo:e, very accurate radiat tonless transttion rates and the $\mathrm{r}$

62 Summary of presentation given at the National Synchrotro Light Source General IJers Meeting, Brookhaven National Laboratory, June 9, 1980. 
energies and widths are required to interpret a large variety of measurements in muclear and atomic physics. Auger widths al so reflect vacancy

- Iffetives and, therefore, can be used to deternine branching ratios and other de-excitation parameters that are cruclal in schemes to optain stimulated entssion. Detafled knowledge of the influence of spectatior electrons and holes is also necessary for the design of an x-ray laser.

During the year, pioneering $x$-ray photoelectron and Auger electron spectroscopy expertient was begun at the stanford Syachrotron padfation Laboratory (SSR,). This experivent represents the first use of synchrotron radiation to exclite Aiger spectra In the hard x-ray region. The experfoent wes carried out in collaboration of th reseal hers fron the University of Oregon and SSRL. Infthal weasurements have concentrated on observing the tenon $L_{3}=\mathrm{N}_{4} \mathrm{H}_{4} \mathrm{~s}$ Auger if he hear resonance, where the Incident photon has an energy near the absorption edge energy. Prelininary data analysis shows that the iuger line undergoes dranatic changes near resonance. We belfeve that the Interaction with spectator electrons excited to bound states magnifies the edge structure. This may allow for precise deteraination of absolute binding energies in edges whose absorption structure is difficult to interpret because of core hole broadening. Such absolute binding energies can test energy shifts due to relativistic, quantu electrodynanic, and correlation effects. 63

Numerous other experiments that exploft the unfque advantages offered. by synchtrotion radiation and Auger-photoelectron spectroscopy are planned in the near future.

1.6.2.2 Deternination of the Cation Site-Occupation Parameter in a cobalt Perrite From Synchrotron-Radiation Diffraction Data 64 - H. L. Yakel

Energy-tuned synchrotron radiation (SR) was used to collect Bragg diffraction intensity data from a single crystal of a cobalt ferrite

63M. Breinig, M. H. Chen, G. E. Ice, P. Parente, B. Crasenann, and G. S. Brown, "Atonic Inner-Shell Level Energles Determined by Absorption Spectrometry witin Synchrotron Radiation," to be published in Physical Review.

64 abstract of paper accepted for publication in the Joumal of the Phystos and Chemletry of Soltds. 
(nominally $\mathrm{CoFe}_{2} \mathrm{O}_{4}$ ). X-ray energies were chosen just below the Fe and Co $K$ absorption edges, where large changes in anomalous dispersion enhance differences in scattering between the two metals. Observations were analyzed by least squares methods to determine the value of the parameter $X$ that describes the distribution of cobalt and iron ions on the octahedial and tetrahedral sites of the cubic spinel structure. Refinements based or over 290 SR data gave $X=0.83 \pm 0.01$ (83\% of the cobalt tons located on octahedral sites); with only 30 specially selected SR data, this value could be fixed at $0.80 \pm 0.07$. Estimates of dispersion correctic:-s -o the $x$-ray scattering factors for iron near the $\mathrm{Fe} K$ edge were obtained through observations of SR diffraction from a magnetite crystal. Results do not differ appreciably irom predicted values in the range 6358 to $7105 \mathrm{eV}$, though the precision in estimates of the imaginary tem is poor at the lower energies.

1.6.2.3 Atomic Distributions in Iron-Chromium Sigma Phases Quenched From Several Temperatures - H. L. Yakel and J. Brynestad 65

Sparse $x$-ray and neutron diffraction data, collected over 20 years ago, 66,67 suggested nonrandom distributions of $A$ and $B$ atoms on the $f$ ive crystallographically independent lattice sites of many binary sigma phases. The distributions deduced were related to the relative sizes of the at oms and the coordination numbers of the sites. Despite favorable differences in scattering cross sections, results from neutron diffraction powder data ${ }^{67}$ were only precise enough ( \pm 0.5 atoms for a typical site) to indicate trends for such sigma alloys as fron-chronium. There would seem to be it:tle chance of using such data to fnvestigate possible changes in

65 Chemistry Division.

$66_{B}$. G. Berman and D. P. Shoemaker, "The Determination of the Crystal Structure of the $\sigma$ Phase in the Iron-Chromium and Iron-Molybdenum i; stems," Acta Crystallogr. 7: 857-65 (1954).

$67 \mathrm{~J}$. S. Kasper and R. M. Waterstrat, "Ordering of Atoms in the o Phase," Acta Crystallogr. 9: 289-9j (1956). 
the distribution parameters from a given sigma phase quenched from various temperatures within the metastable sigma field, though magnetic measurements show that an ordering-type reaction saj occur. 68

Recently developed stra:n-anneal techniques have allowed ironchromium sigma-phase crystals with dimensions up to $100 \mathrm{\mu m}$ to be grown. These crystals are suitable for $x$-ray diffaction studies, including experiments with synchrotron radiation tuned near $\mathrm{Fe} K$ and $\mathrm{Cr} K$ edge energies, where dispersion effects magnify the otherwise small scatering factor differer:es between th? two elenents. Crystals quenched from 790, 740 , and $650^{\circ} \mathrm{C}$ are currently being characterized via extensive conventional Mo $K \alpha$ diffraction data, preparatory to measurements with 0.175 and 6.207-nn $x$ radiation at the Stanford Synchrotion Radiation Laboratory. Anilyses of ito $K \alpha$ data from a $740^{\circ} \mathrm{C}$-quenched crystal have produced precise position, thermal vibration, and extinction parameters based on the three possible space groups $\left(P_{4} / \mathrm{mmm}, P_{4} \mathrm{~nm}\right.$, and $\left.\overline{P_{4}} \mathrm{n} 2\right)$ that are compattble with the observed scattering. Heasures of agreement do not clearly demonstrate the superiorit" of one of these possible groups, but some stitistical tests seem to farsr the noncentric group $\overline{P 4} n 2$.

Several sets of synci.utron-radition diffraction data have been coilected from this crystal at $0.175,0.207$, and $0.220 \mathrm{~nm}$. Analyses are now under way to derive estiniates of the four occupation parameters that with the average composition describe atom distributions at $740^{\circ} \mathrm{C}$. Analagous experiments with r:ystals quenched from the maximum temperature and the minimum temperature $\left(790\right.$ and $\left.650^{\circ} \mathrm{C}\right)$ in the metastability region are planned,

\subsection{ANALYTICAL AND HIGH-VOLTAGE ELECTRON NitCROSCOPY - R. W. Carpenter}

The research effort last year was approximately equally divided among analytical. microscopy research, applications of analytical microscopy to materials science problems, and in situ experiments ${ }^{69}$ in the high-voltage

68p. Bastier and G. Pom, 4 , "Existence of an Order-Disorder Transformation in Iron-Chromium Alloys Near the Equiatomic Composition," C. R. Hebd. Seance.3 Acad. Sci. 239: 1f 36-38 (1954).

69"In situ" is used to describe experiments in which a specimen is observed in the el zctron microscope simultancously wilh some thermal, mechinical, or ciemical treaiment. 
electron microscope. The analytical micruscopy research emphastzed microdiffraction from crystals containing defects, high-resolut ton lagating, and electron energy loss spectroscopy. Several applications of analytical electron microscopy to materials science problems began last year. The applications tnclude structiral analysis of ceramic as well as metallic matertals, and are described below. The filst in sicu deformation experiments in the high-voltage microscope began this year, and propagating ductile cracks were successfully observed. In situ oxidation experiments on refractory alloys and hydrogenation experiments on lanthanum-base incermetallic compounds have been continued to include detailed analysis of reaction froducts first observed last year.

Next year further effort is expected in developing electron energy loss experimental capability. High-resolution imaging will be used in the determination of the structure of interfaces. Several new applications of analytical microscopy that are currently being made to ceramics, geological materials, and wear-resistant matertals will continue. Analycical microscopy will be used as an additional experimental method to measure changes in in situ gas-solid and deformation specimens from the highvoltage electron microsiope.

Deformation of aluminum all .. intalning prectpitate-free zones and the oxidation behavior of vanad . lloys will continue as the main emphasis of in situ research.

\subsubsection{Diffracticn}

1.7.1.1 Three-Dimensional Strain-Field Information in ConvergentBeam Electron Diffraction Patterns 70 - R. W. Carpenter and J.C.H. Spence 71

Convergent-beam electron diffraction (CBED) paiterns contain diffracted beams from higher order Laue zones (HOLZ), in addition to the more of ten observed diffracted beams from the zeroth-order rectprocal lattice zone (ZOLZ) that contains the origin of the reciprccal lattice.

70 Abstracted from a paper accepted for publication in Acta Crystallogmaphica.

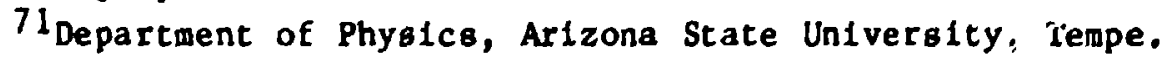


Since HOLZ diffraction vectors have significant nonzero components along the incident el-itron beai direction, they can detect components of static real lattice displacenent fields that lie along the incident electron beam direction, an event not possible for diffracted beams in the zero ozder Laue zone (i.e., ZOLZ diffracted beams). This effect is used in the present work to determine Burgers vectors of straight dislocations and loops in silicon from cbservations of splitting of HOLZ lires within the forward scattered beam Bragg disk and from splitting of Kikuchi lines associated with HOLZ Bragg reflections. The method was also applied with limited success to dislocations in aluminum; here splitting was more difficult to observe because of the rather strong diffuse background in the convergentbeam electron diffraction (CBED) patterns. Calculatior, of HOLZ line splitting due to the presence of a dislocation in the irradiated crystal volume were in good qualitative agreement with the experimental observations. Ef fects on CBED patterns to be expected from some partial dislocations are discussed. This CBED method can be very useful for the determination of non-zolz fault vector components in an atomic resolution structure imaging microscope. These instruments usually have specimen tilt ranges iimited to about $10^{\circ}$; thus conventional Burgers vector analysis is not generally possible. Finally, the present CBED results show clea:ly that the projection approximation generally used to interpret strutcure fringe images is not strictly valid. The changes in fringe images or weak beam images from HoLZ excitations remain to be evaluated.

1.7.1.2 Microdiffraction from Crystals Containing Defects ${ }^{72}-$ R. W. Carpenter

The properties of convergent-beam electron diffraction (CBED) for analysis of vartous types of lattice defects are discussed. The spatial resolution to be expected in various modes of microscope operation and the related angular resolution are compared with experimental requirements for examination of different types of defects in crystals. The use of convergent-beam shadow Images for tilting experiments and placing the electron probe on small areas for microchemical analysis is 1llustrated.

72 Abstracted from an Invited paper for the Microbeam Analysis Society, 15th Annual Meeting, San Francisco, August 1980. 


\subsubsection{Imaging}

\subsubsection{The Observation of "Dumbbel1" fine Structure in $\langle 110\rangle$ Structure Images of Silicon - J. Bentley}

Izui and co-workers ${ }^{73}$ have published structure inages (crossed lattice fringe images) of silicon viewed along $\langle 110\rangle$. Resolution of atomic columns separated by $0.136 \mathrm{~nm}$ was claimed. More recently, Yasuashita et al. 74 have produced similar images from CdTe, which has a slightly larger lattice parameter. We have produced $\langle 110\rangle$ structure images of silicon using a Philips EM400T/FEG analytical electron microscope (AEM), which also show "dumbbell" splitting along $\langle 100\rangle$. These images are remarkable in a number of ways. First, the specimen normal was $\langle 111\rangle$ and the specimen was tilted about $35^{\circ}$ to a $<110$; orientation. Second, this high resolution was obtained in an AEM with $60^{\circ}$ tilting capability and equipped with an $x$-ray energy dispersive detector - not in dedicated highresolution instruments as used by Izul et al. and Yamashita et al. Finally, the exposure time at a magnification of about 450,000 times was only $0.3 \mathrm{~s}$, because of the high brightness and coherence of the 1llumination from the field-emission gun (FEG). An example is shown in Fig. 1.13. The fine structure of these images is an impressive demonstration of the instrument performance, but it can be misleading because the positions of the atomic columns in the crystal are not faithfully reproduced. Careful examination reveals that the images all show a "splitting" along $\langle 100\rangle$, which is $a_{0} / 3$ rather than $a_{0} / 4$ (the $d$ spacing of $\{400\}$ ), where $a_{0}$ is the crystal lattice parameter. The images of Izui et al. and Yamashita et ai. also exhibit this behavior. The "incorrect" spacing can be understood if the splitting is due to \{311\} interferences rather than the (400\} interference, which is required to reveal the corrubated nature of the $\{311\}$ and $\{111\}$ planes. There are then two possibilities to explain the experimental observations. Images can be formed such that interference between the 000 - and 311-type reflections is fulfilled simultaneously with interference between the 000 and both 111- and 223-type

$73_{K}$. Izui, S. Puruno, and H. Otsu, J. Electron Micros. 26: 129 (1977).

${ }^{74} \mathrm{~T}$. Yamashita, P. Ponce, and R. Sinclair, paper presented at $109 \mathrm{th}$ AIME Annual Meeting, Las Vegas, Nevada, February 24-28, 1980. 

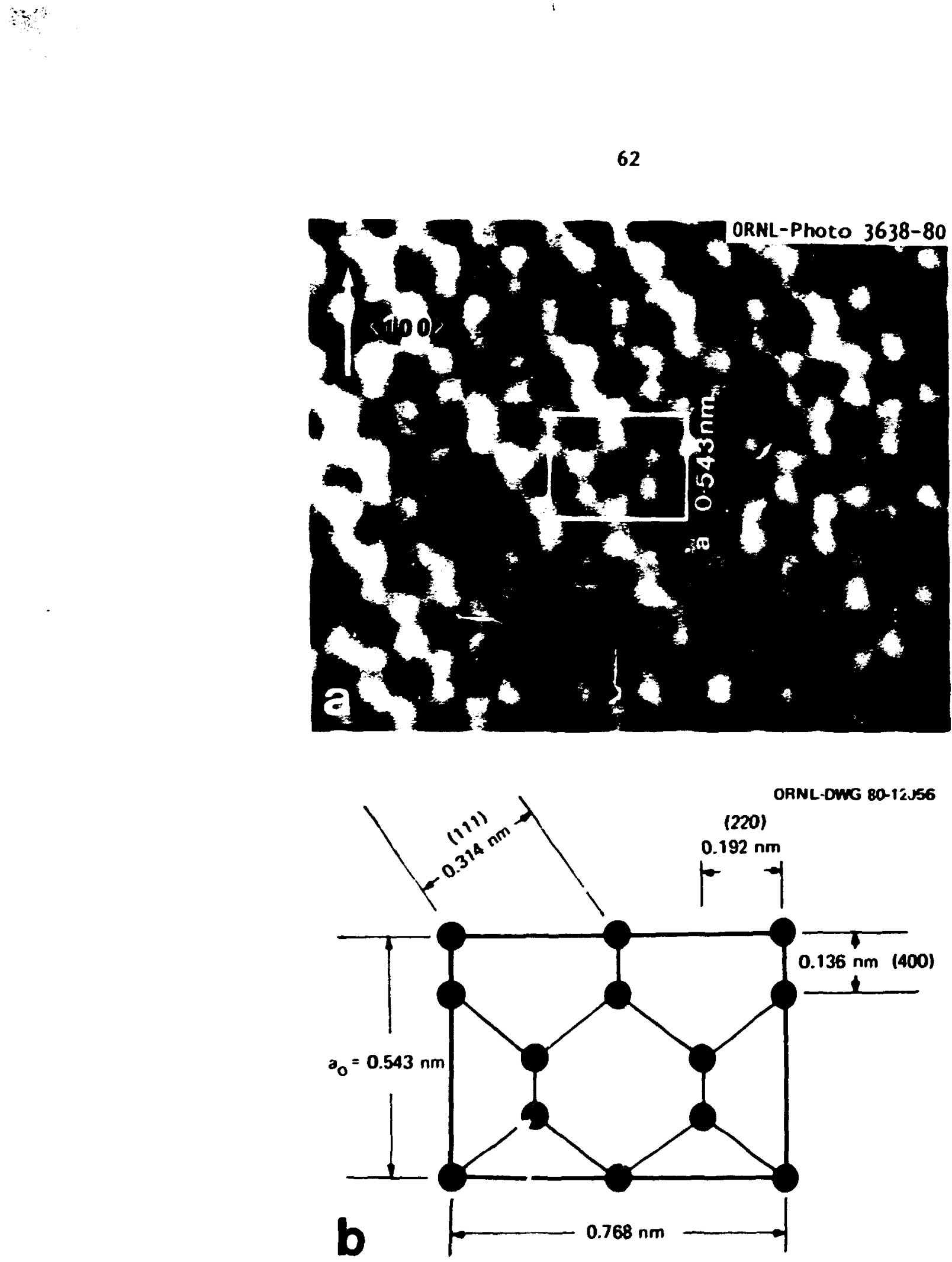

$F_{1} \cdot 1.13$. Structure Image of a Silicon Specimen Viewed Along $\langle 110\rangle$. Foll normal $=\langle 11 \mathrm{l}\rangle$; exposure time $=0.3 \mathrm{~s}$. Nute the "dunbbell" splitting a long $\langle 100\rangle$ with spacing $0.181 \mathrm{~nm}\left(a_{0} / 3\right)$ instead of the "correct" spacing of $0.136 \mathrm{~nm}\left(a_{0} / 4\right)$. (b) Schematic projection along $\langle 110\rangle$ of silicon unit cell showing dimensions. 
reflections. This, in practice, reyuires operating in aberration-freefocus (AFF) imaging conditions. These are generally fulfilled at a particular defocus of the objective lens of soll aberration coefficients. However, in the present case, even with the low energy spread of the beam $(<0.5 \mathrm{eV})$ resulting from the use of the $\mathrm{FEC}$, the chroratic abertation coefficient, $\sigma_{c}$ is suffictently large $(-2.0 \mathrm{~mm})$ that the swallest periodicity for interference involving the axial 000 beam ts about $0.19 \mathrm{no}$. Thus the formation of $\{311\}$ lattice images $\left(d_{311}=0.164 \mathrm{ma}\right)$ is not possible if axial 000-311 interference and $0.5 \mathrm{eV}$ energy spread are used. The convergent-beas illumination exployed in the present case does, however, enable the formation of $\{311\}$ lattice images by another process - namely, achromatic 311-220 interference. (This process is discussed more fully in Sect. 1.7.2.2.) Since the interference is achromatic, it is independent of focus and thus should be observed uver a large range of tocus values. Additional constraints may have to be met, such as simultaneous $111-111$ achromatic interference to produce $\{220\}$ lattice images. This, in fact, is indicated in the present results by the observation that "dumbbell" images are only seen at foil thicknesses where a dark thickness fringe is formed ( $1 . e .$, where the 000 intensity is a minimum and $I I I$ intensity is maximized, conditions favoring achromatic $111-111$ interference). The above hypotheses will be confirmed through an examination of the detailed behavior of the occurrence of "dumbbell" images.

1.7.2.2 Achromatic Interference Efiects in Lattice Images Formed by Using High-Coherence Convergent-Beam Illumination - J. Bent ley

Experience gained when the field emission gun (FEG) is used on a Philips EM400T for lattice and structure imaging studies has revealed the necessity for a theoretical consideration of the effects upon image formation of using high-coherence convergent-beam illumination. Typical lllumination conditions are shown in Fig. 1.14. Each point on the specimen is tllumsnated at different angles, and the diffraction disks in the defocused convergent-beam electron diffraction (CBED) pattern are shadiw images of the illuminated area of the specimen with a resolution determined by the probe diameter at crossover. The above lllumination 
ORNL-DWG 80-14260R

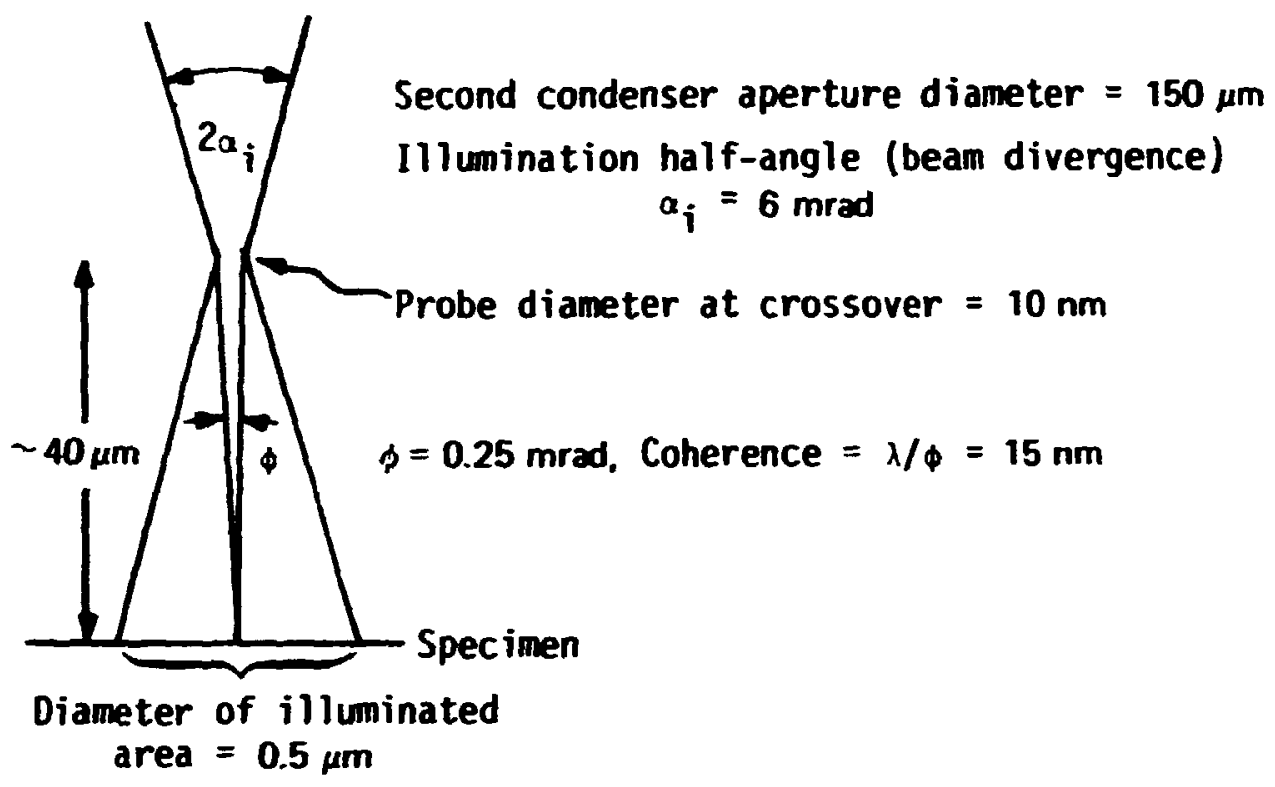

Fig. 1.14. Typical Illumination Conditions Employed in the Phflips EM400T/FEG for Lattice Imaging Studies.

conditions allow achiomatic interference effects, which are not possible with effectively parallel illumination (say $\alpha_{i} \ll 1$ mrad).

The schematic CBED pattern of Fig. 1.15, which represents the $\langle 110\rangle$ zone axis pattern for a diamond cubic material, will be used to lllustrate some of the possible effects. Points within each diffraction disk represent points on the llluminated specimen. For points along the lines labeled in Fig. 1.15, achromatic interference (between beams that are at angles equal to the optic axis) can result, as listed in Table 1.3. For example, for points on the specimen along the line ab achromatic $1 \overline{1} 1-\overline{1} 11$ or $\bar{I} \mid \bar{I}-1 \bar{l} \bar{l}$ interference can result in the appearance of 220 "lactice fringes" 


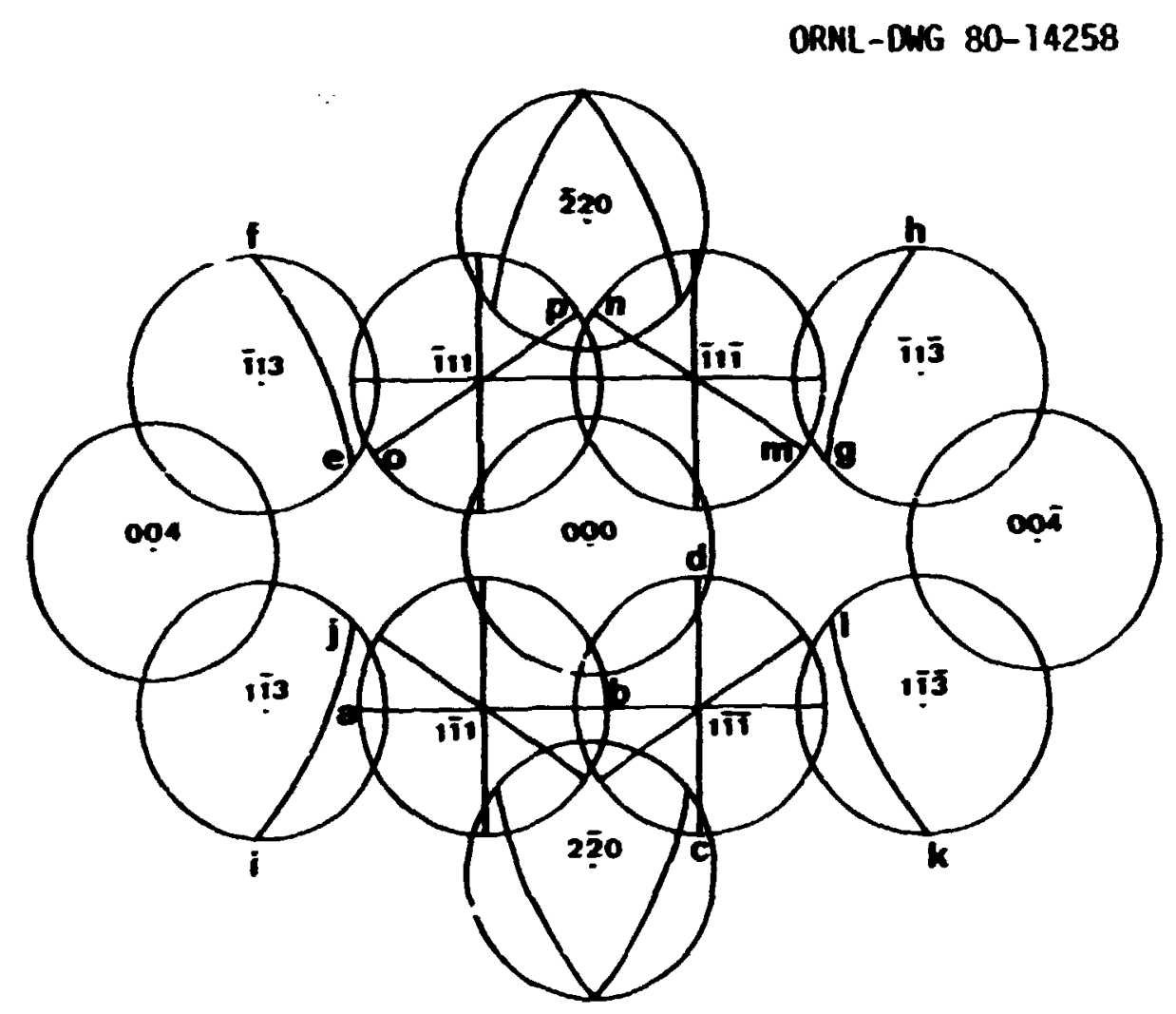

Fig. 1.15. Schematic $\langle 110\rangle$ CBED Patern for a Diamond Cubic Crystal Illustrating Possible Achromatic Interference Effects as Listed in Table 1.3.

Table 1.3. Achronatic Interference Effecrs Possible in the $\langle 110\rangle$ CBED Pattern of Fig. 1.15

\begin{tabular}{|c|c|c|}
\hline Line & $\begin{array}{c}\text { Achromatically } \\
\text { Interfering } \\
\text { Beams }\end{array}$ & $\begin{array}{c}\text { Resulting } \\
\text {-Lattice Fringe" } \\
\text { Inage }\end{array}$ \\
\hline $\mathbf{a b}$ & $\lfloor\bar{l} 1-\bar{\imath} \|, \bar{\imath} \Lambda \bar{\imath}-\lfloor\bar{l}$ & $\overline{2} 20$ \\
\hline cd & $\lfloor\bar{\imath}-1 \bar{\imath}, \bar{\imath}\|-\bar{\imath}\| \bar{\imath}$ & 0,2 \\
\hline ef & $\overline{1} 13-\overline{2} 26$ & $1 \overline{13}$ \\
\hline $\mathbf{g h}^{h}$ & $\overline{11} \overline{3}-\overline{2} 20$ & $1 \overline{13}$ \\
\hline $1 j$ & $1 \overline{1} 3-2 \overline{2} 0$ & 113 \\
\hline $\mathbf{k l}$ & $1 \overline{1} \overline{3}-2 \overline{2} 0$ & $\bar{i} 1 \overline{3}$ \\
\hline mn & 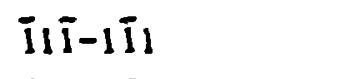 & $2 \overline{2} 2$ \\
\hline op & $\bar{l} 11-1 \bar{l}$ & $\overline{2} 22$ \\
\hline
\end{tabular}


in the image. Elsewhere in this report (Sect, 1.7.2.1) achrowatic 220-311 interference has been argued as being responsible for the formation of "dumbbell" splitting along $\langle 001\rangle$ in $\langle 110\rangle$ scructure inages of silicon. Another effect is the appearance of "torbidden" 200 lattice fringes as shown in the example of Fig. I.16.

The above effects were all possible for nonoverlapping beams. When the bean divergence, $a_{i}$, is great enough that beams o zrlap (generally $c_{i}>f_{B}$, whece $\theta_{B}$ is che Bragg angle), additional effects can occur. This is illustr ted in fig. 1.17, which represents the 〈OOL CBED pattern from a face-centered cubic material. This case has the possibility of forming 200 lattice images from 220-200 achromatic incerference for points zlong the lines $a b, c d$, ef, gh. Only 200-020 achromatic interferences resulting in 22 " lattice images are possible at this orientation for nonoverlappine seams.

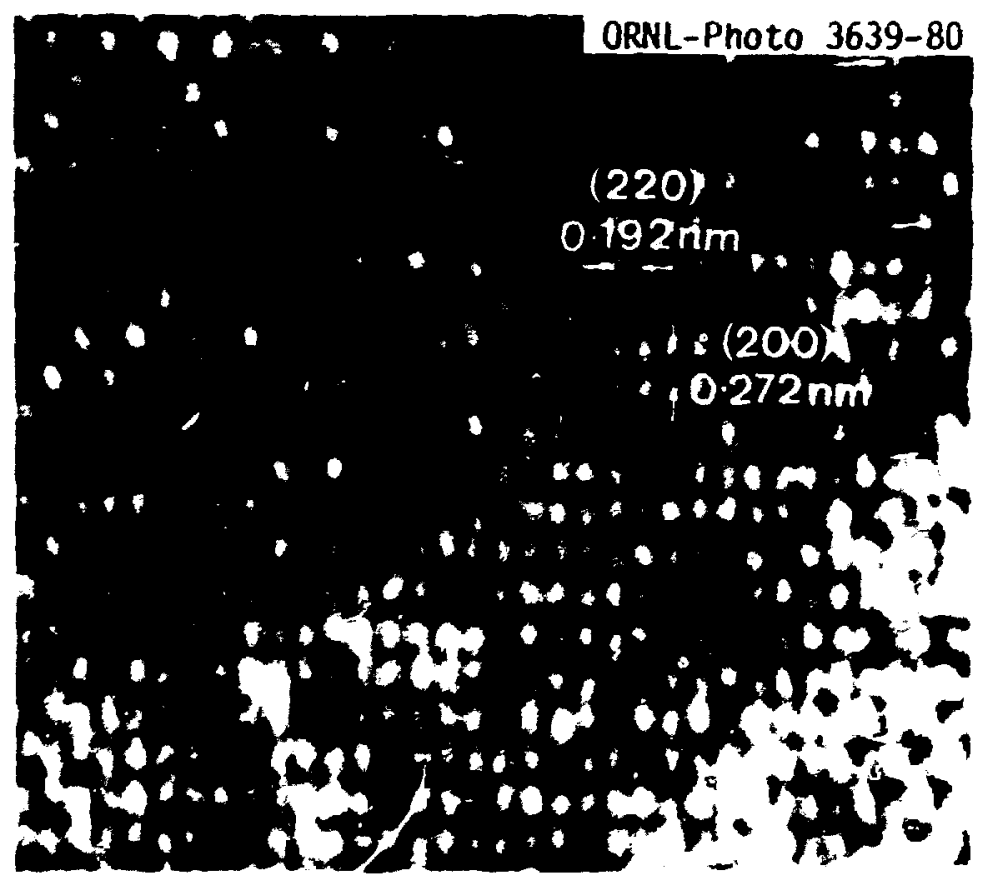

Fig. 1.16. Crossed 220 and "forbidden" 200 fringes Formed by Achromatic inference in $\langle 1 \mid 0\rangle$ Strurture Image of Silicon. 
ORNL-CHG 80-14259

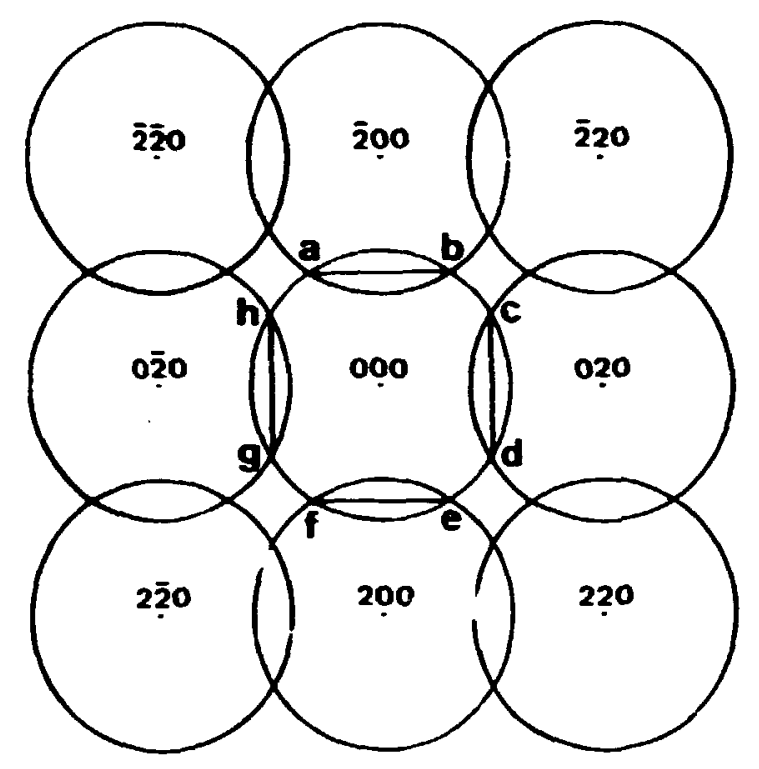

Fig. 1.17. Schematic 〈001〉 CBED Pattern for a Face-Centered Cubic Crystal Illustrating Possible Achromatic Interference Effects then Beams Overlap.

Finally, if the microscope is misaligned, such that the optic axis does not coincide with the center of the CBED pattern, in general the effect is that the symmetry of the described interference effects is reduced. However, achromatic interference, which normally cannot occur, may be possible in a misaligned microscope, even when the beam divergence is small.

From the above discussion it will be seen that the complex interpretation problems of high-resolution structure and lattce images (which involve a detailed knowledge of the specimen thickness, diffracting condttions, objective lens focus setting, lens aberration coefficients, etc.) are more complex when high-coherence convergent beam illumination is employed. However, the information content of the images is higher than in those obtained by using conventional electron sources with lenses of equal electron-optical quality. 
1.7.2.3 Advantages of a Field Emission Gun for a Conbined Analytical and High-Resolution Transmission Electron :icroscope 75 - J. Bentley

Various areas of analytical and high-resolution microscopy can be greatly improved by the use of a high-brighiness field emission gun (FEG). A quantitative evaluation has been made for the instrumentation at ORVL: a Philips E1400T equipped with an FEG, a 6585 STEM unit, an EDAX EIDS detector, and a Kevex 5100 spectroneter.

The brightness $B$ (current density per unit solid angle) normalized to the accelerating voltage, $V_{O}$, is defined by $B=4 I / \pi^{2} d^{2} \alpha_{i}{ }_{i} V_{0}$, where $I$ is the current in a probe of diameter $d$ and divergence $a_{i}$. Results are presented in Table 1.4 for three typical operating conditions. Probe currents exceeding 0.1 HA have ieen obtained in the TEM mode. Such currents are sufficient for work at medium magnifications $(20,000$ to $100,000 x)$. Probe currents were measured from the screen current exposure time system, which had been calibrated with a specially built Faraday cup. Probe diameters in TEM were measured from high-magnification TEM images and in STEM by imaging the STEM raster in the TEl mode. This is possible because of the symmetric objective lens, which can operate at the same excitation in TEY and STEl. An example is shown in Fig. 1.18. The values in Table 1.4 should be compared to conventional tungsten hairpin sources,

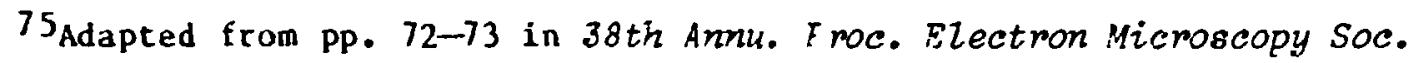
$4 m_{\text {. }}$ Claitor's Publishing Division, Baton Rouge, Louisiana, 1980.

Table 1.4. Measured Valles of B for Philips EM400T/FEC

\begin{tabular}{lcccc}
\hline Mode & $I(\mathrm{~A})$ & $d(\mathrm{~nm})$ & $\alpha_{i}(\mathrm{mrad})$ & $B\left(\mathrm{~A} \mathrm{~cm}^{-2} \mathrm{sr}^{-1} \mathrm{v}^{-1}\right)$ \\
\hline TEM & $3 \times 10^{-8}$ & 15 & 6.9 & $3.5 \times 10^{3}$ \\
STEM (microanalysis) & $7 \times 10^{-9}$ & 4.5 & 11.5 & $3.3 \times 10^{3}$ \\
STEM (imaglng) & $9 \times 10^{-11}$ & 1.0 & 6.0 & $3.2 \times 10^{3}$ \\
\hline
\end{tabular}




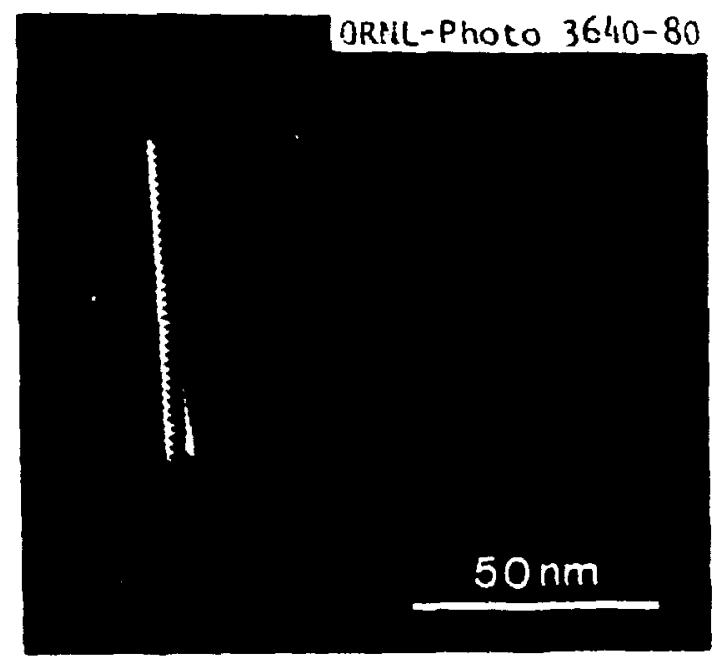

Fig. 1.18. The TEN image of an STQY Raster. Exposure $t i$ ne $2 \mathrm{~s}$. Frane time 0.02 s. Prohe diameter $=1$ nm. This inaging mode is useful in focusing and stigmating the probe for high-resolution STril imaging.

for which $\beta \approx 1$. The important point for microanalysis is that, all other things being equil, a probe of a given size can have greater than $10^{3}$ times as much current as a conventional source. This achieves a greater signal and thus a higher sensitivity.

The minimun detectable mass (:ID:I) and minimun mass fraction (:Lif) define the sensitivity of $x-r a y$ microanalysis. The :lin: is limited by the probe current density and the availability of a low "systems background" signal. For a given probe current, the systems background with an FEG may be lower than with a conventional gun because of a lower emissior current from the FEG. A small specimen of silicon supported on a beryllium grid was used to deternine the :Ib!. The toil thickness was measured iron the CBEU pattern as 22 nn, the probe diameter was about 15 nu, and the prube

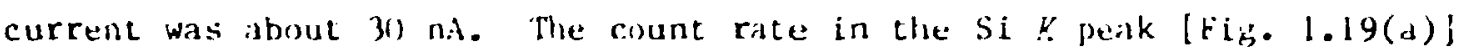
was $2800 / \mathrm{s}$ and that for the inthole signal [fig. $1.19(\mathrm{~h})]$ was $1.1 / \mathrm{s}$. Ising the normal criteria the :Dil is $9 \times 11^{-22}$ b. Even for thid, tavorable specimen geometry the tibit is still limited by the systems background count rate. The rif is limited by the availability of a large number of counts (not usually consistent with the highest spatial resolution) in order for small peaks to be statistically significant above the background. A useful measure of MP sensilivity is the spatial resolution at which bie MMf

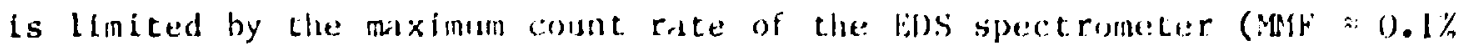
at lou $\mathrm{kV}$ and lou s count lng cime). Ihis has been deterinined co be about 15 run, a spatial resolution that is possible because the hiph current density of the probe produces high tils count rates in folls where beam spreading is sinall. 
ORIL-Photo $3641-: 30$
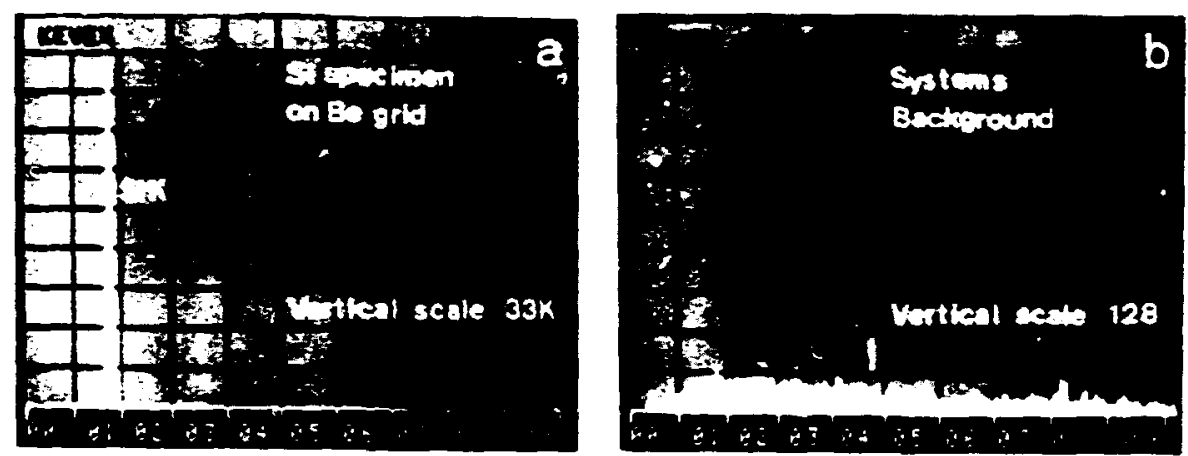

Fig. 1.19. Silicon EDS Spectra. Acquistion time $=100 \mathrm{~s}$. (a) Specimen thickness $22 \mathrm{~nm}$, vertical scale $=33,000$ counts per channel. (b) In-hole signal, vertical scale = 128 counte ver channel.

As regards high-resolution THI imaging, an FEl provides a number of practical advantages. The high brightness available at high magnifications means better visibility on the screen for dstigma:ism correction and focusing as well as short exposure times. The crossover size of about $10 \mathrm{~nm}$ results in high coherence, which, together with the small energy spread of the beam, results in a less rapid damping of the contrast transfer function and hence a high "information limit" lesolution. The "point" or Scherzer resolution limit is determined by spherical aberration and is not improved. Figures 1.13 and 1.16 illustrate performance obtainable.

1.7.3 Electron Energy Loss Spectroscopy - N. J. Zaluzec 76 and K. W. Carpenter

The first electron eneryy loss spectrometer completed and intertaced with a JEOL-LJOCX analytical electron microsrope at the end of last year has been used extensively to examine a number of different specimens of materials science interest this year. This instrument operates in the STEM mode, and is a $90^{\circ}$ symmetric double-focusing magnetic section spectrometer. A number of results obtalued are described below. A new but similar design was created for construction of an electron energy loss sfectroneter to be interfaced with the Philips EM400 analytical microscope.

76Present address: Matertals Sctence Division, Argnine National Latoratory. 
The new spectroneter has a larger radius, $300 \mathrm{mn}$, and therefore a lizge: dispersion. The design will pernit operation of the ricruscope in several m.jdes in addition to ST:̈l, which is an advantage for a number of applications. Two spectrometers of the new design were built. One of these was sent to Argonne vational Laboratory for installation on the Philips E1400 there.

1.7.3.1 The Influence of Diffracting Conditicas on Quantitative Electron Energy Loss Spectrocopy 77 - N. J. Zaluzec, 76 J. J. iren, 78 and R. W. Carpenter

Since many applications of electron energy loss spectroscopy (EELS) deal with microaralysis of crystalline materials, it is relevant to consider the effects uí Lisfracting conditions on an EtLS measurement. It is well known that anomalous effects can be observed during thin-film $x$-ray microanalysis when crystalline materials are oriented under diffracting conditions near deviation parameter $s=0$. It is not surprising, therefore. that similar efiects $w^{2}$ Ll be present in EELS, since this anomalous $x$-ray generation is a result of variations in the ionization cross section witi crystalline orientation. Furtinermore, since multiple scattering effects quickly averaes out these perturbations, one expects the most pronounced effects under conditions appropritte to EELS.

The influence of diffracting conditions on EFLS can be observed experimentally by measuring the relative intensity $\operatorname{rar}^{2} I_{K}^{A}(B, \Lambda) / I_{0}(B, A)$ as a function of 6 . The intensity ratio is equal to

$$
I_{K}^{\dot{H}}(\beta, \Delta) \tau_{O}(\beta, \Delta)=N_{A} \sigma_{K}^{A}(B, \Delta),
$$

77 Adapted from PF. 114-15 in 38tin Annu. Proc. Slectron ifieroscopy Soc. Am., Claitor's Publishing Division, Baton Rouge, Loulsana, 1980.

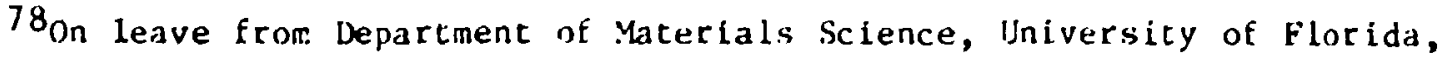
Gainesville. 
where

$$
\begin{aligned}
& I_{R}^{A}(B, \Delta) \text { is the intensity of electruls that have excited a } \quad \text { to inner } \\
& I_{0}(S, A) \text { is the total transaitced intensity, geasured over an energy } \\
& \text { window } \Delta \text { and accoptance ingle } B \text {. }
\end{aligned}
$$

If successive measurements are made of the ratio $I_{p_{0}}^{A} / I_{0}$ at corstant tilickness (hence constant $V_{4}$ ) as a function of 6 , then all variations are due to tha orientation dependence of $\sigma_{K^{*}}^{A}$.

An electropolished single-crystal specinen of vanadium was used to measure the depende:ce of $\sigma_{K}^{A}(B, \Delta)$ on diffracting conditions. Measurements sf $I_{[, 23}^{I} / I_{0}$ wer: aade br stepping a 30 -na electron probe $\left(E_{0}=120 \mathrm{keV}\right.$, bean divergence $a: 3$ mrad) across a $\langle 112\rangle$ bend contour from $\varepsilon<0$ to $6>0$ at constant tuinkness. The local value of is was determined by measuring the separation of the $\pm\langle 112\rangle$ contours and assuming $a$ inear variation across the analyzed region. Then ErLS data were recorded and analyzed by using an integractun window for the $V_{L 23}$ edge of $: 50 \mathrm{eV}$ and a spectrometer acceptance angle $\beta * 6 \mathrm{mrad}$. The specimen thicknesses were determined by using subsidiary bend contour spacings.

Lnder the exp $\geq$ rimental conditions used $\sigma_{L 23}^{V}$ is relatively insensitive co diffracting conditions wher $|.| \gg 0$. However as $|6|+0$, o goes through a shallow minilitr, and at $8=0$ a sharp maximum. The results showed that attempt:rg qua'it ltative EKLS near $\&=0$ can lead to substantial errors since most cross-section formulations used do not take into account an or Lentation dependence of $\sigma$. 


\subsubsection{Microchesical Analysis}

1.7.4.1 un the Linitatlons of $x-k i y$ alicruanalysis of heferogeneous Specimens Usiab analytical Electron Iicruscupy 79 - J. J. Zaluzec, 76 E. A. Kenik, and F. j. Lhziasz

$x$-ray microanalysis in an andytical electron microscope is becoming a routinely used technique in materials science, and it is important to apprecia'e its limitations in the quantitat lve andlys's of inhomogeneous elemental distributions. Situations in which the limitations may occur are in the measurement of precipitate compositions or che determination of concentration gradients at defects or interfaces. This usually amounts to extriction of the precipitate from the parent phase, not always a simple task. We developed a procedure by which gemiquantitative analysis may be obtained in situations where precipitate extraction is difticult or inpossible. For eximple, the analysis of precipitate particles formed in amounts too small to extract under irradiation or metastable precipltates formed during early or intermediate stages of phase transformations.

\section{7 .5 ipplications}

1.7.5.1 Phase Identification Investigation In Silicon ivitride Ceramic Structural Alloys 80 - P. S. Sklad, R. W. Carpenter, N. J. Zalczec, 76 and J. E. Selle

Celanic structural alloys based on silicon nitride $\left(\mathrm{Si}_{3} \mathrm{~N}_{4}\right)$ are of inte. ast for use in high-tenperature applications because of thelr irtractive strength, thermal shock rfsistance, and cortosion resistance. Bojles of S: jis pice fabricated by powder metallurgy methods. Bazauce pure Sigli4 dues not sinter to high density, sintering alds are ordinarlly used to increase densification. Some of these sintering aids can result in glass formation

79 idapted from pp. 132-33 in 38th Annu. Proc. Electron Microscopy Soc. im., Claitor's Publishirig Divisiun, Baton Rouge, Loulsiana, 1980.

${ }^{80}$ Abstracted from paper presented at the 82nd Annuil Meeting of the P.merican Ceramic Socicty, April 27-30, 1980, Chicago. 


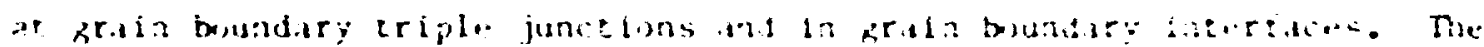

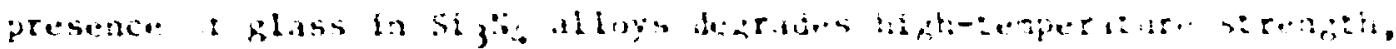

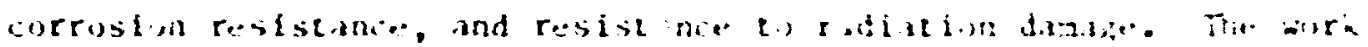

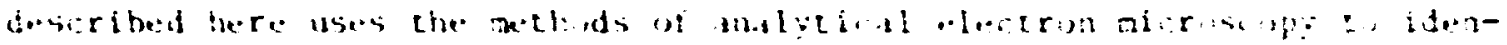

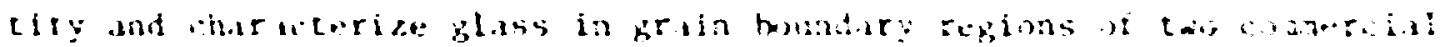

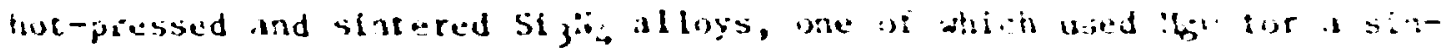
Liting atd and the other $\left.\mathrm{Y}_{2}\right)_{3}$.

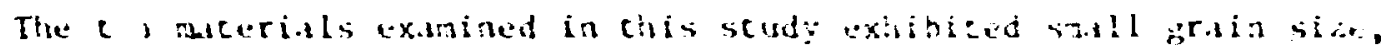

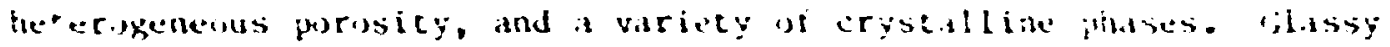

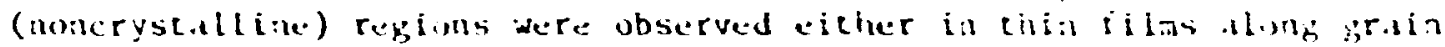
hrenderies or in peskets at mulciple grain jumetions. Figure 1.20 sluows exarales of the nicrostructures observed in each alterial.

The malysis of these complex miersitriseures rejuired the dis of all

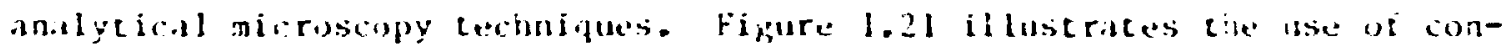

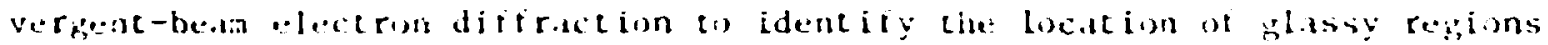

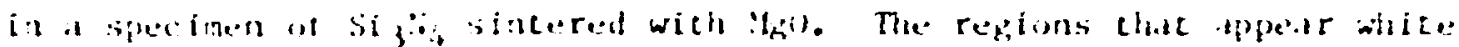
in the upper right are amorplous, as shown in the ditiration pactern in the lower loit. Subsequent $x-r a y$ micromalysis showed that the glassy reg̣ion antained nuphesiun and aluminum as well as silicon (fíg. 1.22).
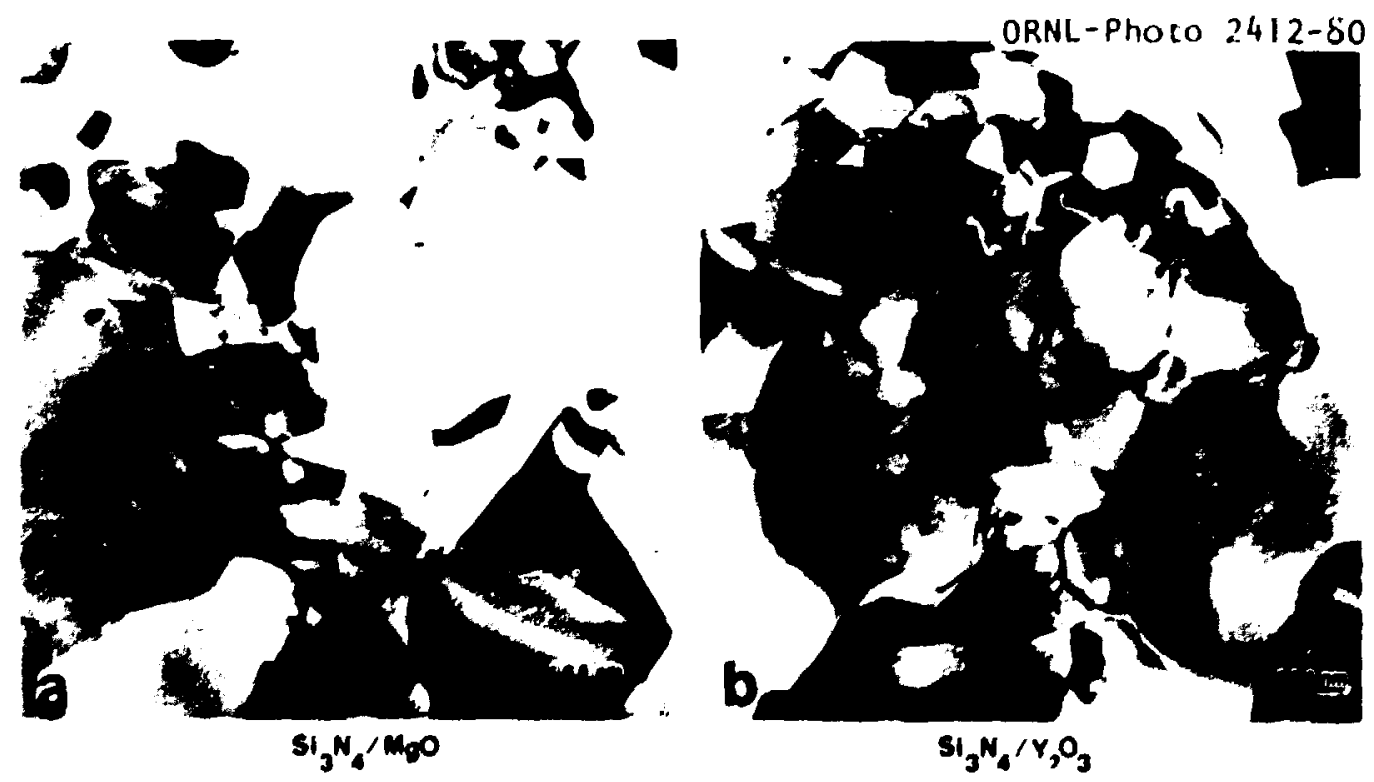

F1g. 1.20. Complex Mlcrostructures Observed ï Stntered Structural $\mathrm{Si}_{3} \mathrm{~N}_{4}$. (a) With $\mathrm{MgO}$ sintering ald. (b) With $\left.\mathrm{Y}_{2}\right)_{3}$ sincering aid. 

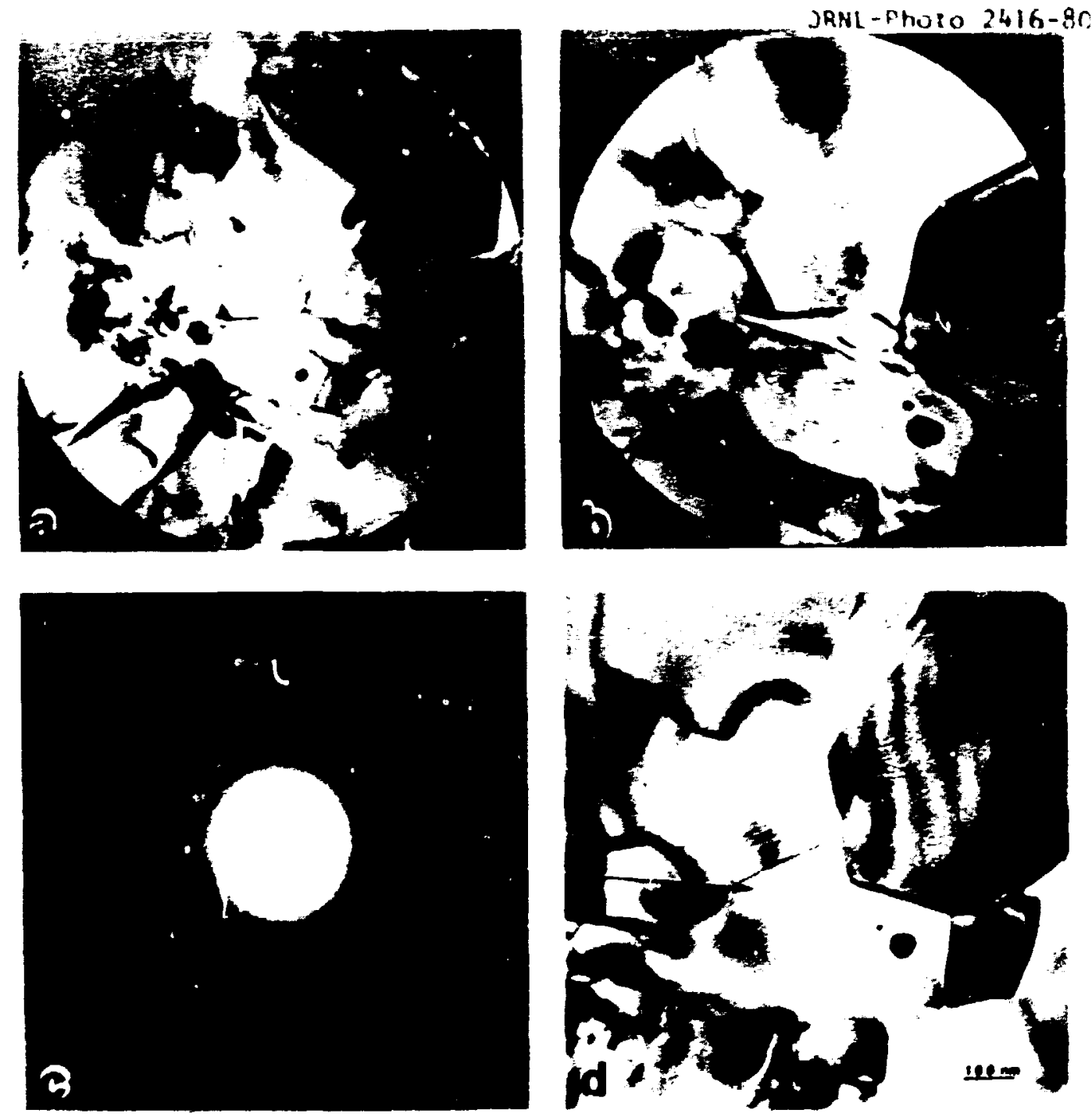

Fig. 1.21. Convergent-Beam Electron Diffraction (CBED) Can be Used to Ident Ify Glassy Regions in $\mathrm{Si}_{3} \mathrm{~N}_{4}$ Sintered Wilh $1 \mathrm{~g} n$. (a) Greatly underfocused CBE.D pattern. (b) Slightly underfocused CBED pattern. (c) Focused CBEU pattern from glassy region. (d) Bright field image of area examined. Note that the camera length used to obtidn the CHED pattern In (c) is much smaller than that used in (a) and (b). 


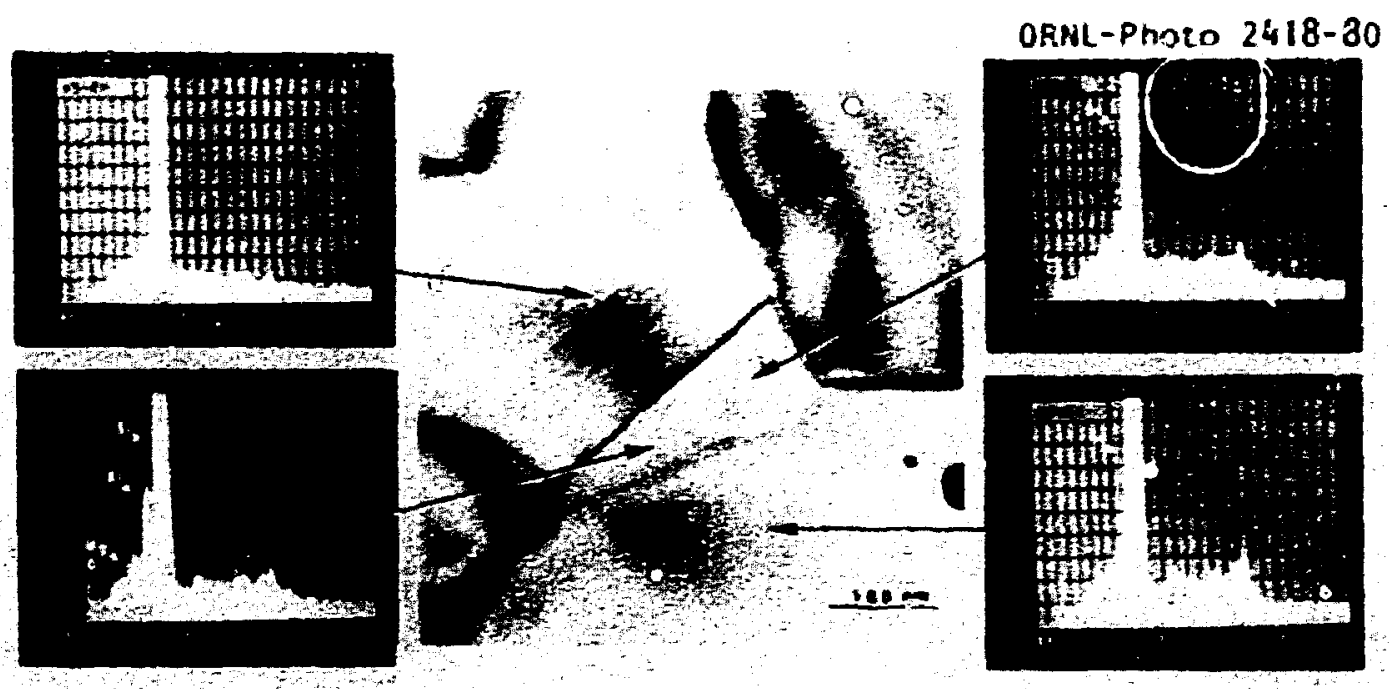

Fig. 1.22. X-Ray Microinalysis Shows That an Arocplious Region in $\mathrm{Si}_{3} \mathrm{~N}_{4}$ Sintered with tgo Contatins Silicon, Magnestum, and Alusinum.

Figures 1.23 and 1.24 illustrate a simllar analysis for the spectuen sincered with $\mathrm{Y}_{2} \mathrm{O}_{3}$. This example shows two phases of interest. The first is a glassy reglon identiffed as the small white criangle in the underfocused CBED shadow image and shown to be noncrystalline by the diffraction pattern in Flg. 1.23(d). The second phase appears black in the underfocused convergent-beam shadow image and is, crystalline, as shown in Fig. 1.23(f). X-ray analysis revealed that the glasisy phase in this case contains silicon but not aluminum, magnesium, or yctrium, while the crystalline phase is rich in yctrfum (Fig. 1.24). A high-resolution axtal fringe image of the ytirium-rich phase is shown in Fig. 1.25. Noce that the fringes run in several directions In several smali areas. This appearance was found in a number of ytcrium-containing regions wichin the spectmen and suggests that micrucrystals may have precipitaled from an yttrlum-contalning glass during processing. These small regions of varlable fringe appearance were not found in any large yttrium-free grains of this material. It was evident from diffraction patcerns of yctriumcontalning grains such as this that the "grains" were not single crystals. 
Our ten:ative con lustion from these observations is that the yttriunEontalining regtons are noncrystalline at the processlig teaperature but are relatively unstable and devictify during cooling.

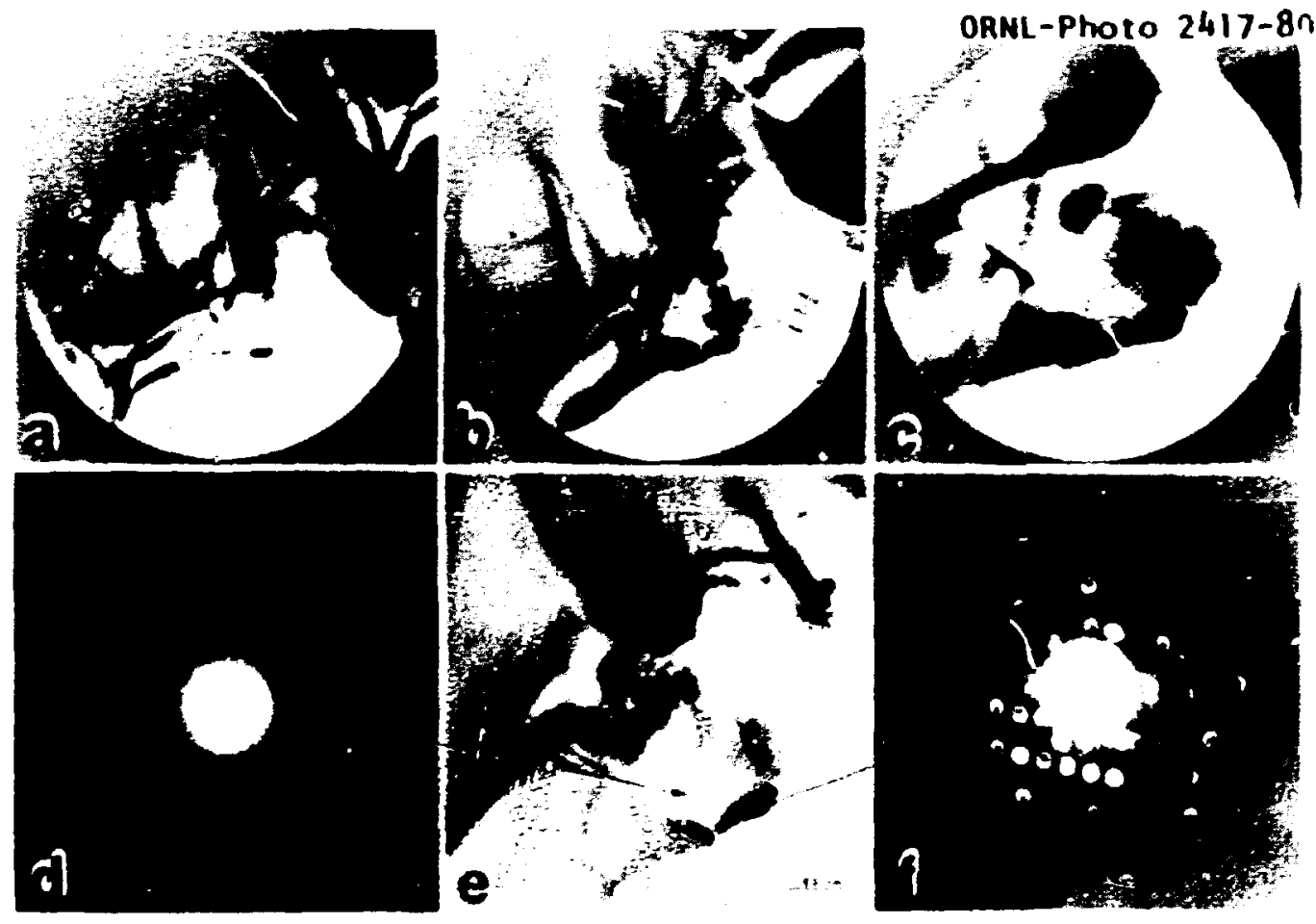

Fig. 1.23. Conver -nt-Beam filectron Diffraction (C.HtD) Can be Used co Identify classy Regions in $33_{3}$ ti sintered wlth $\left.Y_{2}\right)_{3}$. (a) Greatly undertucused CBE.J pattern. (b) Slightly underfucused CBF.l) pattern. (c) Vearly focused CHrI) pattern. (d) focused CBtil) patcern from glassy reglon. (e) bright field image of area examined. (f) focused chtib pattern ron crystalline reglon. Vote that the camera length used lo obtain the Cistb patterns in (d) and (f) was smaller lian the camera length used in (a), (b), and (c). 


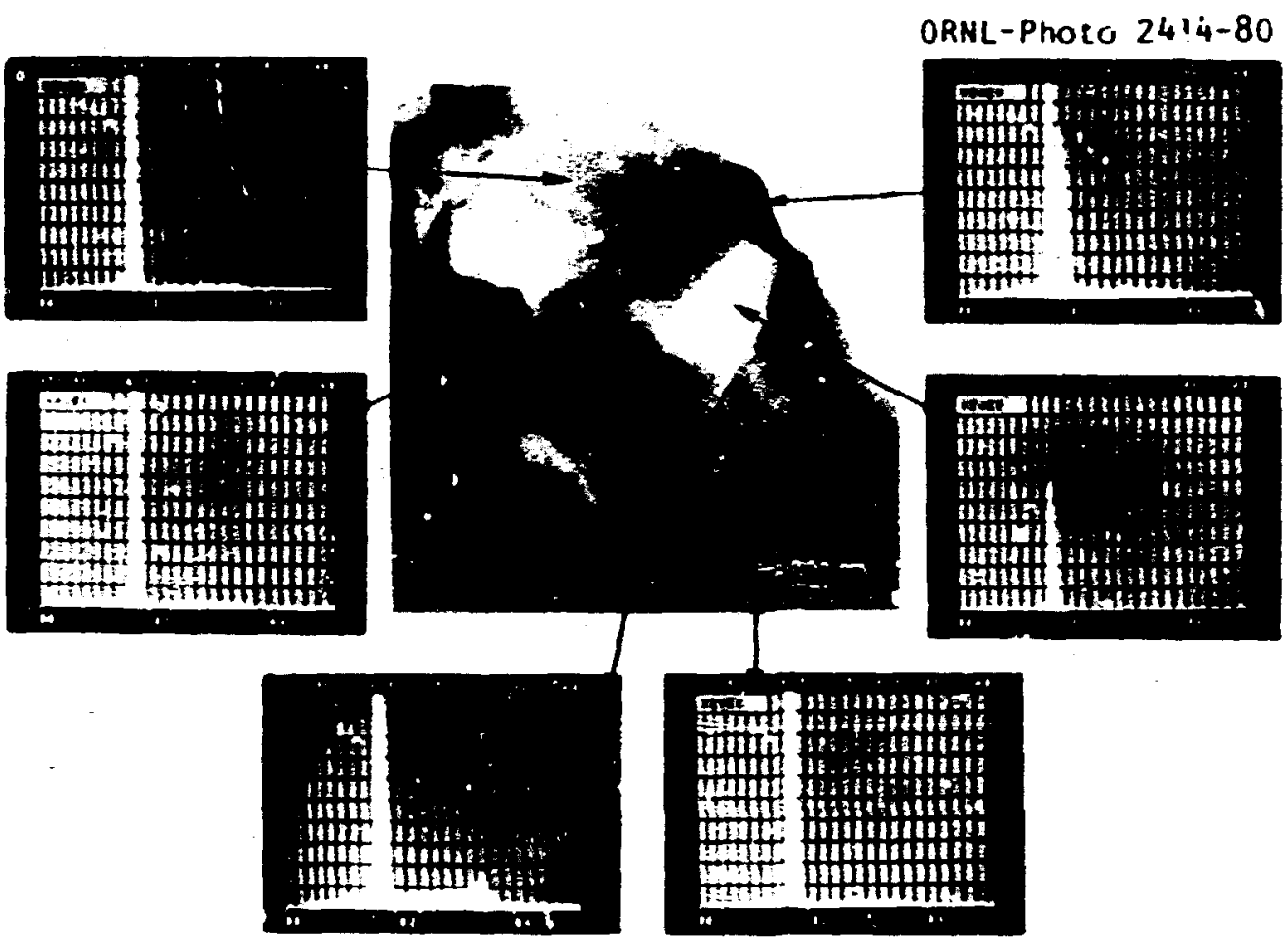

Fig. 1.24. X-Ray Microanalysis Shows the Presence of an Yttrium-Rich Phase as hell as a Silica Glass in $\mathrm{Si}_{3} \mathrm{~N}_{4}$ Sintered with $\mathrm{Y}_{2} \mathrm{O}_{3}$.

This investigation foun.: that Cisto is a very useful and fast method for identification of noncrystalline regions in ceranics because of the very stron;; contrast of these regions in shadow dinages (note figs. 1.21 and 1.23). For very small noncrystalline regions, such as the pocket at the tr:ple junc'ion shown in Fig. 1.26, high-resolution imaging must be used, but it is a much slower method. Also CBtid is uscful for identif Icatlon of crystalline phases. Figure 1.27 shows a bright fleld eiectron micrograph of a large $\mathrm{B}-\mathrm{Si}_{3} \mathrm{~N}_{4}$ grain together with its electron energy loss spectrum and two CBto patterns from the gralw: Silicon nitride commonly occurs in one of two allotropic forms designated $a$ and $B$, both of which have hexagonal structures. The a spacings of allotropes differ by about $2 \%$, and differentiating between the two phases is often difficult. They cannot be distingulshed by use of selected-area diffraction patterns from the basal plane ortentation. However, CBED patterns can be used because they contain three-dimenulonal information in the form of higher 


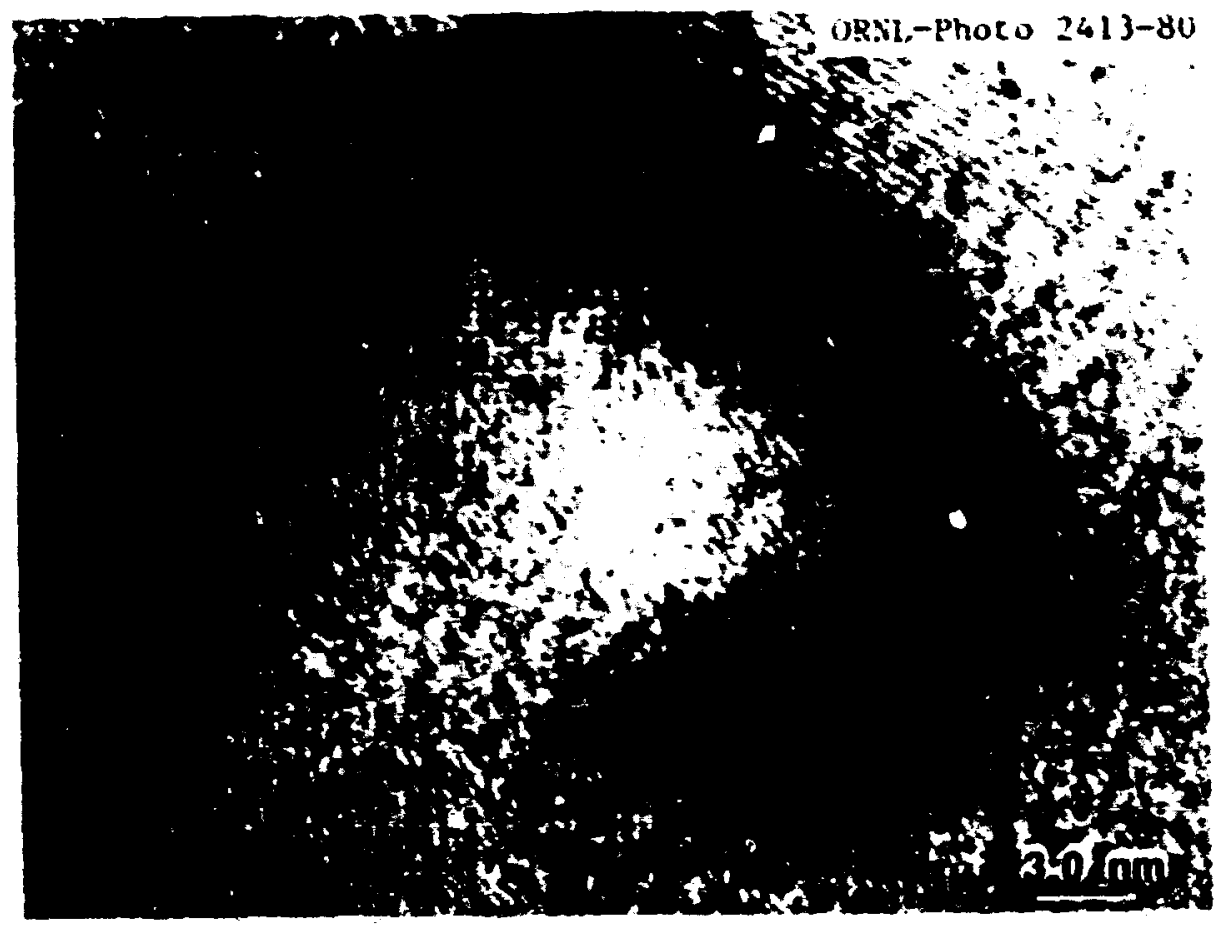

Fif. 1.25. High-Resolution biase Contrast Image of Yccrín-Rich Region in $\mathrm{Si}_{3} i_{4}$ sincered with $\mathrm{Y}_{2} \mathrm{O}_{3}$. winte areas of differently oriented fringes. rringe spacings are about $0.35 \mathrm{~nm}$.

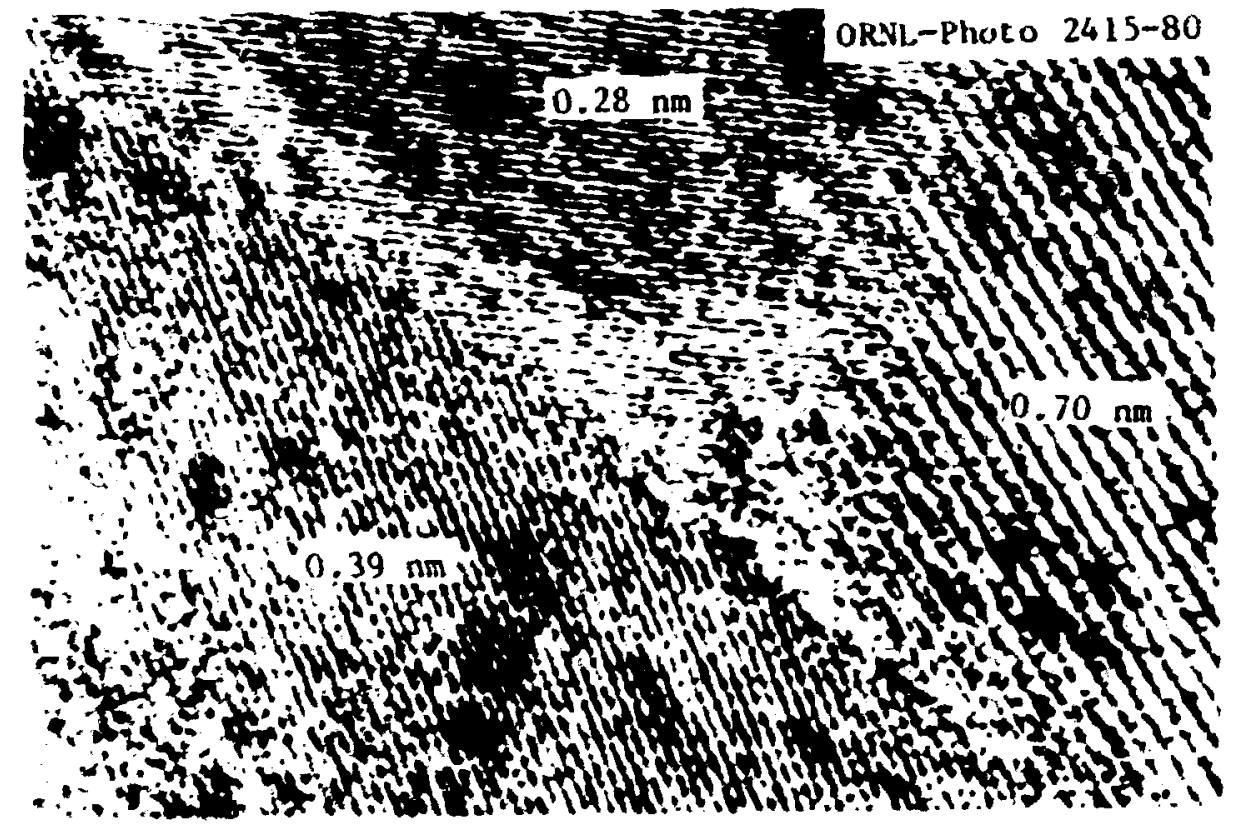

Fig. 1.26. Lattlce Fringe Images of Nelghboring Grains in $\mathrm{Si}_{3} \mathrm{~N}_{4}$ Sintered with $\mathrm{MgO}$. Note the small noncrystalline unfinged regions at t.riple grain junction. 

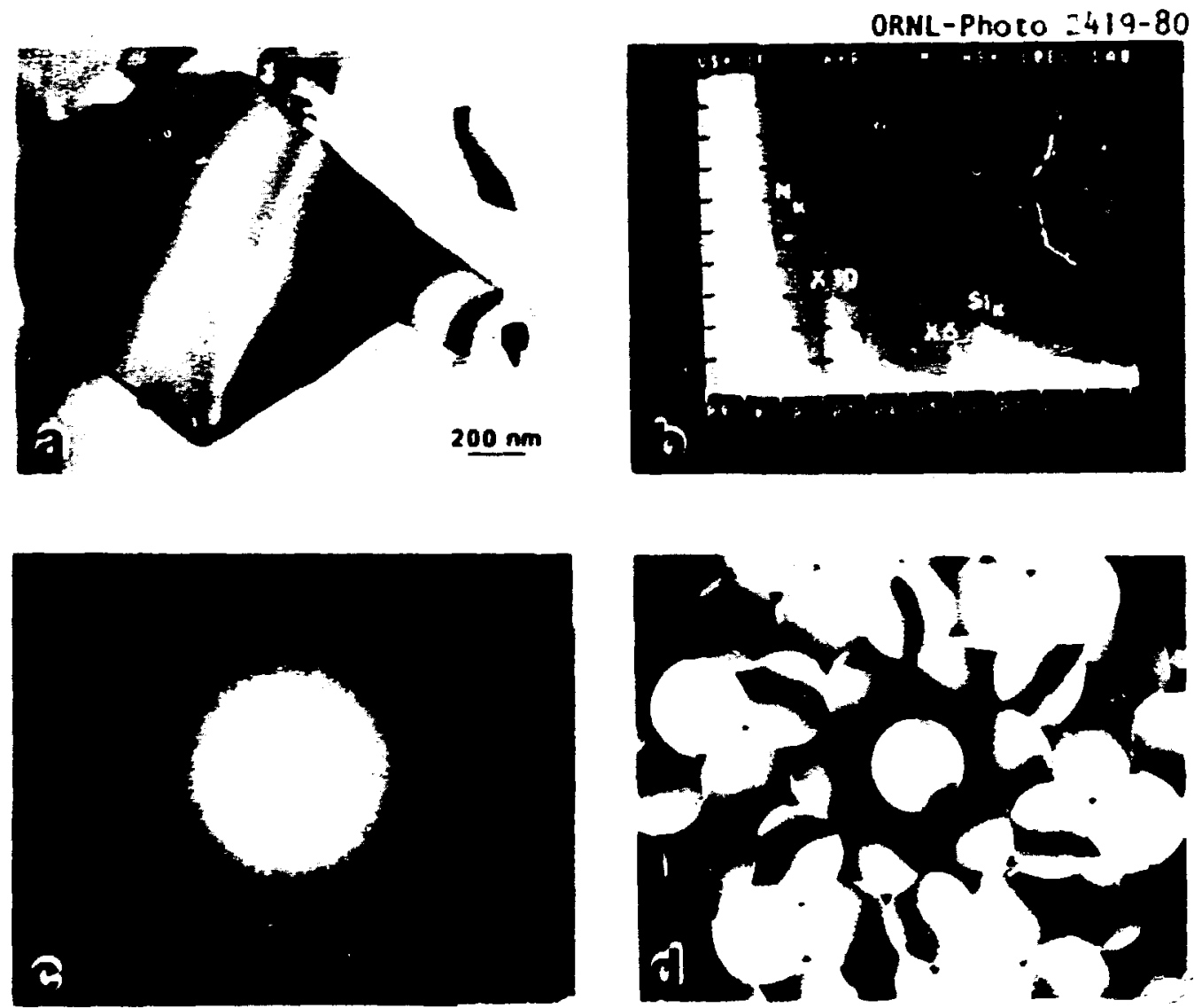

Fig. 1.27. Convergent-Beam Electrun Diffraction (CBED) Can be Used to Obtain Three-Dimensional Information from Materialis. (a) Bright-field image of grain examinej. (b) Electron energy loss speetrum indicating that the material contaiiss silicon and nitrogen. (c) Low-camera-length CBED patcern containing higher order Laue zone ring. (d) High-cameralength CHED pattern fllustrating crystal symetry information contated in Cbtid pacterns.

order Latle zone (HOLZ) rings or reflectlons, which are directly related to the size of the unit cell. In Fig. 1.27 the bright ring in the low-

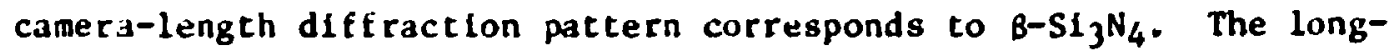
camera-length CBED patterns carry symmetry information about the crystal. In this particular case the dark bands across $\{11 \overline{2} 0\}$ give information about the space group symmetry of the crystal. Electron energy loss spectra are useful for idenifying phases containing light elements, but the peak-to-background ratios for such spectra depend on specimen 
thickness. Acceptable spectr.l can be obtalned unly from spectmen reglons thianer than a few tens of minometers. However, cbell pitceris contintag three-dimensfonal diffraction information can be obtained frop crystals several hundred manometers thlek. It wlll be useful to correlace Er.LS spectra with CBED putterns from crystals contilning light elements and then use CBED patterns for phase identification because of the low thickness limit for useful EtLS spectra.

1.7.5.2 The Intergranular Phase in Hot-Pressed Silicon vitride diloys. 1. Elemental Composition 81 - D. R. Clarke, 92 N. J. Zaluzec, 76 and H. H. Carpenter

Tie demental composition of the noncrystalline Intergranular phase in chrez hgo-fluxed hot-pressed sillicon nitride alloys was determined by $x-r a y$ microanalysis and electron energy luss spectroscnpy in the transmission electron microscope. The composition is similar in all three alloys and lies close to the $\mathrm{Sill}_{2}-\mathrm{IgSiO}_{3}$ tie line, with impurities of calciun, aluminum, and chlorine. No nitrogen could be detected in the noucrystalline phase.

1.7.5.3 The Intergranular Phase in Hot-Pressed Silicon Nitride Alloys. II. Evidence for Phase Separation and Crystallization8I D. R. Clarke, 82 N. J. Zaluzec, 76 and R. W. Carpenter

Compostional and morphological evidence oblained by using transmission electron microscopy indfcates that the noncrystalline phase in a hot-pressed silicon nitride alloy can undergo phase separation. The compositional range determined for the phase separation is close to the known miscibility gap in the $\mathrm{SiO}_{2}-\mathrm{MgO}$ pseudobinary system. Crystallization of $\mathrm{Si}_{2} \mathrm{~N}_{2} \mathrm{O}$ and $\mathrm{MgSiO}_{3}$ from the noncrystalline pilase is also eviden=, suggesting that it can cuntaln some dissnlved nitrogen and that the intergranular phase may be crystallizabie.

${ }^{81}$ Abstracted from paper submitted to Joumal of Amemisan remamic Society.

${ }^{82}$ Structural Ceramics Group, Rockwell Internatinnal Science Center, Thousand Oaks, Callfornla. 


\subsubsection{Observations of Gas Bubbles in an Austenitic Stainless Steel Charged with ${ }^{3} \mathrm{H}^{83}-$ P. S. Sklad}

We are axploring the possibility of using iitronic 40 as a highstrength substitute for 300 series stainless steels, especially in indrogen environments. There is also interest in determining the influence of hellum on the mechanicai properties of this material for use in fusion reactor systems. The alloy is nominally (in weight percent) $21 \mathrm{Cr}, 6 \mathrm{:i}$, $9 \mathrm{ith}$, and $\mathrm{b} 3 \mathrm{Fe}$ and is strengthened by $0.35 \mathrm{wt} \% \mathrm{~K}$.

Smooth-bar tensile specimens approximately $3.5 \mathrm{~mm}$ in diameter with $25 \mathrm{~mm}$ gage lengths were machined from high-energy-rate-forged (HERF) stock. These specimens were then bas-phase charged with ${ }^{-H}$ at 64 MPa pressure at $197^{\circ} \mathrm{C}$ or $3_{\mathrm{HI}}$ at $47.5 \mathrm{MPa}$ at $72^{\circ} \mathrm{C}$ for $1450 \mathrm{~h}$. Following charging, the specimens were stored at about $-23^{\circ} \mathrm{C}$ for 5.5 years. Approximately one-third of the tritium decayed to 3 te during this period, yielding a maximum of $900 \mathrm{ppn}$ of $3_{\text {He }}$ at the surface of the specimens. Tensile tests at $25^{\circ} \mathrm{C}$ revealed a significantly greater loss in ductility in the specimens charged with $3 /$. Following tensile testing, transmission electron microscupe specimens of suitable size were sectioned near the fracture surface, thinned by conventional cechniques, and examined in a Philips bltoOT equipped with a field emission gun.

The microstructures's observed in the two specimens are shown in Fig. 1.28. While both specimens displayed sinilar dislocation

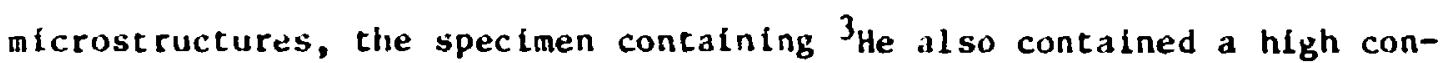
centration $\left(\sim 2 \times 10^{22} / \mathrm{m}^{3}\right)$ of small defects. These defects were noticeably absent from grain boundaries. Examination of Fig. $1.28(b)$ shows that the defects exhitit black-black lobe strain contrast with the line of no contrast approximately perpendicular to the diffraction vector 9 , typical of Ashby-Brown contrast from small coherent particles having spherically symmetrlc strain fields. A number of defects measured approximately $5 \mathrm{~nm}$. However, the strain contrast and small size of the defects make it difficult to determine whether they are small precipitate particles or gas bubbles.

83 Adapled fror. Pp. $388-89$ in 38 ti Annu. Proc. Flectron Mierobcopy Soc. Am., Claltor's Putlishing Diviston, Bator Rouge, Louisiana, 1980. 

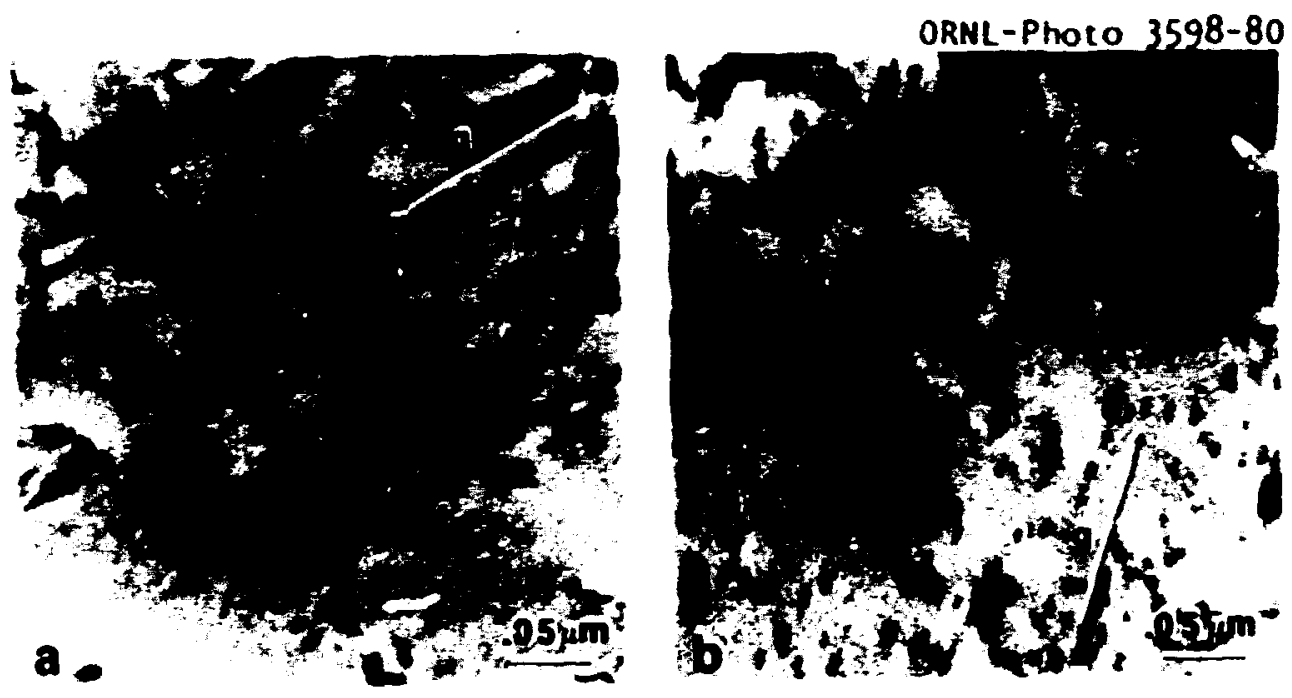

Fig. 1.28. Bright Field licrographs of High-Energy-Rate-Forged (HERF) Nitronic 40. (a) Charged with ${ }^{2} \mathrm{H}$ at $64 \mathrm{MPa}$ pressure at $197^{\circ} \mathrm{C}$ and aged 5.5 years at $-23^{\circ} \mathrm{C} ;=200$. (b) Charged with $3_{\mathrm{H}}$ at $47.5 \mathrm{MPa}$ at $72^{\circ} \mathrm{C}$ and aged 5.5 years ac $-23^{\circ} \mathrm{C} ; g=200$.

To differentiate between precipttate particles and gas bubbles a through-focus serias of micrographs was made. The results are shown 1.1 Fig. 1.29. The objective lens is underfocused at about $8 \mu \mathrm{m}$ in (a), is close to focus in (b), and is overfocused by about $8 \mu \mathrm{m}$ in (c). The defects exhibit contrast behavior characteristic of gas bubbles or voids

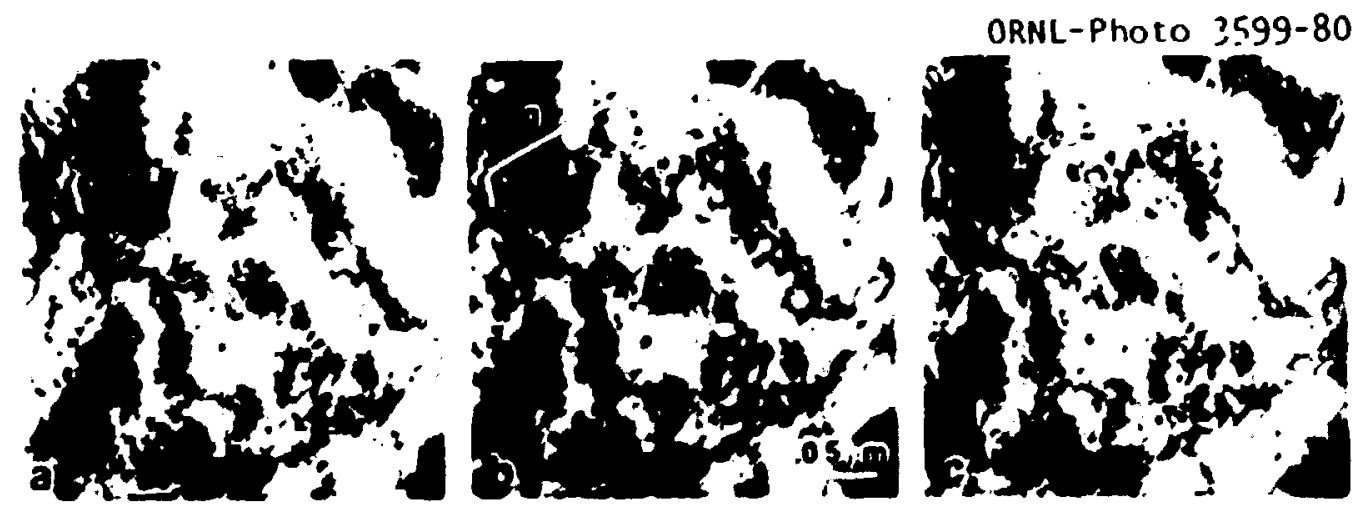

Fig. 1.29. Bright-field Thrisugh-Focus Series of a Nitronic 40 specimen Charged with $3_{H}$ at $47.5 \times 1$ ia at $72^{\circ} \mathrm{C}$ and Aged 5.5 Years at $-23^{\circ} \mathrm{C}$. (a) objective underfocised by about $8 \mathrm{~mm}$; (b) objective near focus; and (c) objective overfocused by abour $8 \mathrm{~mm}$. The diffracting conditions are $s_{g}<0$ for $g=200$. 
(1.e., a bright center dith dark iringes in tou undertocused andi:i in and dark center with bright fringes it the ovectucused (ondition). It is alsis important to note that the best iages were obtained with a negative deviation parameter $\left(S_{j}\right)$. This contrast behavior is normally observed most clearly when the specinen is tn kinematical diffracting cunditions with values of underfocus and overfocus much smaller chan those used in the present example.

We used the number density and size of che detects to estinate the amount of gas present, using the gas law expression for the number of gas atoms in an equilibrium gas bubble. The results are consistent with the estimated helium content of the specimen. We conclude that the bubbles were formed in conjunction with vacancies produced during deforation.

G. R. Caskey, du Pont Company, Savannath River, supplied the specimen material.

\subsubsection{Creep :licrostruciure of ferritic $9 \mathrm{Cr}-1$ :b steel - P. S. sklad, R. W. Carpenter, and V. K. Sikka}

The chemical composition of $9 \mathrm{Cr}-1$ Mo ferricic class steels has often been modified to improve properties such as energy absorption upon fracture and creep st rength. We have examined changes in microstructure during creep in two modified alloys of this type. The basic difference in romposition between the two alloys is in carbon and in the strung carbideforming alsoying elements silicon, vanadium, and nioblum. The alloy with higher energy absorption upon fracture had a higher ratio of strong carbide-forming metals to carbon concentration; however, this alloy also exhibtted lower creep strength. Both materials were homogentzed followed by ait cooling and reheating to temper. The microstructure of each alloy is shown in Fig. 1.30 .

Both alloys contain polygonized subgrains, with the dislocation density in the subgrains being significantly lower in the alloy containing the larger concenicration of carbide-forming elements. Extraction and $x-$ ray experiments showed ': gher precipltate concentration (0.92 wt $\%$ ) in the al loy contalning more strong carbide-forming elements relative to cite 

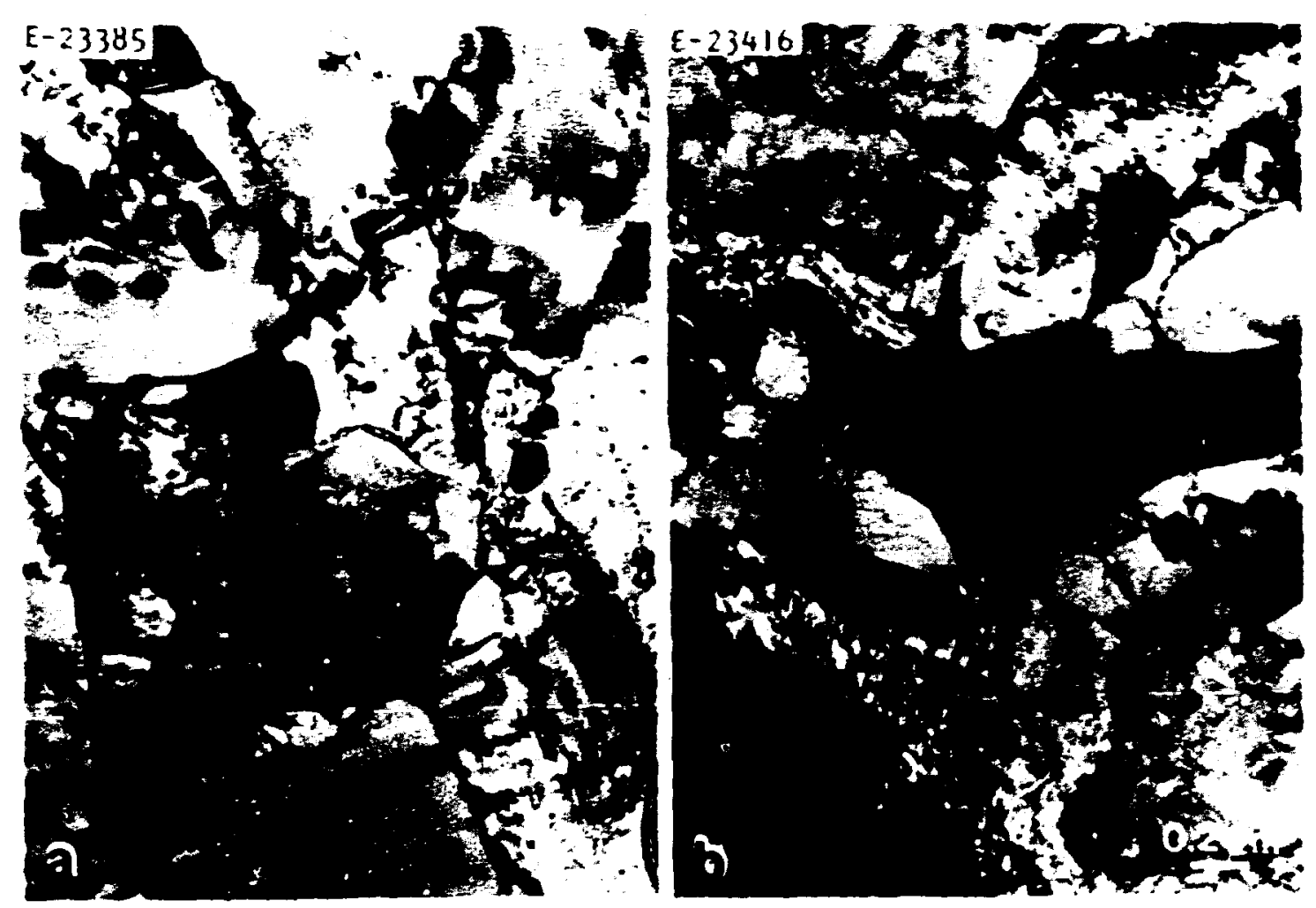

Fig. 1.30. Aicrostructure oi todified $9 \mathrm{Cr}-1$ :to steels Betore Creef: Testing. (a) High carbide-forming element collientratlon. (b) inw carbice-forming element concentration.

alloy of lower concentration (0.57 we precipitate). The piecipitate phases in both cases were primari!y $M C$ and $: I_{2} b_{n}$. After creer testing at $6510^{\circ} \mathrm{C}$ both alloys exhibited greater subgrain size. Exanples are shown in Fig. 1.31 .

The lower dislocation density within polygonized subcolls observed before creep teating in the alloy having the higher carbide-forming element concentration persisted after creep testing. Precipitition occurred during creep cesting in both alloys, with the concentration belng higher ( 1.74 wt \%) in the alloy of larger carbide-formlag element concentrition than in the other alloy ( 1.03 wt \% preclpitate). ibscrvations made: to date suggest that the reason for the difterence in chanical propertes between these alloys is related to preclpitate distribution, in partcislar to fine carbide precipitation on dislocations or nerworks in the alloy of low carbide-forming element concentrat ton. Some ligher resolution 

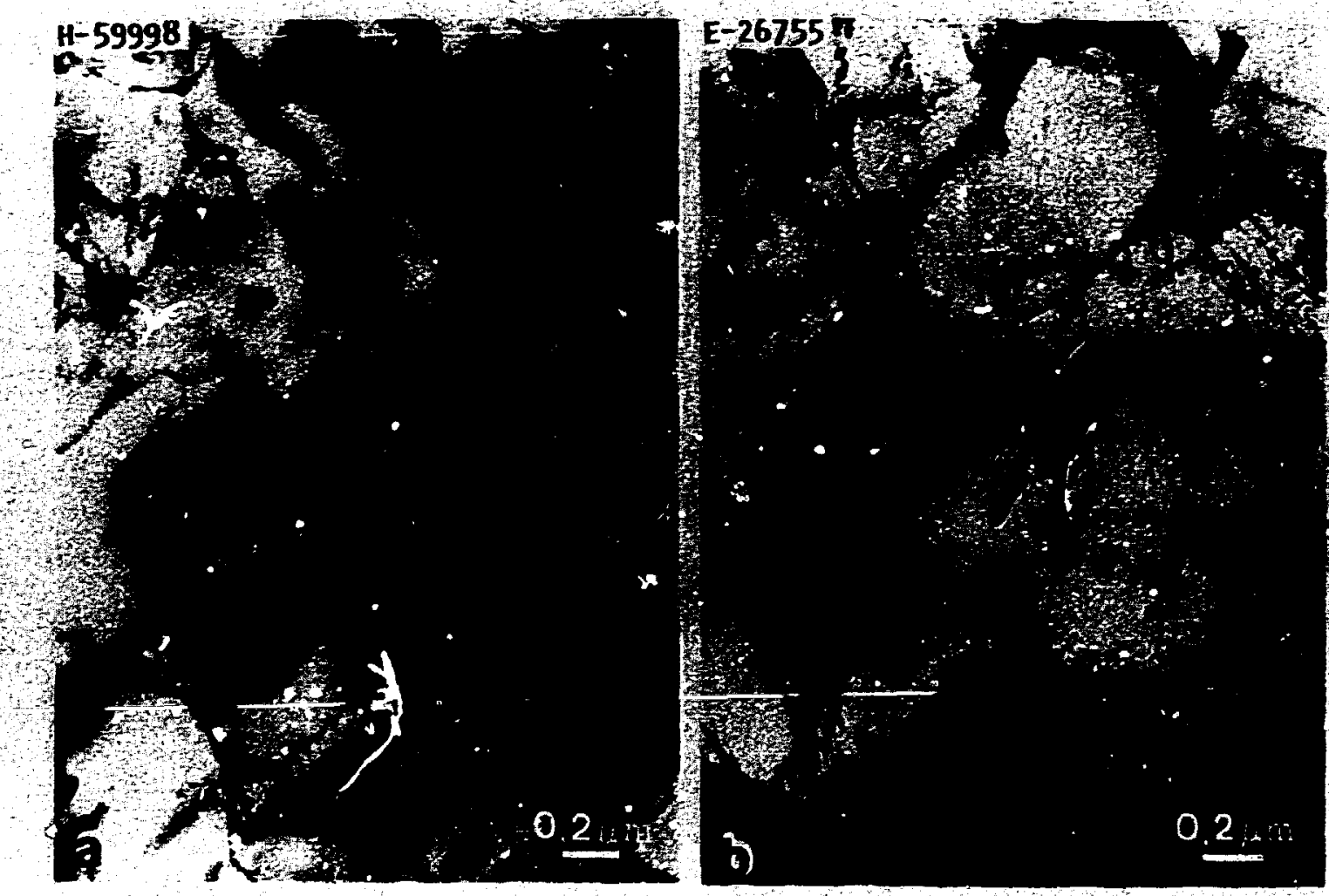

Fig. 1.31. Microstructure of Hodtfied $9 \mathrm{Cr}-1$ Ho Alloys After Creep Deformation at $650^{\circ} \mathrm{C}$. (a) High carbide-forming element concentration. (b) Low carbide-forming element concentration.

Investigations of this phenomenon were made, with not entirely satisfacrory resules. The for harrier to obcaining good-quality high-resolution micrographs is the ferromagnetism of both alloys. The ferromagnetism causes $108 s$ of quality in high-resolution images and is the primary reason for the paucity of electron microscopy results on alioys of this cype. We expect that a specimen preparation method can be developed that will permit reasonably sfwple examination of these microstructures under high resolution condicions (weak beam dark field). All other analytical microscopy methods can presently be used. This work is continuing, and the principal effort is directed to detailed examination of deformation substructure and its relation to precipitate distribution. 
87

\subsubsection{High-Voltage Electron Mcroscopy}

1.7:6.1 Image Decoralng Syste- for Hgh-Voltage etectron Hetoscope Dynate Studies - E. A, Rentk

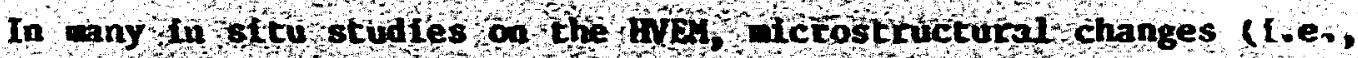

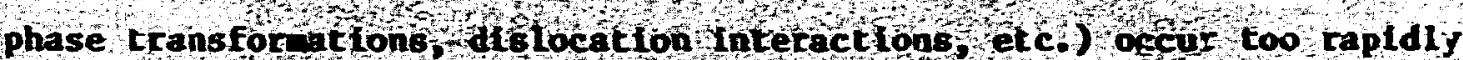
to be observed at peal $t$ te or to be recorted wh conventional fil

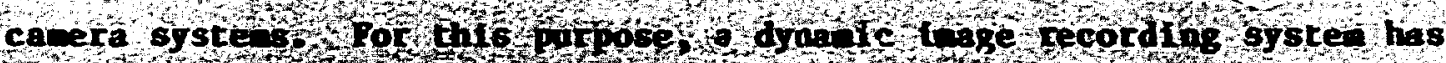

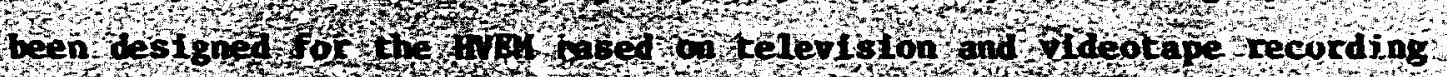

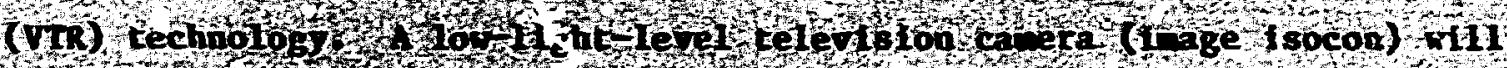

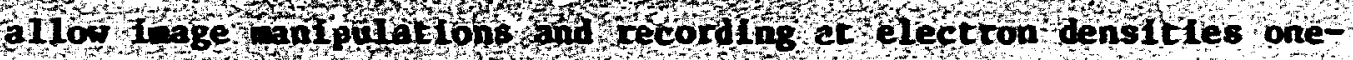
twentieth of less of those of present $q \mathrm{sual}$ observation or convent ional recording. The assoclated VrR syste fill allow low-speed or stop-action exanination of the recorded acrostruclural changes. Particular at tention has been given to watching the resolution and speed limits of the individual units chosen to provide an optimizej system.
1.7.6.2 In Sicu Deformation of Aluminum Alloys $84-$ E. A. Kunik and R. W. Carpenter

Deforwation processes in a series of aluminum alloys have been Investigated by in sicu tenslie deformation ir the high-voltage electron ifcroscope. Both solid-solution-hardened and precipttation-hardennd alloys have been studied. Interactions of slissile dislocations with other dislocations, precipitates, grain boundaries, and other defects were lavestgated, as were the microstructural processes involved in the ductile fallure of such specimens. Figure 1.32 fllustrates the extensive cross-slip ar precipitate particles, which widens the operating slip bands of aluminum alloys. The precipttate strain field produced image forces that promote cross-sifp. Companion experiments on stainless steels indicate a lower occurrance of cross-81ip, presumably the result of the lower stacking fault energy of austenitic alloys.

\footnotetext{
84Adapted from pp. 28-29 in 38th Annu. Proc. Blectron MLeroscopy Soc. Am., Claltor's Publishing Division, Baton Rouge, Loulsiana, 1990.
} 

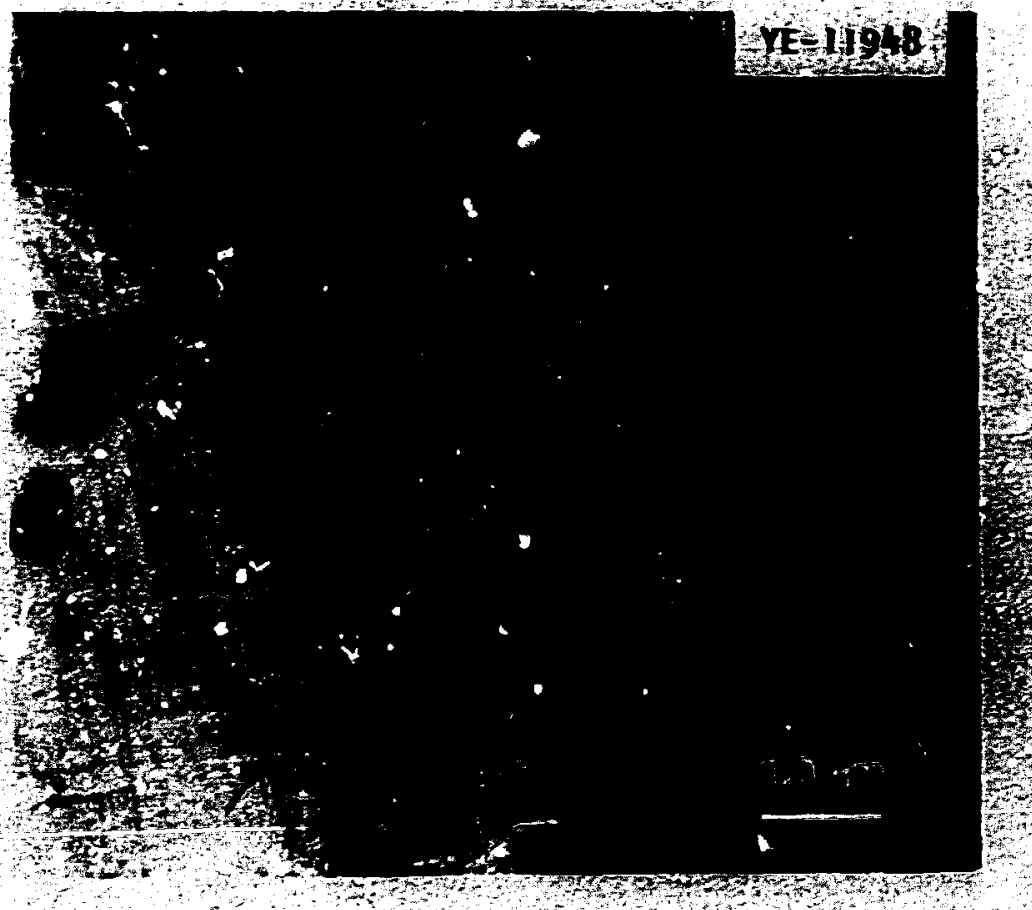

7Ig. 1.32. Intense Cross-S1ip of Gide Dislocations hear Incoherent Prectpitates in Aged 1100 luninum.

In quenched $\mathrm{Al}^{-4}$ wt $: \mathrm{Cu}$ alloy, the interaction of glissile dislocatIons with quenched-in loops results in essentially dislocation-free paths through the loop wicrostructure. This process is sinilar to "channel slip" observed in irradated werals: The speed of interaction precloded deteruining the exact process responsible for the clearing action of the glissile dislocation.

The interaction of glissile dislocatiois with grain boundaries was investigated in annealed 1100 aluminum The dislocations initially pile up fust short of the grain boundary as a result of Image forces. As additional dislocations arrive at the pileup, the leading dislocations are forced tnto che grain boundriy, where they are accomodated, Careful diffraction inaging shows that no dislocacions have been generated in the adjacent grain by either the dislocation pileup or absorption at the boundarv.

P1gure 1.33 11lustrates the propagation wode of a shear crack in an annealed 1100 aluinum alloy. Ahead of the advancing crack, Intense uitiple slip-system deformation results fin a locallzed thinring of the foll and leads to the formation of a hole just ahead of the crack. The 


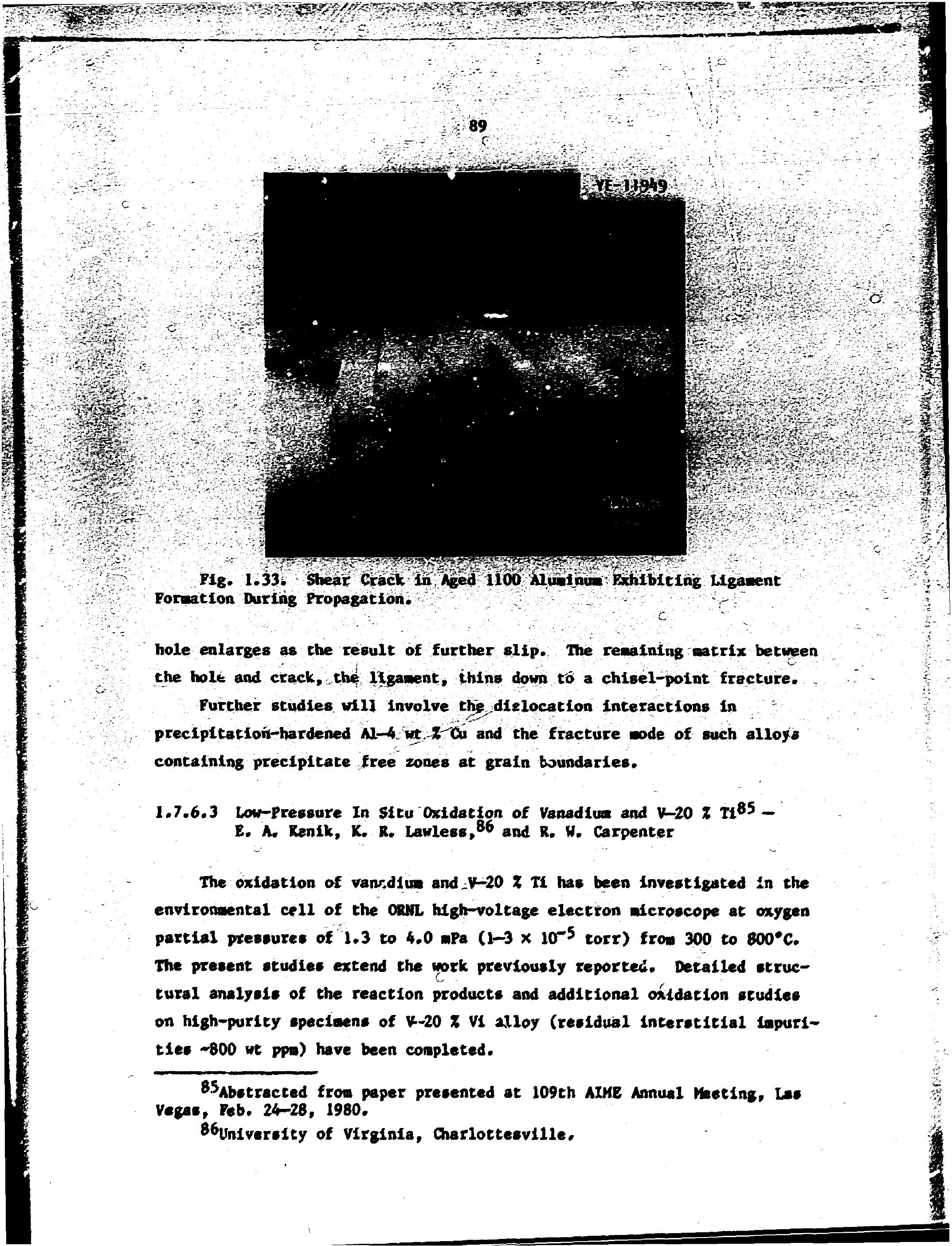


The interaction of irradiation-induced point defects and the oxidation behavior of vanadiu have been reconfinved both by in situ oxidation under irradiation and by in situ oxidation of an ton-nilled speciben. Apparently the oxygen is trapped at the point defects, and the rapid transformation to the ordered ouboxide $\alpha\left(V_{g}\right)$ is suppressed. The possibility of higher oxides foning at irtadiation-produced dislocations is still under investigation.

The phases that for during oxidation of vanadiua depend on both teeperature and oxygen level, Below about $50 \mathrm{C}$, the first phase to for is

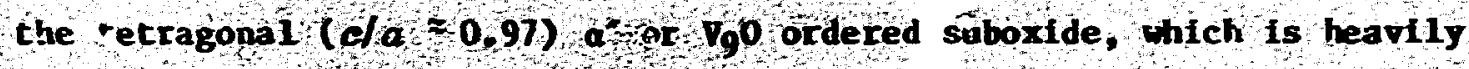
tunned on (110) planes. A the oxidation proceeds, the o first nucleates at the thin edge of the specifen, and the transforwation zone progressively spreads fnto thicket tegions. Concurrent with the latter 6 process, higher oxides for, again at the thin edge, and grow into the thicker region, dissolving the $\alpha$. These higher oxides include the $B$ phase, which is ordered at these temperatures $\left(B^{-}\right)$, and possibly $Y$ phase. The change in the position of the superlattice spots of $B^{-}$in the Jiffraction pattern as a function of oxygen content has been observed. Over the entire range of oxidation conditions studied to date, the siable surface oxide on pure vanadium $\mathrm{Is}_{2} \mathrm{O}_{3}$.

At $500^{\circ} \mathrm{C}$ and above, the first oxide formed was the tetragonal $(c / a \approx 1.1) B$, in agreement with the published $V-0$ phase diagrams. The oxide is twinned on (110) planes and exhibits some diffuse intensity in diffracting patterns, indicating short-range ordering of the oxygen.

The oxidation behavior of $k-20 \% \mathrm{TI}$ differs significantly from that of pure vanadium. The rapid transformation to the ordered a suboxide was entirely cuppressed in the alloy. The first evidences of acrostructural change are diffuse streaks of inter ifty in the diffraction patterns and a "tweed" wicrostructure, both of wich indicate possible clustering of oxygen and titanium atoms. Upon further oxidation, the atrix transforws to an oxide Identical in lattce parameter and crysesl structure witi the $B$ phase observer in pure vanadium. In addition, the stable surface oxide appears to be $\mathrm{V}_{2} \mathrm{O}_{3}$, on the basts of lattice parameter and crystal 
structure: The only difference in the serface oxide formed on vanadiu and on $\forall-20+Z$ is the grain size of the $V_{2} O_{3}$ cryetallites, which is sfgnificanty larger for the $\nabla-20 \mathrm{r}$.

1.7.6.4 Wha In Situ Hydriding of Hydrogen Storage Materials ${ }^{87}$ - E. A. Kenik, J. Millivs, 88 S. Spooner, 88 and B. R. Livesay 88

The efcrostzuctural changes finduced during hydriding have been Investigated by high-roitage electron ficroscopy and in sicu bydriding studies. Thet hydriding generates high dislocation densithes bas inplicathong for the pechanis involved tn the hjdride transfor ation and pogsible ory effects of prior hydrogen exposures on cobsequent hydriding behavior. In sit. hjdriding of LaCos and Lail $\mathrm{L}_{2} \mathrm{CO}_{3}$ has been desonstrated. In addition, an activation bartier to hydriding at low hydrogen pressures was indicated in in situ studies and later confirmed by microbalance wight-gatn measurements. This barrier way be significantly reduced or elfatnated by heating to about $200^{\circ} \mathrm{C}$ under a low partial pressure of hydrogen. Interual stresses generated by hydriding and dehydriding result in cracking and ultinately in the fracture of thin foil spelinens. The hydriding process efther involves a dislocation mechanis such as slip or twinning or generates dislocations by the internal stresses set up duriug hydriding. Purther work wil concentrate on producing large-grain evaporated thin files of the alloys, wich wil allow hydriding to be perforwed without specieen fracture.

1.7.6.5 The Effect of Stackiag fault Energy on Sliding Wear Behavior of Copper-Aluninu Aloye 89 - J. J. Wert, 90 R. W. Carpenter, and S. G. Caldue1190

The addition of aluainum to copper recults in a mell-known reduction of stacking fault energy, which in turi enhances planar slip (1.e., rcstricts croes sifp). We exanined in detall the cubsurface dislocation

87 Abstracted frow Trano. Jpn. Inet. Met. Suppl. 21: 321-24 (1980). 88ceorgia Institute of Technology, Atlanta.

${ }^{89}$ To be publithed in the proceedings of the Third International Conference on Wear of Materials, San Prancisco, March 1981.

90 vandazbilt Universtty, Nachville, Tennesee. 
structure under stylus cear tracks and correlated those observations with the alloy stacking fault energy. At the sane tine, using analytical electron aicroscopy, we exanined the surface topography of the wear track for correlation with the subsurface dislocation structure. In addition, ractoscopic unlubricited 2 liding wear rates were measured for these alloys as a function of aluinum concentralion (1.e., stackfing fult energy). The agnitude and nature of surface vear danage as a function of sliding distance ant nomal load-were exantived by scaning electron mictoscopy. The relationship anoug wear-ioduced dislocation substructure, year rates, and copper-alumiruo alloy stacking fault energy are presented.

1.7.6.6 Wetal Surface Deforwation and Subsurface Defect structure: uicroscopy Correlation study 91 - R. Wo Carpenter, J. J. Wert, 90 and S. G. Calduel1 90

When a metal surface Is deformed by Indentation, sliding war, or sinilar influences, the crystal volume below the surface deformation trace contains an array of dislocations whose density varies with pation relative to the ourface deformation trace. It had been howe ante that the combined lmaging nodes (TEY-STM and SeA) of an analyticsi electron nicroscope permit convenieat and direct correlation between curface-daforpation warkings and subutrface dislocation arrays in aludine. In this note we report observations of defirmation induced at rcom teaperature by single stylus tracks on 3 Cu-8 st $z$ al alloy. The withs of the dence dislocation array at the stylus track determined from fid and the track itself deterwined by SEA are in this case nearly equal. The planar sifp traces extend large distances from the track. These results diffar ofgnificantly from those reported earlier for aluninu, in which the wbsurface dislocations formed a dence array several twes wider than the warface track. They also differed in the ubtence of planar sif traces extending away from the track. This difference is attributed to tise low stacking fault energy of Cu-b w $7 \mu$, which should fnhibit cross-slip and tangling aear the track.

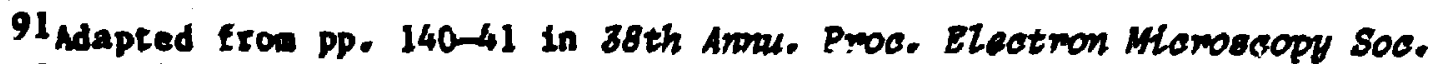
Am., Clattor's Publishing Division, Baton Rouge, Lossisiana, 1980. 
1.7.6.7 Catalog of Computer-Sinulated TEM Images of Sall FCC and BCC Dislocation Loops 92 - Lawrence J. Sykes, 93 Wayne D. Cooper, 93 and John J. tren 93

Interest in rapidly quenched waterials, radiation damage, a.11 nucleation processes has created the nec.l for a wethod to identafy small point defect clusters observed by transaission electron afcroscopy. This report is in outgrowth of this general area of interest and concerns itself priarily with the inages of sall dislocation loops ( $r<0.25$ tines the extinction distance). The various parameters inportant in deternining an mage are presented and a catalog of computer-sinulated Ir tges for a large nuber of loop crystallographies inaged under a large nuber of beas direction and iffracting vector combinations is assembled. The progran that produced the Images is also inscribed and included with annotation.

92Abstracted from a wanuscript to be published as an ORML Technical Menorandus as part of the SlaRE progran.

${ }^{93}$ The University of Florida, Gainesville. 


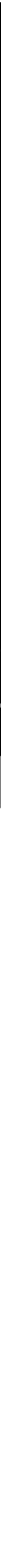




\title{
2. Deformation AND meChanical PROPERTIES
}

\author{
M. H. Yoo
}

The research progran on deformation and mechanical properties is concerzed with the fundanental aspects of mechanical behavior that control the strength and ductility of structural components in energy technology systeas. The progran encompasses mechanical testing, aicrostructural analysis, and theoretical modeling. In both experimental and theoretica? approaches, emphasis is placed on obtaining quantitative relationships betwein microstructure and mechanical properties.

The role of interfaces and impurities in deforwation and fracture at elevated temperatures has been selected as the central topic on which we focus our jer effort. Initially, empasis is placed on the physical mechanisns of intergranular fracture by experimentally investfgating nickel and single-phase nickel binary and ternary alloys as a model syster for both nfckel-base superalloys and austenitic stainless steels. Effects of trace lapurities and inclusions on grain boundary cracking and cavitation are investigated by use of optical wztallography, scanning electron microscopy (SEM), transwission electron microscopy (TEM), and Auger electron spectroscopy (AES). Trace inpurity effects on vacancy clustering and microvold formation are modeled theoretically by use of an efficient numerical integration method. In order to characterize the incergranular fracture processes, a controlled grain boundary exposure technique by liquid-metal embrittlement is being developed. Anelastic and structural recovery data obtaincd by stress change experfments during creep testing provide the basis for understanding of both microstructural mechanisws and macroscopic behavior of high-temperature deformation. Current status of the development of experimertal facilities for deformation and fracture studies are also summarized. 


\section{I INTERGRANULAR FRACTURE}

\subsection{Trace Elenent Effects in Cre:p Cavitation - C. L. White and}

Trace elements and impurities of ten exert large effects on the ductility and failure wode of alloys in elevated-temperature service. Metalloid impurities such as $\mathrm{S}, \mathrm{Sn}, \mathrm{Sb}$, and $\mathrm{As}$ are known to reduce elevated-temperature ductility and induce intergranular failure in nickel and nickel-base alloys. Aside from the general consensus that such trace inpurities nrobably segregate to internal interfaces, the wechanisms for such effects are not well understood.

Noting that these trace element effects are usually assocfated with extensive grain boundary cavitation and cracking, a number of possible mechanisms can be suggested. These include trace element segregation to surfaces and grain boundaries to affect their (1) energies, (2) diffusivities, and (3) vacancy source-sink behavior. The sliding characteristics of grain boundaries are aiso likely to be influenced strougly by trace impurity segregation to them.

\subsubsection{Studfes on Nickel}

We initially considered $\mathrm{As}, \mathrm{Sb}, \mathrm{Sn}$, and $\mathrm{P}$ as "model" impuritfes. These elements were chosen because (1) they are metalloid elements, known to be surface acilve in other transition wetals, and (2) they each have signfficant solid solubility is ndckel at half its absolute melting point $\left(590^{\circ} \mathrm{C}\right)$. It is important to have a significant range of solid solubility so that enough impurity can be added to single-phase alloys to permit relfable bulk chemical analyses and so that a range of sompositions in the solid solution range can he $3 t$ idied. These considerations led to the rejection of sulfur as an intentfonally added inpurity in spite of the fact that it is an important impurity in these alloys.

Preliminary studies involved mechanical testing and analysis of

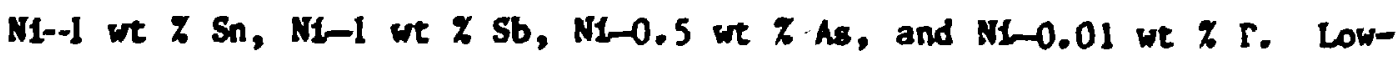
strain-tate tensile testo $\left(\dot{\varepsilon}=1.8 \times 10^{-3} / \mathrm{s}\right)$ were carried out at $600^{\circ} \mathrm{C}$ 
to detenine the effects of these additions on ductility and fallure ade. The MA-l wt $Z$ Sb alloy was nost eabrittled (see Table 2.1), followed by Ni-1 ut $Z$ Sn and N1-0.5 wt $Z$ As. The M-0.01 wt $Z P$ alloy showed nearly the sane ductility as a control alloy having no additions.

Table 2.1. Low-Strain-Rate $\left(\dot{\varepsilon}=1.8 \times 10^{-3} / \mathrm{s}\right)$

Tensile Properties of Mickel Alloys at $600^{\circ} \mathrm{C}$

\begin{tabular}{lcc}
\hline \multicolumn{1}{c}{ N1loy } & $\begin{array}{c}\text { UTS } \\
\text { (MPa) }\end{array}$ & $\begin{array}{c}\text { Elongation } \\
\text { (X) }\end{array}$ \\
\hline M-17 Sa & 182 & 18 \\
Ni-12 Sb & 115 & 9 \\
MI-0.57 As & 85 & 26 \\
N1-0.017 P & 97 & 34 \\
N1 (undoped) & 88 & 40 \\
\hline
\end{tabular}

Optical wetallography and SEA showed the failure mode in the $\mathrm{Sb}$-, Sn-, and As-doped alloys to be primarily intergranular. Extensive Internal cavitation and cracking occurred at grain boundarles all along the gage sections (see Pig. 2.1).

Because the antinony- and tin-doped alloys were the nost severely embrittled, additional testing and analysis were carried out on them. Ductility in $\mathrm{Ni}-\mathrm{l}$ wt $\mathrm{Z} \mathrm{Sb}$ at $600^{\circ} \mathrm{C}$ increased with increasing strain rate, suggesting that themally activated phenimens are indeed taking part in the fallure mode. Variations in testing temperature indicated a broad infuun in ductility near $600^{\circ} \mathrm{C}$ sor the NE-1 wt $Z$ Sn alloy. Constant-10ad creep tests at 34 and $103 \mathrm{MPa}\left(5\right.$ and $15 \mathrm{kg1}$ ) (fü ${ }^{\circ} \mathrm{C}$ ) also show low elongation accompanied by extensive intergranular cracking.

Specimens prepared from cavitated gage sections of $N-1$ wt 7 Sb tensile specimens were fractured in the AES vacuur systew. Auger spectra of the fresh fracture surfaces showed large concentrations of both satianny and sulfur (F1g. 2.2). The sulfur was present as a residual impurity 


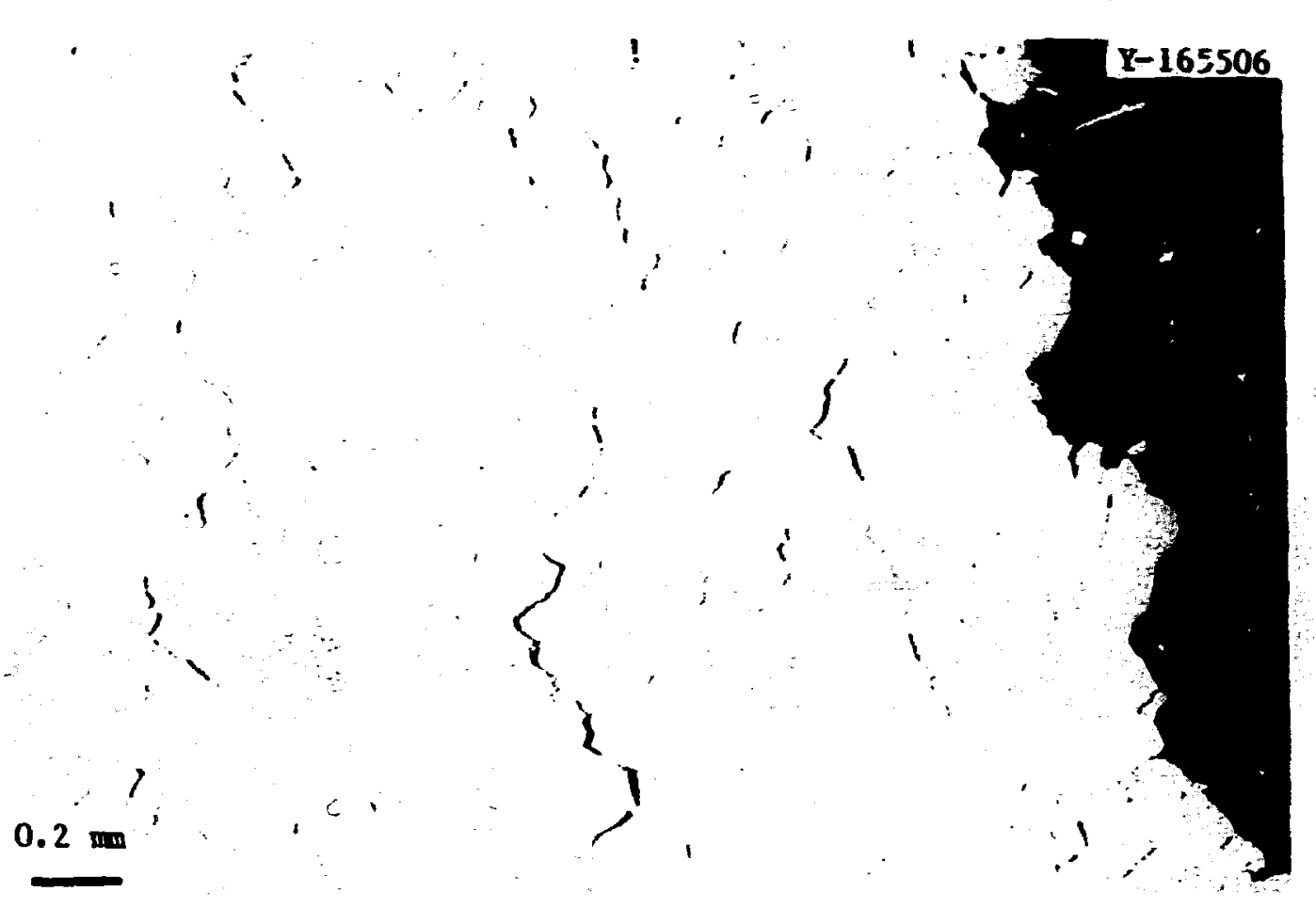

Fig. 2.1. Uptical Micrograph (Unetched) of Ni-l wt \% Sb, Tensile Tested at $600^{\circ} \mathrm{C}, \dot{\varepsilon}=1.8 \times 10^{-3} / \mathrm{s}$. - Note extensive internal cracking and cavitation at grain boundaries.

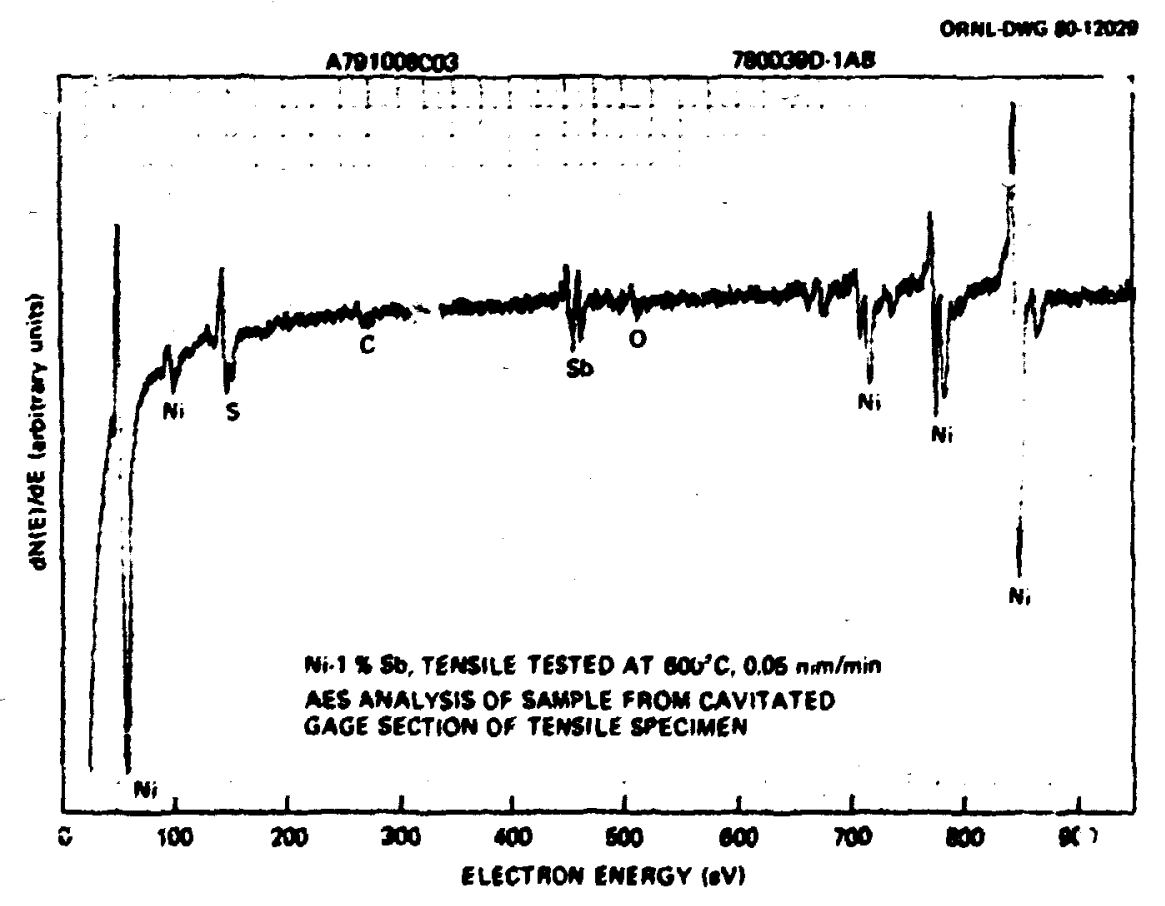

F1g. 2.2. Auger Analysis of Sample From Cavicated Gage Section of N1-1\% Sb Tensile Specimen. The surfuce analyzed was a fresh fracture surface of a specimen fractured in vacuum at room temperature. 
In the alloy at a level of 30 wt ppa. Sputter proflling shored that these elements were enriched at the surfaces, with the concentration decreasing as material was etched away from the surfase.

\subsubsection{Studies on Type 304 Stainless Steel 1}

Extensive characterization of creep cavity growth rates in type 304 stainless steel have been carried out by Chen. 2 After creep deformation between 600 and $775^{\circ} \mathrm{C}$, alloys used in that study were fractured intergranularly at $-196^{\circ} \mathrm{C}$. This intergranular fracture peratted measurement of grain boundary cavity size and distribution as function of tine, stress, and temperatur?.

Because grain boundaries and creep cavity surfaces in these alloys can be exposed by low-temperature fracture, AES analysis of these alloys might allow any trace element segregation to grain boundarles or cavity surfaces to be detected. Preliminary AES studies using uncavitated specimens are under way, and specimens cavitated in creep should be avallable by midsumer.

Auger analysis of the first uncavitated specimen indicates significant segregation of sulfur $\varepsilon$.d phosphurus to grain boundarles. Sall cavities ( -2 diam) where precipitate particles had apparently pulled out showed large concentrations of sulfur, as Indicated In PIgs. 2.3 and 2.4. In general, these cavity surfaces are richer in sulfur than the general grain boundaries. Because of the complexity of this alloy, and the presence of second (and possibly third) phases, detallel interpretation of these results may nt be possible. There seems to be little doubt however, that trace impurities segregate strongly to grain bounderies and precipitate-atrix interfaces.

ITis work is being carried out ia collaboration with $I$. W. Chen and A. S. Argon, Departwent of Mechanical Engineering, Massachusetts Inetitute of Technology.

2I.W. Chen, "Creep Cavitation in Type 304 Stainlees Steel," Ph.D. Thenis, Massachusetts Institute of Technology, Cambridge, 1980. 

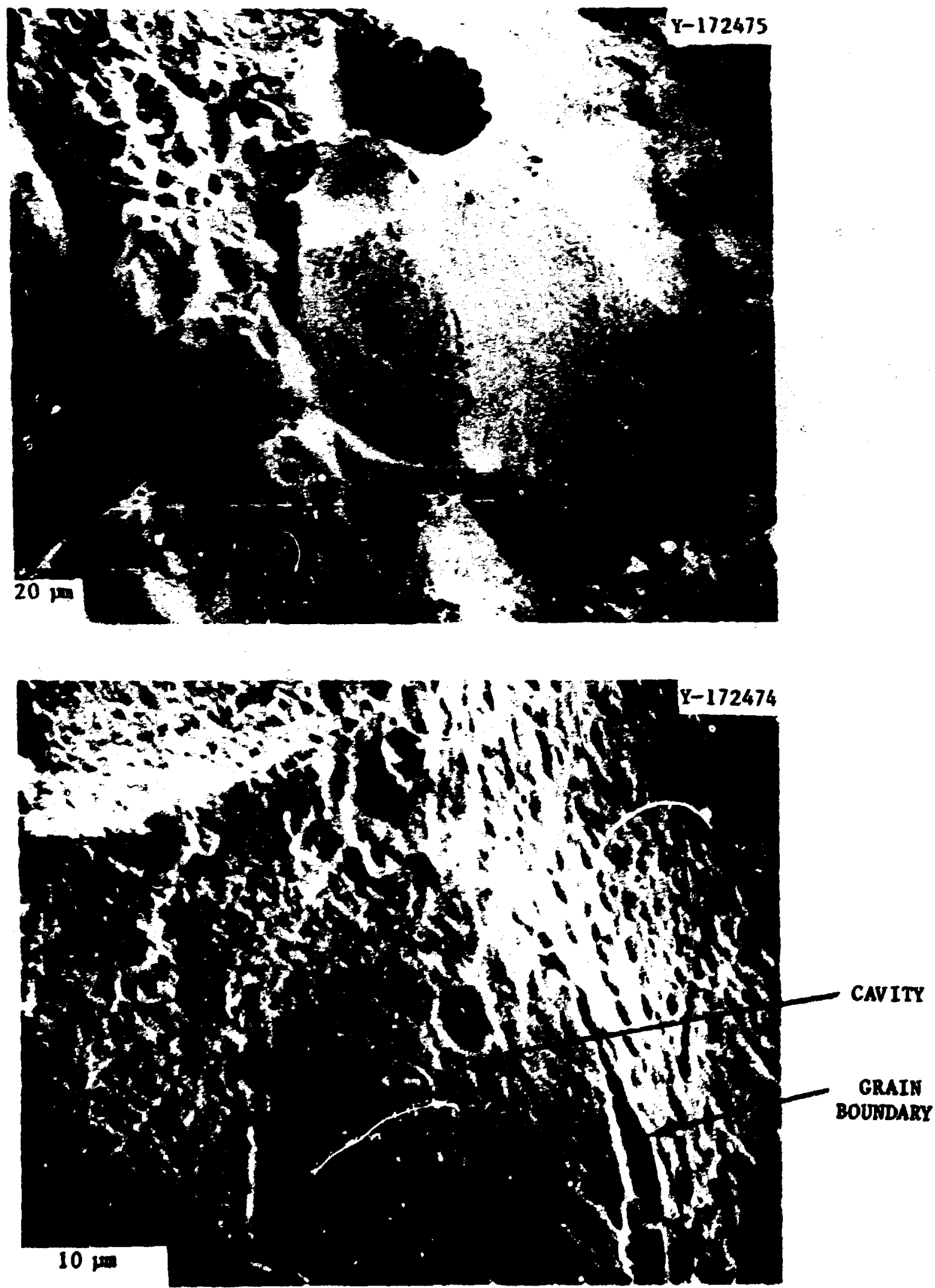

71g. 2.3. Secondary Electron Inages of Practure Surface of Type 304 Stainleas Steel Analyzed by Auger Spectroscopy. 

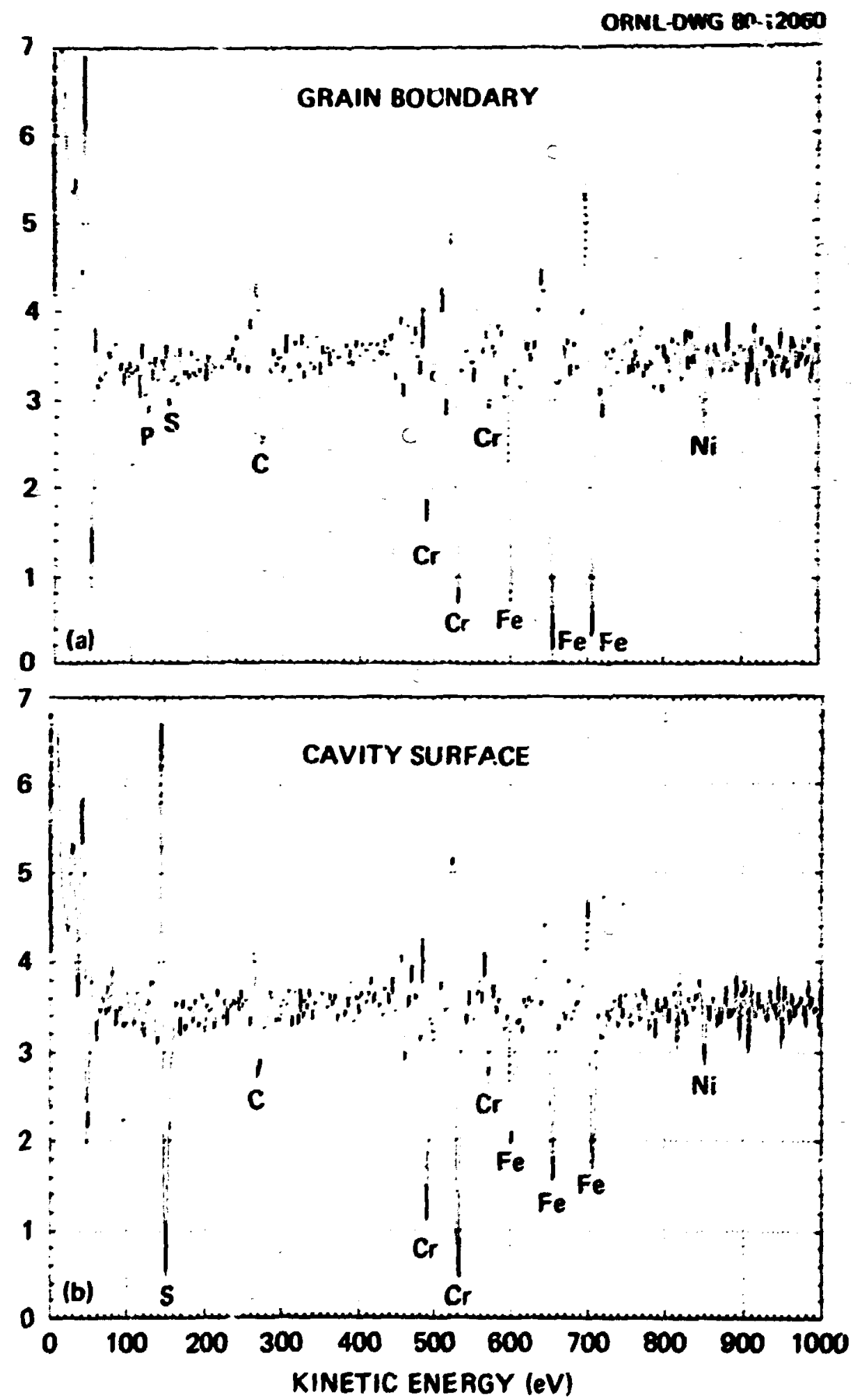

P1g. 2.4. Auger Spectra of Type 304 stainless Steel Iracture Surface at Spot: Indicated on the lower part of P1g. 2.3 


\subsubsection{Trace Elesent Effects on Vacancy Clustering and Bkterogeneous Muclencion of Hicrovolds During Various Thernomechanical Treatnente $^{3}-$ H. H. Yoo}

A theoretical Investigatson of trace elenent effects has been ade by taking the dilute nickel-antinony alluy oystem as an examle. A reaction rate theory codel of Impurity-Induced vacancy clustering was formalated by using a hierarchical grouplng wethod. In characterizing the reaction rate constante, we assuned that caly monovesancies are soblle and bind strongly with antiwony atoms with the binding energy of $\mathrm{Bb}_{t}=0.5 \mathrm{eV}$. The epecific energs of the atcrovold surfare is $r_{8}=1 \mathrm{~J} / \mathrm{a}^{2}$. The nodel is then applited to predict the kinetics of vacancy clustering during a variety of thernonechanical histories of the syeten.

Figure 2.5 shows the evolution of acrovold bize distribution then the Impurity trap atom fraction is $c_{t}=10^{-6}$ and the annealing temperature 1s $T_{a}=608 \mathrm{~K}$. The cluster size increases and the density decreases with Increasing annealing time. The evolution of the mean cluster size and density, $\bar{n}$ and $n_{v}$, 18 shown in F1g. 2.6 for various inpurity concentrations. The Initial vacancy concentration used for this calculation $18 C_{p}=1 \times$ 10-5, whicl, approxinates recovery of a heavily cold-worked $(\varepsilon=0.9)$ dislocation afcrostructure. Figure 2.6 shows that when the Inpurity concentracton exceeds the inflial vacancy concentration, all the annealing curves essentially merge at $t>10^{3}$. We $f$ ind that at $t=3.6 \times 10^{3} \mathrm{~s}$, $n_{v}=5.2 \times 10^{22}, '$ and $\bar{n}=11$, which are wich lower than the values, $n_{v} \approx 10^{24} / \mathrm{m}^{3}$ and $\bar{n} 20$, deternined from positron annihilation experiments4. The calculated results depend sensitively on the Input parameters whch as vacancy formation and algration energies $\left(E_{v}^{f}-1.6 \mathrm{eV}\right.$ and $E_{V}^{N}=1$. eV), free surface energy, dislocation density $\left(L-10^{14} / \mathrm{n}^{2}\right)$, grain size $(d=10 \mathrm{~m})$, Impurity concentration, and vacancy-iapurity binding energy. Pollowing moerous calculations besed on set of

${ }^{3}$ Abatracted from paper to be presented at the Pall Keeting of The Metallurgleal society of AMR, Plttsburgh, October 5-9, 1980.

4G. Dlubek et al., "Inpurity-Induced Vaconcy Clustering in Cold-Worked Mleke1," J. Fhys. F 9: 1961-73 (1979). 


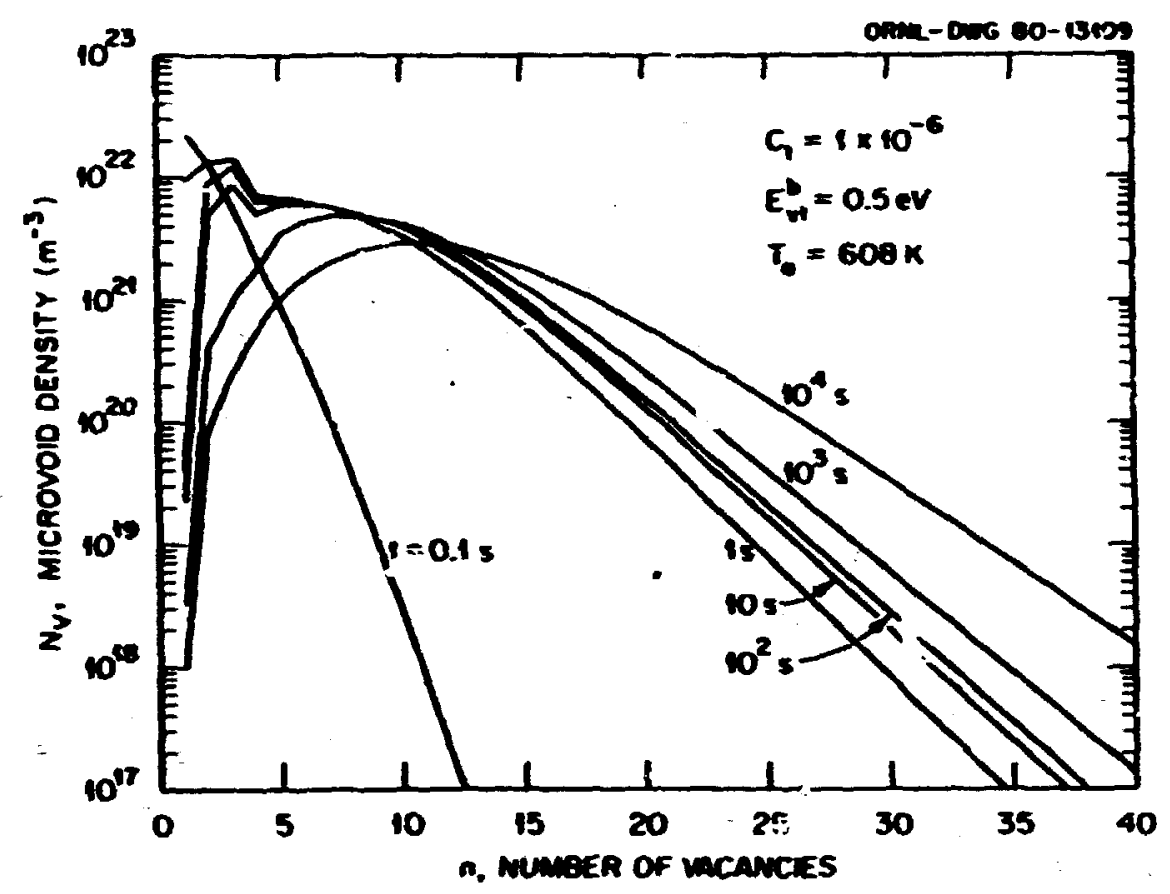

F18. 2.5. Evolution of Merovolds by Inpuriey-Indumed Vacancy Clustering in Mcici at fanenling Teaperature $608 \mathrm{~K}$.

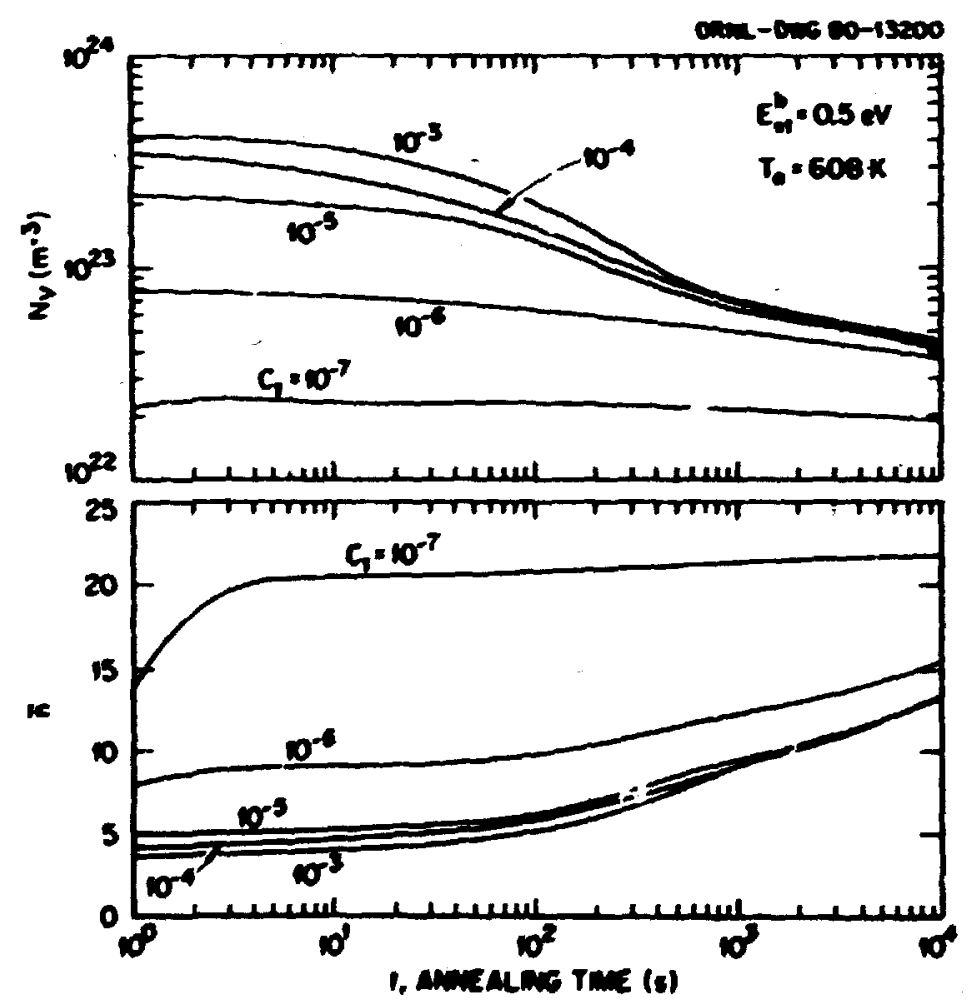

71g. 2.6. Annealing risetice of the Total Denelty and the Maen 8120 of Merovolde for Varlous Impurity Concentrations, $C_{t}$. 
reasonable Input parameters for nickel, 4,5 we find that a high walue of acrovoid density of the order $N_{v}=10^{24} / \mathrm{m}^{3}$ my occur only at relatively short annealing tines $\left(t<10^{2} 8\right)$, but not at $t=1 \mathrm{~h}$.

The calculated results, Figs. 2.5 and 2.6, ay also apply to an annealing historj starting from a vacancy supersaturation of $4 \times 10^{7}$ following quenching frod $1153^{\circ} \mathrm{C}$ to the annealing temperature. An extended applfcation of this model has been inftiated to study grain boundary cavity formation under applled stress.

\subsubsection{Creep Cavity Observation In Mickel Nloys $^{6}$ - T. C. Relley}

The objective of these experinents is the understanding of structural and deformaticn factors leading to the nucleation and growth of creep cavitiex, In the past there has been severe difficulty in finding a techalque that allows convenient observation of these cavities at an early 8 tage $(-0.1 \mathrm{~mm})$. Thus, the first eiforts are directed toward finding such a technique. In the last reporting period the use of liquid metal eabitclement as a technique for exposing grain boundaries was first applited tc aluminum, with early pronise of success. In this period a new material was chosen for study, $\mathrm{NH}-4$ wt $\% \mathrm{H}$, an fec alloy with a low stacking fault energy and shown previously to forw creep cavitles. 7

The technique used Involves first creep testing the ateria', then at a much lower temperature applying a load in the presence of liquid metal, leading to Intergranular fallure. The mechanisa of liquid metal embrittlement (LKR) for polycrystals shows a variety of phenomenology,

5. H. Yoo and J. O. StIegler, "Growth Rinetics and 'Preference Factor' of Frank Loops in Mickel During Electron Irradiation," Philos, Mag. 36: 1305-15 (1977).

610st of this work was performed in the Institut fü Festkörperforschung, XPA-Jilich, during the author's year of foreign aseignwent.

7W. R. Johnson, C. R. Barret, and H. D. M1x, "The Hgh-Temperature Creep Behavior of Mickel-Rich $M I-W$ Solld Solutions," Metall. Thane. 3: 963-69 (1972). 
but it Is generally pictured as a surface-energy-driven process in which grain boundary decohesion at the cract tip proseeds at a lower stress thas would be possible without the ixquid netal. The stress and temerature dependent kinetics of liquid wetal delivery and, perhrps. edsorption at the creck tip are ipportant to UE. Nso, WE is specif ic to certain netal couples, and the following rules senerally apfly: (1) the metals should have low mituel solubilities (a factor that alds in the wse of UrE to observe uadisturbed grain buadary fentures) and (2) the netals should

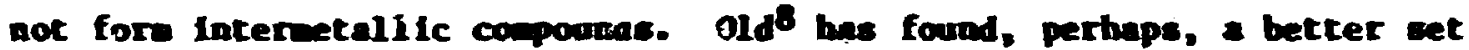
of criteria baced on heats of colution.

Consistent with the above rules, thallim and lead were individually applied to recrystallized $M-47 \mathrm{~W}$ in two wechaical testing mechines bullt for this porpose. Doth liquids were strong enbrittling agents at $625 z$. Without the presence of Ilquid the ultinate tensile strength of M-42 W was $275=10 \mathrm{gPa}$ at $625 \mathrm{k}$, with a straln to fallure of $30 \pm 3 \pi$. With the liquid metals, fallure stressev were reduced belm $50 \mathrm{LPa}$ for thallifu and below 30 upa for lead, with fallure stralns belou about 17. Lead was a nore effective enbrictilng sgent, given Its faster rate of delivery. Fresuably reflecting a higher grain boundary diffusivity. Pigure 2.7 shows a lowmagnification fracture arface scanning electron alctograph (SEH) of Mi-4 74 tesied vithout liquid netal and one teated in thallium. The thallio was chealcally removed. The grain boundaries are exposed in rather good detall. Features having diameters at least as all as 0.1 pa $r g$ be studied with this technique. Pigure 2.8 shows SAls of at- $7 \mathrm{~W}$ fractured in the presence of lead, giving siallarly detalled grain boundary features. If forte to exanine creep cavities aralt the preparation of well-cavitated apecinene.

\footnotetext{
8. F. Old, private comminication.
} 

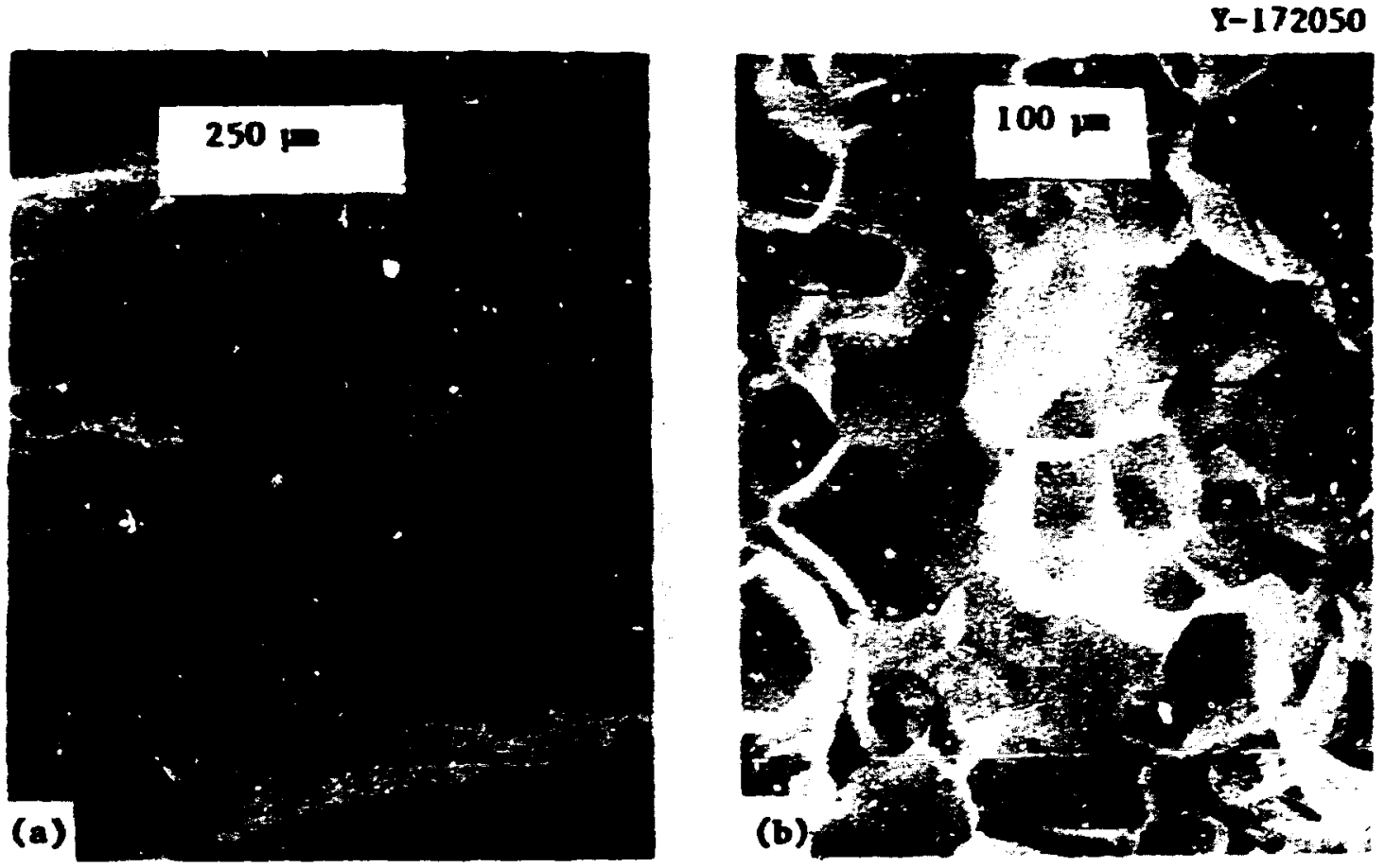

F18. 2.7. Fracture Surface of $14-4 Z \mathrm{~W}$. (a) Deformed 307 at $625 \mathrm{~K}$ at $275 \mathrm{MPa}$. (b) Deformed less than 17 under $50 \mathrm{MPa}$ at $625 \mathrm{~K}$ in the presence of liquid thalliu.
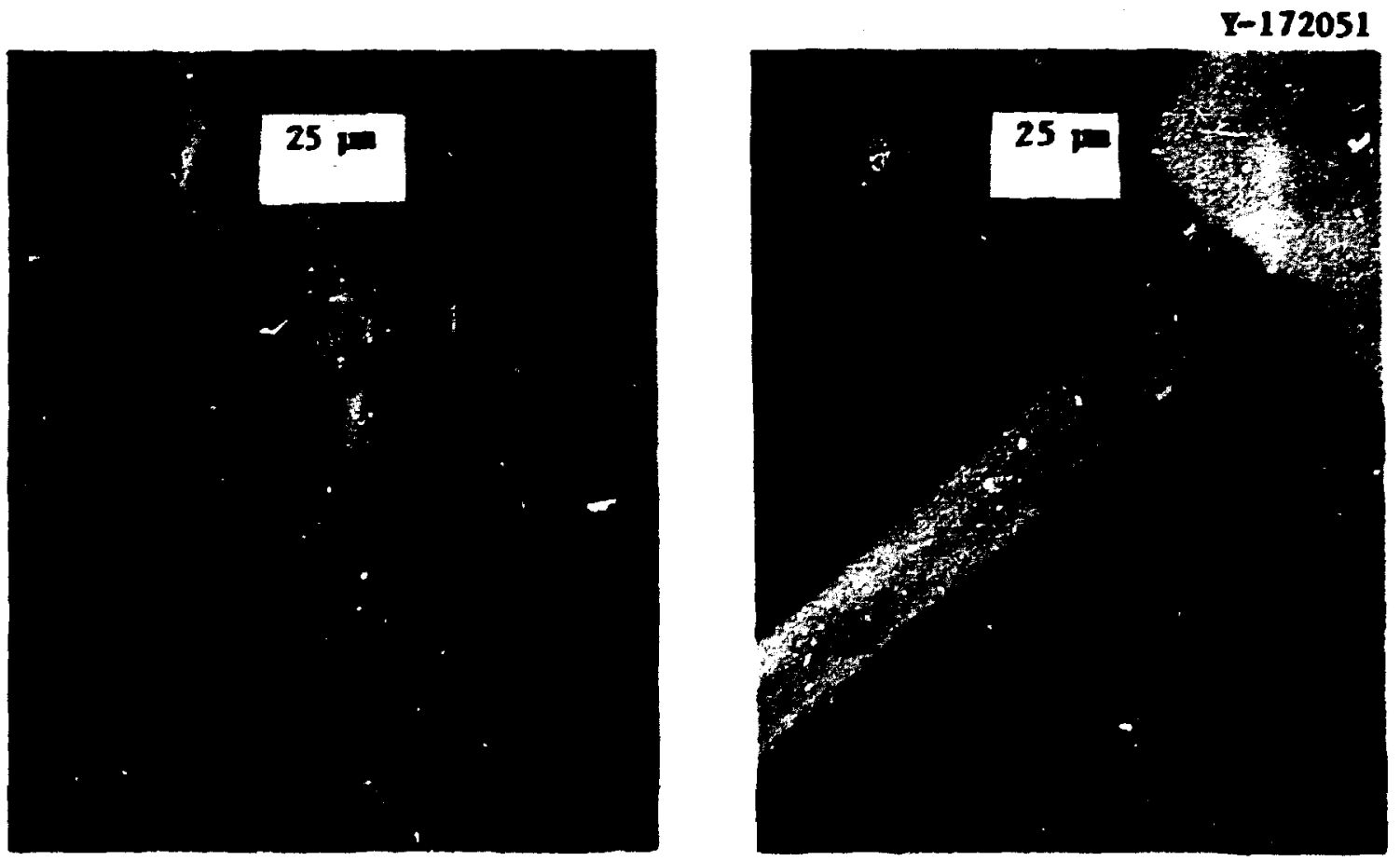

718. 2.8. Trecture surfaces of $\mathrm{HI}-\mathrm{Z} W \mathrm{~W}$ Deformed Lese Then 18 at $625 \mathrm{X}$ in the presence of liquid lead. 


\subsubsection{Microcavities and Their Effects on Elevaited-Teaperature Hechanical Ptoperties of Austeritic Stainless Steel - R. M. Surndean and R. Parrell}

At high teperatures comercial alloys of ten exhibit several fallure nodes. These include plastic instabllity (P-type) and intergranular separation through wedge cracking (W-type) ot ictocavity grourth and conlesence (R-type). Delow 0.6 thes the absolute melting point, $T_{\text {m }}$ the first two mechanisus doninate at the stressed and times convenient for laboratory testing; hence, It is difficult to study aicrocavity foration. Yer, In structures Intended for service thes exceeding $100 \mathrm{Ms}$, fallure by atcrovoid growth and coalescence ts expected, and a proper danage accunlation model wist account for this fact.

Receat1y, wiscovered a heat of type 304 stainless steel that exhibits the R-type fallure in creep at $593^{\circ} \mathrm{C}\left(0.5 T_{m}\right)$ in less than $1 \mathrm{Hs}$. The creep ductility and the creep-fatigue resistance are cubstantially below the norms for type 304 stainless steel. Optical metallography reveals extensive cavitation [F1g. 2.9(a)], and SEY of the fracture surface shows Intergramular volds assoctated with carbide particles [PIg. 2.9(b)]. Transalssion electron wicroscopy shows considerable precipitation of $\mathrm{H}_{23} \mathrm{C}_{6}$ on grain boundaries and dislocation cell walls. Host creep cavities are too large to be excomassed in the TEY folls, but a few mall cavities are found on grain boundaries, where they tend to be hidden by the prec1pitates grown during the test. Precipitation is accelerated by plastic strain and is, therefore, a antmur in the unstrained heads of the specimens. A careful Tal exanination of the heads of specisens revealed any alcrovolds on the grain boundaries. Further investlgation ahowed that these cavities are present in the as-received, untested stock from which the creep apecinene were cut. These preexisting cavities are enell (5 to $50 \mathrm{~m}$ ), and each ose is attached to a precipitate or inclusion particle [P1g. 2.9(c)], the cavity often being hidden by a particle. On some boundaries the cavities are spaced only 0.2 to 0.5 p apart. Before such cavities can grow to a size Just visible in an optical alcroscope, $1 w$ or so, they wil interconnect and form a martow, continuous grain 

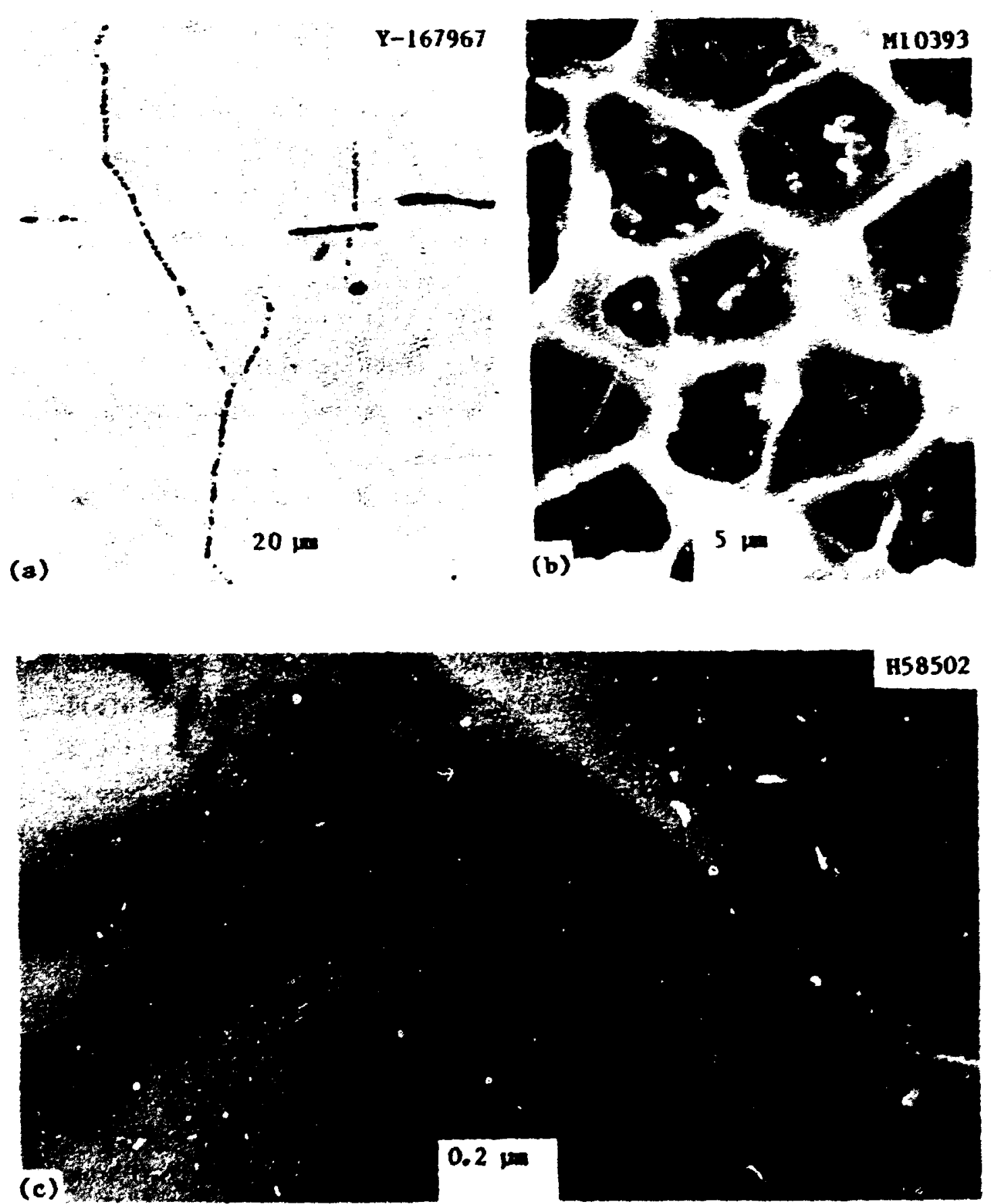

P1g. 2.9. Grain Boundary Cavities In Type 304 Stainleas Steel. (a) Optical alcrograph of a eample creep sested at $138 \mathrm{MPa}$ and $593^{\circ} \mathrm{C}$ for $5.3 \mathrm{Ms}$. Unetched. (b) Scanning electron alcrograph of the fracture surface of a sample creep tested at $241 \mathrm{MPa}$ and $593^{\circ} \mathrm{C}: 0.3 \mathrm{Mr}$. Cavities contain $\mathrm{M}_{23} \mathrm{C}_{6}$ particles. (c) Sall grain boundary crivities attached to inclusion particles in unstrained part of creep-fat Igue opecimen. 
bounda:y crack. We suspect that these cavities are produced during manufacture of the alloy product and are responsible for the degraded creep properties. Such preexisting cavities would elfinate the incubation period for formation of creep cavities.

Cavities of this type aight occur comonly during thermomechanical processing of aterials, but are unobserved because of their small size. They could be responsible for some of the wide heat-to-heat variations in nechanical properties of alloys of the sane nominal composition. If so, appropriate accomodation must be ade for then in cumulative danage models based on phenomenological considerations. The causes of these initial cavities require investigation since the answers may lead to control measures that aight elininate substandard mechanical response and may even offer the possibility of raising the general level of mechanicai properties. A few cursory tests we have ade on this alloy indicate that aging at $815^{\circ} \mathrm{C}$ can substantially inprove creep behavior.

\subsubsection{Fracture Initiation at Grain Boundary Inclusions - Internal Stress Effects - M. H. Yoo}

Fracture strength and ductility of polycrystalline solids are influenced significantly by the presence of inclusions or precipitate particles in grain boundaries. Under creep and high-temperature fatigue condictons, the function of an inclusion and a grain boundary is usually the principal site of cavity nucleation. We investigated theoretically the effect of internal stresses due to grain boundary inclusions, in the absence of applied load, on crack infitiation and cavity mucleation.

Two relevant stress components, the normal $\sigma_{n}$ and the shear stress $\tau$, resolved on a grain boundary were calculated with Eshelby theory, 9 and the results are shown in Fig. 2.10. The stress component normal to the Inclusion-zatrix interface is $\sigma_{n}=-2 \sigma_{n}$ at the interface. These interas stresses may be reduced by (1) localized deformation by the dislocation

9. D. Eahelby, The Determination of the Elastic Field of an Ellipsoidal Inclusion and Related Problew," Proc. R. Soc. London A241: 376-96 (1957). 


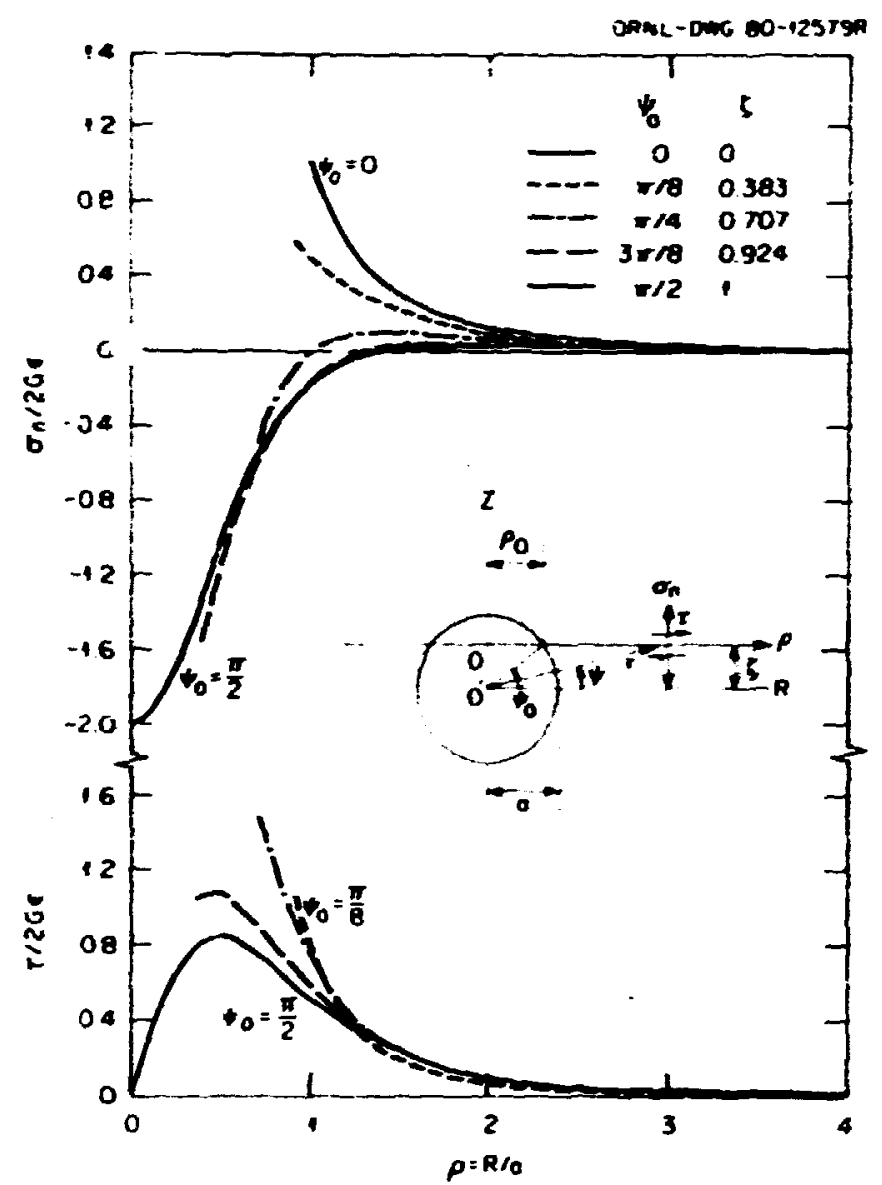

Fig. 2.10. Normal and Shear Stress Components, $\sigma_{n}$ and $\tau$, Resolved on a Grain Boundary. These stresses are induced by a spherical inclusion with the afsfit cransforsation strain $E$; $G$ is the shear codulus of the matrix.

generation, (2) crack Initiation by the boundary decohesion, and (3) diffustonal flow of atons along the boundaries. Pour possible wodes of crack intiftion are depicted In Fig. 2.11, which suggests (a) and (d) as the likely wodes of grain boundary cracking and interfactal cracking, respectiveig. If the origin of the internal stresses is due to a difference in the 1inear theral exponston coeffictents of atrix ard incluton a and $a^{*}$, then the final strais is $e=\left(1+3 x^{*} / 4 G\right)\left(\alpha^{*}-\alpha\right) \Delta T$, where $X^{*}$ 1s the bulk codulus of the inclusion and $\Delta T$ is the temperature change. In order for $\sigma_{n}$ for the case of $P t_{g}$. $2.11(a)$ to exceed the threehold stresses of grain boundery decoheston, nownally $10^{-3} G$, 12 is generally required that $\Delta T>1000 \times$ with $\left(\alpha^{*}-a\right)-10^{-6} / \mathrm{R}$. 

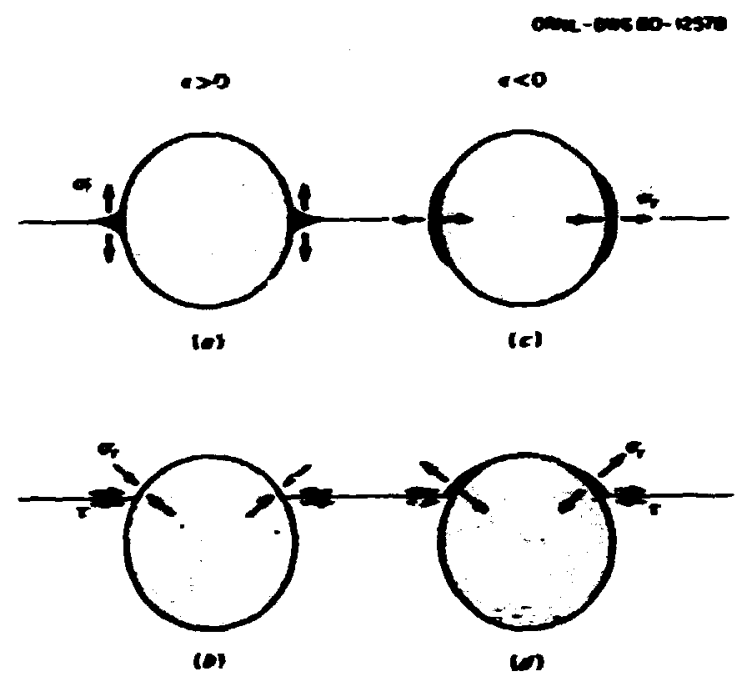

Fig. 2.11. Possible Modes of Crack Initiation by Decohesion of the Grain Boundary and the Inclueion-Hatrix Interface.

When the internal stresses are too low for grain boundary cracking but temperature $18 \mathrm{high}\left(>0.3 \mathrm{~T}_{m}\right)$, the stress relaxation by diffusional flow becones of relat:ve inportance. The characteristic tios for this relaxation is approxinated as $\tau_{c}=k T / G D_{b} \delta$, where $k T$ is the Boltzmann factor, $D_{b} \delta$ is the product of grain boundary diffusivity and grain bourdary width, and the value of $\tau_{c}$ for nickel at $773 \mathrm{~K}$ is estinated to be only $2 \mathrm{~ns}$. The influence of the excess chemical potential for atoms created by the transient internal stresses on the formation of grain boundary microcavities is belng Investigated according to the vacancy clustering wodel (Sect. 2.1.2).

\subsubsection{Low-Temperature Grain Boundary Fracture - C. L. White and}

Brittle Intergranular fracture of metals at low temeratures of ten renults from trace element aegregation to the grain boundaries. Less wellknow are the beneficial effects of certain elewents when the: segregate to grain boundarien. Several collaborative efforts have been sarried out or are currently under way to characterize and understand the relationship between trace elenent hegregation and intergranular fracture at low temperatures. 
2.1.6.1 Fracture Energy Keasurements in Fe-37 Si Bicrystals 10

Transformer steel ( $\mathrm{Fe}-3 \mathrm{Si}$ ) was doped with varying amounts of phusphorus and piven an eubrittling step-cool heat treatment. Auger electron spectroscopy was used to determine that large increases in intergranular phosphorus concentration oncurred in approximate proportion to che bulk phosphorus level througl: an equilibrium segregation mechanism. Bicrysi: 3 of his material were fractured at 300,77 , and $4.2 \mathrm{~K}$. Grain boundary fracture energy, $r_{f}^{g b}$, was determined as a function of iritergranular phosphorus roncentration at $4.2 \mathrm{~K}$. An analysis of $\gamma_{f}^{g b}$ and irricture mode as a function of temperature was used to evaluate the ralative merits of irteryranular fracture models baged on reduced interatomic separation energy (Gibbs-Griffith model) and reduced interatomic cohesive strength (Seah model). The reduced interatomic separation energy model fitted the experimental findings better.

\subsubsection{Grain Boundary Segregation and Intergranular Failure 11}

Trace elpments and impurities of ten segregate strongly to grain boundaries in metals and alloys. Concentraitons of these elements at grain boundaries are often $10^{3}$ to $10^{5}$ times as great as their overall concentration in the alloy. Because of such segregation, certain trace elements can exert a disproportionate influence on material properties. Ores frequently observed consequence of trace elemer.t segregation to grain

${ }^{10}$ This work was carried out in collaboration with R. G. Thompson (Clemson Untversity), J. J. Wert (Janderbilt University), and D. S. Easton (ORNL) as pazt of Thempson's thesis research at Vanderbilt University. A manuscript entitled "On the Mechanism of Intergranular Embrittlement by Phosphorus (In Transformer Steel)" Is it, preparation for submission to Metallurgical Transactions.

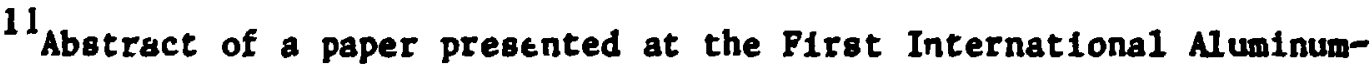
Lithium Conference, Stone Muntaln, Georg1a, May 19-21, 1980. A paper by the same title is to appear in the proceeding of that conference. Work on Al-3\% $\mathrm{LI}$ alloys $1 \mathrm{~s}$ being carried out in collaboration with $T$. Sanders, Georgia Inst tute of Technology Fracture and Fatigue Research Laboratory, under auspices of the SHaRE Program. 
boundarfes is the occurrence of grain boundary fallure and low ductility. Less well-known are incidences of inproved ductility and inhibition of grain boundary fracture resulting from trace element segregation to grain boundaries In certain systens.

Trace element segregation and intergranular fallure in a variety of alloy systems as will as prelininary results from studies on Al-3\% Li have been characterized.

2.1.6.3 Boron Segregation to Grain Boundarles and Improved Ductility in Pt-30 wt $Z$ Rh-8 wt $X$ w12 $^{12}$

Boron additions of up to 75 wt ppm have been observed to improve the room-temperature strength and ductility of a Pt-30 wt $Z$ Rh-8 wt $Z \mathrm{~V}$ alloy. Alloys without boron fall intergranularly, and those with 75 it ppm B added fall in a mixed intergranular-transgranular mode. Auger electron spectroscopy on Intergranular fracture surfaces indicated that boron segregates strongly to grain boundarles in the boron-doped alloys. Transmission electron microscopy of alloys with and without boron indcated tiat both were free of internal precipitates. The observed improvements in strength and ductility appear to be related to boron enrichment within a few atomic distances of the grain boundary.

\subsubsection{A Study of Grafn Boundary Embrittlewent in Cu-37 Al-1Z Si Using AES 13}

Single-phase Al-S1 bronze alloys are used in a variety of applications requiring good corrosion resistance, ductility, and strength. These

12 Abstract of a paper belng prepared for submission to Metallurgical Traneactions. Work on $\mathrm{Pi}_{i}-30$ wt $\% \mathrm{Rh}-8 \mathrm{wt}, \mathrm{W}$ alloys has been carried out In collaboration with J. R. Keiser and D. N. Braski of 03NL. This work ras partially supported by the DIvision of Advanced MucJear Systems and Projecto.

${ }^{13}$ Abstract of a paper presented at the 12, th Annual Technical Meeting of the International Metallographic soclety and to appear in the proceedings of that meeting. Work on Cu-3\% AI-1\% 51 alloye has been carried out in collaboration with T. R. OdOm (PGDP) and R. E. Clausing (ORN). Th1s work was partially supported by Enriching Operations DIvision of DOE. 
fcc alloys nomally exhibit tensile elongatioi $s$ between 20 and 602 , depending on anneallng conditions, and are not uoually prone to istergranular fallure. However, material from several difierent bars of an alualnum-silicon bronze $\left(\mathrm{Cu}_{-3}\right.$ wt $₹ \mathrm{~N}-1$ wt $\chi \mathrm{S} 1$ ) has been found to fall Intergranularly, with unusually low tensile elongation. Bulk chemical analysis of these bars indicated higher than noral concentrations of lead In the alloys. Auger electron spectroscopy (ABS) of intergranular fracture surfaces has shown the grain boundaries to be highly enriched in lead. There seens to be little doubt that this lead errichent is responsible for the abnormally low ductility and intergranular fallure in this aluninum-811icon bronre.

\subsection{DEFORMATION MECHANISHS}

\subsubsection{Anelastic Creep Recovery In N1ckel - T. C. Reiley, M. H. Yoo, and R. H. Shannon}

The goal of these experiments is to understand the origin and wechanisms of high-temperature anelastic recovery and, in particular, to prepare a technique to evaluate the amount of grain boundary sliding (GBS) as a function of deformation wode, strain rate, stress, and temperature by monitoring the strain recovery kinetics. Creep fallure 18 thought to Involve grain boundary sliding as the primary mechaniow for cavity nucleation; however, it is not possible to predict the awount of GBS assoclated with deformation for a given grain size, strain rate, stress, and temperature. Furthermore, accurate masurements of GBS are difficult and tedlous. Therefore, we are looking for a correlation between the abount of grain boundary sliding and kinetics of strain recovery in a manner inilar to that of Gibeling; 14 however, for our experinents we have available the accuracy and stability of the Irradiation Crecp Paclifty (ICF) at ORNL.

$14 \mathrm{~J}$. C. Gibeling, The Use of Strees Change Experlmente to Study the Mechaniems for Elevated Temperature Deformation, Ph.D. theels, Stanford Unlversity, 1979. 
The first experiments have been exploratory, almed at deternining resolution 1inits. Data are shown for pure nickel in Fig. 2.12, giving the strain recovery after stress reductions from 30,20 , and $10 \mathrm{MPa}$ to approximately $2 \mathrm{MPa}$, at an average teaperature of $845 \mathrm{~K}$. The total strain recovery depended linearly on stress reduction and at this tem perature was essentially complete in about $10 \mathrm{ks}$, although for these large-grain-sized speciwens (approaching the specimen thickness, $125 \mathrm{~m}$ ) the slower triple-point-stress-driven recovery processes should have been greatly reduced under that expected for bulk aterial. Purther experinents using ICF on an elastic creep recovery in nickel and Its alloys will deal with sheet specimens of fine grain size, and these experinents will be complenented by stress relaration studies of bulk specinens using a new apparatus desiribed in Sec:. 2.4.2.

OANL-DNG 8012028

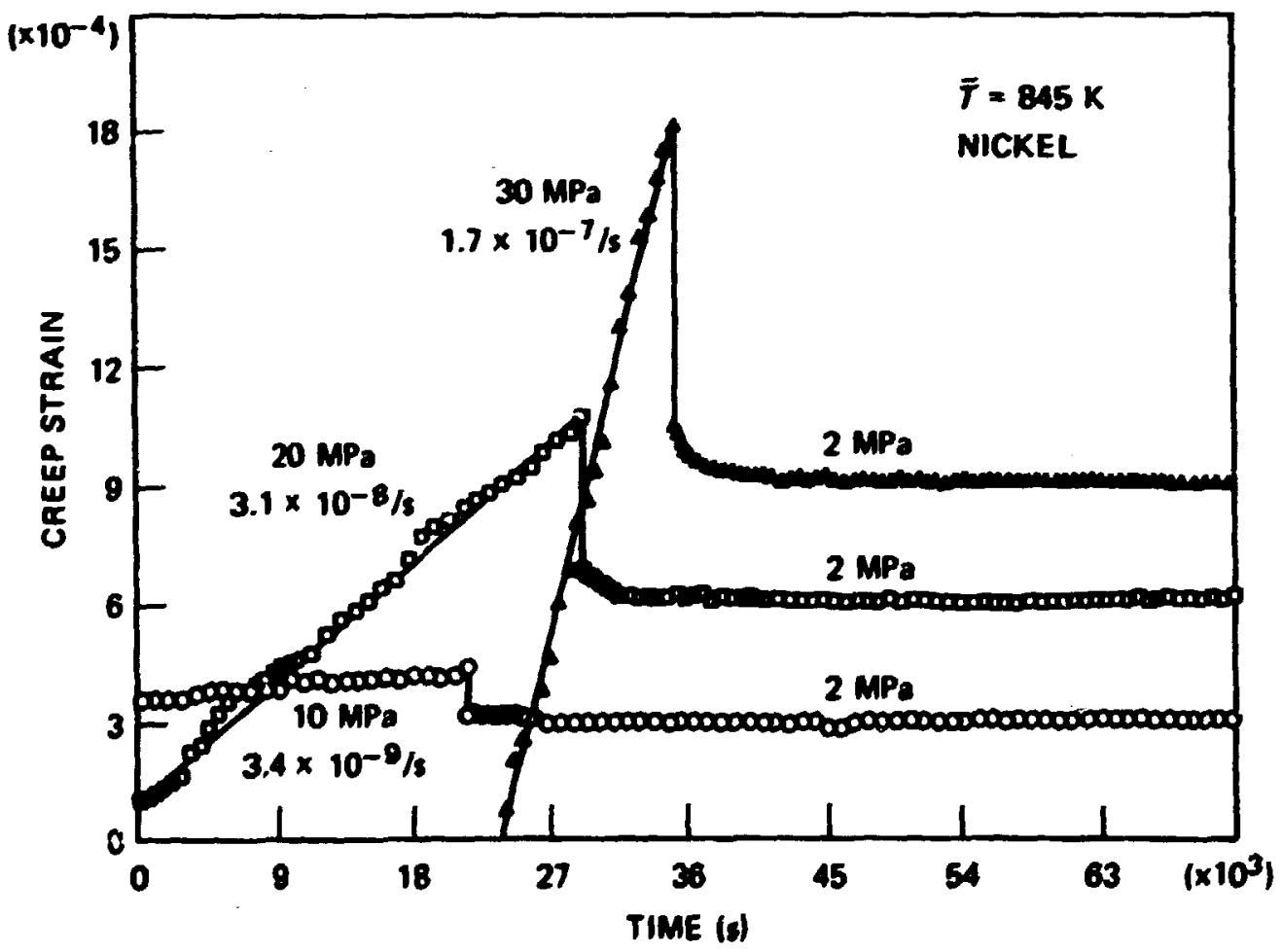

P18. 2.12. Creep Strain Besponses to Strece Changes in Mikel at 845 Heasured In the Irredistion Creep Pacility. 
2.2.2 Radius Dependence of the Stnk Strength of a Dislocation Loop 15 W. A. ghlan and M. H. Yoo

Diffusinn of point defects under the influence of a force field is an important pr.ysical process involved in phase transforations, radiation damage, and high-teuperature deformation of aterials. When the force field originates frov the interaction of a point defect with another defect or defect cluster, such as a dislocation loop, the role of such interaction in the drift flow of point defects becones particularly inportant in the overall diffusion kinetics of aicrostructure evolution. In this work, a theozetical Investigation has been ade on the physical sources of the dependence of the capture efficiency, or the sink streagth, of a prismatic dislocation loop on its size.

The siak strength of a prisnatic loop was calculated by using a numerical method developed earlier. 16 The capture radius of a single loop, $r_{\infty}^{*}$, is defined as the radius of an equivalent spherical reaction volume hased on the analytic solution for an electrostatic analog. The numerical results may be summarized by an empirical equation as

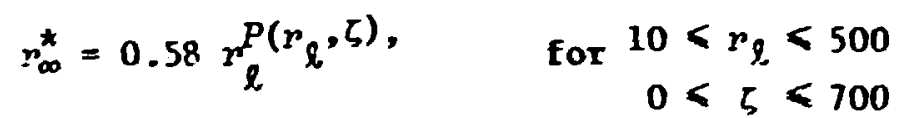

where

$$
\begin{aligned}
& P=0.9852+2.779 / r_{\ell}{ }^{1.25}+0.05492\left(\zeta / r_{\ell}\right)^{0.75}-0.0023\left(\zeta / r_{\ell}\right)^{1.5}, \\
& \zeta=\mu|\Lambda V| / \gamma k T, \\
& Y=3(1-v) /(1+\nu),
\end{aligned}
$$

and both $r_{\infty}^{*}$ and the loop radius, $r_{\ell}$, are in units of the Burgers vector, $\mu$ 18 the shear modulus, $U$ is the Polsson's ratio, and $\Delta V$ is the defect

15 Abstracted from a paper presented at the International Conference on Dislocation Mor ! Ing of Physical Systeme, June 22-27, 1980, Gainesville, Florlua.

16. A. Coghlan, "Transient and Steady State Diffusion Solution for Point Defects in a Stress Pleld," pp. 166-76 in Proc. Conf. Computer Simulation for Materiale Application, R. J. Arsenault, J. I. Beeler, and J. A. S1mons, eds., Galthersburg, Maryland, Apri1 19-21, 1976. 
relaxation volume. The sink strength per init lengch of edge dislocation IIne (fIE. 2.13) Hllustrate that Eq. (1) for a single loop predicts lacreasing sink strength with decreasing loop size, which is consistent with our previous calculations ade for sall loops. Figure 2.13 also shows that the sink strength of many coexisting loops with the density of $n_{l}=10^{20} / \mathbf{m}^{3}$ increases with increasing loop size $\left(r_{l}>100\right)$ because of the effect of overlapping diffusion fields. The current result enables us to characterize the reactior rate constants in modeling studies of lowp growth and other applicatlons of reaction rate theory, such as the annealing kinetics of a heavily deformed alcrostructure.

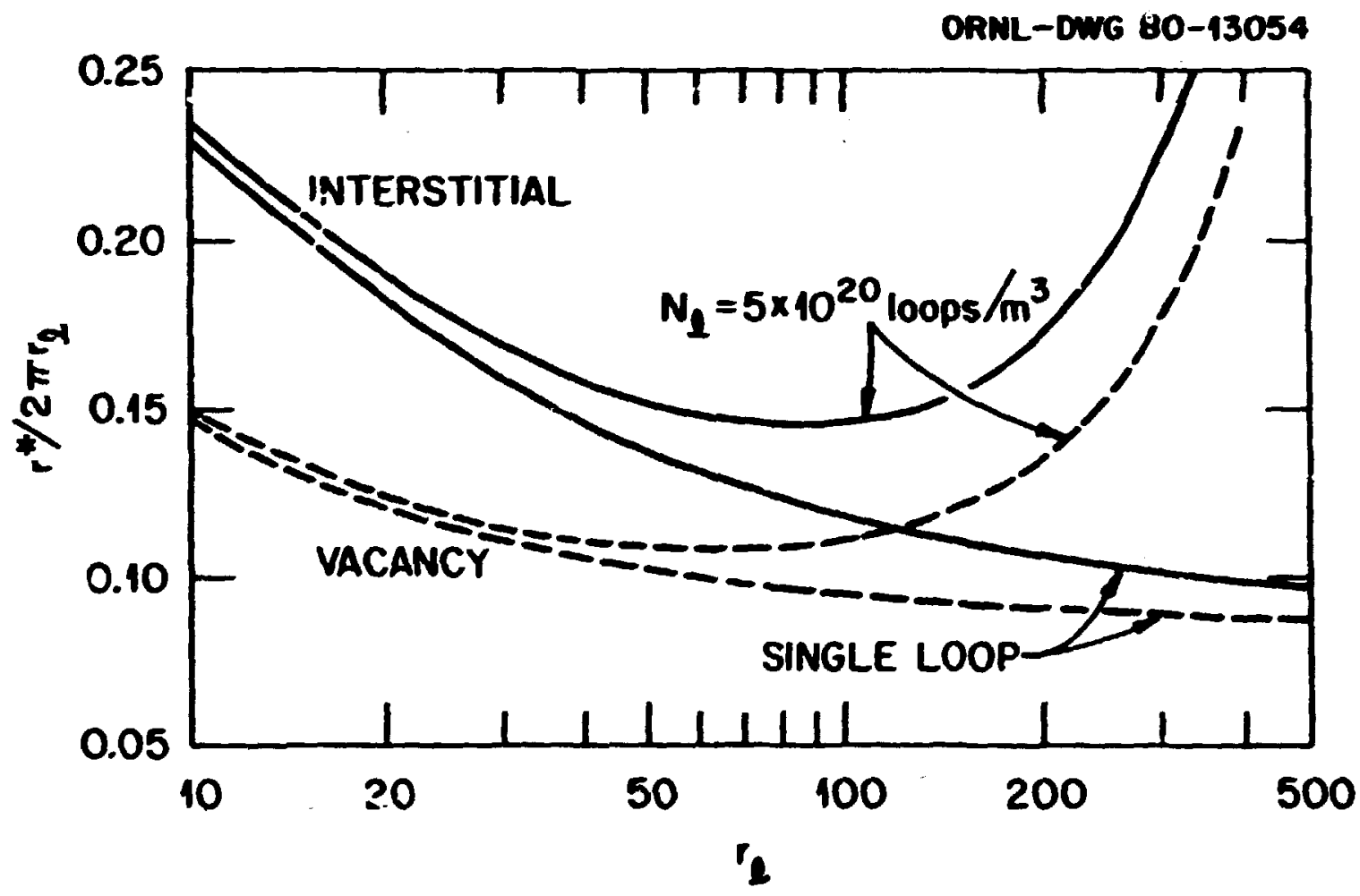

F1g. 2.13. A Sumary of the Defect Strength of a Loop Per Unit Length Edge Dislocation. 
2.2.3 The Rolling and Recrystallizacion of (110)[110] Tantalu Single Crystals 17 - R. A. Vanderwer and U. B. Sayder, Jr. 18

A deleterious duplex alcrostructure and very intense texture sonet ines are observed when large-grained, electron-beam-melted tantalum ingots are fabricated to plate and sheet. To understand the origin of the aicrostructure and -referred orlentations, we investigated the rolling and recrystalIlzation behavior of specific tantalu single crystals. Single-crystal studies have been and continue to be useful in providing Information concerning grain reorientation during deformation and recrjstallization in wrought and annealed products. Little was known about tantalum unt il this research was carried out.

In this study, which is a companion to one published earlier, 19 (110) [1̄̄o] oriented single crystals were found to be unstable during rolling and underwent substantial reorientation. The final texture after 807 reduction in thickness consisted of altiple components. Deforation bands were a proninent feature of the atcrostructure. Several reorientation paths were charted as a function of deformation, these being the cause of considerable fragmentation of the crysts:. On a macroscopic scale the deforwation was shown to be extrenely nonhsmogeneous, and through-the-thickness texture variations were comon. While wost regions exhibited witfcomponent textures, occastonally large regions displayed a single-component texture. Accompanying acrohardness, lateral widening and alcrostructural gradients also correlated with the texture gradient. By changing elther the geowetry of the zone of deformation In rolling or roll friction, the macroscopic inhomogeneities could be dininished, but a deformation-banded microstricture persisted. We noted minor changes in texture and attribute them to changes in the degree of lateral strain.

17 Sumary of paper to be subalted to Texture.

18 Group Leader, Electronice Divioion of Unton Carbide Corporation, Greenville, S.C.

19R. A. Vanderweer and W. B. Snyder, Jr., "Recovery and Recryetall1zation in Bolled Tantalum single Cryetale," Metall. Trane. 10A: 1031-44 (1979). 
The rolling texture results were interpreted in terns of the Taylor theory of plastic deforation. The reorientation paths and the terture after 800 reduction were consisteat with the theoretical predictions of stable orientations in rolling of bec aterials. The changes in texture with Increasfing Jateral widening were greater than the predictions of theory.

Recrystallization took place at temperatures as $10 \mathrm{w}$ as $600^{\circ} \mathrm{C}$. Gradients of recrystallizution proclifity peralleled the macroscopic rolling texture gradients. Deglons with oaly a single-component texture recrystallized less easily than reglons with deforantion bands and wit1component textures. The ease of recrystallization correlated directly with the exteat of lattice curveture. The recrystallization texture always was the sane as the rolling texture.

2.3. Honogen II Mtals - R. Fartell and M. B. iewls

Most austenitic stainless steels resist hydrogen eabrittlenent unless they are cathodically hydrogenated in a polsoned electrolyte. Even then, thin specinens ( $65 \mathrm{~m}$ ) are often required before significant eabrittlenent is manifest, suggesting a surface-related phenomenon. Onder wuch cathodic hydrogenation the hydrogen conceatration in the ourface layers of the specisen is expected to be very high, with a steep deciline at deeper stes.

The wethod of muclear analysis ueing a probing bean of lons with shal_ow penetration offers a mans of deternining the true hydrogen distribution. We have wed this technique, together wth near-surface tranentssion electron afcrosp spy (TW), to gain come revealing insight: Into the hydrogen distribuction wear the aurface of stalniess steel. The steel was a stable type 310 (Fo-21X $\mathrm{H}-23 \mathrm{C}-2 \mathrm{~W}$ ) in the amealed condition. It was hjdrogenated at roon temperature in $1 \mathrm{~A} \mathrm{D}_{2} \mathrm{SO}_{4}$ with arcentc polson for periode up to $24 \mathrm{~h}$. Deuterim was used to factiltate detection wth a probing been of lons in a particle accelerator using the nuclear reactlons $\left[\left({ }^{3}, \rho, \alpha\right) A\right.$ and $D(d, p) T$. $A$ near-curface deuteriu concentration of about 40 at. $I$ was found inediately after 
hydrogenation. Measurewents of the decay of this hydrogen-rich region with posthydrogenation time allowed derivation of a room-tenperature diffuston cuefficient of $1.4 \times 10^{-16} \mathrm{~m}^{2} / \mathrm{s}$. Diffusion laws indicate that during a 24-h hydrogenation the deuteriun front should penetrate to a depth of only $5 \mathrm{p}$. We are now weasuring such a depth by progressively renoving surface layers by electropolishing. In the meantine we have used TEM techniques to observe the damage profile resulting from the hydrogenation treatment. Dasage began with the generation of dislocation loops at the specimen surface and at surface inclusions for electrolysis tines of less than $30 \mathrm{~s}$. With increasing time dislocations were created at grain boundartes and internal inclusions, and the surfaca-generated loops evolved into a dense dislocation structure containing heavy twinlike bands. At about 15 win surface cracks formed around inclusions and propagated along grain boundaries and at the dislocation bands. After a 24-h treatment the cracks penetrated no wre than $1.5 \mathrm{~m}$, whereas some dislocation danage had penetrated $5 \mathrm{~m}$; there was no danage at a depth of $45 \mathrm{~mm}$, implying that the daage profile was probably following the deuterius profile. Further deuterium profiling wll test this hypothesis.

These results show clearly that before hydrogen embrittlenent of stainless steel can be addressed and understood it is necessary to carefully examine the conditions of hydrogenation, which may result in considerable surface prestraining and cracking of the test plece.

\subsection{FACILITY DEVEI.OPAENT}

2.4.1 High Spat1al Resolution AES - C. L. White and R. A. Padgett

Because trace element segregation to interfaces results in solute enriched reglons that are only a few atom layers thick, surface analysis technifues are very useful in atudying this phenosenon. During the past year we purchased 20 a high-epatial-resolution scanning Auger acroprobe,

20 This Instrusent was purchused with capital funds frow five different ORN progran, Including BES Deformation and Practure. 
which allows us to analyze the cop few aton layers on surface areas as sall as $200 \mathrm{~nm}$ in Hianeter. This results in an analysis volune contafning only a few willion atoes, within which a concentration of 0.1 to 1.0 at. $Z$ inpurity can of ten be detected. In addition to greatly inpioved spatial resolution, this system is equipped with a swall computer, which perforns some of the data acquisition and processing. This new AES factlity is proving to be of great value in studying trace element segregation effects in elevated-temperature carit:-ton. 21

\subsubsection{Bigh-Teaperature Mechanical Tegting Facility - J. C. Ogle and L. J. Turner}

The mechanical testing laboratory is being wodified and inproved to Increase the range of test temperature and the control of test environent. A high-temperature vacuun furnace is being designed for a universal testing machine, which will pump to about 1 uPa $\left(10^{-8}\right.$ torr) at a maximum temperature of $1000^{\circ} \mathrm{C}$. This machine will be used first for uniaxial tensile testing and will be codifled later to do fatigue testing at elevated temperatures.

A complete system of a dual-purpose stress relaxation and creep tester and a capacitance strain gage systen are being purchased. This syste enables creep tests or stress relaxation tests up to loads of $44.5 \mathrm{kN}(10,000 \mathrm{lb})$ in elther vacuus of $0.1 \mathrm{ma}\left(10^{-6}\right.$ torr) or inert atwospheres up to $69 \mathrm{kPa}(10 \mathrm{psi})$ and at temperatures up to $1200^{\circ} \mathrm{C}$. Ramp rates are avallable for straln or load from 0.8 to $190 \mathrm{kN} / \mathrm{s}$ ( 3 to $700 \mathrm{lb} / \mathrm{m}(\mathrm{n})$, and the transducers are accurate to \pm 2 pm or better with a resolution of $1 \mathrm{pm}$. These combined systems will be used to conduct the second series of tests for anelastic creep recovery studies.

${ }^{21}$ See, for example, results on type 304 stainless steel (Sect. 2.1.1.2) that would have been impossible to obtain with the lower resolution fac111ties that were previously avallable. 



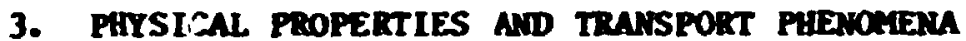

\section{I MECHANISHS OF SURFACE AND SOLID-STATE REACTIONS - J. V. Cachcart}

A major scientific objective of the research of this group is to develop a beter understanding of the cobility and structure of point defects in solids and to apply this knowledge in investigations of diffusion and oxidation (sulfidatioa) phenomena of relevance to the DOE elssion. Defect mobility is the deternining factor in the kinetics of various nass transport processes in solids (e.g., scale grouth during corrosion, radiation damage, recovery processes, etc.). Polnt defects can Influence tine electrical and thermal properties of materiuls. Also, mechanical properties, particularly of cerante materials, are sensitive to defect concentration and character. Mearly, the phenowena we study are basic to a variety of technologically ioportant processes.

The research consfats of both theoretical and experimental prograns. The conceptual development of defect diffusion theory continues to provide the central theme of our theorecical work. Progress has been ade in understanding correlation effects related to Interstitial defect interactions and in the area of weling diffusion in erystals containing large defect concentrations. This latter effort is particularly germane to diffuston in highly nonstolchionetric compounds wch as $\mathrm{Pe} 1-\mathrm{x}^{\mathrm{S}}$. In a parallel series of experimental studies we are investigating the pressure dependence of the culfidation kinetics and sulfide scale alcrostructure of Iron. Tracer and instrinsic diffusivity measurements in Pe 1-xS, specif 1cally designed to elucidate transport processes in PeS and to test our theoretical wodel, are in the planning atage. The angle crystals of Pes needed to Initiate this effort have been grown.

A significant fraction of the previous research of this group is being phased out this year in order that we aight concentrate core fully on sulfidstion studies. Included in this category is an investigation of the high-tempeature oxidation characteristics of the Important class of refractory wetals and alloys eyplfied by zirconiu, niobiu, and hafnium. Th1s work has special relevance to reactor afety concerns, and projects completed this year included determinations of the infiuence of oxide 
phase transformations, specimen genmery, and gaseous impurities on the steas oxidation kinetics of zircnnitm and zirconium-base a!loys. The effect of alloving on oxidation kinetics and on oxygen diffusivicies in the oxide scale and oxygen-stabilized a-zirconium layer was iso determined. An irvestigation of tritiud diffusion in alumina in the cerperature range 800 to $1000^{\circ} \mathrm{C}$ emphasized the i-jportance of mechanical darage (e.g., dislocation arrays) to $t$ th permeability of $\mathrm{Al}_{2} \mathrm{n}_{3}$ to hydrogen. This s: $\mathrm{y}$, now complete, is relevant to the tritium containment probler in fusion reactors and to the hydrogen embrittlement of metals.

\subsubsection{Sulfidation Studies}

Our sulifidation studies deal with transport phenomena in $\mathrm{Fe}_{1-x^{5}} \mathrm{~s}$ and with the influence of pressure on the kinetics and microstructural evolution of sulfide scales formed on iroc. These and planned fucure scudies are designed to parallel appl fed investigations of sulfidation in fluidized bed combustors for coal currently being carried out in the Macerials Compatibility Group of the Metals ard Ceranics Divisiou.

3.1.1.1 Evolution of Scale Microstructure and the Pressuze Dependence of the Sulfidation Rate of Iron - R. A. Mckee and R. E. Drusche:

The rate of sulfidation of $t r, n$ in sulfur vapor was measured at $700^{\circ}$. at sulfur pressures ranging from 1 to $100 \mathrm{~Pa}$. The parabolic sulfidation rate constant at I Pa differed by a factor of 2 trom that determined by Fry $l$ et $a:$, who made their measurements in $\mathrm{H}_{2}-\mathrm{H}_{2} \mathrm{~S}$ mixcures. The cause of this difference, which may have importane implications for the point defect structure of $\mathrm{Fe}_{1-x} \mathrm{~S}$, has not been completely determined. One possible explanation lies in the difference between the micrustructures of the sulfide scales formed in our experiments and those observed by Fryt et al. Both sets of results agree in that low-pressure sulfidation

1E. M. Pryt, V. S. Bhide, and W. H. Smeltzer, "Growth of Iron Sulfide

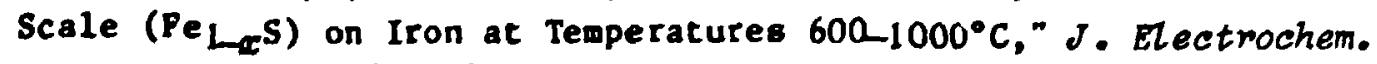
Soc. 126: 684-88 (1979). 
(i.e., I $\mathrm{Pa}$ ) favors the development of a colunnar FeS scale with the $a$-direction of the FeS oriented perpendicular to the sample surfaces. However, at higher pressures in our experinents the columar structure of the scalo Jisappears, and no evidence exists for the transition to preferred grcwth in the a-direction, as was suggested by Fryt et al. This behavior is Illustrated in Fig. 3.1.

It should also be noted that the enhanced grain growth in the PeS at the higher press:res is the opposite of what is normally expected; that is, the higher the pressure of an oxidant gas, Ir general, the saller will be the grain size of the reaction product. Understanding the cause of this behavior ay be important to the question of the mechanical stability of sulfide scales, and, if short-circuit diffusion is at all iaportant in the sulfidation of irort, this property of growing sulfide scales mist have = controlling effect on sulfidation kinetics under conditions of transient-; ressure sulfidation.

3.1.1.2 Iron and Vacancy Diffusion in Fe $1-x^{S}$ (Ref. 2) - R. A. McKee

A theoretical analysis of diffuston in the cation-deficient compound $\mathrm{Fe}_{1-x} \mathrm{~S}$ is undertaken to account for the effects of site exclusion and vacancy correlation on diffusion in highly nonstolchiometric compounds. The dependence of the refect stiucture on temperature and sulfur pressure is used to develop an understanding of defect diffusion kinetics in this material. He show that the strong repulsive interaction $(\sim 0.3 \mathrm{eV})$ of the cation vacancles causes them to diffuse in a highly nonrandom manner. Using a recently developed theoretical treatment (see Sect. 3.1.2.1 below) to account for this phenomenon, we explain the concentration dependence of both tracer and intrinsic diffusion in compounds of this type.

2 Abstract of paper prepared for submission to the Joumal of the American Ceramic Socitiy. 


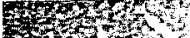

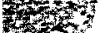

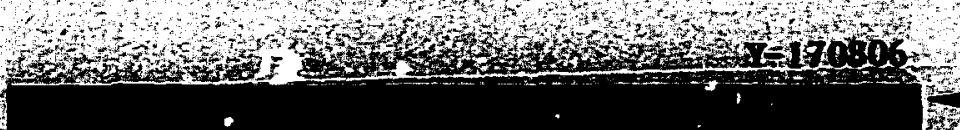
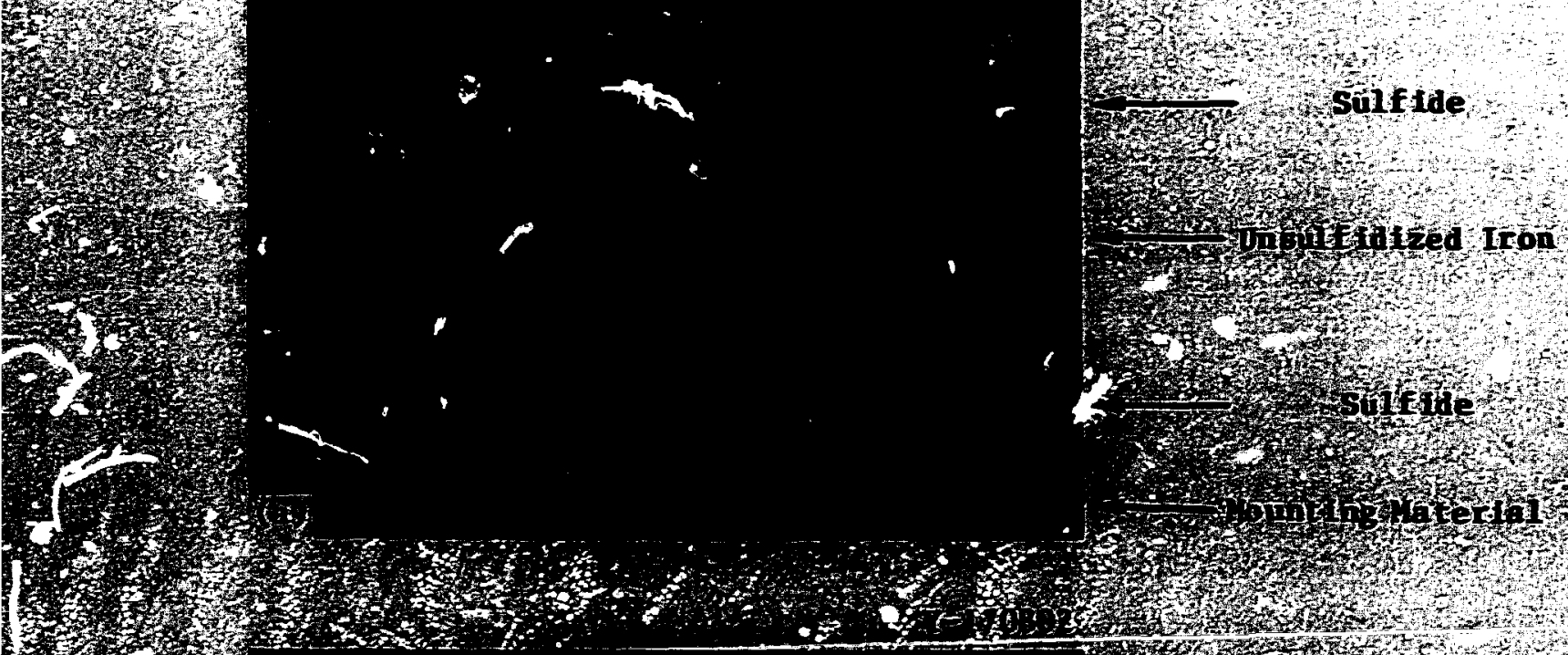

(1)
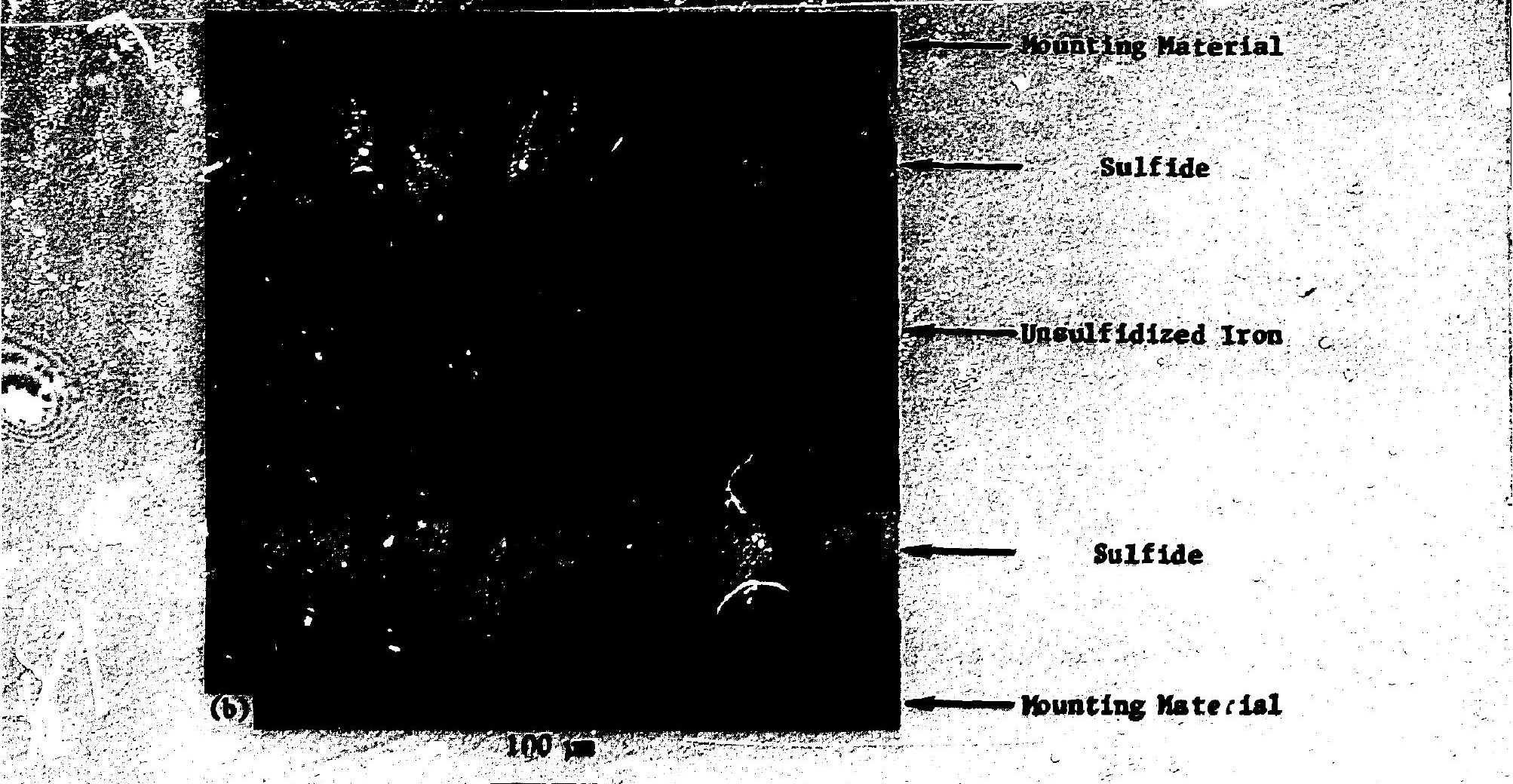

718. 3.1. Crose Eections Through Iron Spectwens After Deaction in Sulfur Vapor at $700^{\circ} \mathrm{C}$ Viewed in Polarized Light. Note difference in grain structure in the sulfide ccales on the two epecinens. (a) sulfidized 14 als ae I Pa sulfur. (b) sulfidized 2.5 ain at $100 \mathrm{~Pa}$ sulfur.

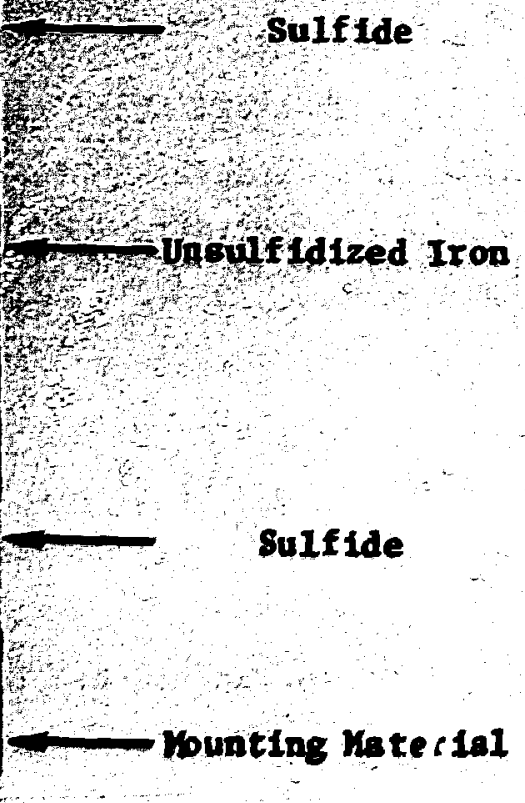




\subsubsection{Diffusion Theory - R. A. Hekee}

We utilize the wodeling of diffusion processes as a guide in wch of our experimental work. Recent developments are sumarized in the abstracts listed below.

3.1.2.1 Diffusion in a Pure, High-Vecancy-Content Crystal ${ }^{3}$ - R. A. McKee

The Ided that vacancies can follow a nonrandon walk in a solld has been developed and put into a quantitative form for diffusion in a pure, high-vacancy-content crystal. Intrinsic and tracer diffusion in a metal have been analyzed, and the electrical wobility in an lonfc solld has been expressed in terns of the tracer diffusion coefficient and the separate correlation factors for atims and vacancies. The dexcription uses classical methods of diffusion theory, and generalized results that account for nonrandon vacancy walk have been shown to reduce to those obtained by Howard and Lidiard in a system where the vacancy noves randonly as a 1solated point defect. Experimental data for carbon diffusion in fcc Iron have been exanined to illustrate the interstitjal-vacancy analog that was used in this analysis, and the general result has been applied specifically to discuss vacancy diffusion in $\mathrm{Fe}_{1}-x^{S}$.

\subsubsection{Therwodynancs and Kinetics of Ircerstitial Diffusion in a Tro-Component Syeten 4 - R. A.Mckee}

Diffusion theory is developed for a two-component system in which only the interstitial element is mbile. A thermodynanic formal ism is ueed In direct parallel with a kinetic theory to construct a mechaniomIndependent relationship between tracer and chealcal diffustion coefficients.

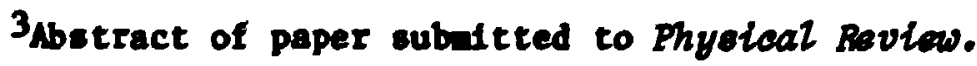

4abstract of paper accepted for publication in Physloal Revlew.
} 
A result is that

$$
D I=\frac{D *}{f} 1+\frac{\partial \ln \gamma}{\partial \ln C}
$$

Here, $D I$ is the intrinsic or chemical diffusion coefficient for the interstitial, $D^{\star}$ is the tracer diffusion coefficient, $f$ is the correlation factor, and $\gamma$ is the activity coefricient. This expression accounts for site exclusion, correlation, and drift effects that occur as the interstitial content changes. Ceneralized phenomenological coefficients that are deternined in this analysis can be used for standard representations of diffusion in electric fields and temperature gradients. Horeover, the forms that the phenomenological coefficients take for the interstitial systen are the same as those previously derived for vacancy diffusion. A test of this predicted relationship between tracer and chenical diffusion coefficlents is developed and uses a comparison between theory and experiment for carbon diffusion in fec iron.

\subsubsection{Site Blocking and Correlated Defect Hotion in Tracer and Chemical Diffusion 5 - R. A. Mckee}

A method is developed for analyzing defect diffusion coefficients. Defect diffusion 18 an integral part of considerations in diffusion theory for atom wotion in crystals, but it has not been developed as a distinct concern In diffusion kinetics. An "alloy" of tracer and nontracer atoms occupying octahedral Interstices of the fcc lattice has been used as a model to develop quantitative descriptions of site blocking, correlation, and flow effects that are all characteristic elements of defect diffusion k'netics. Correlated walk of vacancies in and near a divacancy can be discussed by using these results, and this analysis suggest a wethod for generalizing theoretical treatments of atom-defect and dafect-defect interactions in diffusion related phenomena.

5abetrace of paper accepted for publication in Phyoloal Revlow. Th1s work was Inftiated whlle the author was assigned to the Theoretical Physics Division, ARRe, Harwell. 


\subsubsection{Alloy Oxidation at Elevated Tenperatures - R. E. Pavel}

We have now completed a comprehensive series of interrelated studies of the stear-oxidation characteristics of crystal-bar zirconiu and the zirconiun-base alloy Zircaloy $-4(\mathrm{Zr}-1.6$ wt $\mathrm{Z}$ Sa-0.25 wt $\mathrm{Z}$ Fe-0.12 at $\mathrm{Z} \mathrm{Cr}$ ) over the terperature range 1000 to $1400^{\circ} \mathrm{C}$. Previous precision kinetic measurements were augented by investigations of the influence of oxide phase transformation, specinen geometry, and gaseous inpurities on oxifation kinetics. Other studies have detalled the effect of alloying elements on oxide aicrostructure and on the diffusivity of oxygen in the oxide and in oxygen-stabilized a-zirconiu. This bojy of results provides the basis for a wch improved wechanistic understanding of the oxidation behavior of zirconiu and Its alloys and has enabled the computer wodeling of the $\mathrm{high}_{\mathrm{g}}$-temperature oxidation of these materials under a variety of conditions.

We also describe $: 1$ this section a further analysis of previously measured oxidation-in lused stresses in tantalum-base alloys. These results explain the catastrophic oxidation sometimes observed in these alloys and delfneate the role of alloying additives such as hafnium as saturable oxygen traps.

3.1.3.1 The Oxidation of Zircontum from 1098 to $1416^{\circ} \mathrm{C}-$ R. E. Pawel and J. J. Campbel1

The rates of thickening of the oxide and oxygen-stabilized alpha layers during oxidation of pure crystal-bar zirconium in stean were measured at 1098,1200 , and $1416^{\circ} \mathrm{C}$. In the early stages of oxidation parabolic grouth rates were observed for both phases. The experimentally determined parabolic rate constants plus that calculated for total oxygen consumption are given by:

$$
\begin{aligned}
& 8 \frac{2}{\phi} / 2=4.361 \exp (-176500 / R T) \mathrm{mm} 2 / \mathrm{s} \\
& 8 \frac{2}{\omega} / 2=26.91 \exp (-185400 / R T) \mathrm{mm}^{2} / \mathrm{s} \\
& 8 \frac{2}{\tau} / 2=49.48 \exp (-187300 / R T) \mathrm{kg}^{2} / \mathrm{m}^{4} \mathrm{~s}
\end{aligned}
$$


where left-hand nembers are the parabolic-rate constants and the subcripts, 4, $a, t$ refer to oxide and alpha growth and oxgen consunption, respectively. Activetion energies are expressed in joules.

These rate constants differ sigaificantly from those for zircalos-4. At $1098^{\circ} \mathrm{C} \delta_{\phi}^{2} / 2, \delta_{\alpha}^{2} / 2$, and $\delta_{\tau}^{2} / 2$ for 21 rcaloy are 259,64 , and 1972 of the corresponding values for pure zirconiu. These differences are onaller at $1400^{\circ} \mathrm{C}$, but the sase tread continues.

3.1.3.2 Oxjgen Diffusion and Diffusion Wodering in the Zircontur Oxygen Systen - R. E. Pawel and J. J. Camplell

On the basis of on a witiphase, woring boundary diffusion nodel, we previousiy derived equations that relate the effective chenical diffusion: coefficients for oxygen in the groining oxide and alpha phases to the neasured parabolic rate constants for phase growth. 6 Applying these equations to the oxidation data for pure zirconiun, we found that the oxygen diffusion coefficient in the oxide on pure zirconiu varied from 0.5 to 0.7 times that in the oxide on Zircaloy-4, although the difference In the oxygen diffusion coefficients for the alpha layers was statist cally negligible. Thus, in opite of the existence of marked differences In the growth kinetics of both product layers on zirconiun and zircaloy-4, only diffusion in the oxide phase is influenced to a reasurable extent by the alloying additions in zircaloy-4. For oxidation of zirconiun in stean from 1098 to $1416^{\circ} \mathrm{C}$, the effective oxygen diffusion coefficient in the growing oxide phase is given by

$$
D_{\phi}=46.84 \exp (-168,500 / R T)=2 / 8,
$$

where the activation energy is expressed in Joules.

Having established the oxygen diffusivities in the growing product phases for the zirconilu, we then used these values as input to a finitedifference-based computer code, Murinas, which peraitted diffusica to be

6R. E. Pawel, "Oxygen, Diffucion In the Oxide and Alphe Fhaces During Reaction of Zircaloy 4 with stean frow 1000 to $1500^{\circ} \mathrm{C}, " J$. Electrochem. Soc. 126: 1111-18 (1979). 
codeled for a variety of experibental conditions. For exaple, this nodeling accurately predicted the changes in the grouth of the alpha layer as a function of opecimen thickness for extended oxidation, where the beta phase tends to be cone saturated with assen during the experinent. Aditionally, these techniques bre proved useful in providing Insight Into a mechanion that can expiain anoalies in the oxidation behavior apparently caused by phase changes in the oxide.

\subsubsection{Effects of . Pinite Specinen Ceonetry on the oxidation Uinetice of Zircaloy 4 - R. E. Pavel and J. J. Complell}

The oxidation of zirconil and zirconiu-base allojs at temeratures

above the alphimbets transition involves the growth of lajers of oxide and oxsen-stabiliced alpha into the bost beta phase. If the grouth is governed by diffusion processes, the kinetics of lajer grouth on thin specimens will vary eignificently if the reaction continues long enough to promote large changes In the degree of saturation of the underlying wetal with oxygen. We have exanined this effect for the oxidation of zircaloy-4 In stean by nodeling analyses and by a series of extended-tine oxidation experinents at $1300^{\circ} \mathrm{C}$. These experinents confimed the predicted increase In the rate of alpha layer growth as the beta phase becane saturated. For example, at $1300^{\circ} \mathrm{C}$ the rate constant wre than doubles. While the appesrance of "alpha Incursions" lesding to an Irregular alpha-beta interface also seem to be initiated at this tine, the experimental observations generalls agreed well with those predicted on the basis of the codellng analysts. This behavior clearly needs consideracion in the Interpretation and comparison of oxidation date, particularly where large differences in the spectinen geonetry or dinensions are involved.

7Abstract of paper accepted for publication in the Joumal of the Eleotrochentoal soclety. 


\subsubsection{Sone Experiments and Calculations Regarding the Effect of Specimen Dinensions and Oxygen Solubility on Oxidation Kinetics 8 - R. E. Pawel and J. J. Campbell}

For the oxidation of pure zirconiun and zircaloy-4 ( $z r-1.6 z$ sa-0.25z Fe-0.127 Cr) at temperatuses above the alpha-beta transition, the products of the reaction, oxide and oxygen-stabilized alpha, form as uniform layers growing into the host beta phase. In the early stages these layers exhibit parabolic kinetics consistent with growth by diffusion control. We have analyzed this kinetic systew as a wltiphase woving boundary diffusion problea. Using a finite difference computer progran, MULThN, we exanined the effect of specimen thickness and the degree of oxygen saturation in the beta phase on the oxidation kinetics for a model systen. Experimental results for both zirconiun and zircaloy-4 agree well with the predictions of this aspect of diffusion modeling. Furthernore, because prolonged oxidation of pure zircontum is not accompanied by alpha "Incursion" formation as in the case of Zircaloy-4, the observed layer growth rewains in accord with the idealized diffusion wodel for longer times.

\subsubsection{The Oxidation Kinetics of Zirconfum at $1000^{\circ} \mathrm{C}-\mathrm{R}$. E. Pawel and} J. J. Campbel1

The growth of the oxide and oxygen-stabilized alpha layers during oxidation of crystal-bar zirconfum in steam at $1000^{\circ} \mathrm{C}$ is characterized by complicated kinetics. At one stage, for example, it appears that the oxide layer actually decreases in thickness as the reaction proceeds. Figure 3.2 illustrates this behavior, showing departures from parabolic growth for both the oxide and aupha layers. We interpret these features as being due primarily to changes in the structure of the oxide phase during oxidation. The structural changes reduce the effective diffusivity

${ }^{8}$ Abstract of a paper presented at the Spring Meeting of the Blectrocheafeal Soctety, St. Louls, May 11-16, 1980. 


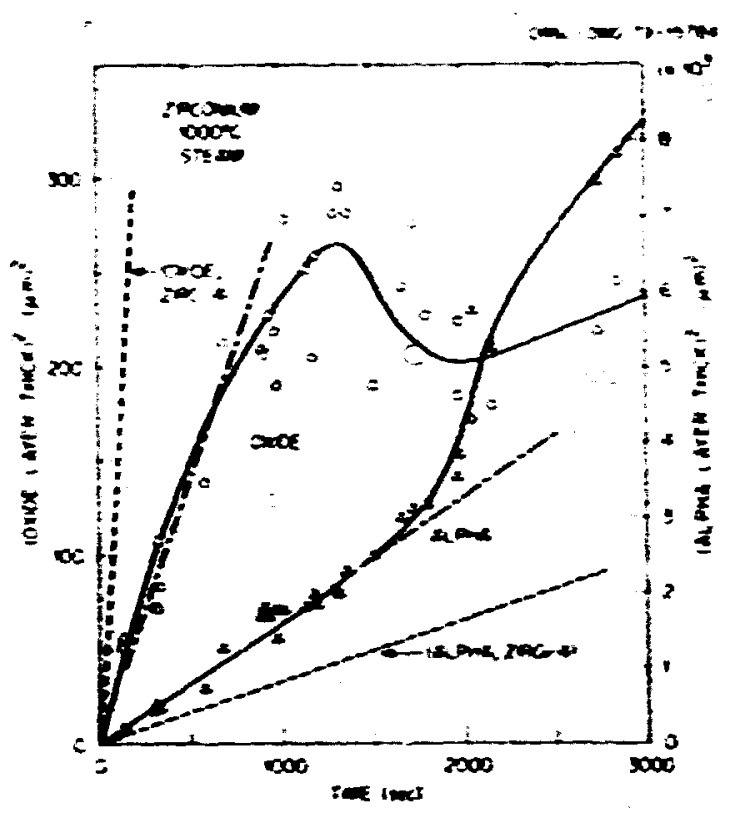

Fig. 3.2. Growth of Oxide and Alpha During Oxidation of Crystal-Bar Zirconiu in Stea at $1000^{\circ} \mathrm{C}$. The dashed lines indicate the corresponding parabolic kinetics exhibited by zircaloy-4 uoder the sampe conditions.

of oxygew In the oxide, and this perturbation, influences the rates of growth of both product layers. Hodeling analyses predict that for an abrupt change in diffusivity the transition to the new steady-state condition can involve a temporary thinning of the oxide layer.

\subsubsection{Ef fects of the Monoclinic-Tetragonal Transformation on Oxidation Rinetics of ZirconIun - R. E. Pawel and J. J. Canpbell}

In order to test our hypothes is that the monoclinic-tetragonal transformation for $\mathrm{ZrO}_{2}$ influences the oxidation kinetics of $z$ irconium (and Zircaloy-4) under certain couditions, we perforwed several experiments in which specinens were oxidized at $1100^{\circ} \mathrm{C}$ for varying tises. At a specified tine during these exposures, each specinen was quenched to $600^{\circ} \mathrm{C}$ and then quickly reheated to the reaction temerature. This cycle causes the existing tetragonal oxide to transform to the monocilnic form. Then, because of the hysteresis thought to exist for the reverse transformation, subsequent oxidation at $1100^{\circ} \mathrm{C}$ results in the persistence of the monoclinic oxide rather than the continued growth of the tetragonal wodification 
that would normally occur for isotheral reaction at this teaperature. The suddenly different diffusional characteristics of the oxide result in spectacular changes in the growth kinetics for both product layers. Diffusion wodeling is being utilized to interpret the kinetic data.

\subsubsection{Oxidation of Zirconium in Oxygen and Oxygen-Stean Mixtures -} R. E. Pawel and J. J. Campbell

Zirconiu, Ifke Zircaloy-4, exhibits sall but reproducible differences in the reaction kinetics at high temperatures, depending upon whether the oxidant is stéan or oxygen. Such a result is unanticipated on the basis of a difference in oxygen partial pressure alone if the oxidation mechanis is entirely one of diffusion via anion vacancies in the oxide lattice.

We oxidized crystal-bar zirconif in dry oxygen at $1210^{\circ} \mathrm{C}$ and found that the parabolic rate constant for oxide growth was about $40 \mathrm{z}$ higher than that for oxidation in stean. (For 2ircaloy-4 at $1253^{\circ} \mathrm{C}$, the corresponding difference was about half as wch.) Sall additions of stean to the oxygen had little effect on the kinetics, although the surface luster of the oxide was altered noticeably. On the other hand, anall additions of oxygen ( $\sim 501 \quad 7$ ) to stean produced measurable increases in oxide growth without a change in the appearance of the oxide surface.

\subsubsection{A Comparison of the High-Temperature Oxidation Behavior Z1rcaloy-4 and Pure Zirconlug' - R. E. Pawel and J. J. Campbell}

Oxidation rate data for Zircaloy-4 in stea woder lsothernal conditions in the temerature range 1000 to $1500^{\circ} \mathrm{C}$ indicate that the kinetics of layer growth and oxygen consumption can be described by virtually ideal

\footnotetext{
9Abstract of paper for presentation at the ASTH-AMS Pifth International Conference on Z1rconiu in the Muclear Industry, Boston, Aug. 4-7, 1980. The paper will be published as part of an Asm Special Technical Publication in August 1981.
} 
parabolic behavior. Thus, the grouth of the two product phases, oxide and oxygen-scabilized alpha, is presuned to be controlled by diffusion processes leading to unifor thickening. We have measured the oxidation rate of pure arc-elted crystal-bar zirconiu under sinilar conditions and have found differences in the reaction characteristics cosparei with 21rcaloy-4. At temperatures from 1098 to $1416^{\circ} \mathrm{C}$, while parabolic kinetics is still observed, the grouth rates for both phases are weasurably different. Our analysis of these data in terws of a witlayer diffusion nodel suggests that the effective chencal diffusion coefficlent for oxygen in the oxide phase has been altered. Hovever, despite the kinetic differences, the analysis also concludes that the diffusion coefficient of oxygen in the alpha lajers is identical, a finding consistent with the results of -independent measurements. Such responses are inportant in defining $t^{\text {he }}$ varlous effects of alloying on oxidation and diffusion processes in thit and sinilar oystew.

In addition to the analler oxygen diffusivity in the oxide phase on pure zirconiun than in that on Zircaloy-4, a higher activation energy was also observed, suggesting the possibility that some wechanistic differences exist. Without additionsl infornation, it is not possible to attribute these differences to changes in oxide defect structure as a result of alloying. However, Eetallographic observations reveal sigaificant worphological and gratn size differences in the columar oxide growing on the two aterials. Thus, such complications, perhaps assoctated with the relative contributions to oxide growth from shor'-eircuit diffusion, could be responstble for this behavior.

3,1.3.9 The Interaction of Stress and Mechanical Property Effects During Oxidation of Tantalu-bace Alloys - R. R. Pawel and J. J. Canpbell

Specinens of the tantalumbese alloys $\mathrm{T}-10 \% \mathrm{~W}$ and $\mathrm{T}-10 \% \mathrm{H}-2.5 \%$ af (T-222) 1gnited after prolonged 1sothermal oxidation at elevated tenperatures. The characterietice of this behavior were exanined, and the time-teaperature regies in wich one aight expect this catastrophic response to oxidation of thin epeciens was defined. Ignitition of epec1nens was the final etep in a equence that Involved oxygen penetration 
Into the alloy in advasce of the oxide-metal interface, a resulting embrittlement and stress bulldup, and finally a release of the strain energy of the systen through a sudden disintegration of the specimen along grain boundaries. This sudden increase in metal surface area led to a violent ignition.

3.1.3.10 The Influence of Alloying Elements on Oxygen Diffusion in Tantalu-Base Alloys - R. E. Pawel and J. J. Canpbell

Experimental data dealing with the flexure of spectens of tantalia and cantalum-base alloys exposed on one side to oxygen at low pressures were reexanined with regard to oxygen diffusion and oxygen solution effects. Difusion coefficlents for oxygen in $\mathrm{Ta}$, $\mathrm{Ta}-10 \mathrm{~W}$, and $\mathrm{Ta}-10 \mathrm{~T}$ W-2.57 Hf (T-222) were calculated from the flexure measurements on the basis of a simple strain-diffusion relationship. The results indicated that both tungsten and hafniu influence oxygen diffusion in tantalu and that a wodel with hafniue serving as a saturable trap for oxygen is consistent with the observations.

\subsubsection{Diffusion In Oxldes - J. V. Cathcart and L C Manley, Jr.}

The completion of our studies of tritiun diffusion in $\mathrm{Al}_{2} \mathrm{O}_{3}$ arks the end of our current investigations of incerstitial diffusion in oxides. Ualng the constant-source solution for the diffusion equation, we obtained apparent tritiu diffusivities along the c-direction of $\mathrm{ar}_{2} \mathrm{~N}_{2} \mathrm{O}_{3}$ single crystals ranging from $10^{-15}$ to $10^{-12} \mathrm{a}^{2} / \mathrm{s}$ as the temperature was increased from 800 to $1000^{\circ} \mathrm{C}$. The corresponding d!ffustvity measured in the a-direction at $1000^{\circ} \mathrm{C}$ was a order of magnitude larger. We observed, however, that tritlum diffusivity values were highly sensitive to the curface treatwent given apecinen. For example, the value cited above for diffusion parallel to the a-direction of an $\mathrm{N}_{2} \mathrm{O}_{3}$ crystal was obtained with speciwens that were wechanically polished through lin dianond paste and preannealed for $4 \mathrm{~d}$ at $1000^{\circ} \mathrm{C}$ in hydrogen at about $500 \mathrm{~Pa}$ before being annealed in tritium at the sase pressure and temperature for $8 \mathrm{~h}$. When a - Inilar epecinen was eubjected to a $24-\mathrm{h}$ preanneal at $1300^{\circ} \mathrm{C}$ before being 
given the same treatment described above, the tritiun activizy in the first 10 we below the specinen surface had been reduced by an order of agnitude, and the penetration distance into the sample at which background activity levels were approached was also reduced by an order of magnitude or wre. This result suggests a i00-fold reduction in the triciu diffusion coefficient. It appears clear that both the effective solubility (and hence the perweability) and the diftusivity of tritiun in $\mathrm{Al}_{2} \mathrm{O}_{3}$ depend on the extent of mechanical dame of the sample.

\subsection{Physical PRoperties Research - D. L. HeEl roy}

We develop and apply accurate measurement techniques to obtain thermal conductivity, electrical resistivity, Seebeck coefficient, thermal expansion, and specific heat data for metals and nonmetals in the range fron 4.2 to $2600 \mathrm{~K}$. Analysis of these data provides useful jescriptions and improved understanding of particular relations between these properties for specific solids. This measurenent and analysis approach yields several benefits, ircluding property estimates for systems where data are - Issing, ways to improve and control properties, improvement in measurement techniques and standards, and experimental tests of theoretical models for energy transport phennena, such as for scattering mechanisus involving electrons and phonons. A by-product of thi! research is the capacity to measure theraal conductivity and electrical resistivity at high temperatures to evaluate innovative materials of construction for use in power generating systens.

\subsubsection{Transport in Metals}

3.2.1.1 Experimental Determination of the Phonon and Electron Components of the Thermal Conductivity of bec Iron $10-R_{\text {. }} K_{\text {. Willians, }}$ D. W. Yarbrough, J. W. Masey, 11 T. K. Holder, 11 and R. S. Graves

A study of the factors that affect the thermal conductivity of a-1ron and its solid solutions is described. The results of these experisents

10 Abstract of paper subatted to Joumal of Applied Physho. 1 loraU Graduate Fellow from Tenneasee Technological University. 
define the phonon and electrunit components of the thetal conductivity of pure $\alpha$-iron between 90 and $450 \mathrm{~K}$. The phonon conductivity can be analyzed to Identify the strengths of electron-phonon and phonon-phonon scattering, and the latter resistance agrees well with theoretical estimates. The scatterang of phonons by electrons is internediate between the sall values of the noble metals and the strong scattering found in niobium and tantalu. An experinental estinate of the electron-phonon mass enhancement factor, 0.4, is derived from the results. Finally, reexanination of the data for ten solfd-solution alloys suggests that both phonon scattering mechanisms are influenced by the alloying elements.

\subsubsection{Theral Transpor Properties of Moblum and Some Mobium-Base Alloys fron 80 to 1600 K (Ref. 12) - J. P. Moore, R. S. Graves, and R. K. Hillians}

The electrical resistivities and absolute Seebeck coefficients of 99.8 at. $Z \mathrm{Nb}$ with a resistivity atto of 36 , No-4.8 at. $Z \mathrm{H}$, No-5 at. $Z$ Mo, No-1D at. $z \mathrm{Mo}$, and $N b-2.4$ at. $Z$ Ho-2.4 at. $Z \mathrm{Zr}$ were weasured frow 80 to $1600 \mathrm{k}$, and the thermal conductivities of the nioblum and $\mathrm{Mb}-5$ at. $Z \mathrm{~W}$ were measured from $8 n$ to $13 n 0 \mathrm{~K}$. A technique is described for weasuring the electrical resistivity and Seebeck coeffictent of a specimen during radial heat flow weasurewents of the therwal conductivity. The transport property results, which had uncertainties of \pm 0.47 for electrical resistivity and \pm 1.47 for therwal conductivity, showed the influence of tungsten and wolybdenum solutes on the transport properties of nfobtum and were used to obtain the electronic Lorenz function of pure nlobium, which was found to approach the Somerfeld value at high temperatures.

3.2.1.3 Phonon Conductivity of Mobiua - J. P. Hoore, R. K. Williams, R. S. Graves, F. J. Weaver, F. J. PInsk1,13 and K. H. Butler

Therwal and electrical conductivity data for a zone-refined nioblua (resletivity ratio - 325) specinen and three nloblum-base alloys (5 at. $\%$

12 Abstract from a paper subnitted to Bigh Temperatures - High Presoures.

13 Gucst sclentist frow State University of liw York, Stony Brook. 
Ho, 10 at. $Z \mathrm{Ho}, 2.4$ at. $Z$ Ho-2.4 at. $Z \mathrm{Zr}$ ) were analyzed to obtatn phonon conductivity, $\lambda_{p}$, estinates fcr pure niobiu over the 80 to $300 \mathrm{~K}$ range. These results show that electron-phonon scattering, $V_{\text {ep. }}$ is very strong and wch wre effective than phonon-phonon scattering in liaiting $\lambda_{p}$ An experimentally derived numerical constant used to describe $\nu_{\text {ep }}$ appears to be about $30 \mathrm{z}$ larger than the theoretical estinate, 14 and about 3 tines as large as a sirilar estinate obtainzd from very low-teperature daca. 15 The $30 \%$ difference between theoretical and experimental values is aboul equal to the experimental uncertainty, and sinilar differences in $W_{\text {ep }}$ values derfved from low and internediate-temperature data have previously. been noted for tungsten and taitalu. The results also suggest that the $\lambda_{p}$ values for the nlybdenu alloys are higher than the $\lambda_{p}$ of pure niobium. This can be explained by the change in the density of states on alloying, and low-temerature experimental datals have also been interpreted in this fashion.

As shown by Fig. 3.3., the electroni: thermal conductivity values obtained in this study agree well with first-principles theoretical calculations. These calculations include the full complexities of the electronic band structure and phonon dispersion; however, they employ the "rigid-nuffin-tin" approxisation for the electron-phonon matrix elewents. The good agreement between theory and experiment gives confidence in the validity of this approximation for transition metals. The differences between our experimental results for the electronic thenal conductivity and previously accepted values are due to improved experimental accuracy, a purer sample, and the inclusion of a correction for phonon conduction.

14W. H. Butler and R. R. Hilliam, "Electron-Phonon Interaction and Lattice Therwal Conductivity," Phys, Rev. B 18: 6483-94 ; 1978).

15J. B. Sousa, "Latefice Thermal Conductivity of Ta-ibb and Bo-10 Solld Solution Alloys in Borzal and Superconducting States," J. Phys. C 2: 62?-39 (1969). 
ORNL-DWG 80-12059

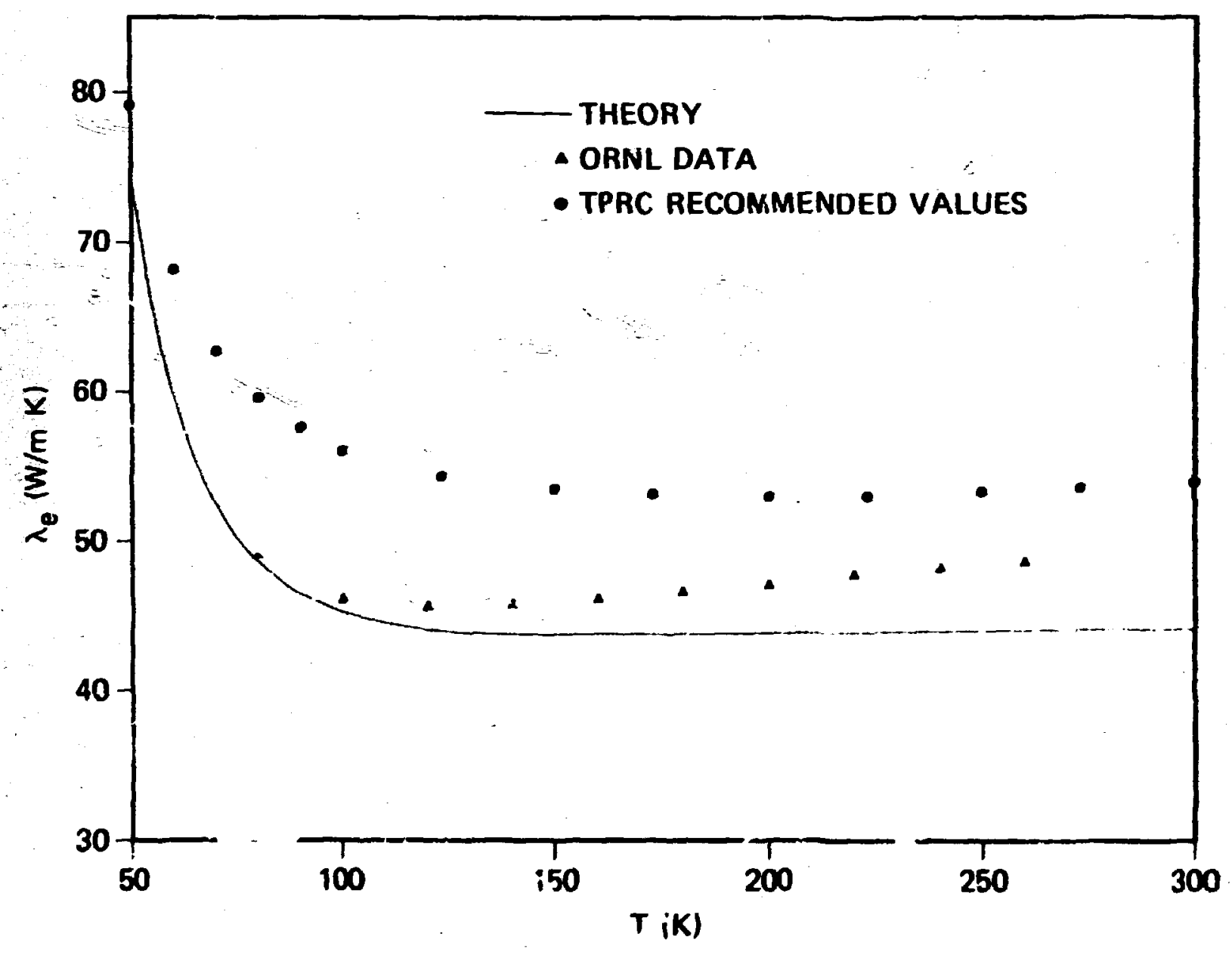

F1g. 3.3. An Improved Theoretical Calculation of the Eiectronic Theraal Conductivity Is in Relattyely cood Agreement with New Experimental Data for Noblum. The literature values [C. Y. Ho, R. W. rowell, and P. B. Llley, J. Phys. Chem. Ref. Data 3: Suppl. 1 (1974)] were not corrected for phonon transport, ami the Improvewon: 1 s due to both this correction and the Improved accuracy of the new experimental data. 

3.2.1.4 The Theraal Conductivity, Electrical Resistivity, and Seebeck
Coefficient of 3RM-73516 - R. S. Graves, R. R. Willans, and
J. P. Moore

The scarcity of recognized thermal conductivity standards has been a problem in the development of therwal conductivity techniques for many years. The National Bureau of Standards now supplies an austenitic stainless steel to fill one therwal conductivity range, but the standard values are based on few data. We have recently cested two apparatuses using this standard. One apparatus measured the thermal conductivity, electrical resistivity, and Seebeck coefficient from 300 to $1000 \mathrm{~K}$ with total deterwinate Easurewent errors of $\pm 2.27, \pm 0.47$ and $\pm 0.3 \mu V / K$, respectively. The other apparatus was installed in a helfum-cooled cryostat at the Rernsforschungzentrum, Karlsruhe, West Cermany. The Imited sensitivity of Chramel-vs-constantan thermocouples limited the lowest temperature of the thermal conductivity measurements to $20 \mathrm{R}$, and the combination of temperature measurement and geometry errors 1 imited the accuracy to \pm 3.57 at $300 \mathrm{~K}$ and $\pm 6 \%$ at $20 \mathrm{~K}$.

All electrical resistivity $(\rho)$ rcsults were within the $\pm 2 \%$ uncertainty claimed for the standard. The maximum deviation between any thermal conductivity datum from the high-temperature apparatus and the calibration value was $-3.2 \%$ at $470 \mathrm{~K}$, which is within the uncertainty of the standard. Thermal conductivity data from the low-temperature apparatus for temperatures above $60 \mathrm{~K}$ were within the $2 \%$ uncertainty of the standard, but results between 20 and, $0 \mathrm{~K}$ were as wuch as $4 \%$ higher than the standard values. This is still well within the combined uncertainties of the standard and experimental values. Thus these present results support the calibration values of the stainless steel. Analysis of the data indicates that the phonon component, $\lambda_{D}$ is dominant in this stainless steel below $150 \mathrm{~K}$ : $\nu$ that $\lambda_{p}$ has a broat maximum near $100 \mathrm{~K}$.

16Abstract fron a paper to be published in Thermal Conductivity 16, Plenum Press, New York. 
3.2.1.5 The Electrical Resistivity and Theral Conductivity of MobiuTitaniu Alloys at Low Temperatures 17 - J. P. Moore

The electrical resistivities (p) of severai superconducting niobiumtitaniug alloys were measured from their critical temperatures $\left(T_{c}\right)$ to $300 \mathrm{R}$, and the thermal conductivity $(\lambda)$ of one of then (Nb-78 at. $Z \mathrm{TI}$ ) was measured at temperatures above $5 \mathrm{~K}$. The $N$ b $78 \mathrm{et}$. $\mathrm{Z}$. TI was fabricated from an electron-bean-melted rod, and measurenents were wade on this rod first after a dianeter reduction from 12 to 5 and then after an anneal at $1120 \mathrm{~K}$ for $2 \mathrm{~h}$ followed by a slow $\operatorname{cool}$ to roon teaperature. In both states, $\lambda$ showed a slope change at $r_{c}$ and $\lambda$ decreased rapidiy on cooling below $T_{c}$. Although $p$ and $\lambda$ both changed on annealing, the nost drastic change occurred in the lattice component of the theral conductivity. The teaperature dependences of the lattice component indicate that this large shift may be due to a reduced dislocation density in the annealed specinen.

\subsubsection{Tantalu - R. K. Hillians, J. P. Hoore, R. S. Graves, and F. J. Heaver}

Electrical and therwal conductivity data for an Isoelectronic tantalum-base alloy $\ldots$ itaining $2.5 \% \mathrm{~W}$ and $2.5 \%$ Hf were obtained. These results indicate that the electron-phonon scattering $\left(H_{e p}\right)$ for this element is surprisingly close to the value for niobium. A zone refined tantalum specimen has been obtained as a further experimental test of the result because we had anticipated 14 that the $W_{e p}$ values for the two elements would differ by about a factor of 2 .

\subsubsection{Measurements on A15 Compounds - R. K. H1111ams and F. J. Heaver}

The electron-phonon interaction is especially strong in high-T 115 compounds, such as $\mathrm{Mb}_{3} \mathrm{Sn}$, and we are atteupting to produce bulk samples

17 Work completed during assignment to Institut fur Kernphysik, Kernsforschungzentrum, Karleriche, BRG. 
of $\mathrm{Mb}_{3} \mathrm{Sn}$ alloyed with zirconiun and nolybdenu to deteraine the phonon conductivity at internediate temperatures. This would extend our studies of the interelenent variation of $V_{e p}$ and the ${ }^{b}$ gh normal state electrical resistivities of the compound. Prellainary work on bronze-process sanples aade with $\mathrm{nb}$ silojed with $\mathrm{H}_{0}, \mathrm{ZC}$, and $\mathrm{TI}$ indicates that the $\mathrm{T}_{c}$ values follow the trend predicted by application of the rigid band theory to the detalled band structure calculations. 18 substfution of aall acounts of zirconiu and citanion in $\mathrm{Wb}_{3} \mathrm{Sn}$ enhance $T_{c}$, wile wolybdenu additions depress $T_{c^{*}}$ We have noted that zirconiu and titaniu additions enhance the grouth rate of the $\mathrm{kb}_{3} \mathrm{Sn}$ layer by a factor of about 30 .

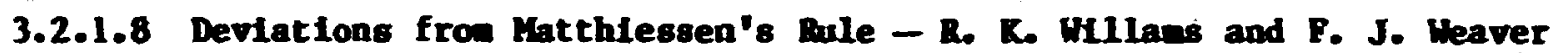

Deviations fron Hatthiessen's Dile (DiR) In transition netal alloys are currently of interest because of recent theoretical progress. The electrical resistivity of palladiu (resistivity ratio 1460 ) and $P d-0.1$ and 0.5 at. $7 \mathrm{TI}$ alloys were measured between 4.2 and 300 K because published results 19 Indicate that the DiR do not reach a constant positive value at high temperatures. The new data confirn this behavior but do not contain the anomalous concentration dependence of the original data set. The lor-temperature $p$ values for the pure palladiu follow the data of Schindler and Rfce 20 and appear to vary as $T^{2}$ up to about $8 \mathrm{~K}$. Data for the 0.1 at. 7 TI specimen show $40 \%$ larger $T^{2}$ coeffictent and no unusual behavior. An anomaly was detected for the 0.5 at. I TI specinen. In this case the $p$ varies wore strongly at the lowest temperatures and then becones on iy weakly tewperature dependent in the 10 to $15 \mathrm{~K}$ range.

18B. M. KleIn, L. L. Boyer, D. A. Papaconstantopoulos, and L. F. Hatheissen, "Self-Consistent APW Biectronic structure Calculations

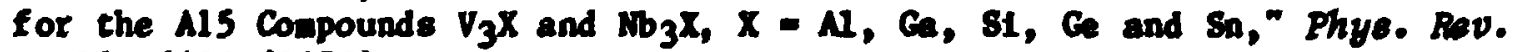
B. 18: 6411 (1978).

19E. K. Azarbar and G. Willaa, Matthiesoen's Bule Breakdown in Some Pt- and Pd-Based Alloys," Phys. Rev. 14: 3301-n9 (1976).

20A. J. Schindler and M. J. Rlce, "8-Election-Paranagnon scattering In Dilute Pd-N1 Alloys: Theory and Experinent," Phyo. Rev. B. 164: 759-64 (1967). 


\subsubsection{Equipment Development}

\subsubsection{Analysis of Apparatus with Radial Sypetry for Steady-State Heasurements of Thermal Conductivity 21 J. P. Hoore}

Steady-state radial heat flow apparatuses, which use specinens in the shape of right circular cylinders for measuring the thermal conductivity of solids and powders, were analyzed in detafl. A finfte-difference heat conduction code was used to deternine the temerature distributions in radial heat flow apparatuses. The distributions demonstrated the failure of wost systems to conform to normally assuned boundary conditions and were used to calculate apparatus errors due to nonideal heat flow. Analyses of a simple apparatus and selected experinental apparatuses showed clearly the importance of system symetry, end guards, and specimen length-to-diameter ratio to measurement errors. The temperature profile along the ain heater was found to be extremely Influential. The application of an "isothemal correction" wil reduce errors due to nonideal heat fluw. This correction reduces errors from as high as 617 ciown to 27 . This study has provided the background for accurate experimental meastrewents on pouder systems consisting of gas plus spherical oxide particles, which should have reproducible and predictable thermal conductivities.

\subsubsection{Multiproperty Apparatus - J. P. Moore}

The primary components for as apparatus designed for measuring several therwophysical properties of electrically conducting solids to tenperatures of $2600 \mathrm{~K}$ have been assenbled. The vacuu systen 18 ready for test and evaluation, and other components, which will be required for property measurements, are being acquired. We have decided to use a tungsten specinen for initial tests of the apparatus ince the hightemperature projerties of tungeten have been etudied and since our group

21 Sumary of chapter prepared for the The compendiun on ThemoPhyoloal Property Neasurement Wothods, K. O. Maglic, ed., publisher not decided. 
has seasured its eleccripal resistivity to high teaperatures. The latter is important since a knowledge of $p \nabla s$ is essential for measuring the thereal conductivity with this apparatus.

\subsubsection{The Theral Conductivity of Pouders of Microspheres - R. O. A. Ball, 2- J. P. Hoore, R. S. Graves, and D. Ir, McElroy}

A radial heat flow technique was used to neasure the thenal conductivity ( $\lambda$ ) of four $\mathrm{DO}_{2}$ alcrosphere beds and an $\mathrm{Al}_{2} \mathrm{O}_{3}$ microsphere bed at conditions given in Table 2.1. The $\lambda$ results show the influence of teiperature, gas type and pressure, sphere size, and bed density. For example, $\lambda$ of the denser beds 3 and 4 decrease with increasing teaperature, increase with gas pressure, and increase with decreasing gas nolecular melght, $\lambda(\mathrm{Be})>\lambda\left(\mathrm{H}_{2}\right)>\lambda(\mathrm{Ir})$. Bed 4 has a $\lambda 50 \mathrm{~g}$ greater than bed 3 because of its greater density ( $87 \% \mathrm{vs} 80 \mathrm{~K})$. The temperature dependence of $\lambda$ is positive for the large-sphere beds, 2 and 5 , but negative for the fine-sphere bed 1. Since pouders of known $\lambda$ do not exist, the results on bed 5 support it as a candidate reference material, and further testing is planned.

22V1siting scientist from A E.R.E., Harwell, U.K., until April 1980.

Table 3.1. Microsphere Bed Characteristics, Measurement Conditions, and Theraal Conductivity Results at $400 \mathrm{R}$

\begin{tabular}{|c|c|c|c|c|c|c|c|c|}
\hline \multirow[t]{2}{*}{ ied } & \multirow[t]{2}{*}{ Macertal } & \multirow{2}{*}{ sise } & \multirow{2}{*}{$\begin{array}{c}\text { Danolty } \\
\text { (2 of } \\
\text { Theoretical) }\end{array}$} & \multirow{2}{*}{ 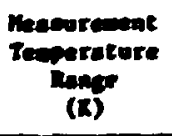 } & \multirow[t]{2}{*}{ Ceses } & \multicolumn{2}{|c|}{ Cese } & \multirow{2}{*}{$\left(w / e^{2} x\right)$} \\
\hline & & & & & & $(n+b)$ & $(a t a)$ & \\
\hline 1 & $\boldsymbol{D O}_{2}$ & 110,50 & 58.5 & $400-600$ & wo & 0.1 & I & 0.6 \\
\hline 2 & $\infty \infty_{2}$ & Cource, 1200 & 61.6 & $100-900$ & we & 0.1 & 1 & 1.2 \\
\hline \multirow[t]{2}{*}{3} & $\infty_{2}$ & 50.1200 & 79.9 & $400-1100$ & wo & $\begin{array}{l}0.1 \\
0.3 \\
0.6\end{array}$ & $\begin{array}{l}1 \\
3 \\
6\end{array}$ & $\begin{array}{l}1.6 \\
1.6 \\
2.1\end{array}$ \\
\hline & & & & & $n_{2}$ & $\begin{array}{l}0.1 \\
0.3 \\
0.6\end{array}$ & $\begin{array}{l}1 \\
3 \\
6\end{array}$ & $\begin{array}{l}0.9 \\
1.1 \\
1.2\end{array}$ \\
\hline \multirow[t]{3}{*}{4} & $\infty_{2}$ & $30,300,12000$ & 26.7 & $400-1100$ & wo & $\begin{array}{l}0.1 \\
0.3 \\
0.6\end{array}$ & $\begin{array}{l}1 \\
3 \\
6\end{array}$ & $\begin{array}{l}2.1 \\
2.7 \\
3.1\end{array}$ \\
\hline & & & & & $\boldsymbol{v}_{2}$ & $\begin{array}{l}0.1 \\
0.3 \\
0.6\end{array}$ & $\begin{array}{l}1 \\
3 \\
6\end{array}$ & $\begin{array}{l}1.0 \\
1.9 \\
2.0\end{array}$ \\
\hline & & & & & $x$ & 0.1 & 1 & 1.1 \\
\hline 5 & $\mathbf{N}_{2} \mathbf{O}_{3}$ & nedico, soo & 60.7 & $400-100$ & $v_{2}$ & 0.1 & I & 0,3 \\
\hline
\end{tabular}

aplbretorsly competed bed; ofhare wre poures. 


\subsection{Metastable materials - C. C. Koch}

This year completed the transition period in which research on superconducting saterials was redirected to studies of metastable aterials. Metastable materials, a prime example of which is metallic glasses, open numerous possibilities for the formation of new naterials not obtainable

$c$ under equilibriu conditions. The properties of netastable aterials can differ markedly from their crystalline counterparts. Wotable are the unique properties of metallic glasses in terns of nechanical strength conbined with ductility, corrosion resistance, and favorable ferronagnetic properties. The research in this field is advancing rapidly, and applicatlons are beginning to be reallzed. The initial research efforts in setastable naterials in our progran involve development of facilities to produce anorphous alloys, studies of the formation and stabllity of amorphous phases, and the weasurement of selected properties. The first property of vetallic glasses that we are exphasizing is superconductivity. Our Interest will probably sh1ft to mechanical behavior in the next few years. This report will first sumarize the superconducting experiments that were completed during the reporting period and culfinated in two Invited papers at the International Cryogenic Materials Conference, Brookhoven Mational Laboratory, May 27-29, 1980.

\subsubsection{Sumary of Cowpleted Superconductivity Experiments}

\subsubsection{Evidence for Microstructural Effects Under Strain In Bronze Process Mb3Sn 23 - D. M. Kroeger, D. S. Easton, C. C. Koch, A. DasGupta, and J. O. Scarbrough}

In both wono- and wultfilanent conductors, we have found that the axima in the critical current density, $J_{C}$, and the upper critical field,

23Abstracted from an It.vited paper given at International Cryogenic Materials Conference on Filasentary AlS Superconductors, Upton, M.Y., May 28-29, 1980. 
$B_{C_{2}}$, as functions of strain do not colncide. This indicates that variation of the equilibrio property, $B_{C_{2}}$, does not sccount for all ha variation of $J_{C}$ with strain and sussests that aicrostruc:ural effects associated with the pinning centers are imvolved. Comparison of the strain dependences of the transition temperature, $F_{c}$, and the slope, $\left(d B_{c} / d P\right) T_{c}$, near $r_{c}$ indicates that the relationship between then is not unique. The relationship changes when strain is increased bejond that required to produce maine in $T_{c}$ and $\left(d B_{c_{2}} / d r\right) T_{c^{*}}$ since $\left(d B_{c_{2}} / d r\right) T_{c}$ is proportional to $\mathrm{rP}_{n}(\mathrm{r}$ - electronic specific heat coerricienk, in - avimas state resietivity) and $T_{C}$ is deternined by the density of states near the Fend energs, or $T$, the relationship between $T_{c}$ and $\left(d B_{c_{2}} / \mathrm{d} Y \mathrm{~T}_{c}\right.$ is expected to be be deternined uniquely by cryetal structure and resistivity.

From weasurements of $J_{C}$ and $B_{C_{2}}$ as functions of strain and temperature, the forefactor $A$ in the senieapirical expression for $P_{p}$, the bulk pining force density,

$$
F_{p}=A B_{c_{2}}^{n} b^{2}(1-b)^{m}
$$

wo found to depend strongly on strain. In this equation $A$ is deternined by pln strength, pin density, and the Ginzburg-iandau paraneter, $K$. Measurenents of $\left(d B_{c_{2}} / d T\right) T_{c}$ and $T_{c}$ as functions of strain Indicate that variation of $K$ with strain does not account for the change in $A$. Therefore, a microstructural effect, associated with the pins, is implied.

Microstructural effects that could account for these resulte include a stress-induced matensitic transformation, twinning, atcrocracks, and changee In the strese distribution about pinaing aites. If pinning Involves a recond aperconducting phace, change in the ouperconducting propertles of the cecond phese with straln could alter the pin etrength. 
3.3.1.2 Superconducting and Mechanical Properties of $\mathrm{Nb}_{3} \mathrm{Sn}$ Conductors Under Tessile Stress 23 - D. S. Easton, D. M. Kroeger, and C. C. Koch

Studies at ORH on stress effects in comerclal wltifilamentary $\mathrm{Nb}_{3} \mathrm{Sn}$ superconductors have resulted in the following ajor findings: (1) Degradation of the critical current density, $J_{C \text {, and critical }}$ temperature, $T_{C}$, occurs with either compressive residual strain or applied tensile strain. Maximan values of $J_{c}$ are found when the $\mathrm{Mb}_{3} \mathrm{Sn}$ is in a near zero strain condition. (2) Calorinetric measurenents show that significant anounts of heat are generated both when a tensile strain is applifed to a conductor in wich the $\mathrm{m}_{3} \mathrm{Sn}$ is under compressive residual strain and when stress cycles on the conductor produce hysteresis loops in the stress-strain curve. (3) Kirkendall voids at the filament-atrix interface can lead to reduced wechanical properties, thernal instabilities, and crack initiation in the filanents. (4) The residual stress state in $\mathrm{N}_{3} \mathrm{Sn}$ composites can be estinated by a relatively simple analytic aodel.

3.3.1.3 Flux Pinning by Sall Perturbations in the Superconducting Order Parameter in Type II Superconductors 24 - A. DasGupta, D. M. Kroeger, C. C. Koch, and Y. T. Chou 25

The calculations reported last year were extended to enable interpretation of the flux pinning results by grain boundaries in niobiu bicrystals.

Fron the first-order perturbation of Ginzburg-Landau free energy, the effects of local variation of the upper critical field $H_{C_{2}}$, and GinzburgLandau paraneter, $K$, are combined. The Interaction energy

$$
\left[-|x|^{2}\left(1-|x|^{2}\right)\right]
$$

24Abstracted in part from a paper accepted for pullication in the Philosophical Magasine.

25Departaent of Metallurglcal and Matertals Englneering, Lehigh University, Bethlehed, Pennsylvania. 
thus obtained, varies locally, where $|a|$ is the superconducting order parameter. The elementary pinning force, $f_{p}$, is calculated from the Interaction energy as a function of the agnetic induction, $B$, and agres well with the results in several flux pinning systens, including grain boundary pinning in nioble bicrystals.

\subsubsection{Equipent Developent}

3.3.2.1 Arc-llamer - quenching From the Ifquid State- - D. M. Kroeger, D. S. Easton, J. O. Scarbrough, and C. C. Koch

Our modil of the spreading and cooling of the sample In the archamer process indicates, and weasurements confirm, that the final thickness, and th.ns the cooling rate of the spectmen, is very weakly dependent upon hamer mass. Increasing hamer speed, however, does appreclably Increase the cooling rate. Accordingly, we have oodifted the archamer apparatus by lightening the hamer and propelling it toward the hearth by means of springs. By so doing, we have increased the maximum avallable hamer speed from 5.5 to about $10 \mathrm{~m} / \mathrm{s}$.

\subsubsection{Melt Spinning Apparatus - Quenching Frow the Lquid State - D. S. Easton, C. C. Koch, and C. E. Zachary}

A aelt spinning apparatus has been constructed, and ribbons (1-2 um wide, 10-20 un thick) of several alloys have been formed. The ribbon is produced by forcing a jat of witen metal through a small orifice in a quartz crucible onto the surface of a copper wheel rotating at speeds up to 10,000 rpa. The surface velocity of the wheel, and thus the rate of ribbon produced, can be controlled to rates up to $80 \mathrm{~m} / \mathrm{s}$.

A ribbon of $\mathrm{Pd}-6 \mathrm{CO}$ Cu-16\% SI is shown in PIg. 3.4 as it is being formed at rate of $60 \mathrm{~m} / \mathrm{s}$. Some small droplets of wolten material can be seen in addition to the ribbon. 


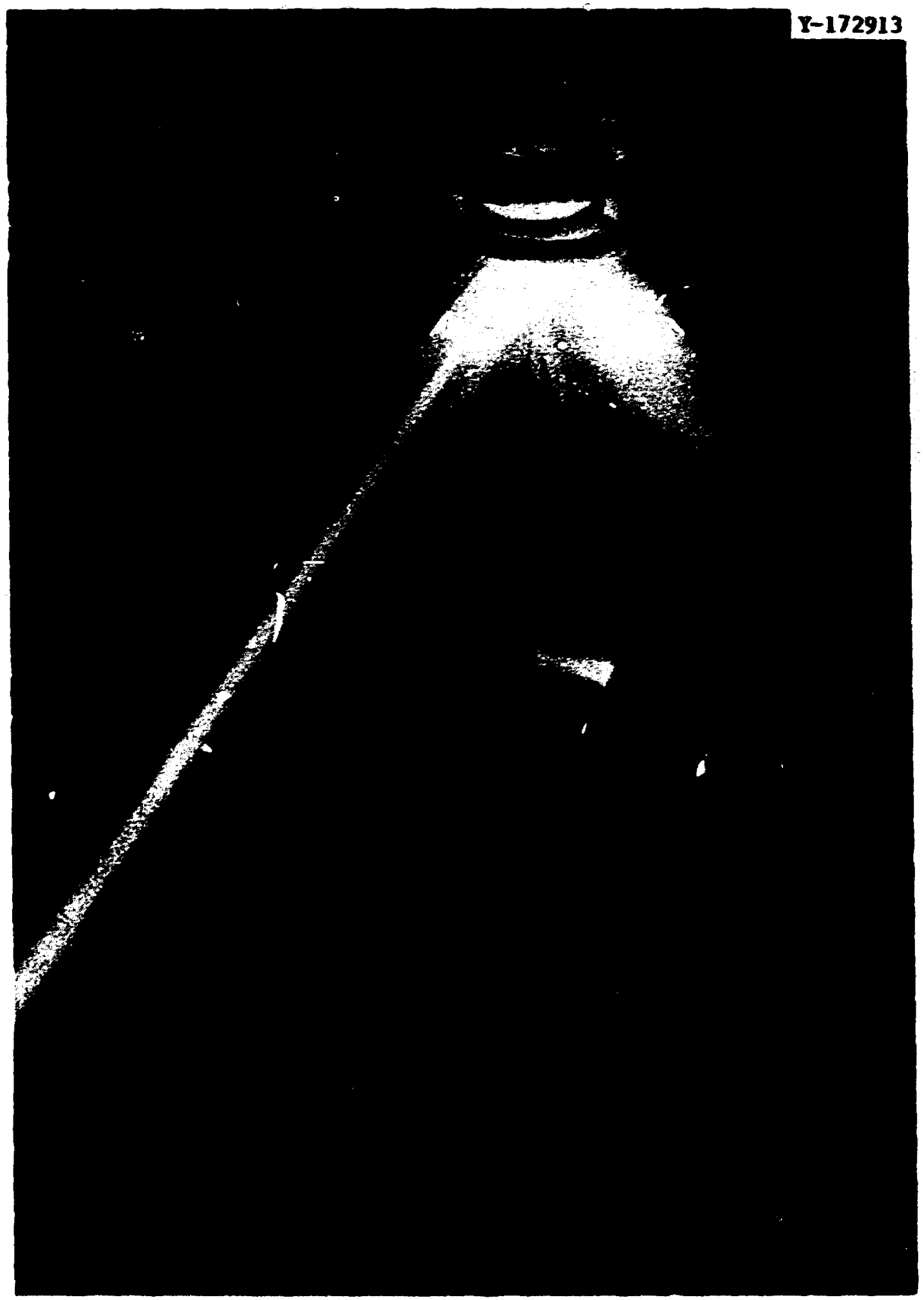

P1g. 3.4 Molten Pd-67 Cu-167 S1 A1loy being Spun from Botating Copper wheel at Tangential Velocity of $60 \mathrm{D} / \mathrm{s}$. 
The wethod allows quenching rates comparable to those achieved in the a re hamer $\left(-10^{6} \mathrm{C} / \mathrm{s}\right)$ as well as the production of a large volume of materfal in a very short tibe. In addition to the fornation of wetallic glasses and metastable alloys, the method is very useful to produce naterial directly from the welt without the necessity of internediate defornation operations. A typical ribbon of an Fe-20z B alloy is shown in Fig. 3.5.

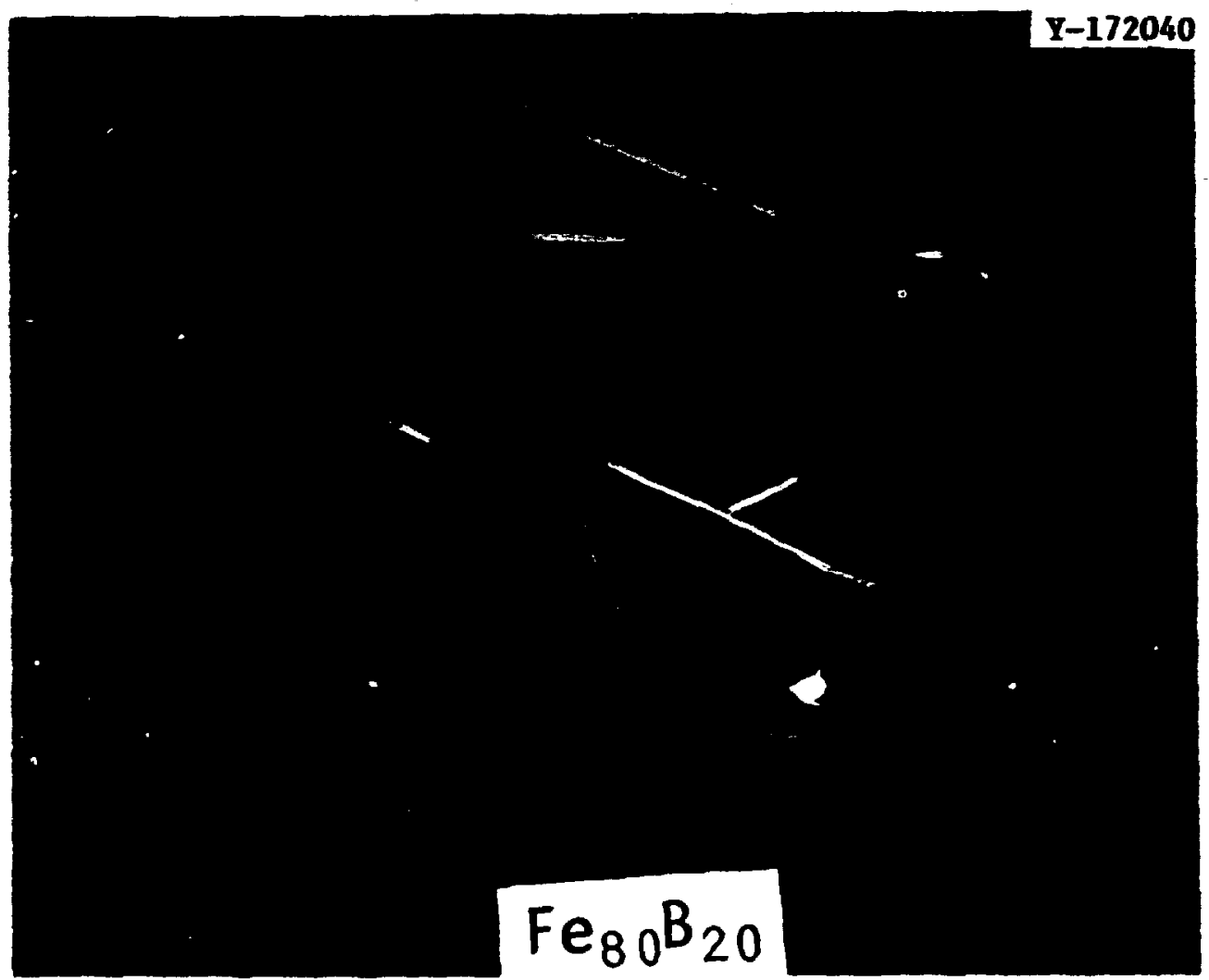

718. 3.5. Rabbon of Morphous Fe-20Z B Alloy Made by Melt Spinning.

3.3.2.3 Vapor Deposition Apparatus: Quenching Prom the Vapor State D. S. Easton, C. C. Koch, and C. E. Zachary

An electron-bean deposition eysten, expluying an Arco Trigon electron-beam source, has been inctalled, and prelininary teeting and 
calibration are under way. This apparatus, shown in Fig. 3.6, can simultaneously or sequentially evaporate three different materials. This permits the production of an almost unlimited range of alloy compositions. Substrate temperature; can be controlled from 4.2 to $300 \mathrm{~K}$ by the use of a liquid helium refrigerator shown entering the system by a central feedthrough on the chamber dome.

A Dektak thickness measuring instrument is used to measurc films deposited on the surface of the substrate. Initial deposition rate as a function of pow:r has been tested on several elements. The deposition rates of selected elewents at about 407 power are as follows:

\begin{tabular}{cc} 
Element & Deposition Rate $(\mathrm{m} / \mathrm{s})$ \\
\cline { 2 - 2 } & 2.5 \\
Nb & 0.50 \\
Mo & 2.7 \\
Zr & 1.4
\end{tabular}

Coppar-zirconium alloys can be easily produced in the amorphous state by rapid quenching from the liquid state; however, we have found no reference in the literature whereby amorphous copper-zirconium has been made by evaporation. We have deposited an $11.4-\mu m-t h i c k$ Cu-50Z $\mathrm{Zr}$ alloy (deposition time $70 \mathrm{~min}$ ) that appears to be amorphous when examined by routine $x$-ray diffraction, although examination of this material by a high-resolution, long-exposure diffraction technique detects a small fraction of crystalline phase in the material.

Extensive calibration tests of the rate and thickness controllers are continuing. A residual gas analyzer to monitor the environment during deposition will soon be installed.

3.3.3 Quenching Rate Studies in the Arc-Hammer Apparatus - D. M. Kroeger, W. A. Coghlan, D. S. Easton, C. C. Koch, and J. O. Scarbrough

The most widely used apparatus for rapidly quenching small amorphous alloy samples is known as the arc-hammer or piston and anvil. A small button of the alloy is arc-melted on a flat copper hearth and then quenched by dropping or propeliling a flut copper hamer onto the molten sample, squeezing 1 to a thin $(20-40 \mathrm{um}$ thick) sheet from which the heat 


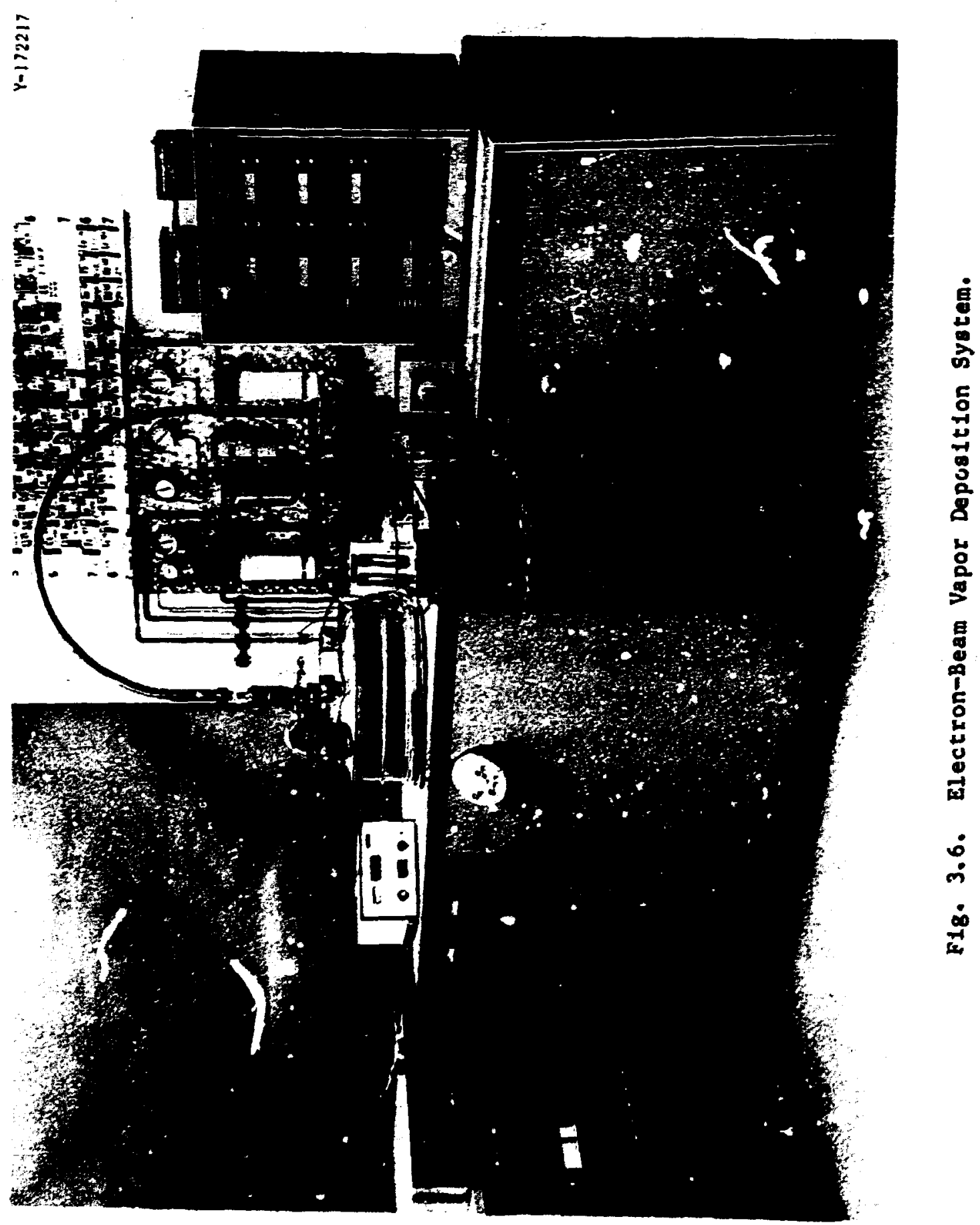


is rapidly extracted by the copper hicarth and hamer. The method has the advantages that samples are uniform in thickness, that their properties are reproducible, and that no crucible is required, so that high-nelting alloys can be prepared. The glass-forming terdency of an alloy has been rather loosely defined in terms of the ease with which it can be made glassy by such a process. Knowledg's of the cooling rates obtained by this process is essential to studies of the kinetics of alloy glass formation. $A$ numer of studies have been made of cooling rates in the arc-namer and splat quenching piocesses, but until recently no atteapt had been made to model mathewatically the spreading and cooling of the drop. Myazawa and Szekely 26 have piesented such a model in which they assune that the sample crystallizes at the melting point. Solidification fronts propagate from the surfaces, and spreading of the sample is arrested by meeting of the fronts at the cinter of the sample. A two-dimensional calculation of heat flow during the spreading of the drop was plso carried out. We have modified their model to describe the forwation of a glassy rather than a crystalline specinen.

We assume that during cooling the sample remains liquid at all times, but with an ever-increasing viscosity, the temperature dependence of which we describe by elther the Vogel-Fulcher expression or one derived more recently by Ramachandrarao, Cantor, and Cahn. 27 We assume that, since the sample does not crystalli-e, wost of the latent heat of fusion 18 retained in tie solid. Sample deformation is arrested by the increase in viscosity of the specimen as it coois belcw its melting point. The increased complexity resulting from assuming a temperature-dependent viscosity made It desirable to assume Newtonian or interface controlled cooling. That 18, we assume that the:e are no temperature gradients within the sample, and that all the temperature difference between sample and copper lies in

26X. Miyazawa and J. Szekely, "A Mathematical Model of the Splat Cooling Process Ueing the PIstor and Anvil Technique," Metall. Trans. B 10: 349-58 (1979).

$27_{R}$. Ramachandrarao, B. Cantor, and R. W. Cahn, "Pree Volume Theorles of the Glass Transition and the Special Case of Metallic Glasses," J. Mater. Scl. 2: 2488-2502 (1977). 
the interface beiween them. Although this approxination is reasonably good after the sample has been squeezed to its final thickness, heat flow calculations performed by Ruhl 28 for thin samples of static dinension Indicate that Newtonian cooling is not a good approxination during the early stages of spreading. However, Ruhl's calculations do not take account of the mechanical mixing that accompanies spreading of the drop. We belleve this wixing acts strongly to suppress temperature gradients. We have included the work done on the sample by the haner during deforation and found that, under sose conditions, it can represent an important heat input to the sample. Pinally, we found that the mechanical response of the structure supportiag the hearth to the striking of the hamer mot be Included so that the nodel would predict the correct dependenise of final sample thickness on hamer speed.

bsing the mechanical wodel shown in Fig. 3.7 and the heat flow sssumptions outlined above, we reduced the problem to a series of coupled first-order differential equations. These equations were solved by using the standard Runge-Kutta technique. The resulting calculations predict not only the sample temperature as a function of time during the quench, but also the effect on foll thickness, $d$, of such variables as hammer speed, hammer mass, sample mass, sample superheat, and the Interface heat transfer coefficient, $h$, between the sample and the copper surfaces. We have measured $d$ as a function of hammer speed, sample mass, and hammer mass in three alloys, $\mathrm{C} .34 \% \mathrm{Zr}, \mathrm{Ta}-45 \% \mathrm{Ir}$, and $\mathrm{Nb}-45 \% \mathrm{Rh}$ and compared the results with the calc"'; inn. The heat transfer coefficlent, $h$, was used an an adjustable par $\cdots$ : to fit the data for one hammer speed, $3 \mathrm{~m} / \mathrm{s}$. Not only does the mod accurately predict the foll thickness at other hammer speeds, as shown In $\mathrm{FIg}_{\mathrm{g}}$. 3.8. for $\mathrm{Nb}-45 \%$ th alloy, but the best fit to the data for all three alloye was provided by the same value of $h(2.0 \times$ $10^{5} \mathrm{~W} / \mathrm{z}^{2} \mathrm{~K}$ ). These results not on $1 \mathrm{y}$ Indicate the essential correctness of the model but suggest that the rate of heat transfer across the Interface between samples and copper is determined primarily by properties of the

\section{R. C. Ruhl, "Cooling Rit:es in Splat Cooling," Mater. Sel Eng. 1:} 313-20 (1967). 
ORNL.DWG 80.12057
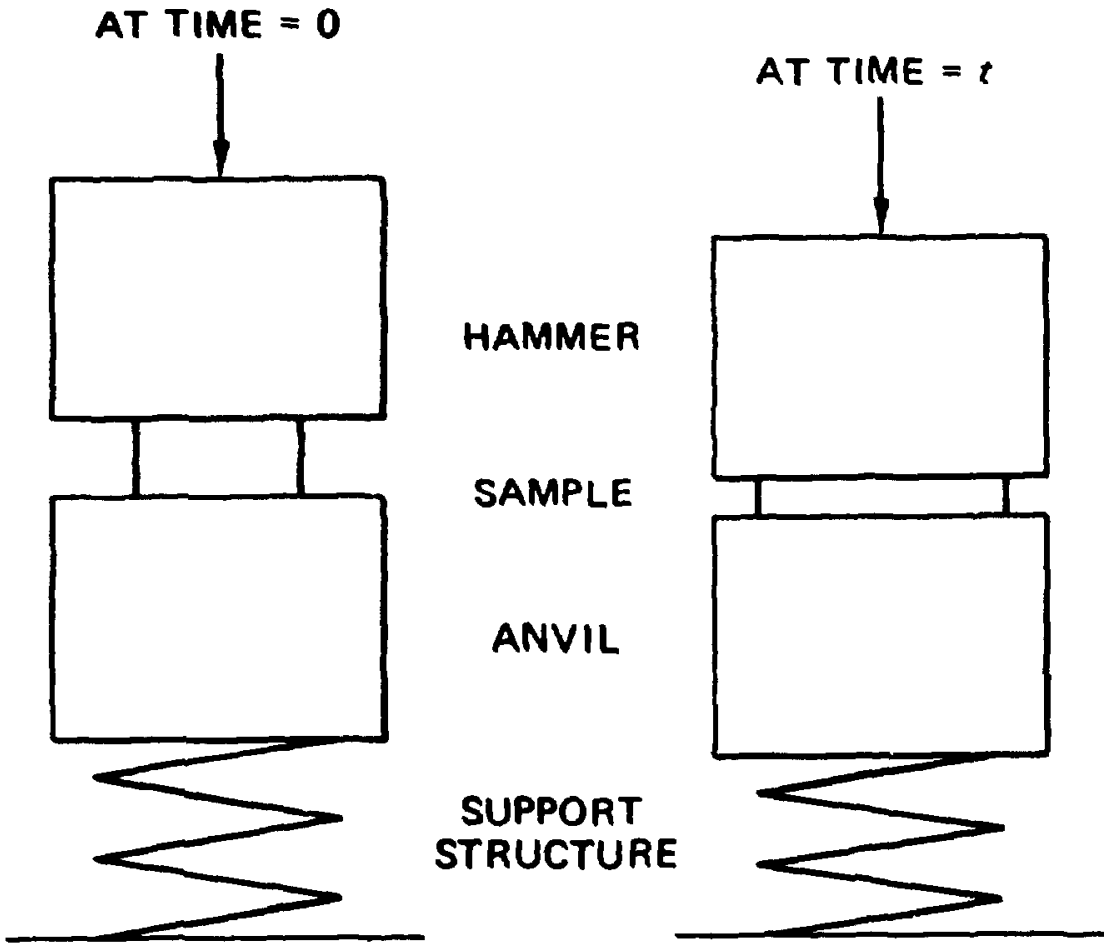

F18. 3.7. Mechanical Elements in the Model for Quenching Rate Studies in the Arc-Hammer.

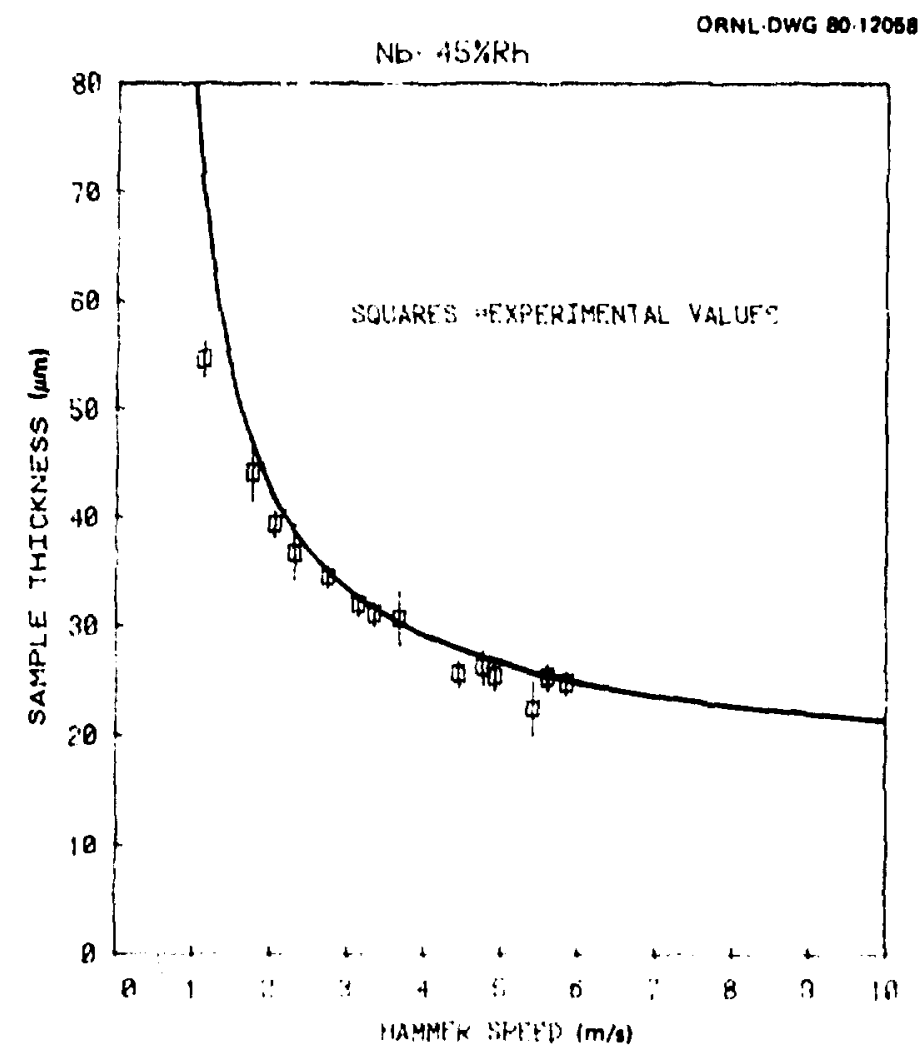

F18. 3.8. Sample Thlckness vs Hammer Speed for $\mathrm{Nb}-45 \% \mathrm{Rh}$ Samples. Solid line is the model calculation; squares are experimental values. 
copper surfaces, perhaps by an oxide layer. Additionally, the calculated cooling curves indicate that the sample is well above the glass transition temperature when deformation stops. This is confirmed by high-speed photography in which the sample remains incandesent to smaj.l dimensions. The model also predicts the experimental observation that $d$ is nearly independent of hammer rass.

These results suggest that the model is realistic and give us some confidence in the cooling curves that can be calculated from it. He intend to use the model as a tool in studies of the kinetics of $b$. iss forwation and glass forming tendency.

\subsubsection{Stability and Physical Properties of $\mathrm{T}_{5}-\mathrm{T}_{9}$ Amorphous Alloys - A. DasGupta, C. C. Koch, and J. O. Scarbrough}

The physical basis and systemitics of the thermal stability of metalmetal glasses are uncertain at the present time. To understand this phenomenon, differentiai thermal analysis (DTA), electrical resistivity, microhardness, and x-ray aiffraction studies of both binary and ternary $\mathrm{T}_{5}-\mathrm{T}_{9}$ metallic glasses (where $\mathrm{T}_{5}=\mathrm{Nb}$ or $\mathrm{Ta}$, and $\mathrm{T}_{9}=\mathrm{Ir}$ or $\mathrm{Rh}$ ) have been performed. In Ta55- $x^{N b_{x}} I_{45}$ glasses, where the subcripts denote atomic percentages, the crystallization temperature $T_{x}$ decreases monotonically with Increase of $x$. In the above series of alloys, the ternary compositions show a double peak in DTA upon crystallization, whereas a single peak is found for the two binary end members, namely $\operatorname{Ta}_{55} \operatorname{Ir}_{45}$ and $\mathrm{Nb}_{55} \mathrm{Ir}_{45}$. In the binary alloy system $\mathrm{Ta}_{x} \mathrm{Ir}_{100-x}$, the glass formation range has been extended to compositions such as Ta65Ir 35 , which have not been previously atcainable.

Presently the physical properties are being measured in an extensive series of alloys to establish the systematics of thermal stability.

\subsubsection{Amorphous Superconductors}

The best amorphous superconductors exhibit fundamental superconducting propercles comparable to the crystalline alloy superconductors 
such as niobiur-titaniun. While the superconducting conpounds, such as $\mathrm{Nb}_{3} \mathrm{Sn}$, have superior superconducting properties, they have problens such as brittleness and sensitivity to radiation damage, which can be avolded In anorphous superconductors; thus, anorphous alloys with superconducting properties only somewhat better than exist at present (e.g. $T_{c}>10 \mathrm{~K}$, $\left.H_{C_{2}}(4.2 \mathrm{~K})>12 \mathrm{~T}\right)$ would be of practical interest. The inteial studies of properties of anorphous alloys in this prograa are concentrating on the systematics of superconductivity and certaln structure-property relationships.

3.3.5.1 Superconductivity in forphous " $\mathrm{T}_{5}-\mathrm{T}_{9}$ " Transition Hetal Alloys 29 C. C. Koch, D. M. Kroeger, J. O. Scarbrough, and B. C. Giessen 30

The superconducting transition temperature, $T_{c}$, has been measured for amorphous $T_{5}-T_{9}$ alloys (where $T_{5}=$ or $T a, T_{9}=$ th or $I r$ ) as a function of composition. Nobium and tantalum doninate the $T_{C}$ behavior, with $T_{c}$ for niobium alloys $\approx 4.8-5.1 \mathrm{~K}$ and $T_{c}$ for tantalum alloys $\approx 3.1-3.3 \mathrm{R}$. Changing the average group number by varying the $T_{5} / T_{9}$ ratio had little effect on $T_{c}$ within the -10 at. $Z$ range of composition in which the amorphous alloys form. Also, $T_{C}$ decreased approxinately linearly with $x$ for $\left(\mathrm{Nb}_{1-x} \mathrm{Ta}_{x}\right)_{55} \mathrm{Rh}_{45}$ and $\left(\mathrm{Nb}_{1}{ }_{x} \mathrm{Ta}_{x}\right)_{55} \mathrm{Ir}_{45}$. The electrical resist1vity, $f_{n}$, and the upper critical fleld, $B_{C_{2}}$, were measured as functions of temperature. The Somerfeld constant, $r$, was calculated from $P_{n}$ and $\left(d B_{c_{2}} / d T\right) T_{c}$ by using the Ginzburg-Landau-Abrikosov-Cor'kov theory. The Debye cemperature, $\theta$, was calculated from measurements of Young's modulus. The above parameters allowed calculations to be made of $\sigma\left(E_{P}\right)$, the density of electronic states at the Ferwi level, end $\lambda$, the electronphonon coupling constant. We found that $\lambda$ wore accurately reflected the $T_{C}$ behavior thas did $\pi_{\left(P_{P}\right)}$ and that both electronic and phonon contributlons had to be consideried in the determination of $\lambda$.

29Abstracted from a paper subaitced to Physical Review $B$.

30Materials Science Division, Institute of Chemical Analyois, Northeastern UnIversity, Boston, Massachusetts. 


\subsubsection{The Effects of Cold Rolling on Fluxold PInning in a Superconducting Metallic Glass 31 - C. C. Koch, J. O. Scarbrough, D. M. Kroeger, and A. Dascupta}

The Influence of cold rolling on fluxold pinning in a metallic glass superconductor, (Mo0.6 $\left.6^{\text {Dur }} 0.4\right)_{82^{B}} 18$, was deternined. Inhowogeneous deformation up to 202 reduction in thickness does not change either the superconducting transition temperature, $T_{C}$, or upper critical field, $H_{C_{2}}$, but It does degrade the critical current density, $J_{C}$, by as wch as 342 from the value in the as-cast condition. Possible nechanisas for this degradation of $J_{c}$ involve surface pianing, pinaing by unresolved crystalline precipitates, and inhomogeneities in bulk compostion or structure. The experinental evidence appears to favor the last mechanisw. Work is in progress to letcer define the bechanisa responstble for the degradation of $J_{C}$. Fluxold pinning measurements may be good probes of the structure of netallic glasses.

31 Abstracted from a paper subitted to Applled Phyotos Lettere. 



\section{RADIATION EFFECTS}

L. K. Masur

The Radiation Effects task is developing an understanding of the nechantsas by which irradiation changes physical and echanical properties of netals and alloys. The progran is focused on the phenomena and conditions typically encomtered or anticipated in fission and fusinn reactors. The scope includes wid and bubble swelling, frradiation creep, and enbrittlenent. An Integrated theoretical and expertuental approach Is brought to bear on ajor problen areas. The chief observational techniques used are electron alcroscopy and analytical electron alcroscopy for the direct observation of aicrostructural and aicrocompositional changes. For producing radiation effects, the reactors EBR-II, HFIR, and ORR are used, and, to supplement these, accelerated charged particle bombardments are carried out with the S-MV Van de Graaff - 0.4 MV Van de Graaff facility, the 1-MV high-voltage electron afcroscope (HVM), and the Oak RIdge Isochronous Cyclotron. A sophistlcated Irradlation creep apparatus has been constructed and is in operation at the cyclotron. It is presently being used to study the characteristics of and to understand the mechanisns leading to irradiation creep. The Van de Graaf is a dual- and triple-beaw systen, where nickel lons typically are used to produce the displacement danage, and helfwe and/or deuterium lons are injected simutaneously to simulate neutron-induced transmuted gases. Nuclear microanalysis techniques that use the accelerated particles to probe the chentcal cosposition as a function of depth in the target are beiug exploited.

Developing the theory of radiation effects continues to recelve a ajor eaphasts. In the recent past this effort has focused on two areas. One is oodeling the effect:; of the large incresses in danage rate and the marked spatial vartacion in swelling during charged particle bombardment. The other is the generalization of the theory to Include the effects of Iapurities and alloying eleaents. The ofcen-observed large reductions in vold nucleation and the allder reductions in vold growth and creep can be explained by our theory of polnt defect trappling. The effects of hellum, 
a wost potent inpurity, are presently being elucidated. The developwent of the theory of basic processes is also continuing, lncluding the calculation of the efficiencies of sinks for the absorption of point defects and the analysis of mechanisas of irradiation creep. In this general area, we have also developed a cascade diffusion theory to more realistically describe the fluctuating nature of the local point defect concentrations.

This task is performed in the Radiation Effects and Microstructural Analysis Group of the Metals and Ceramics Division, wich includes investigators pursuing related probleas in prograns for breeder reactors and magnetic fustion energy. These applfed prograns are part of national alloy development prograns coordinated by HEDL and ORNL, respectively. Work on this progran also complements the radiation effects activities of the ORNL Solid State Division,, which are directed at understanding the prieary production of defects by particle irradiation. Our facilities have been used by General Electric and Uestinghouse in connection with the applied prograns and by a nuber of universities in the Basic Energy Sciences prograw International cooperation is maintained through exchanges of $p \in$ sonnel with the U.K., FRG, French, and Japanese nuclear energy establis.ments.

\subsection{NEUTRON RADLATLON EFFECTS} 4.1.1 Defect Structures in Neutron-Irradiation Iron - J. Bentley,

The secondary defect structures forwed in tron by neutron irradiation have received little attention relative to both the bcc refractory and fcc metals. This is surprising in view of the importance oi ferritic steels but may be partly due to the difficulty of transmisston electron microscope (TEM) examination of ferromagnetic materiala. We have performed a TEM study of Iron neutron-1rradiated in the Oak Ridge Research Reactor at temperatures from 182 to $500^{\circ} \mathrm{C}$ to about 1 dpa and at 650 and $740^{\circ} \mathrm{C}$ to about $0.5 \mathrm{dpa}$. The specimens were fabricated from two-pass zonerefined Perrovac $E$ Iron $\left(0.003 w^{*} \% \mathrm{C}\right)$, and disks were 1rradiated in 
sealed capsules. We performed TEA exanination at $120 \mathrm{kV}$ in a JEM $120 \mathrm{C}$ equipped with a special objective lens pole-plece (AMG) for the observation of agnetic materials to enable high-angle tilting experiments.

The dislocation component of the various microstructures observed is illustrated in Fig. 4.1. At $182^{\circ} \mathrm{C}$ "black-spot" defects saller than $6 \mathrm{~m}$ in dianeter are present at a concentration of about $1 \times 10^{22} / \mathrm{n}^{3}$. Ar $275^{\circ} \mathrm{C}$ the sall loops cluster to form localized groups of about 30 loops. The concentration of these $-200-n n-d i a n$ clusters is about $2 \times 10^{19} / \mathrm{m}^{3}$. The reason for cluster formation is not clear but may be related to the foration of rafts of $(a / 2)<111\rangle$ loops observed in neutron-irradiated bce refractory metals. At irradiation temperatures from 350 to $450^{\circ} \mathrm{C}$ a fairly homgeneous dists:bution of loops with some network segments is present. Loop size increases and loop concentration decreases with increasing temperature. Eventually only a coarse network is evident, and at 650 and $740^{\circ} \mathrm{C}$ the dislocation density is very swall. The geometry and nature of the loops have been analyzed. The dislocation loops were found to be
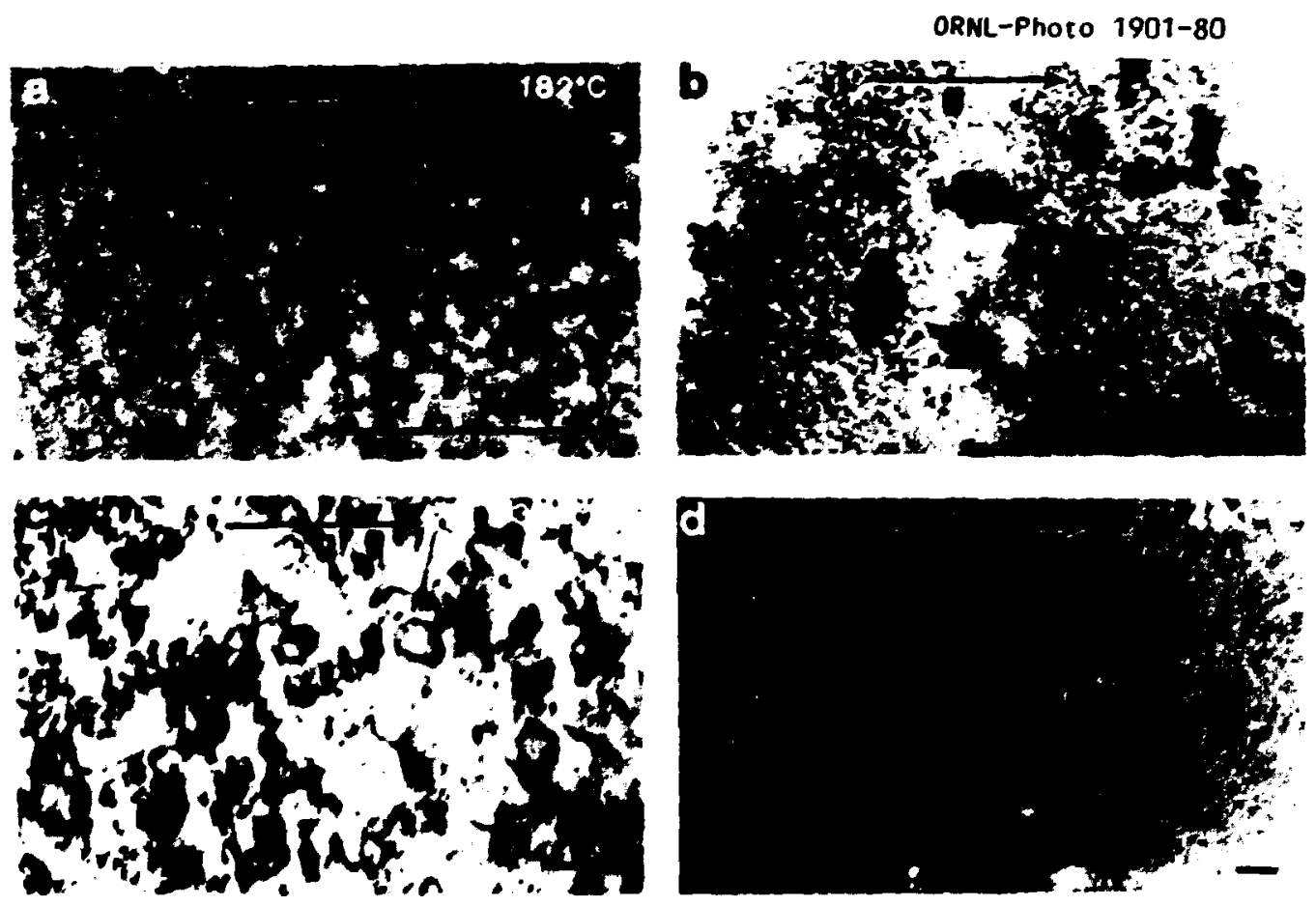

P1g. 4.1. Development of Dislocation Structures In NeutronIrradiated Iron. Irradiation temperatures indicated. Diffraction vector $g=01 \overline{1}$. Deviation parameter $w_{g} \approx 1$, Beam direction $\approx \approx 111$. Scale markers $=0.2 \mathrm{~m}$. 
interstitial, near edge with $\vec{b}=a\langle 100\rangle$, in agreement with previous observations by various investigators. As is evident in Fig. 4.1, some loops intersect the foil surfaces without gliding out - an indication that they are pinned. Cottrell atmospheres may be responsible since no precipitates were observed. At some irradiation temperatures cavities are also present, as shown in Fig. 4.2. At $275^{\circ} \mathrm{C}$ the cavities tend to form only near the clusters of dislocation loops, illustrating the cooperative growth of dislocation loops and cavities. At $350^{\circ}$ the distribution of - 18-nm-diam cavities at a concentration of about $1 \times 10^{21} / \mathrm{m}^{3}$ is wuch wore homogeneous, but at $450^{\circ} \mathrm{C}$ the distribution is again inhomogeneous, with some cavities associated with precipitates. At 650 and $740^{\circ} \mathrm{C}$, in addition to isolated cavities on grain boundaries, high local concentrations of cavities were observed in damage halos, which are suspected of being centered on particles containing $10_{\mathrm{B}}$. These observations illustrate the stabilizing effect that isoluble gases have on cavities formed at high temperatures. Damage halos were also observed at low temperatures, but only high concentrations of small loops without any cavities were visible. In general the results have revealed a lower point defect retention in clusters than in other bec and fcc metals of simflar purfty. This may be due in part to the dominant role that carbon plays in the behavior of a-iron, both through segregation at defect clusters and through trapping of point defects.
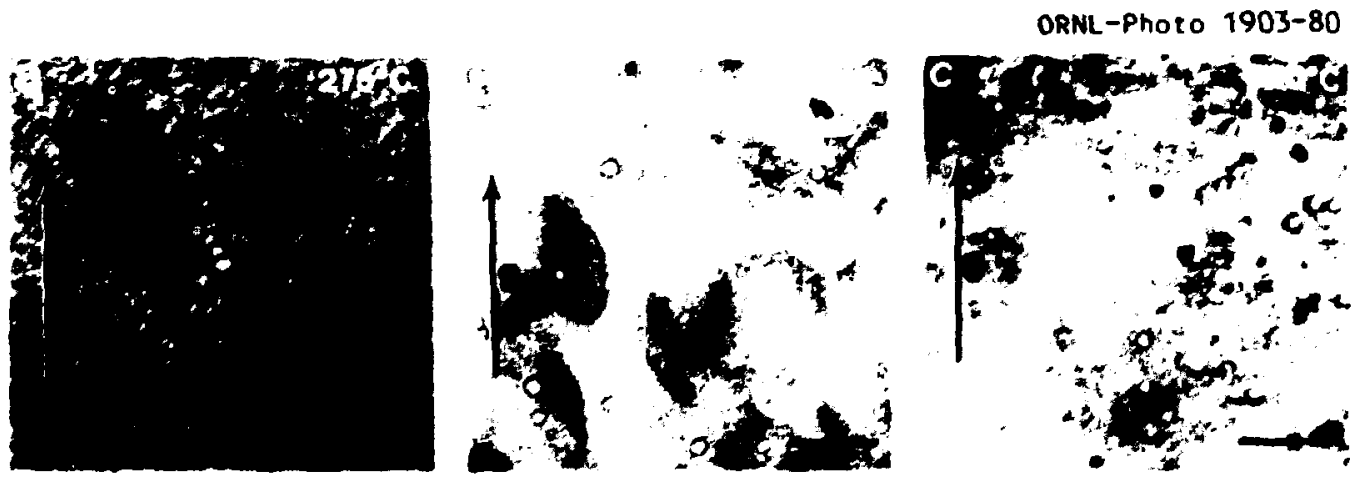

F18. 4.2. Cavity D18tributions in Neutron-Irradiated Iron. Irradiation temperatures indicated. The structure in (c) is in $z$ damage halo. $g=03 \overline{3}, w_{g}>0, z \approx 111$. Scale markers $=0.1 \mathrm{~m}$. 


\subsubsection{Microstructure and Tensile Properties of Heavily Irradiated 5052-0 Aluminum Alloy $-\mathrm{K}$. Farrell}

Many aluminum alloys depend on precipitates to provide strength for industrial applications. The 6000 series alloys, for example, contain magnesium and silicon in proportions required to produce precipitates of stochiometric $\mathrm{Mg}_{2} \mathrm{Si}$. The 5000 series alloys, however, are not precipitation hardened; they derive their strength from solid solution hardening by ragnesium additions. The 5052 alloy contains $2.5 \mathrm{wt} \mathrm{ZMg}$ and is used for the poolside tank face of the Oak Ridge Research Reactor and for the calandria of the British SGHH Reactor. This alloy in the " 0 " temper (1.e., fully annealed condition) was examined for its response to highlevel neutron irradiation.

Tensfle specimens of 3-m gage diameter were irradiated in the High Flux Isotope Reactor at $328 \mathrm{~K}\left(0.35 T_{m}\right)$ for periods up to 3.5 years. The maximum fast fluence reached was $1.8 \times 10^{27} \mathrm{n} / \mathrm{m}^{2}(>0.1 \mathrm{MeV})$, corresponding to $260 \mathrm{dpa}$. Thermal fluences were 1.7 times the fast fluences and were responsible for the creation of up to $6.9 \mathrm{it}$. $\%(7.15$ wt $\%$ ) Si from the reactions ${ }^{27} \mathrm{Al}(n, \gamma){ }^{28} \mathrm{Al} ;{ }^{28} \mathrm{Al}+{ }^{28} \mathrm{Si}+B_{\text {. Neutronically generated gases }}$ ranged up to 85 at. ppm He and 500 at. ppm $H$.

Before Irradiation the microstructure of the alloy consisted of a solid solution matrix containirig a few inclusion particles. The first signs of radiation damage appeared at a fast fluence of $1 \times 10^{25} \mathrm{n} / \mathrm{m}^{2}$ ( $1.5 \mathrm{dpa}$ ) in the form of dislocation loops at grain boundaries and residual inclusions. With increasing fluence a general dislocation structure and a finely divided precipitate of $M_{2} \mathrm{Si}$ appeared. The precipitate is the product of interaction of the transwutation-produced silicon with the dissolved magnesium. At the higher fluences the silicon levels greatly exceeded that needed to satisfy the $\mathrm{Mg}_{2} \mathrm{Si}$ reaction, and the excess silicon, which is insoluble, was incorporated as a precipitate. Only a few Irregularly dispersed cavities were created.

lpresented at the ASTM Tenth International Symposium on Effects of Radiation on Materials, Savannah, Georgia, June 3-5, 1980; to be published. 
Tensile tests were made at a strain rate of $7.4 \times 10^{-5} / \mathrm{s}$ in afr. In tests at $323 \mathrm{~K}$ the unirradiated alloy displayed a well-defined yleld point and continuous serrated flow throughout the test. Progressive irradiation eliminated both the yieid point and the strated flow. Considerable radiation strengthening occurred, as shown in Fig. 4.3. The ultimate tensile strength was raised continuously from 220 to $600 \mathrm{MPa}$, and the $0.2 \%$ flow stress was increased by a factor of 6.5. Correspondingly, the ductility fell from $26 \%$ elongation for the inirradiated material to about $8 \%$

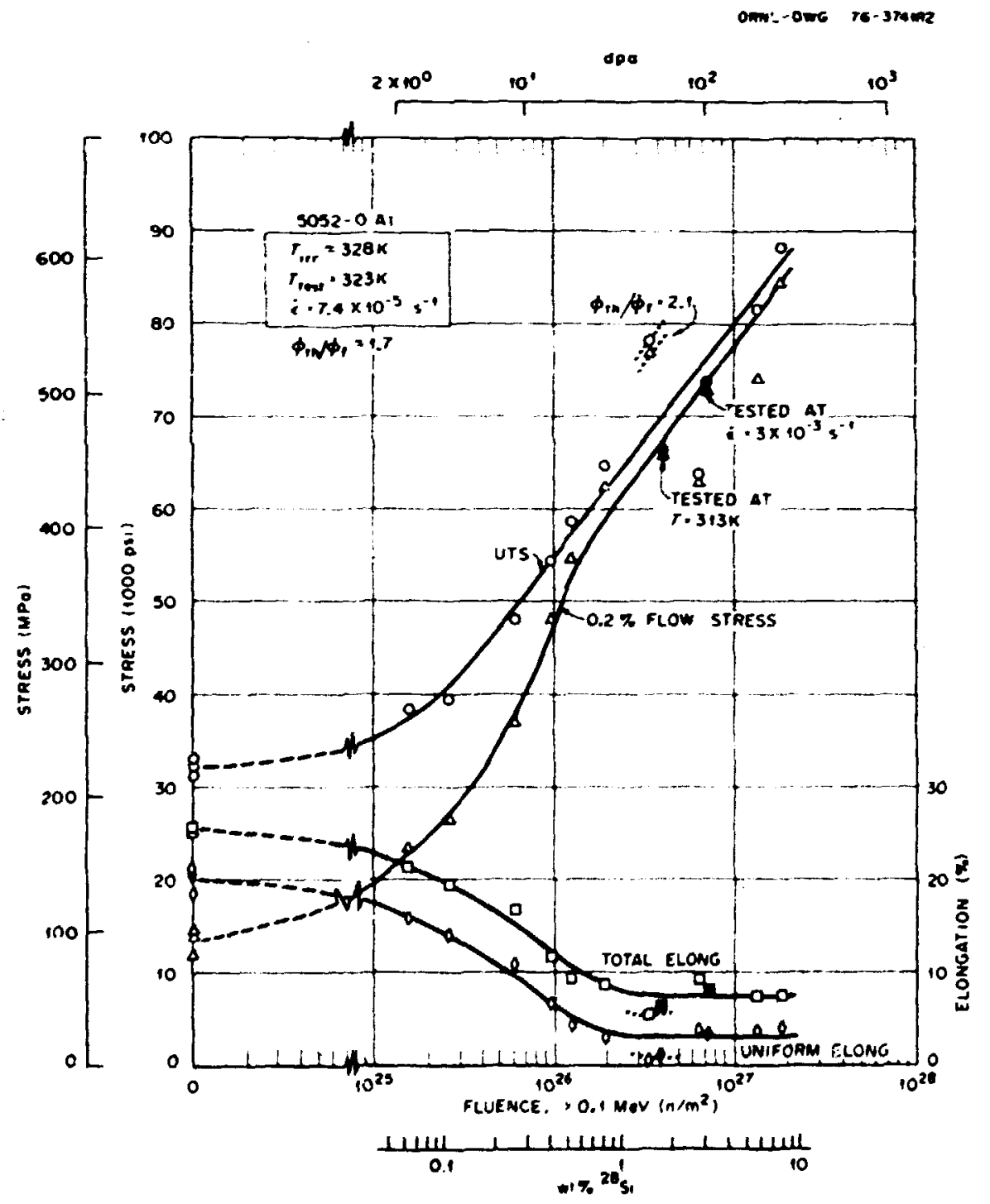

F18. 4.3. Pluence Dependence of Tenslle Propertles of Aluminum Alloy $5052-0$ at $323 \mathrm{~K}$. 
at a fast fluence of about $2 \times 10^{26} \mathrm{n} / \mathrm{m}^{2}$. At higher fliences the ductility was seemingly indepenaint of fluence. The loss in ductility was caused entirely by loss of uniform strain associated with the increased strength. The fracture mode was transgranular and invariant.

At higher test temperatures of 373 and $423 \mathrm{~K}$ similar patterns of fluence dependence of tensile properties prevailed, but the strengths ard ductilities were lower, with only about 37 total elongation at $423 \mathrm{~K}$ and no measurable uniform elongation. At the highest fluence at $423 \mathrm{~K}$ the fracture mode changed to a faceted, seemingly intercrystailine type. Increasing the thermal-to-fast ratio to 2 caused more hardening and ductility loss than anticipated rrom a simple increase in silicon level.

In summary, when the solid-solution 505? aluminum alloy is irradiated to very high exposures in a mixed neutron spectrum it is converted to a precipitation-hardened 6000-tvpe alloy containing excess silicon. It displays good resistance to swelling and suffers severe hardening and associated loss in ductility. It does not undergo sudden brittle failure.

\subsubsection{Grain Boundary Segregation and Radiation Effects - C. L. White and G. R. Gessel}

The effects of teutron irradiation on the properties of structural materials frequently involve internal interfaces such as grain boundar:es, precipitate-matrix interfaces, and internal free surfaces (e.g., of voids and bubbles). The properties of these in'erfaces are likely to be strongly influenced by trace element segregation. Reductions in both fracture stress and total elongation for tensile tests have been observed to coincide with equilibrium segregation of metalloid elements to internal interfaces. Thermodynamic arguments, as well as experimental observations, show that equilibrium segregation to interfaces decreases interfacial energy. Modest changes in interfacial energy associated with segregation can, in turn, profoundly affect other material behavior.

While much of the literature connecting impurity segregation itth embrittlement addresses only equilibrium segregation, irradiated materials may also experience nonequilibrium segregation. Nonequillbrium segregation 
results from the flux of irradiation-1nduced peint defects to intrinal sinks. Impurities or alloy constituents can be enriched or depleted ar grain boundaries depending upon hor these elements and the point defects interact. In adition, significant guantities of heli m can be produced via $(n, a)$ reactions in many alloys. Segregation of l:elium to internal interfaces could significantly affect alloy behavior.

Whon segregation occurs in a very thin region at an interface, it can be very difficult to detect with conventional analytical techniques. luger electron spectroscopy (AES) is a well-established tool for examining thin interfacial regions when they can be exposed as extermal ourfaces. Subsurface regions can be exposed for analysis by sputtering with inert gas ions. Alter:ate AES and sputtering permit information about the depth distribution of sogregated species to be obtained. An important requirement for the use of AES to study interfacial segregation is that the interface in question must be exposed as a free surface. In the case of internal interfaces, this is normally achieved by fracturing the specimen along those interfaces.

In order tc study the effects of neutron irradiation on grain boundary compositior in simple alloys, a series of 14 binary slloys based on $\mathrm{Fe}, \mathrm{NI}$, and $\mathrm{V}$ and one ternary (Fe-5\% $\mathrm{NI}-5 \% \mathrm{Cr}$ ) allos (Table 4.1) was

Table 4.1. Compositions of Binary and Ternary Alloys in the Row 7 Experiment $a$

\begin{tabular}{|c|c|c|c|}
\hline $\mathrm{Fe}$ & Base & N1 Base & V Base \\
\hline $\begin{array}{l}\text { Fe-5\% } \\
\text { Fe-5\% } \\
\text { Fe-5\% } \\
\text { Fe-0. } \\
\text { Ye-5\% } \\
\text { Fe-4\%: } \\
\text { Fe-3\% } \\
\text { Fe-2\% } \\
\text { Pe-5\% }\end{array}$ & $\begin{array}{l}\mathrm{NI} \\
\mathrm{Cr} \\
\mathrm{V} \\
3 \% \mathrm{Nb} \\
\mathrm{W} \\
\mathrm{N} \\
\mathrm{TI} \\
\mathrm{N} 1-5 \% \mathrm{Cr}\end{array}$ & 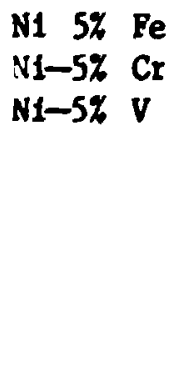 & $\begin{array}{lll}V-5 \% & M 0 \\
V-5 \% & \mathrm{Ni} \\
V-5 \% & 0.5 \text { Ti }\end{array}$ \\
\hline
\end{tabular}


irradiated in the EBR II-Row 7 (AAX) experimeits. Tensile AES specimens of each alloy were exposed at $400,525,575,625$, and $700^{\circ} \mathrm{C}$. Neutron fluences at $525^{\circ} \mathrm{C}$ were about $4 \times 10^{26} \mathrm{n} / \mathrm{m}^{2}$; fluences at all other temperatures were about $3 \times 10^{26} \mathrm{n} / \mathrm{m}^{2}$.

Unirradiated specimens of the same Fe-5\% $\mathrm{Ni}$, Ff $-5 \%$ ir, and Fe-2Z Ti alloys as were in the EBR-II, row 7 experiment have been heat-treated and then fractured at $-196^{\circ} \mathrm{C},-76^{\circ} \mathrm{C}$, and $26^{\circ} \mathrm{C}$. Scanning electron microscops of the resulting fracture surfaces indicates that the Fe-2Z Ti fractured at $-196^{\circ} \mathrm{C}$ is likely to fail at least partially along its grain boundaries and hence be amenable to Auger electron spectroscopy (AES) studies. The next step will be to fracture a similar specimen inside the AES system to provide baseline information on grain boundary composition in the unirradiated alloy, foliowed by analysis of irradiated specimens. Hydrogen charging of both irradiated and unirradiated alloy 706 has been carried out to produce partially intergranular fallures at room temperature. A similar charging procedure may be useful in inducing intergranular fracture in the nickel-base binaries in the row 7 experiment.

\subsection{CHARGED PARTICLE RADIATION EFFECTS}

4.2.1 Depth Profiles of Swelling in Ion-Bombarded Nickel - N. H. Packan,

Simulation of neutron damage structure by heavy-ion bombardments has come complications involving aepth deperdence of the damage. These are the strong depth damage gradients resulting $r$. Om nonuniform dissipatior of energy along the path of the lons, the Implantition of the bombarding lons, the diffusional spreading of the point de jects from their region of generation, and point defect losses to the specimen surface. The Implanted lons interfere with development of damage micrustructure. Diffusional spreading broadens and lowers the point defert concentration profiles with cespect to the peak displacement damage profile.2 Helium

2The theoretical methods for calcu'dating these effects and the resulting spatial dependence of 3welling are described by $L$. $K$. Mansur and $M$. H. Yoo, "Advances in the Theo."; of Swelling in Irradiated Metals and Alloys," J. Nucl. Mater. 85 sud 86: 523-32 (1979) and were reported in Metals and Ceramics Division Matemlals Science Prognam Annu. Prog. Rep. Jume 30, 1879, ORNL-5589, PP. 168-71. 
implantation introduces further depth complexities since the hellun concentration pofile is usially not symetric with the heavy-ion dabage profile, causing a variation in the/dpa ratio along the superimposed profiles. Consequently, with implanted heliur chere is more cause for concern over both the cholce of the depth at which the damage aicrostructure is measured and the accuracy with which this depth is a tained.

In studying the microitructural detalls, the usual moth is to excise Tt.y samples parallel to the carget surface at a depth calculated to include the peak damage region or at a depth corres onding to some particul.- estimated He/dpa ratio. The full microstructure-depth profil. is rarely assessed. In principle, such an assessment can bo done by , overing the narrow damaged region with an electrodeposited overlay, then sectioning TEM samples normal to the bombarded surface and thinning them at the electroplate-target interface. In practice, it is very difficult. With perseverance, we were successful with several specimens of pure nickel bombäded with nickel fons at $600^{\circ} \mathrm{C}$ to damage levels of 1 and 50 dpa. In these experiments, the ef fects of cold-preimplanted and simultaneously implanted helium on the damage microstructure at a nominal prak He/dpa of 20 are measured. Figure 4.4 shows an example for the full-depth afcrostructure observed for nominally $50 \mathrm{dpa}$ and $1000 \mathrm{at}$. ppm cold-preimplanted helium.

Some salient features of the experimental data in Fig. 4.4 are:

(1) Point defect losses to the surface affect a layer about $0.1 \mathrm{~mm}$ deep.

(2) The maximum concentration of cavities occurs at a depth of about

$0.7 \mu \mathrm{m}$, which is the predicted depth for maximum atomic displacements and is at the center of the implanted helium distribution. (3) Cavily parameters change notably with depth. This je:unnstrates the need for accurate control of depth sectioning in preparing conventional TEM specimens. (4) Crvities are seen at depths significantly beyond the estimated ispth for damage production and hel Ium implantacion. This is an expected result of diffuslonal spreading. (5) The sizes and concentrations of cavitles, and hence the degree of swelling, are sensitive to the local dpa and he:lum Jevels; that 18, to the varying He/dpa ratio along the heavy lon range. Generally, with increasing He/dpa the cavity 


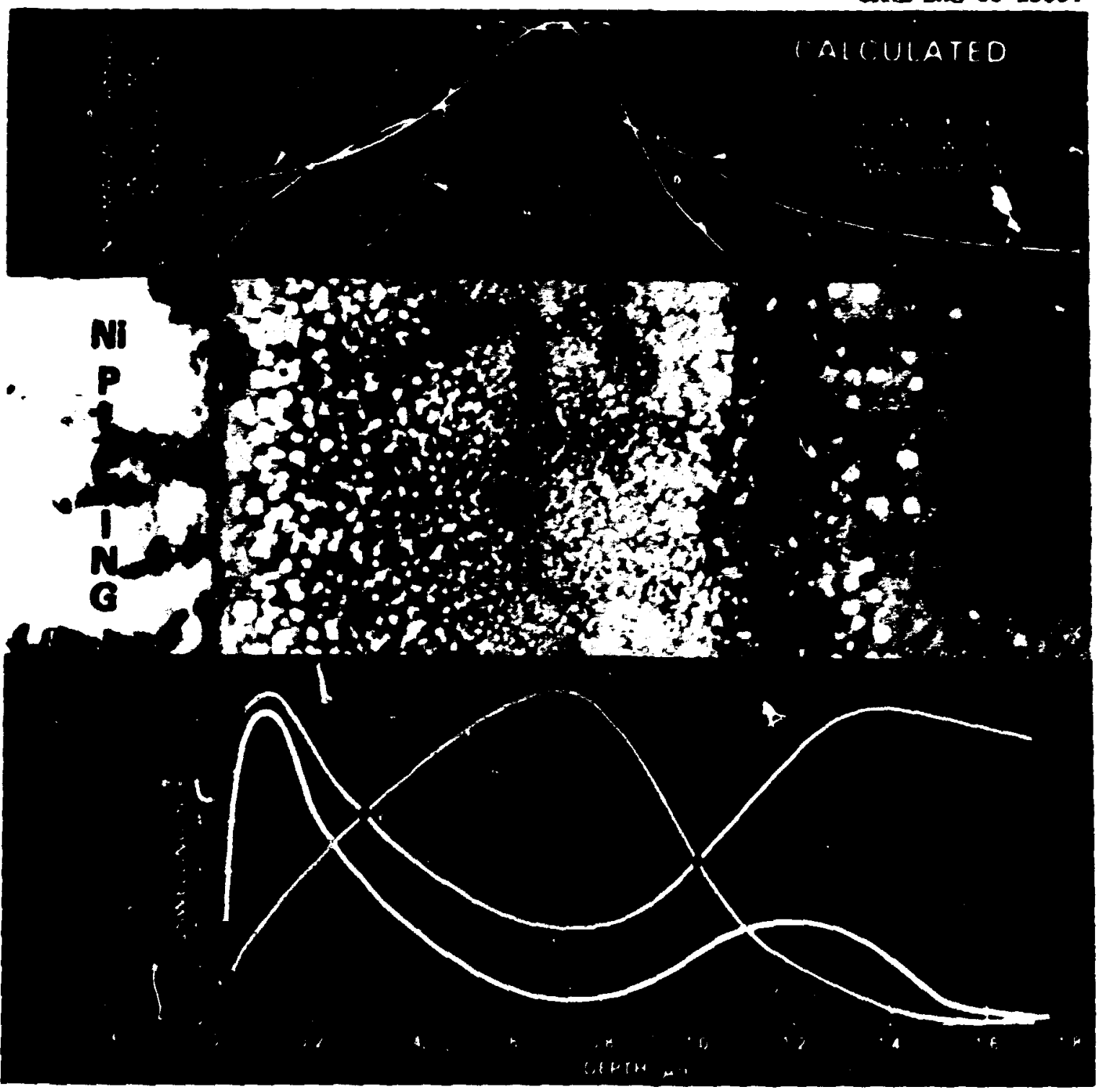

Fig. 4.4. Variation of Swelling, Cavity Size, and Cavity Coricentration with Depth in Pure Nicke! Bombarded with 4-MeV Nickel Ions. The upper curves show the predicted discribution of damage and hellum based on theory. 
concentration is increased and the cavicy size and swelling are decreased, but chere are deviations from this patcern in the deepest regions of the cavity profile.

\subsubsection{Experimental Observations of Effects of Inert Gas on Cavity Formation During Irradiation ${ }^{3}-K$. Farrell}

Experimental results on the effects of gases on formation of radiation damage microstructure were reviewed and assessed. Gas appears to be essential for establishing the structure and especially the formation of cavities. Degassing renders a metal immune to visible damage formation, whereas gas implantation markedly promotes damage structure. Inert gases are more effective than chemically active gases. Helium has received the most attention because it is always created during neutron Irradiations.

The primary role of helium is to promote cavity nucleation. In neutron irradiations the concentrations of cavities increase linearly with the generation rate of helfum at low fluences, tending to a slower increase at higher fluences. This behavior is consistent with the supposition that the helfum forms tiny gas bubbles, of which only those that reach a critfcal size can survive as viable cavities. As these cavities develop, the point defect sink strength is increased, reducing the population of excess vacancies and thereby requiring a larger critical bubble s1ze, that is, more hellum per cavity, for continued nucleation of cavicies. Higher temperatures also require a larger critical size. Calculations based on experimentally observed cavity concentrations and hellum levels in pure aluminum and nickel neutron irradiated at $0.35 T_{m}$ Indicate a critical bubble diameter of 1 to $2 \mathrm{~nm}$; in stainless steel and Nimonic PB16 alloy Ion irradiated at about $0.5 T_{m}$ preexisting hellum bubbles longer than about $3 \mathrm{~nm}$ grow into cavities. In ty!ng up vacancles in bubbles and cavities the hellum allows the corresponding interstitial atoms to increase the nucleation and growth of dislocations. Since the fluxes of point defects to these sinks induce a coupled flow of dissolved impuritles and alloying elements, constltuent elements redistribute to or

3 Presented at Consultant Symposium or. Rare Gases in Metals and Ionic Sol1ds, Harwell, Englind, September 10-14, 1979. To be published in Pruceedings, Also avallable as ORNL/TM-7193 (April 1980). 
frow the sinis, resulting in phase instablifty. Hellua, therefore, increases the concentrat lons of all point defect sinks and thereby af fects phase decoapositions.

The influence of hellum on alcrostructural evolution is sensitive to the method of inplanting the hellum. If the hellum is colaplanted slowly with the danaging particles, as it is in neutron irradiations, the heliun usually accelerates the foration of damage structure. If it is implanted before the dasage process, as is often the case in damage simulation ejperlments using charged particle boubardwents, it can elther enhance or depress the danage structure. When hellum is preimplanted to high levels or at temperatures significantly lower than the danage temperature, cavity nucleation is so pronounced that the cavities become the dominant point defect sinks and recombination sites; damage evo ion is retarded and swelling is diminished. This is particularly evident at irradiation temperatures in the lower end of the swelling range. At higher temperatures, high heifum levels pronote cavity nuclel by reducing therwal emission from cavities. The swelling range is therefore extended to higher temperatures. The implantation technique is thus a critical factor in assessing damage simulation experiments for relevance and reacior applications. Advanced simulation techniques using colmplantation of hellum are now overcoming some of these difficulties.

\subsubsection{Comparing S1multaneous vo Prelmplantation of Hellum In Radiation Damage Simulation ${ }^{4}$ - N. H. Packan and K. Farrell}

In the simulation of neutron damage microstructures using energetic electrons or Ions, a serious question is how an important transwutation product, hellum, should be introduced. (See Section 4.3 .2 for theoretical d1scussion of this process.) Since hellum 18 known to promote the nucleation of cavities, infection of the hellum before bombardment, wich is the usual practice, may overstimulate vold forwit! on and give a microstructure that is not representative of the required neutron damage structure. A

${ }^{4}$ Part of this work 18 described by N. H. Packan and K. Farrell, "Simulation of First Wall Damage: Effects of the Method of Gas Ioplantation," J. Nucl. Mater, 85 and $86:$ 677-81 (1979). 
more approprtate siaulation of neutron irradiation is to begin with no helium and to build it up continuously thereafter (i.e., simultaneous implantation).

This question was addressed by directly comparing the effects of preinjected hellum and simultaneously injected helfum on swelling in an ionbombarded austentic alloy of composition Fe-17\% Cr-16.7\% Ni-2.5\% Mo-0.005\% C (b) weight). This single-phase alloy swells readily and is free of radiation-induced phase instabilities. Ion bombardments were carried out by using the ORVL dual-accelerator irradiition facility, 5 whose main accelerator provides a beam of damage-creating 4-ike $58_{\mathrm{Ni}}$ ions, while the secundary acceleratur injects helium at cyclically varying energies $(0.2-0.4 \mathrm{YeV})$ in order to distribute the implanted atoms throughout the heavy-ion damage rebion. The bombardment temperatures wers $570,630,680$, 750 , and $825^{\circ} \mathrm{C}$; the displacement rate in the peak damage region was about $6 \times 10^{-3} \mathrm{dpa} / \mathrm{s}$; and the nominal duses achieved were 1,10 , and 70 dpa. For simultaneous injection of hellum the rate was set at 20 at. ppm He/dpa to simulate fusion reactor first-wall conditions; for preinjection the equivalent quantities of helium corresponding to the final dpa level were implanted at room temperature. Sperizens bombarded without any helium ("Ni lons" only) constituted the reference condition.

Thie temperature dependence of swelling is shown in Fig. 4.5 for doses of $1 \mathrm{dpa}$ (lower part) and $70 \mathrm{dpa}$ (upper part). Together with the results for $10 \mathrm{dpa}$ (not shown), there is a consistent increase in the peak swelling temperature of about $50^{\circ} \mathrm{C}$ for either gas implantation method above that for no gas. At all three doses simultaneous helfum implantation causes swelling to persist to the highest temperatures. The representative vold characteristics for the 70 dpa dose are shown in Fig. 4.6. Cavities in the preimplanted material are the smallest and most numerous at every temperature; fuithermore, they exhibit a bimodal size distribution (not observed for simultaneous implantation or for no helium) at all temperatures. These features can be seen :n Fig. 4.7, which presents example microstructures for each technlque at temperatures on each side of the peak swelling temperature. The population of small cavities in preinjected material 18 more discernable in the enlarged inset pictures.

5M. B. Lewis, N. H. Packan, G, F. Wel18, and R. A. Buh1, "Improved Techniques for Heavy-Ion Simulation of Neutron Radiation Damage,"Nuct. Instrum. Methods 167: 233-47 (1979). 

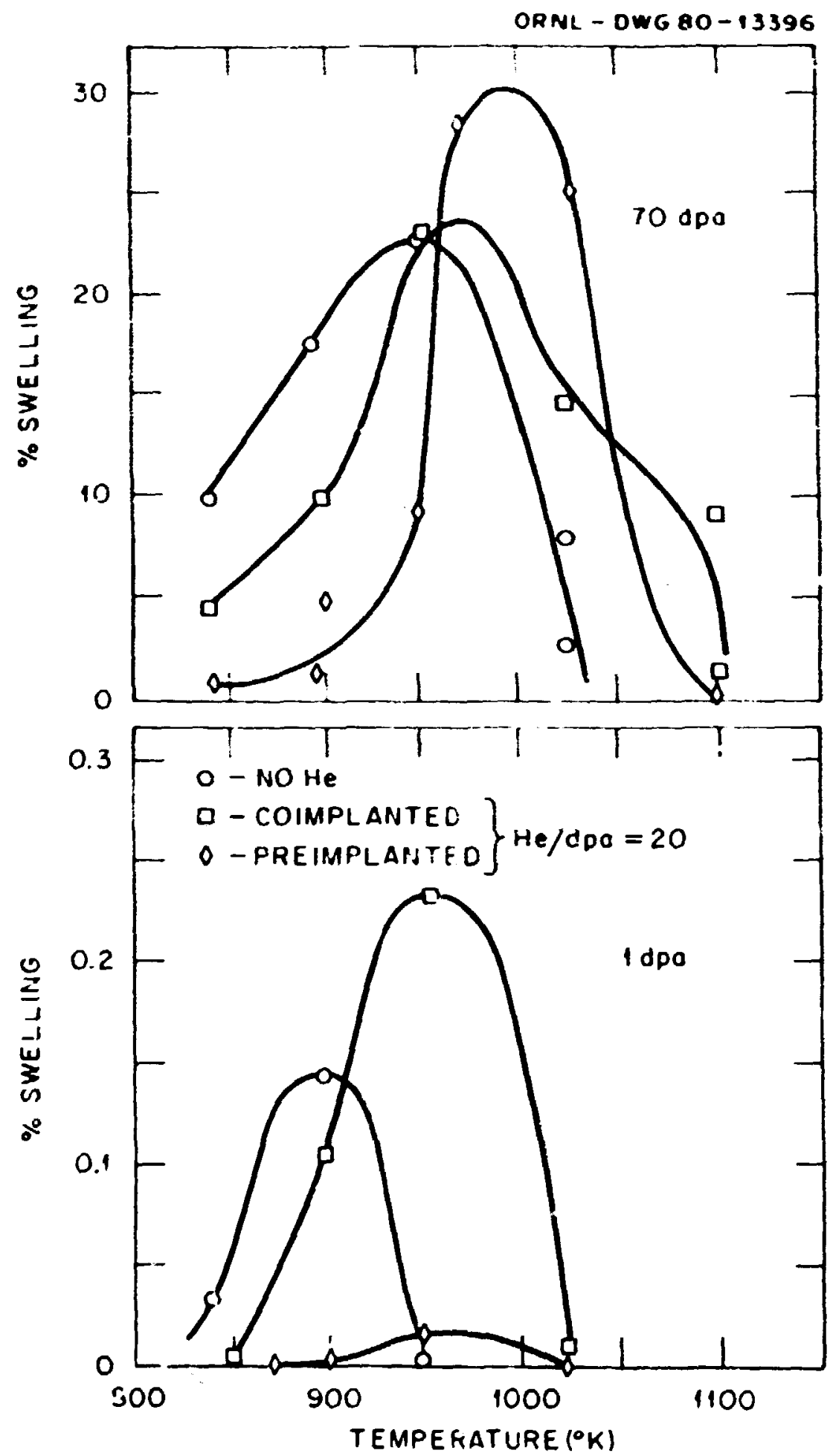

F1g. 4.5. Dependence of Swell1ng upon Bombardment Temperature at Doses of 70 and 1 dpa. 

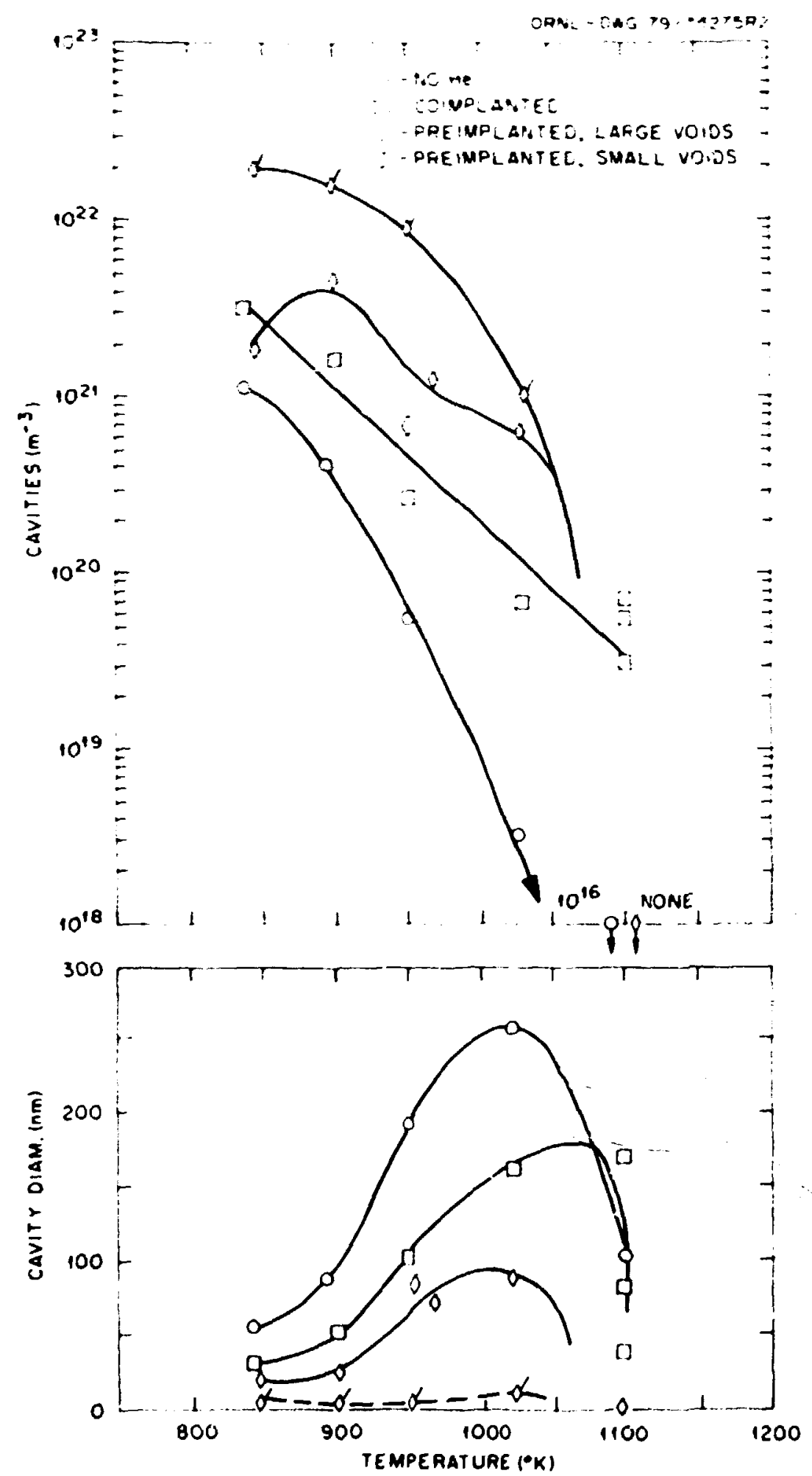

818. 4.6. Varlation of Cavity Concentration (Upper) and Mean Diameter (Lower) with Temperature. 


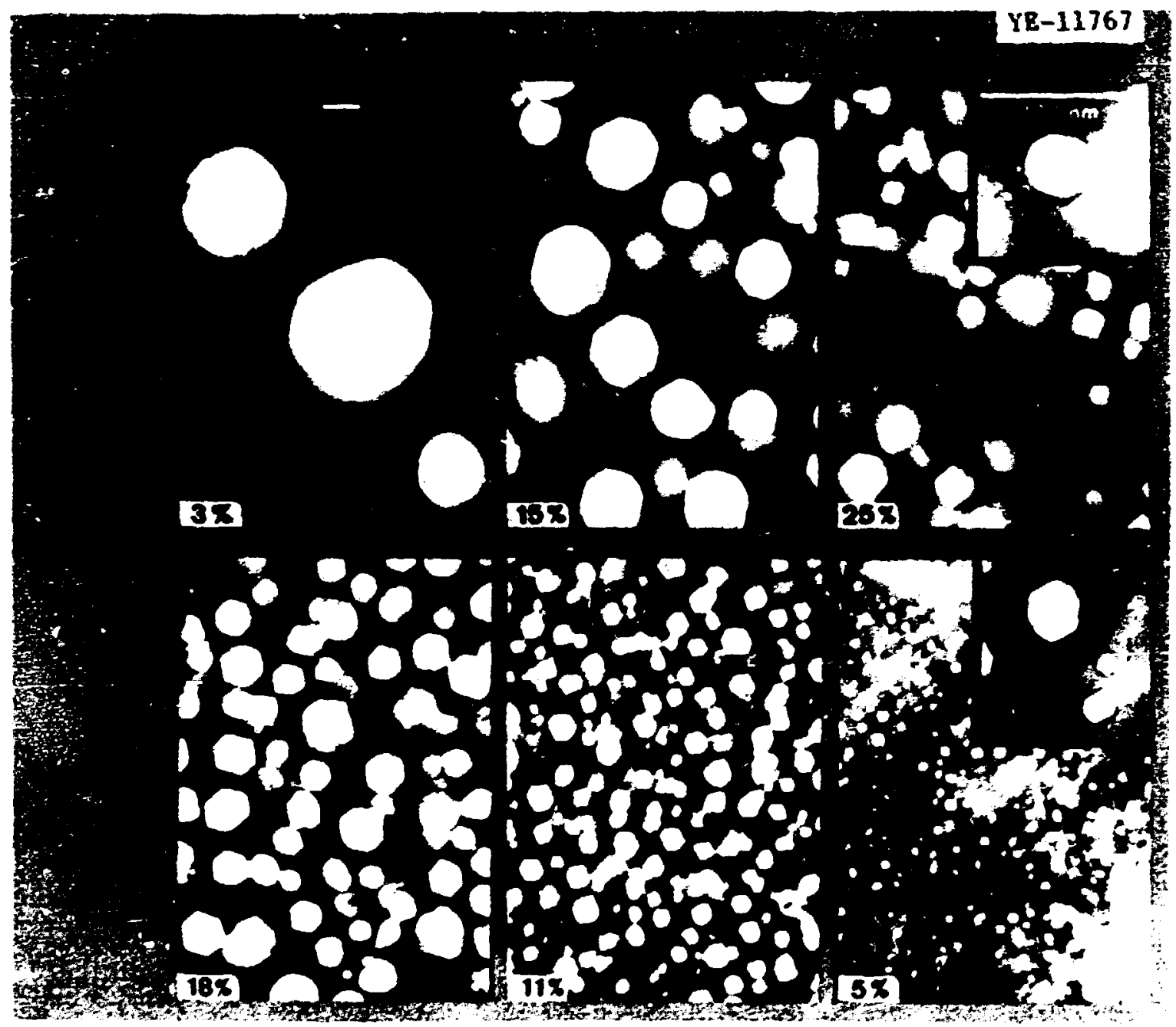

F18. 4.7. Representative Microstructure of Materials Bombarded to $70 \mathrm{dpa}$ at 1025 and $900 \mathrm{~K}$. 
Hellum toplantation at this high gas/dpa ratio indured sall cavietes (presuably gas bubbles) on the grain boundaries of preloplanted and also (not shown) coimplanted materlal. However, in contrast to these major changes in suity statistics for the different implanta:ion techniques, the dislocation densities were essentially insensitive to the introduction method or even the presence of hellum.

The behavior of the alloy without injected gases is noteworthy for its high swelling - a result of relatively few but very large cavities. These voids were also frequently found in patches or strings. This implies nucleatio.i on gases (this material contained about 0.1 at. $\% 0$, by analysis) or other heterogeneously distributed indigenous impurities. The high vold growth rate is thought to be the result of early nucleation on relatively few preexisting sites such that subsequent void growth took place in a microstructure where the dislocations were the dominant sink.

The addition of $20 \mathrm{at}$. ppm He/dpa had the general effects of increasing the peak swelling temperature about $50 \mathrm{~K}$ and producing essentially uniform spatial distributions of cavities. The method of introducing helius proved to be a strong varlable. Room-temperature preinjection generated profuse cavity nucleation and a bimodal cavity size distribution, the smaller population of which stayed about the same size $(<10 \mathrm{~nm})$ regardless of dose or temperature. This behavior evokes a piccure of rapid nucleation at the beginning of bombardment, with the cavitizs the dotainant sink, resulting in reduced cavity growth rate. The use of dual-oeam simultaneous helium implantation, which did not produce such behavior, is clearly to be preferred for experiments to simulate neutron radiation damage, where hellum is generated simultaneously by $(n, \alpha)$ transmucation reactions.

\subsubsection{Growth of Interstitlal Loops in Electron-Irradiated Nickel -} J. Ł. Spruiell, 6 W. A. Coghlan, and E. A. Kenik

During the past year, research has been performed to measure and model the growth rates of Frank interstitial loops in pure nickel under HVEr irradiation. The objectives are to test quantitatively the present

\footnotetext{
GPart time employee from University of Tennesset.
} 
understanding of 1 oop growth and to extract the basic defect parameters required for accirale codeling of radiation effects. This work extends the work reported iy loo and stiegler 7,8

Folls were cut from a zone-melted single-crystal rod of 99.99\%-pure nickel so that a $[100]$ zone axis was approximately perpendicular to the surface. After thinning, the Irradiations were carried out in the hot stage of the Hitachi HVEM at 400,450 , and $500^{\circ} \mathrm{C}$ with 1-MeV electrons. The point defect generation rate under these conditions is estimated at $9.6 \times 10^{-5} \mathrm{dpa} / \mathrm{s}$. The diameters of 30 to 60 loops in each irradiated area were determined from the largest dimension of the projected image.

Attempts were made to obtain foll thickness, loop number density, and loop position in the foil by stereomicroscopy. Each specimen was given a 5-min irradiation at room temperature to nucleate loops of satisfactory density and uniformity for the elevated-temperature loop growth experitaents. The loop density remained approximately constant unt fl unfaulting began.

ihe experimental measurements of average loop radius as a function of $t$ ime are presented in Fig. 4.8. The radius is given as $r / b$ where $b$ is the magnit ide of the Burgers vector. In the temperature range studied, the averag 2 loop size varies linearly with time. This agrees with the work of other investigators ${ }^{9}$ who have studied loop growth in nlckel. The lines shown in Fig. 4.8 do not pass through the origin of coordinates because of the preirradiation at room temperature. The slope of each line gives the measured average growth rate. The growth rate of loops in each speciwen is given in Table 4.2.

It is clear from both Fig. 4.8 and Table 4.2 that the average growth rate tends to increase with increasing irradiation temperature, but it also varies significantly from specimen to specimen at a given temperature. The differences at a given temperature are related to differences in foll thickness, loop number density, and perhaps other factors

7M. H. Yoo and J. O. Stiegler, "Growth Kinetics and 'Preference Factor' of Frank Loops in Nickel Durinf Electron Irradiation," Philos. Mag. 36: 1305-15 (1977).

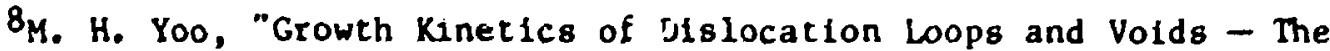
Role of Divacancies," Philos. Mag. A 40: 193-211 (1979).

${ }^{9} \mathrm{~K}$. Urban, "Growth of Defect Clusters in Thin Nickel Folls During Electron Irradiation," Phys. Status Solidi a) 4: 761-72 (1971). 


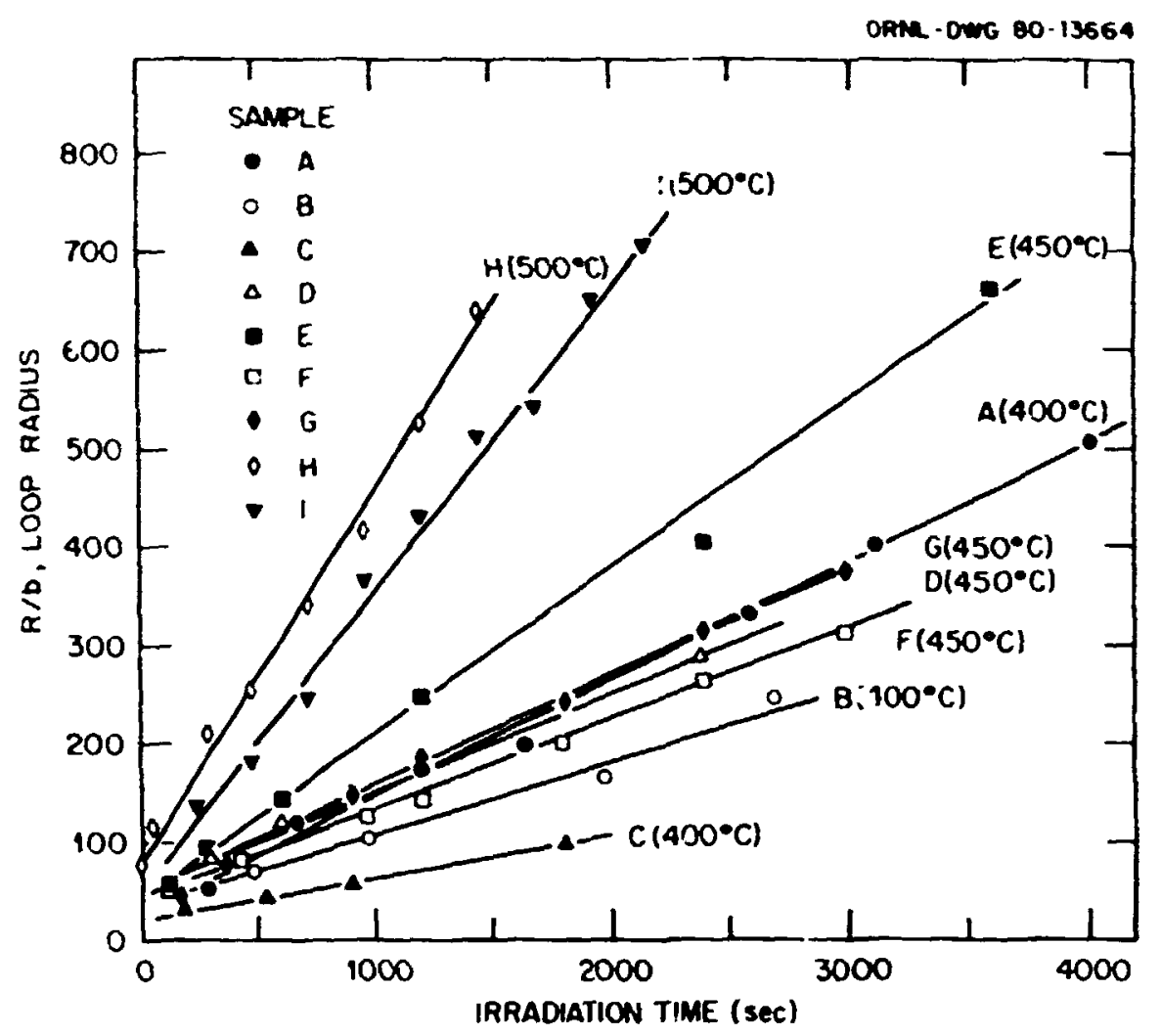
Time.

Fig. 4.8. Radius of Interstitial Loops as a Function of Irradiation

Table 4.2. Measured Interstitlal Loop Growth Rates

\begin{tabular}{|c|c|c|c|c|}
\hline \multirow{3}{*}{ Specimen } & \multirow{3}{*}{$\begin{array}{c}\text { Temperature } \\
\left({ }^{\circ} \mathrm{C}\right)\end{array}$} & \multicolumn{3}{|c|}{ Growth Rate ${ }^{a}$} \\
\hline & & \multirow{2}{*}{$\frac{d(R / b)}{\left(s^{-1}\right)}$} & \multicolumn{2}{|c|}{$d D / d t, \mathrm{~nm} / \mathrm{s}$} \\
\hline & & & Specimen & Average \\
\hline $\begin{array}{l}A \\
B \\
C\end{array}$ & 400 & $\begin{array}{l}0.119 \\
0.073 \\
0.044\end{array}$ & $\begin{array}{l}0.0484 \\
0.0299 \\
0.0180\end{array}$ & 0.032 \\
\hline $\begin{array}{l}D \\
E \\
F \\
G\end{array}$ & 450 & $\begin{array}{l}0.097 \\
0.169 \\
0.091 \\
0.091\end{array}$ & $\begin{array}{l}0.0396 \\
0.0688 \\
0.0373 \\
0.0449\end{array}$ & 0.048 \\
\hline $\begin{array}{l}\mathbf{H} \\
\mathbf{I}\end{array}$ & 500 & $\begin{array}{l}0.375 \\
0.305\end{array}$ & $\begin{array}{l}0.1530 \\
0.1244\end{array}$ & 0.139 \\
\hline
\end{tabular}

$a_{D}$ is loop dameter in nanometers. 
juch as suridce condition of the till. h' ligithary evaluation indicates that nubber density no vary signiticantly. for eximple, the loils irradiated at $403^{\circ} \mathrm{C}$ all sppear to have thicknesses in the range 3 w to sut kn, br: their number densities vary from $2.0 \times 10^{19}$ loops/a ${ }^{3}$ for speciaes at to $7.0 \times 10^{20} 100 \mathrm{~s} / \mathrm{m}^{3}$ for $\mathrm{l}$. The higher number donsity results in luwer growth rate, as would be intuitively expected. This crend also agrees with the lower growth rates measured $i$. the present experiments compared with those reported by Urban. 9 The gruwth rate reported by liou and stiegler at $450^{\circ} \mathrm{C}$ lies below the present results, but their number density was well above the number densities observed in the present pasurements. In the original experiments ${ }^{7}$ the growth of faulted loops in nickel was measured at $450^{\circ} \mathrm{C}$, and the model $\mathrm{b}=$ able to predict this growth as a function of time with reasonable accuracy. In the subsequent report ${ }^{8}$ the inclusion of divacancies in the analysis cumplicated the picture, since more parameters are involved and divacancy parareters are not well known.

The computer model was modified to explore several difterent physical effects to reproduce our observed str.n.: temperature dependence. The effects explored included (1) utilizing loop capture radii recent ly calctlated from elasticity and diffusion theory, (2) the eftect of divacancies, (3) reaction control of the vacaucy at the foll surface, and (4) modeling the dislocation loop sink strength as proportional to the iength of disiocation line contalsed in the loop, a form used previously by Heald and speight. 10 only (3) and (4) show a reasonable possibility for explaining the strong temperature dependence. In addition, foll t..ickness, loop density distributions, and loop growth rate as functions of depth will be explored.

\subsubsection{Precipitation of $\mathrm{Mo}_{2} \mathrm{C}$ in Nickel-Molybdenum Alloys During High-} Temperacure Ion Irradiation Experiments - $W$. Kesternich, 11 E. A. Kenlk, R. W. larpenter, and M. B. Lewls

Nickel-ion and high-voltage electron mlcroscope lrradiation experiments have shown nickel-molybdenum alloys and the ordered composition

10P. T. Heald and M. V. Spelght, "The Influence of Cascade Damage on Irradlation Creep and Swelling," J. Nucl. Mater. 64: 139-44 (1977).

l'Kernsforschurigsanlage Jülich, FRG. 
$\mathrm{Ni}_{4}$ Mo in particular to be highly resistant to vold sweling. However, unpredicted precipitates were observed by transa!ssion electron alcroscopy in spectmens that had been ion irradiated. These alloys are normally single-phase, urdered $\mathrm{MH}_{4} \mathrm{Ho}$ (with structure $\mathrm{Dla}$ ) or are a face-centered-

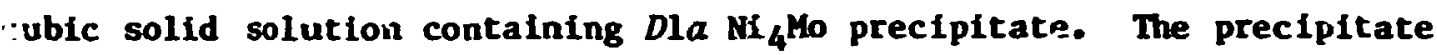
that forwed under Ion irradiation was not of the Dla structure, although analytical electron microscopy showed it to have a high wolybdenum concentration. The volume fraction of this precipate increased with ion dose.

The nickel-molybdenum spectaen alioys used were prepared from highpurity materials. For example, the carbon concentration was 46 at. ppu. Thus the appearance of the pracipitate was not attributable to siaple impurity effects. A detalled analysis of the precipitate structure was undertaken by using adcrodiffraction. Composition variation in the nearsurface regions of the specimens was examined by nuclear wicroanalysis. The precipitate was fcund to have hexagonal structure corres?onding to $\mathrm{Mo}_{2} \mathrm{C}$. The crystallographic habit was

$$
\begin{aligned}
& (0001)_{\text {ppt }} \|(111)_{\text {matrix }} \\
& (10 \overline{1} 0)_{\text {ppt }} \|(11 \overline{2})_{\text {matrix }} .
\end{aligned}
$$

Using measurements of precipitate volume fraction in the damage layer of nickel-ton trradiated specimens and alloy composition, we showed that the specimens had insufficient carbon near the irradiated volume to account for the precipitation observed. Nuclear uicroanalysis showed that the carbon concentration in Irradlated specimens was high on the Incident ion surface and decreased monotonically with depth into the specimen, and that the carbon concentration depended on ion dose. The source of the additional carbon responsible for the precipitation observed appears to be contamination during the irradiation experiments, probably by surface diffusion from the surrounding area. However, the magnitude of cat son contamination does depend on total dose, so a simple time-at-temperature diffusion model is not sufficient to explain the observations. These 
results emphasize that stringent precautions are necessary in specinen preparation and irradiation procedures to control and identify chenical contanination.

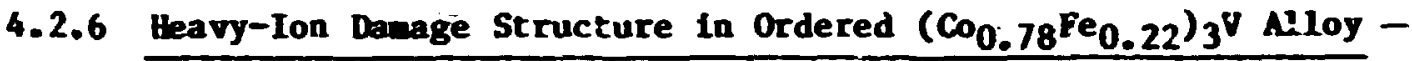 D. N. Braski and R. Parrell}

The alloy $\left(\mathrm{CO}_{0.78} \mathrm{Fe}_{0.22}\right)_{3} \mathrm{~V}$ is one in a class of $\mathrm{Ll}_{2}$ long-rangeordered (LRO) alloys developed at ORN for elevated-temperature applications. To assess its potential for reactor use, we are studying the microstructural changes. Induced by bervy-ion irraliaticn.

The alloy was quenched from $1080^{\circ} \mathrm{C}$ and aged for $8 \mathrm{~h}$ at $800^{\circ} \mathrm{C}$ (i.e., $-150^{\circ} \mathrm{C}$ above the critical ordering temperature). Irradiations with 4- $\mathrm{HeV}$ nickel lons were done at $570,625,680$, and $750^{\circ} \mathrm{C}$ to a damags level of $70 \mathrm{dpa}$. The unfrradiated acrostructure of $\left(\mathrm{Co}_{0.78} \mathrm{Fe}_{0.22}\right)_{3} \mathrm{~V}$ consisted of grains containing approximately equal numbers of extrinsic or interstitial-type fau? ted loops. These loops were decorated with vC particles and intrinsic or vacancy-type stacking faults, which were always free of precipitate. Aging the heat-treated alloy at the irradiarion temperatire for $3 \mathrm{~h}$ to sinulate the theral exposures during irradiation produced no discernable change in microstructure, as shown in Fig. 4.9(a). The microstructure alsc contained theral antiphase boundaries (APBs), and these have been imaged for the same area [Fig . 4.9(b)] by using a (100) superlattice reflection in dark field. The fart that most of the faults terminate on APBs suggests that cooperative growth between these two features occurred during the preirradiation heat treatment. The APBs were wavy, with no preference for any perticular cryotallographic orientation. Transmission electrun microscope contra3t experiments using superlattice reflections showed that the displacement vecror for thest APBs was of the $(1 / 2)\langle 110\rangle$ type and, consequently, only two-thirds of the APBs are visible by use of the (100) diffraction vector, as shown In F1g. 4.9(b). Besides being structural defects, the stacking fiults also serve as APBs because a "chemical" discontinuity in 

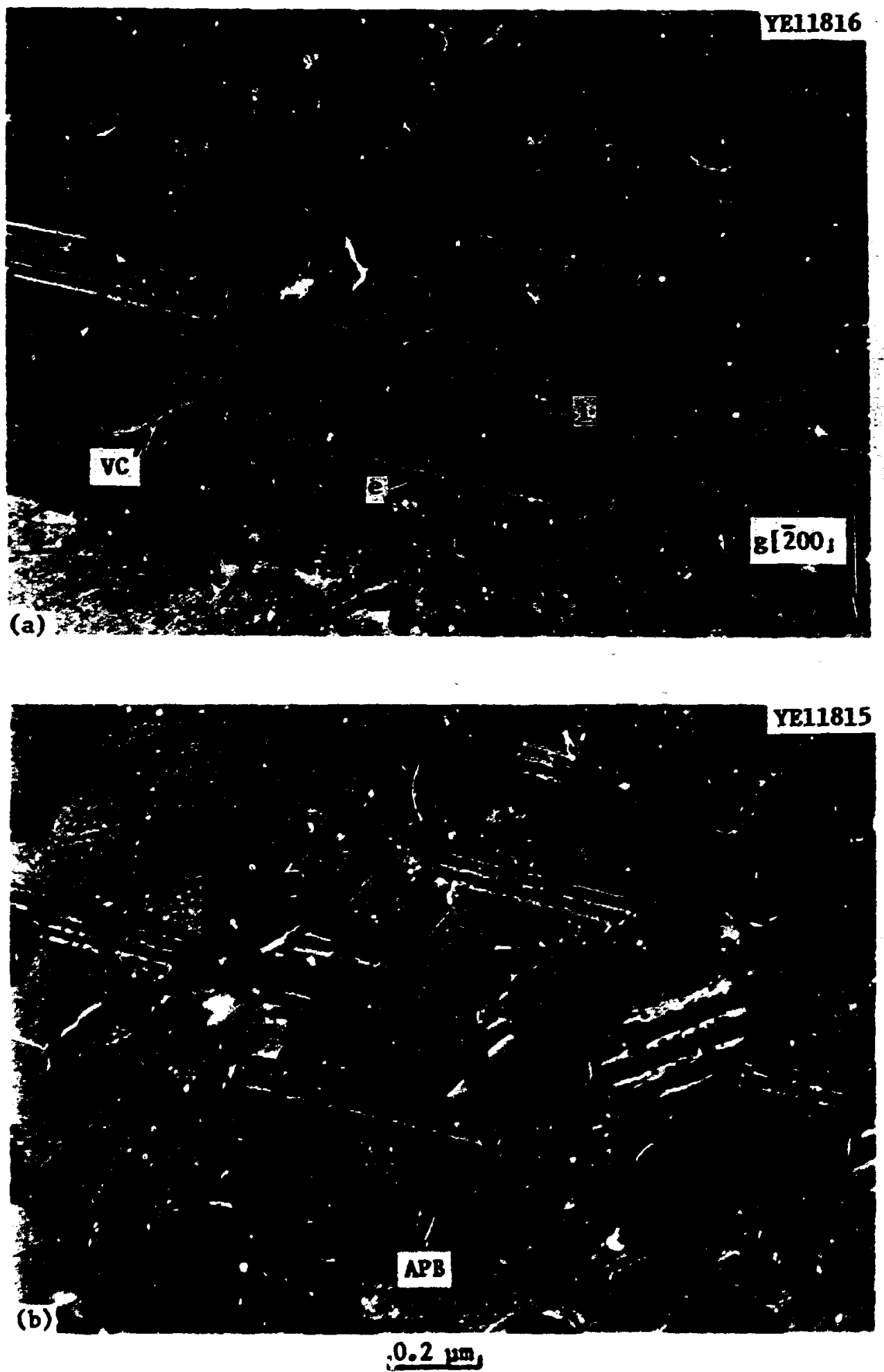

P18. 4.9. Microstructure of $\left(\mathrm{CO}_{0.78} \mathrm{Pe}_{0.22}\right)_{3} \mathrm{~V}$ Quenched In Water from $1100^{\circ} \mathrm{C}$, Annealed at $800^{\circ} \mathrm{C}$ for $8 \mathrm{~h}$, and Annealed at. $570^{\circ} \mathrm{C}$ for $3 \mathrm{~h}$. (a) Bright fleld showing extrinsic faulied loop (e), intringic stacking faults (1), and VC precipitate. (b) superlatt lce dark field of same area ottained by using (100) rafiection, showing faults and antiphase boundaries. 
ordering exists across thea. However, these latter APBs possess displacement vectors of the $(1 / 6)\langle 112\rangle$ type and 11 e on $\{111\}$ planes. Therefore, the ordered domains were bounded by two types of APBs - wavy or therwal APBs and stacking faults.

Irradiation of $\left(\mathrm{CO}_{0.78} \mathrm{Fe}_{0.22}\right)_{3} \mathrm{~V}$ with 4-HeV nickel tons to $70 \mathrm{dpa}$ did not aisorder the material, but it did reduce the donain size and introduce other afcrostructural features. The wost obvious addition was a high density of stacking faults on [111\} planes and dislocations, as shown in $\mathrm{Fig}$. 4.10(a) for a specimen irradiated at $570^{\circ} \mathrm{C}$. Again, roughly half the faults were extrinsic, while the remaining were intrinsic. The introduction of additional faults into the atcrostructure effectively reduced the domain size as shown in Fig. 4.10(b) [comare with Fig. 4.9(b)]. The radiation-induced faults actually subdivided the original dowains, producing the wch finer size. Sall cavities less than 7 in dianeter were also created and are shown in Fig. 4.10(c). The cavities were usually located on matrix dislocations or on dislocations bounding grown-in faults and radiation-induced faulced loops.

With increasing irradiation teaperature, lower number densities but larger sizes of faulted loops and cavities were produced. Higher Irradiation temperatures also increased the donain size toward that before Irradation, while the amount of VC precipitation was decreased. Swelling from the cavities was less than $0.05 \%$ at all temperatures. Simultaneous injections of $3 \mathrm{ppm} / \mathrm{dpa}$ of helium and $12 \mathrm{ppm} / \mathrm{dpa}$ of deuterfum to simulate a first-wall fusion reactor condition increased the arelling to values as $\mathrm{high}$ as 0.27 . However, these values were st111 substantially lower than the $2 \pi$ maxioum owelling measured for a 20\%-cold-worked type 316 stainless steel bombarded under sinilar conditions. The potential for $L R O$ allnys as nuclear reactor aterials appears good. 

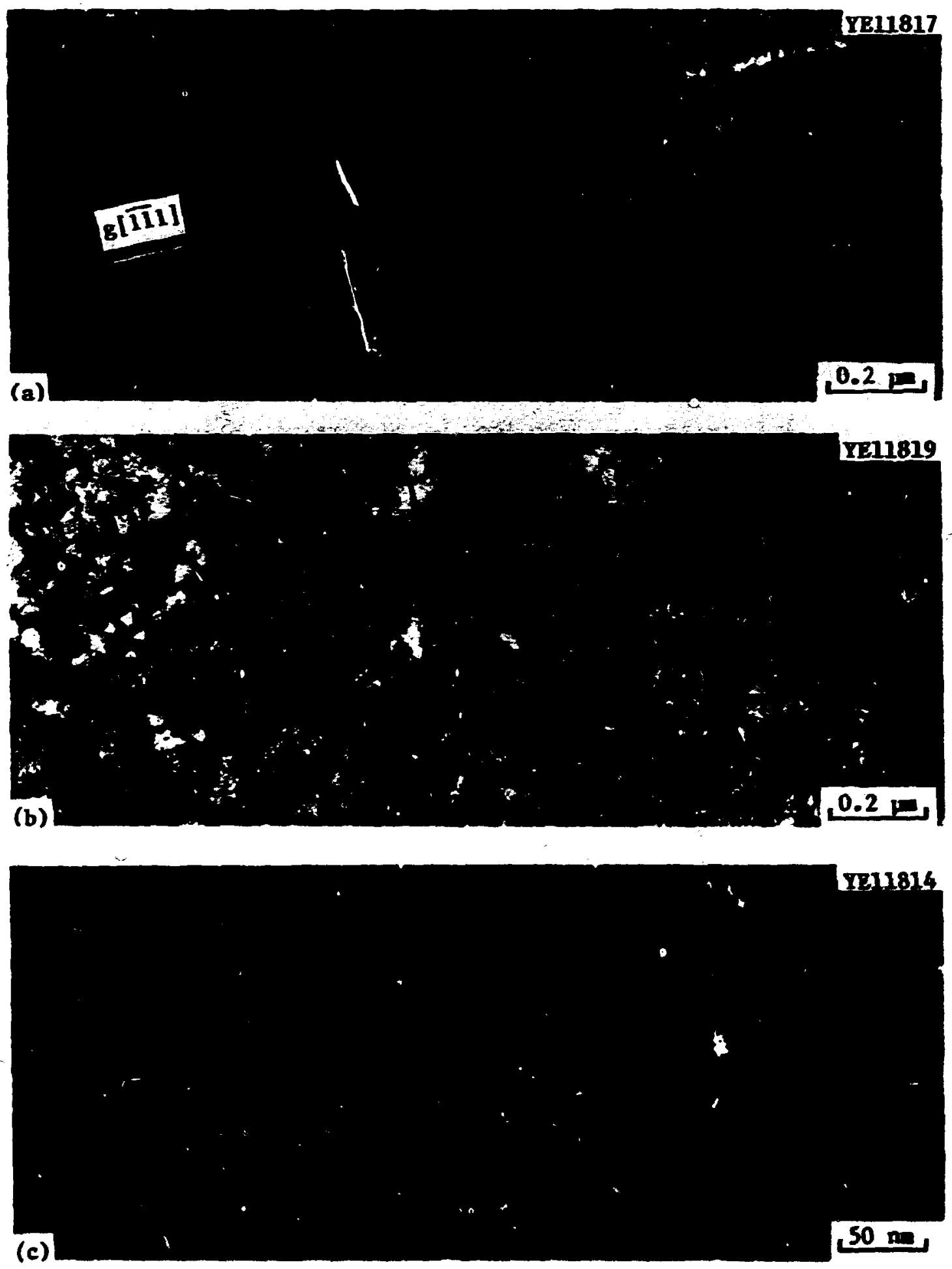

F18. 4.10. Microstructure of $\left(C_{0} .78^{\mathrm{Pe}} 0.22\right)_{3} \mathrm{~V}$ Quenched, Aged at $800^{\circ} \mathrm{C}$ for $8 \mathrm{~h}$, and Irradiated wth 4-HeV Nickei Ions to $70 \mathrm{dpa}$ at $570^{\circ} \mathrm{C}$ $(3 \mathrm{~h})$. (a) Bright field, showing high deneity of faulted loops and tiny cavitles. (b) Dark field of sane area imaged by using (100) superlattice reflection to show ordered dorains. (c) Bright field at hizher aggnification to show cavities. 
4.2.7 Irradiation Creep Using Light Ions - T. C. Relley. P. Jung, 12 and

Host of the work described below is a collaborative effort of Reiley and Jung performed at RPA-Jülich on the cyclotron there. These experiments sought to prepare sjecimens with a vell-characterized and homgeneous microstructure. This was accouplished for type 316 stainless steel through a treatment of solution annealing plus deformation at $600^{\circ} \mathrm{C}$ and $275 \mathrm{MPa}$ for $24 \mathrm{~h}$. Although this steel (as well as wost other materials) normally forms dislocation cells or subgrains during deformation, the above treatment leads to a homgeneous distribution of dislocations 13 at a density neasured to be $1-2 \times 10^{14} / \mathrm{n}^{2}$. The origin of this unusual structure is very likely associated with the carbondislocation interaction, as Indicated by the strain aging occurring at this temperature. Purtherwore, Class I solid solutions, in wich solute atwospheres affect dislocation otion, also is not form subgrains.

Two kinds of type 316 srainless steel specimens were prepared: PC, pre-crept as described above, and A-PC, aged (200 h at $\left.552^{\circ} \mathrm{C}\right)$ and pre-crept. The aging treatment was designed to cause precipitation of $\mathrm{M}_{23} \mathrm{C}_{6}$ - Also prepared vere specimens of $\mathrm{MI}-4$ wt $Z \mathrm{U}$, Class II solid solution with a fairly low stacking fault energy, chosen as a wodel systen for stainiess steels. Specimens of these materials were tested in a 5.5-HeV proton bean in the cyclotron at sevieral stresses and tenperatures. The creep rates, dislocation densities, and loop densities were measured. The structural results are shown in Table 4.3. The creep behavior of the PC type 316 specimens is given in Pig. 4.11 along with earlier work of C. Schwaiger, P. Jung, and H. UJlmaier ${ }^{14}$ on $20 Z$ cold-worked type 316 stainless steel. The creep of the $\mathrm{Mt}-\mathrm{ZW}$ is shown in P1g. 4.12.

12RPA-Junich, PRG.

$13_{\mathrm{D}}$. Chalienger and J. Hoteff, "Quaritiative Characterization of the Substruct a'e of AISI 316 Stainless steel Resulting fron Creep," Metall. Tronse. A. 4: 749-55 (1973).

${ }^{14} \mathrm{C}$. Schwaiger, P. Jung and H. U1lasier, International Conference on Fundanan" a: Mechanlsas of Radiation-Induced Creep and Growth, Chalk River Nucleer 'aboratories, Chalk RIver, Canada, May 1979. 
Table 4.3. Structural Features After L1ght-Ion Irradiation

\begin{tabular}{|c|c|c|c|c|c|c|}
\hline \multirow{2}{*}{$\begin{array}{l}\text { Alloy } \\
\text { Conditiona }\end{array}$} & \multirow{2}{*}{$\begin{array}{c}\text { Irradiation } \\
\text { Temperature } \\
\left({ }^{\circ} \mathrm{C}\right)\end{array}$} & \multirow{2}{*}{$\begin{array}{l}\text { Displacement } \\
\text { Damage } \\
\text { (dpa) }\end{array}$} & \multicolumn{2}{|c|}{ Dislocation Density, $10^{14} / \mathrm{m}^{2}$} & \multirow{2}{*}{$\begin{array}{l}n n_{1} \text { Loop } \\
\text { Density } \\
\left(10^{20} / \mathrm{m}^{3}\right)\end{array}$} & \multirow{2}{*}{$\begin{array}{l}\text { Maximum Loop } \\
\text { Diameter } \\
\text { (nm) }\end{array}$} \\
\hline & & & $P_{n}$, network & $P_{t,}$ total & & \\
\hline \multicolumn{7}{|c|}{ Type 316 Stalnless Steel } \\
\hline $\begin{array}{l}\text { Solution } \\
\text { annealed }\end{array}$ & & 0 & $\sim 0.01$ & & & \\
\hline $\begin{array}{l}20 z \text { cold } \\
\text { worked }\end{array}$ & & 0 & $>10^{b}$ & & & \\
\hline $\begin{array}{l}\text { Neutron } \\
\text { Irradiated }\end{array}$ & 450 & 20 & $1-3$ & $1-3$ & $\sim 1$ & $150^{\circ}$ \\
\hline PC & & 0 & 1.3 & & & \\
\hline$A-P C$ & & 0 & 1.4 & & & \\
\hline PC & 300 & 0.1 & 1.8 & 2.2 & 13 & 30 \\
\hline$A-P C$ & 300 & 0.1 & 1.7 & 2.1 & 6 & 60 \\
\hline PC & 375 & 0.2 & 1.3 & 1.7 & 2 & 160 \\
\hline PC & 420 & 0.2 & 1.6 & 1.6 & $<1$ & \\
\hline \multicolumn{7}{|c|}{$N 1-4 X W$} \\
\hline $\begin{array}{l}202 \text { cold } \\
\text { worked }\end{array}$ & & & $>10^{b}$ & & & ' \\
\hline $\begin{array}{l}20 x \text { cold } \\
\text { worked }\end{array}$ & 300 & & 3.0 & 3.6 & 11 & 50 \\
\hline
\end{tabular}

$a_{\mathrm{PC}}$ - precrept $24 \mathrm{~h}$ at $600^{\circ} \mathrm{C}$ and $275 \mathrm{MPa} ; \mathrm{A}-\mathrm{PC}=$ aged $200 \mathrm{~h}$ at $550^{\circ} \mathrm{C}$, then precrept; 1rradlation 18 with 5.5-MeV protons unless otherwise Indicatud.

$b_{P_{n}}$ way vary ore than a factor of 10 between cell wall and cell interfor.

QAverage loop size, not maximum. 


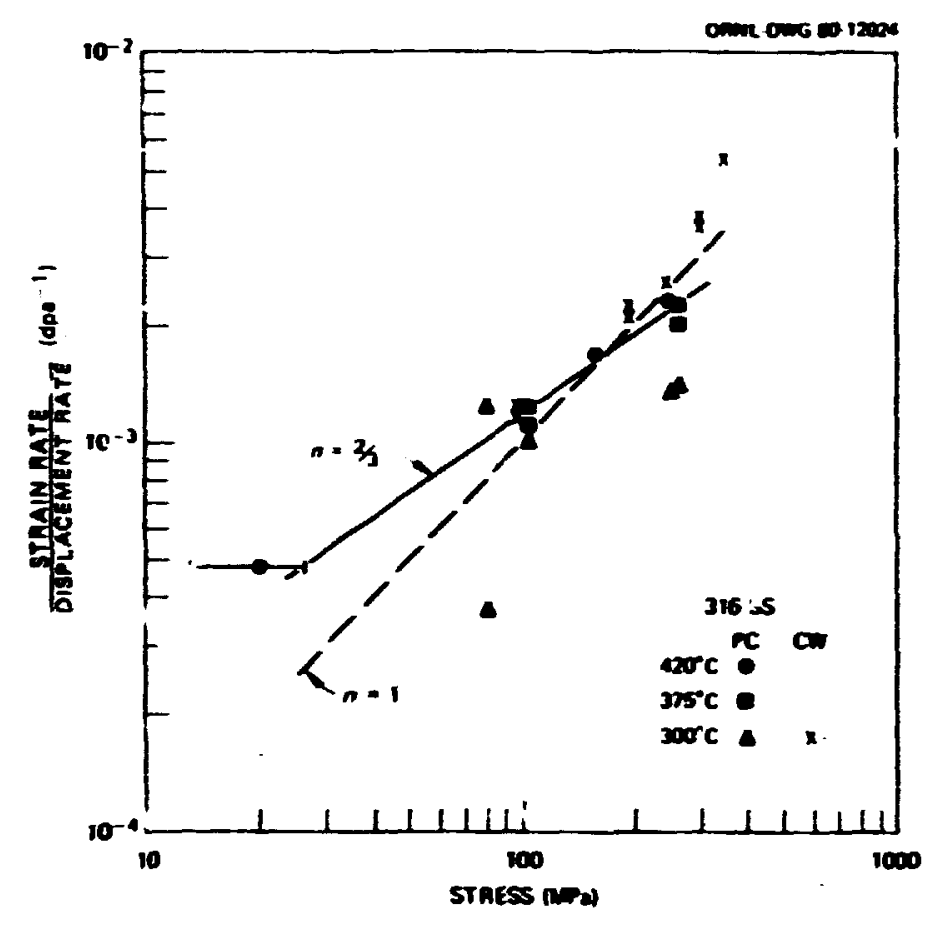

Fig. 4.11. Normalized Irradiaticn Creep Rate of Precrept Type 316 Stainless Steel Under 5.5-MeV Protons. Al 30 shown are data for coldworked material under 7-MeV deuterons.

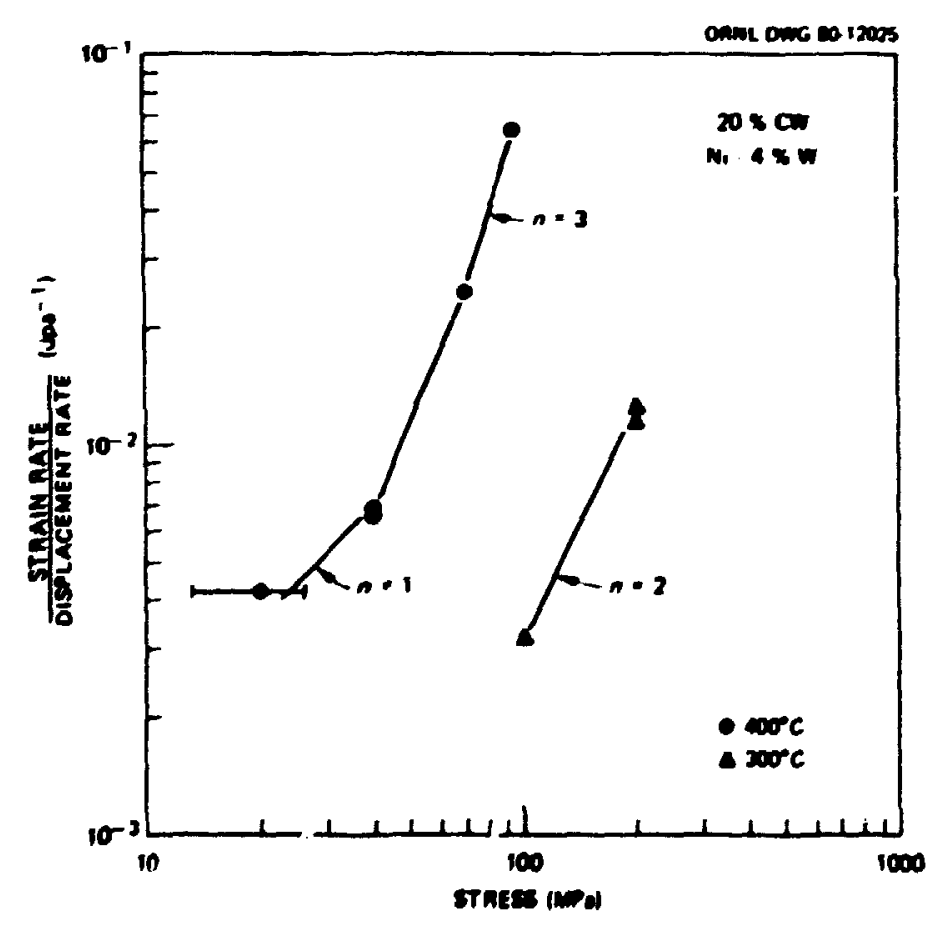

818. 4.12. Norwalized Irradiation Creep Rate of Cold-Worked NI-4\% W Under 5.5-MeV Protons. 
The structural results ${ }^{15}$ for type 316 stainless steel neutron irradiated to $20 \mathrm{dpa}$ at $450^{\circ} \mathrm{C}$ is given in Table 4.3 as an indicator of the desired agnitule of loop and cislocation densities in stablized irradiated aterial. Both PC type 316 and A-PC type 316 have sinilar values of $\rho_{n}$, the network dislocation density, and reain essentially unchanged after irradiation. The loop density, $n_{l}$, of these mterials after lightIon irradiation is conparable to that of the stablized meterial, although loop sizes are much differ nt, reflecting the short period for loop growth during the light-ion experier is. There is a slight difference in loop size between the PC and A-PC ateriais, indicating an effect of carbon in solution on loop growth rates, perhaps through trapping. The loop growth rate Increases and the number density decreases with an increase in temperature.

The norwalf :ed creep rates (strain rate/displacement rate) for type 316 stainless steel under light ions show (1) a low stress exponent, :1, at low to moderate stresses; (2) a swall temperature dependence; (3) a very anall, if any, dependence on dislocation density or worphology for $\rho_{n}>10^{14} / \mathrm{m}^{2}$. These features are all consistent with predictions of preferred absorption climb models; however, climb-glide wolels can not be ruled out.

The data for Ni-4Z W. given In Fig. 4.12, show a higher average stress exponent, which probably indicates a transition fron a low (Irradiation creep) to high (thermal creep) exponent. For this material as the degree of therwal creep increases, the stress exponent clearly increases.

A comparison anong cownercial cold-worked type 316 stainless steel, cold-worked "pure" type 316 (wth low inpurity levels, espectally carbon), $\mathrm{NL}-4 \mathrm{ZW}$, and nickel shows a significant difference in irradiation creep rates, even though elastic noduli anó diffusion activation energies are quite sinflar. A factor that correlates well with the observed differences 18 stacking fault energy (low stacking fault energy, low creep rate). Given the influence of this facter on dislocation cliab and crosssilp processes, it is reasonable to expect that creep processes involving the wotion of network.dislocations, at least, should be influenced by stacking fault energy. The theorles do not include stacking fault energy effects, even though dislocation climb and climb and glide are the deformation mechanisms. This nay indicate major deficlency in the theory.

15r. J. Barton, B. L. E;re, and D. A. Stow, J. Nucl. Nater. 67: 181 (1977). 
The work performed at own included several instrument improvenents and two irradiation creep experiments on cold-worked type 316 stainless steel at the end of the reporting period. Results froe these experiments are sifllar to earlier experimental results.

\subsection{THEORY $N \cdot$ MODELING}

\subsubsection{Effective Diffusion Coefficients of Point Defects in Inpure Materials 16 - L. K. Mansur}

When vacancies or interstitials diffuse in a merial containing impurities, the point defect diffusion coefficients characteristic of the pure aterial ace altered. An effective diffusion coefficient way be calculated from the diffirion coeffictent in the pure material and detailed knowledge of the point defect-impurity reactions. The effective coefficient wy be used for some purposes as if it were a simple coefficient characteristic of the aterial.

Where Impurity-point defect complexes are inmobile and there is no Irradiation, the impurities are characterized as traps and the effective point defect diffusion coefficient, or as it is sometines called, delayed diffusion coefficient, is the free point diffusion coefficient reduced by a factor calculable from the trap characteristics. The result has been shown to be given by

$$
D_{v}^{e f}=D_{v} /\left(1+\kappa_{v} \tau_{v} C^{t}\right)
$$

where $D_{v}^{B f}$ is the effective vacancy diffusion coefficient. Here $D_{v}$ is the vacancy diffusion coefficient in the pure aterial, $K_{v}$ is the capture coefficient of the trap for free vacancies, $c^{t}$ is the trap concentration and $\tau_{v}$ is the mean tive a vacancy is trapped before therwal release. The result for self-interstitial diffusion is siaply obtained here and in what follows by subetituting the subscript $i$ for $v$.

Where vacancy-inpurity complexee are mobile, a generalized form of Eq. (1), again for the iace of no Irradiction. has been given as

16Paper to appear in Aota Metallurgloa. Also ayailable as ORM/R-7247. 


$$
D_{v}^{e f}=\frac{D_{v}+D_{v}^{*}{ }_{v} \tau_{v} C^{t}}{1+\kappa_{v} \tau_{v} c^{t}}
$$

where $D_{v}^{*}$ describes the transport of vacancies associated with both formation and migration of wbile vacancy-impurity complexes.

Under irradiation, however, the effective diffusion coefficients contain additional terus. For the case where the ccsplexes are mbile, were vacancy-interstitial reconbination and liss of vacancy-impurity complexes to sinks are accounted for we have derived the foilowinz expression

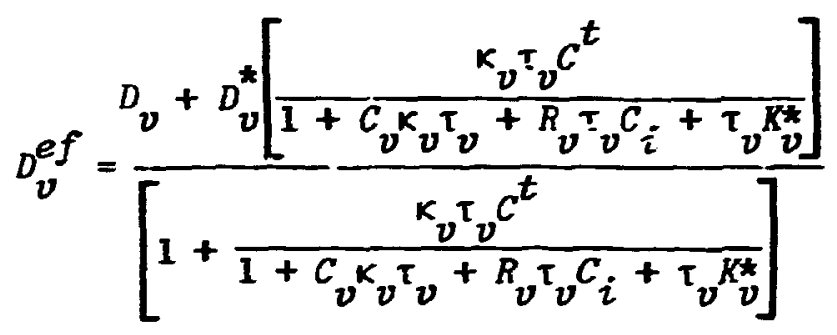

Here $C_{v}$ and $C_{i}$ are the free vacancy and interstitial concentrations, $R_{v}$ is the recombination coefficier.t for free interstitials with bound vacancies, and $K_{v}^{*}$ is tise loss rate to internal sinks of vacancy-impurity complexes per unit complex concentration.

The effective diffusion coefficients, which have been set forth in the literature frow tine to time by ourselves and others, including Eqs. (1) and (2), are limiting or approximate forms of Eq. (3) that are obtalned for spectal conditions, namely, no irradiation, low vacancyimpurity binding energies, or low internal sink strength.

The effective diffusion coefficienc of point deferts in a material contalning impurities is a convenient and usefui concept. It is convenient because in terms of overail transport of point defects what is obtained is a composite weasure of the effects of several point derectinpurity processes. Knowing that the measured diffusion coeffictent is actually a composite entity allows interpretation and testing in terms of more fundamental parameters. It is shown in Ref. 16 that the equations describing the fates of free and bound vacancles under irradiation (and theraliy) in terms of free and impurity-associated diffusivities, trapping rate, thermal release rate, and bound recombination rates are Indistinguishable from a set of two equations characteristic of a system with no impurities, ,rovided the diffusion cosficients in the new 
equations are effective diffusion coefficients. As one application of these ideas, consider that the irradiation-induced swelling observed at one temperature has of ten been quantitatively fit with numerical values for vacancr igration energies characteristic of siaple diffusion coefficients oy using simple rate equations (i.e., not accounting for inpurities) and using the point defect concentrations computed from these in the expressions for void swelling. The theoretical forms for the effective diffusion coefficients given here show how the effective diffusion coefficients are actually expected to vary with temperature.

The effective diffusion coefficient is a useful concept because it is a composite of terms, each describing a physical process, constructed in precisely the correct way to permi: evaluation of the relative infortance of the processes for a given materia!. In $E_{i}$. (3) the cerms in the denominator of the term multiplying $D_{v}^{*}$ and $\geq 1$ so appearing in the lower denominatcr describe the processes controlling the concentration of bcund vacancies. These terms determine the contribution of the bound vacancies to the effective diffusivity.

Thus fur processes are now accounted for in determining the concentration of bound vacancles. The terms above, whin are norwalized to $\tau_{v}{ }^{-1}$ in the form shown, can be Identified with vacancy thezmal release, trapping, recombination of bound vacancies with free interstitials, and impurity-associated transport to sinks. We have examined the conditions under which the trapping, bound recombination, and impurity-associated transport terw's may be important with respect to the thermal release term In determining the concentration of bound vacancies. Expiessions are given for the requirements on the parameter values of the system to enter these various regimes.

\section{3.? Applications of the Theory of Cavity Growth to Dual-Ion Swelling Experiments 17 - M. R. Hayns 18 and L. K. Munsur}

Hellum may be infected in:o a metal or alloy during irradiation as the result of reactor neutron-induced transmutation reactions, or during accelerator tombardment with the use of dual beams of hellum and a more

17 Abstracted frow peper resenced at the ASTM Tenth International Symposium on Effects of Rot.jation on Materials, June 3-5, 1980, Savannah, Georgla; to be published in the proceedings.

180. assignment to ORNL from Theoretical Physice Division, AERE, Harwell, England. 
highly damaging heavy ion $(t .8 ., \mathrm{NI})$. In this work we are coacerned with the effect of $h$ un on cavity swelling. In parficular, the effect on the temperature dept...ence of swelling is emphasized. The results can be separated into three parts. (1) Expressicns are derived showing that the primary effect of the helfum is in pressurizirig cavities and that a secondary effect is in altering the microstructural sink strer.gths. (2) Recent experimental data of Packan and Farrell (Sect. 4.2.3, this repurt) or. swelling of a pure stainless steel type alloy under dual nickel and helium-for Dombardment is interprezed and can be explained satisfactorily by the theory. ( 3 ; Model studies for physically rossonable paraneters reveal the importaice of the Heidpa ratio.

The method employed to find the temperature shift due to helium is similar to that developed previously 19 to derive the temperature shift of cavity growth with changez in dose rate, changes in the primary point defect loss processes, and rhanges in microstructural sink strengths. It is based on the fact that the cavity growth rate can be approximately expronaed as the difference betwe n a radiation-driven term and a thermal shrinkage term. We may select the ratio of the second term to the first ters to be any constant $A$, and this value vould define a specific temperature $T_{A}$. If the gas pressur's or sink strength (or dose rate) were changed, then a new temperature could be found where this ratio wou'd again be $A$. These new conditions would define a tempirature shtfe in the temperature $T_{A^{*}}$. The value of $A$ vartes from zero at temperatures near the peak sweling temperature to unity at the swelling cutoff temparature. Thus the analysis here applies to temperatures above the peak awelling temperature up to the upper swelling cutoff temperature. Requiring that the ratio $A$ be retained at two different gas pressures or sink strengtins, we obtain an expression giving the temperature shift, $\Delta T$, in terms of changes in the gas prescure within the cavities and in terms of the changes in microstructural sink strengths. For typical parameter values applicable to stainless steels we obtaln a predicted $\angle T$ of about $50^{\circ} \mathrm{C}$.

Flgure $\rightarrow$. I shows swelling versus temperature for hellum-free and helium-colmplantation bumbardment experiments where the ratio of the gas

19L. K. Mansur. "Correlation of Neutron and Heavy-Ion Damage I.I. The Predlcted iemperature Shift of Swelling with Changes in Radiation Dose Rate," J. Nuol. Mater. 78: 156-60 (1970). 


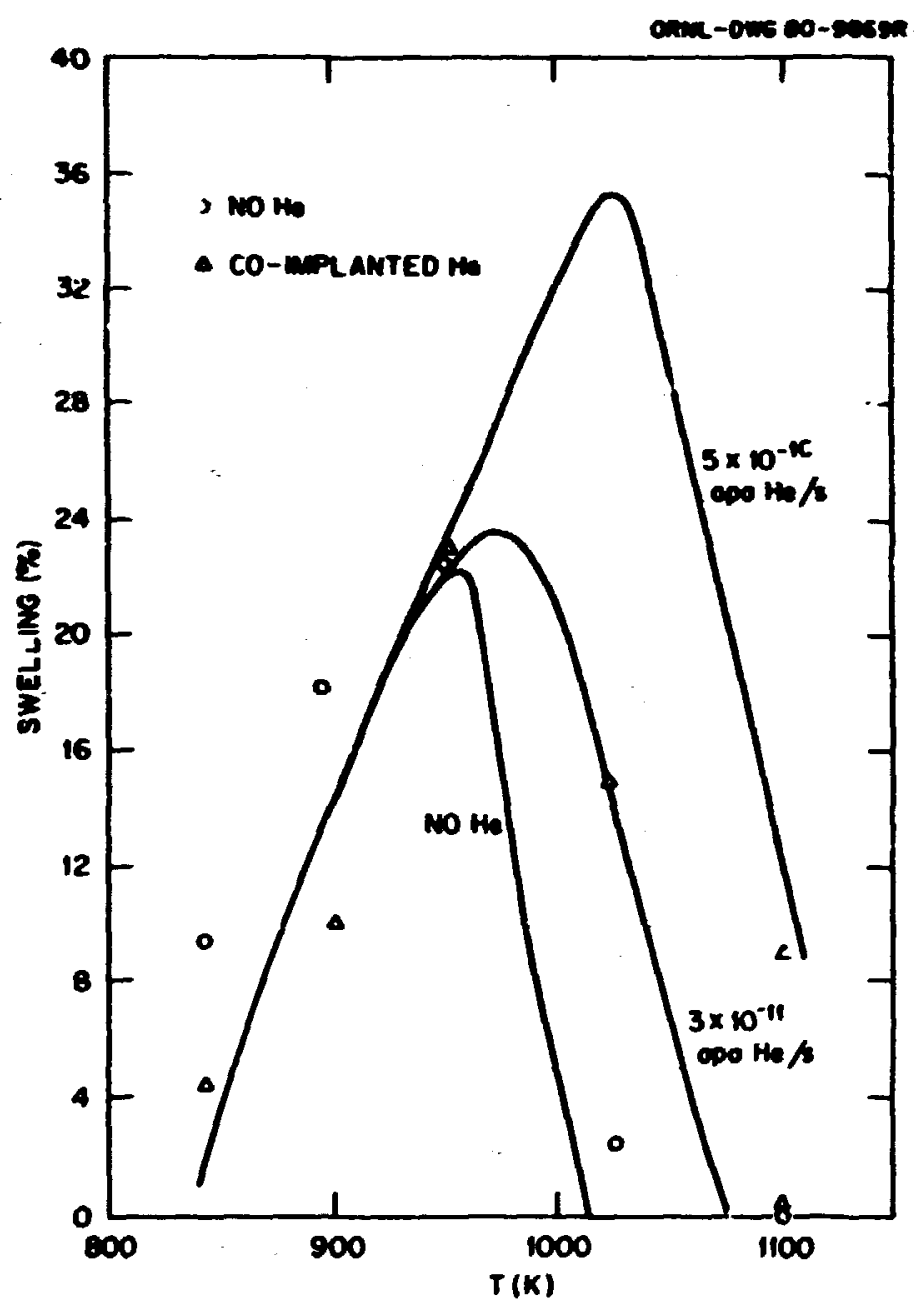

Fig. 4.13. Measured and Calculated Swelling at 70 dpa. Circles represent measurements for no gas. Triangles represent simultaneous bombardment. The lower curve represents the calculated curve fitted to no-gas points. The two upper curves use tile paramecers obtained by this fit to predict the effect of gas. Calculations for $3 \times 10^{-11}$ and $5 \times$ $10^{-10}$ atoms He per atom metal $\mathrm{r}: \mathrm{r}$ second bracket the lata.

to displacement production rate is 20 at. ppm He/dpa. The points represent the experimental measurements, while the curves represent the calculations. The main effects of the gas are to increase the owelling temperature range by 50 to $100^{\circ} \mathrm{C}$ and to raise the peak swelling value. The calculational procedure consis:s of fitting the hellum-free points by varying the rate theory parameters within a physically reasonable range and then attempting to predict the swelling behavior with continuous 
helium coimplantation using this fixed set of parameters. Placing all the generated gas into the cavities, 20 at. ppo He/dpa (or about $10^{-7}$ apa $\mathrm{He} / \mathrm{s}$ ) (apa the means atoms helium per atom of metal), results in much too high a swelling at high temperature. In order to explain the experimental results it is necessary to reduce the rate of gas introduction into cavities to about 0.1 at. ppa He/dpa for doses where the cavitles are below their critical radius. A reasonable basis for this large reduction from the injection rate is the partitioning of gas among the various sinks in the microstructure. 20

The results of gas preinjection experiments were also analyzed. If the cavity number density measured was used in the rate theory cavity growth calcilations, results could also be explained satisfactorily.

After the values of the parameters appearing in the theory had been fixed witn the he'p of the experimental data, the relative effects of varying the amount of helfum implanted simultane usly wich displacement damage were investigatid. Figure 4.14 gives the calculated swelling with temperature for the range 0 to 2 at. ppm He/dpa injected into cavities. The injection rate of helium into the specimen is stmply related to this injection rate into cavities by mulfiplying the cavity injection rate by the ratio of the cavity plus dislocation sink strength to the cavity sink strength. Below about $2 \times 10^{-3}$ at. ppo He/dpa, the hellum has little effect on volf growth. When the ratio is 0.02 , however, the swelling increases substantially at high temperatures. When the ratio is further increased by a factor of 100 a further substantial increase in swelling is seen at high temperature, although the increase per helium atom is not as lare? as for the Initial dose increase.

20.M. H. Yoo and L. K. Mansur, "The Inclusion of Mobile Helium in a Rate Theory Model of Vold Swelling," J. Nuct. Mater. 85 and 86: 571-75 (1979). 


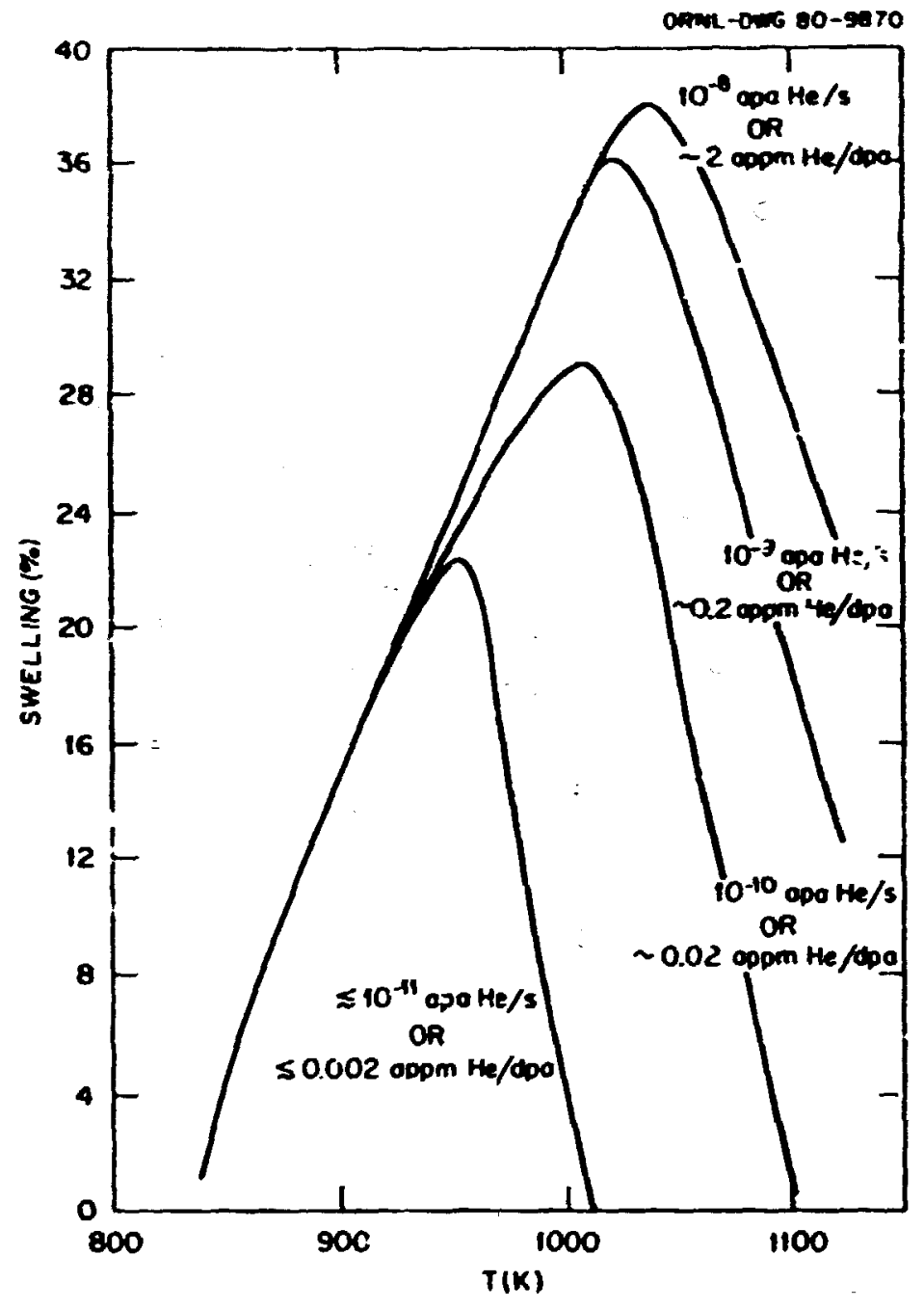

Fig. 4.14. Calculated Swelling at 70 dpa tor a Range of Helium Injection Rates into Cavities. Parameters obtained by fitting the no-gas case are used. Since sink strengths at all injection ratcs have not been measured, the values measured at this injection rate of $10^{-7}$ at. ppo He/dpa into the opecimen were used.

\subsubsection{The Dependence on Cascade S1ze of Polnt Defect Pluctuations Calculated by Using the Cascade Diffusion Theory - L. K. Mansur}

The tine--dependent point defect concentrations at a point in an Irradiated material have been calculated as a function of cascade size. These calculations account for the spatially and temporally discrete nature of point defect production in cascades. The diffusion of defects from each cascade occurring in the material is followed unt1l all the defects are 
absorbed. 21 In principle, the point defect concentration at a point is obtalned by the superposition of the contributions from all cascades that have occurred at earlier times at discrete positions in the material. In calculations using realistic interstitial and vacancy diffusion coefficlents, only the vacancy concentration is composed of the integrated contributions of my decaying cascades. Since interstitial diffusion is so rapid, the interstitial concentration is nearly always the concentration resulting fro:s the most recent cascade within the region of material that can contribute to the concentration.

In the present work the size of cascades, that is, the number of defects in a cascade, was varied fron sizes typical of fast reactor irradiations to that typical of fusion reactor irradiations. The spatially averaged Iisplacement ratc was kept constant at $10^{-6} \mathrm{dpa} / \mathrm{s}$ since dose rates in both types of reactors are expected to be near this value. Thus the fission reactor case corresponds to more cascades of swaller size while the fusion reactor case corresponds to fewer cascades of larger size (although these way be composed of subcascades).

Figure 4.15 shows the vacancy concentrations corresponding to cascades induced by primary knock-on acoms of damage energies 10, 50, and $250 \mathrm{keV}$. The number of defects per cascade was computed by the IAEA recomended relacion, $N=\beta E_{\mathrm{dad}} / 2 E_{d}$, with $\beta=0.8$ and $E_{d}=40 \mathrm{eV}$. To account in a rough way for in-cascade recombination the number of defects produced was reduced to $20 \%$ of th- value given by the equation above and used as the cascade strength in $t$. rource term for the present calculations. The material and defect parameters are given in Ref. (21).

As seen from Pig. 4.15, the larger and less frequent the cascades, the lower is the "background" level of vacancy concentration and the wore jagged is the concentration versus time profile. The background is contributed manly by the wore numerous cascades at large distances, and the spikes are contributed mainly by the fewer nearby cascades. The interstitial concentration 18 nearly always zero, punctuated by very large

2l L. K. Mansur, W. A. Coghlan, and A. D. Brallsford, "Swelling with Inhomogeneous Point Defect Production - A Cascade Diffusion Theory," $J$. Nucl. Nater. 85 and 86: 591-95 (1979). 

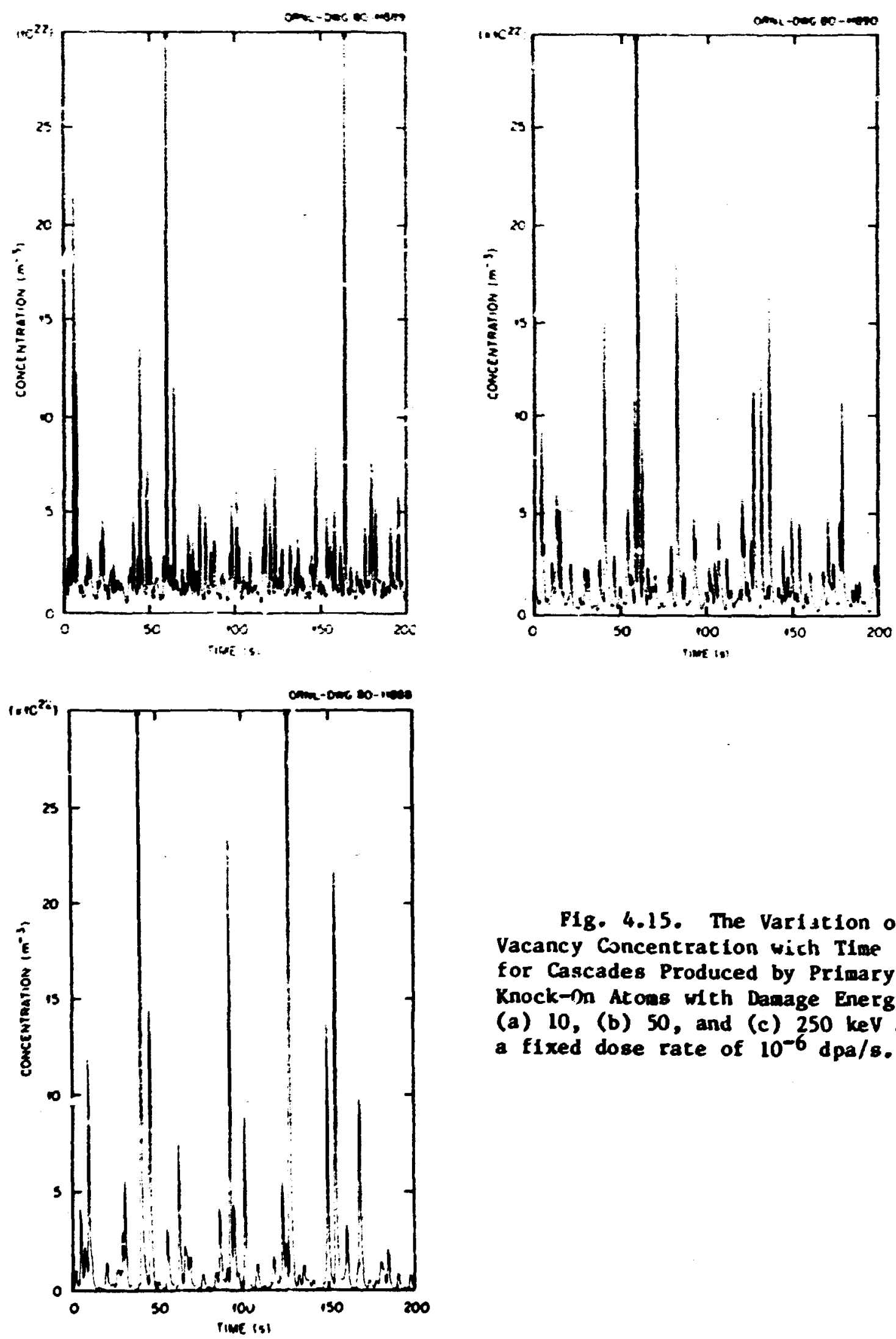

FIg. 4.15. The Variation of Vacancy Concentration wich Time for Cascades Produced by Primary Knock $\rightarrow n$ Atons with Danage Energy (a) 10 , (b) 50 , and (c) $250 \mathrm{keV}$ at a fixed dose rate of $10^{-6} \mathrm{dpa} / \mathrm{s}$. 
spires with instantaneous concentrat tons exceeding $10^{19} / \mathrm{a}^{3}$, whicil decay in less than 0.5 us. On che average these spikes are separated in time by 22, 110, and $550 \mathrm{~ms}$, respectively, for cascades of 10, 50, and $250 \mathrm{keV}$ and a sink strength of $i \times 10^{15 / m^{2}}$.

The significance of the present work is that

1. quanticative descriptions of fluctuations in point déect concentrations have now been extended to explore the inportant paraweter cascade strength;

2. Subsequent efforts to characterize irradiation creep and cavity n.tcleation in the presence of point defect concentration fluctuations should stress fusion reactor conditions since the fluctuations are wo pronounced in that case.

\subsection{FACIL.ITY DF.VELOPHENT AND NLCLEAR MICROANALYSIS}

\subsubsection{Nuclear Microanalysis as a Probe of Inpurity-Defect Interactions ${ }^{22}$}

The techninue of nuclear microanalysis using an fon bean probe is a nondestructive ' thod of measuring the quantity aid depth distribution of Impurity atoms in the nea-surface reglons of the target aterial. It can measure changes in the original pssition and shape of the impurity profile with sespect tu time, temperature, displacive irradiation, and other impurities. It, therefore, yields information on kinetics of aigration of the impurity on a small scale. It Is especially useful for the lighter elements such as $\mathrm{C}, \mathrm{H}, \mathrm{He}, \mathrm{O}$, and $\mathrm{N}$, which are of ten difficult to follow on a afcroscopic scale by other analytical techniques. These elements are known to be Intimately involved in nucleation of the radiation dasage microstructure.

Hith nuclear microanalysis, vacancles and interstitial atoms are created by atomic displacements by the probing beaw and by any Ion bean used to implant a selected impurity. This may be a drawbsck for some

22Abstracted from paper presented at Symposium in Advanced Techniques for the Characterization of Microstructures, 109th AIME Annual Meeting, Las Vegas, Nevada, Pebruary 24-28, 1980; to be published in proceedingz. 
applications, but for radiation damage studies it can be used co advantage to deteraine important fundamental pardseters. Procedures are out lined for exracting impurity diffusion coefficients, inpurity-point-defect binding energies, and trap generactor coeffictents of hravy ions used to create displacement damage. Examples involving the impurticies deuterfun and helium in austenitic stainless steels and nickel are described. Prelinit :ry values are given for the bulk diffusion coefficient of deuterica in austente at $25^{\circ} \mathrm{C}\left(1.4 \times 10^{-16} \mathrm{~m}^{2} / \mathrm{s}\right)$, the binding energites of deuteriun with point defects an austenite and of $3_{\text {He }}$ in nickel $(0.33$ and $2.1 \mathrm{eV}$, respect(vely), and a room-temperature trap generation coefficient for deuterium in nickel-ion-bcabarded austenite of about 15 per incident nickel Ion.

\subsubsection{Ari Ion-bean Technique for the Measurenent of Deurgriue Diffusion Coefficlents $^{23}-$ M. B. Lewis and K. Farrell}

The method of nucleat aicroanalysis using the reaction $p(d, p) t$ has been used to measure profiles of deuterfu in austentic steels. Targets were prepared by electrocharging (in deuterated solutions), electropolfshing, and ion inplantation. The electrucharged speciwens absorbed deuceriun up to concentrations of $40 \mathrm{at}$. $z$. By masuring the time release of deuterium from these specinens, diftusion behavior of deuterium in type 310 stainless steel was deduced. The specimens that were elertropoIIshed in deuterated solutions were subsequently measured to have less than 100 at. ppo bulk deuterium and less than one monolayer of surface deuterium. When the electropolishing was carried out at $223 \mathrm{~K}$ the values were even less: <0.1 monolayer and <10 at ppa.

When the deuterium was introduced by Ion implantation, the normal bul: diffusion of the Iaplanted gas was not observed. Instead the gas appeared to be crapped near the site of Implantation. Subsequent thermal aging ard remeasuring the deuterium concentration profiles found that wost of the gas detrapped near $400 \mathrm{~K}$. A computer program utllizing the differential equation colver GEAR was witcen and applied wo diffuston and

23abseract of paper accepted for publication in Applted Phystce Lettere. 
trapping in the above type of experiments. In this way a deuterfun-defect bindiag energy in type 316 stainless steel has been deduced.

4.4.3 Carbon Migration and Contamination Studies - M. B. Lewis, K. Farrell, N. H. Packan, and E. Kenlik

The examination of type 316 stainless steel samples that had been implanted with titaniun and subsequently ion bmabarded at $600^{\circ} \mathrm{C}$ showed the formation of titanium carbide in the peak damage region. This suggests the presence of excessive carbon in the bulk of the specimen. For this reason, ${ }^{12} \mathrm{C}$ cencentration profiles were measured by the ${ }^{12} \mathrm{C}(1, p)^{13} \mathrm{C}$ reacton technique. Even carefully polished specinens contained about 10 monolayers equivalent of carbon on their surfaces. Yeasurements of samples that had been Ion bombarded to levels of 1 and 70 or 100 dpa were also made. All measurements indicate a carbon concentration gradient that peaks at the specinen surface and decreases with increasing depth. All measurements indicate that the longer or higher dpa runs show greatly enhanced carbon concentrat ion to depths of at least 1 im below the specimen surface. Table 4.4 sumarizes some of the concentrations at the peak damage depch, $0.7 \mu \mathrm{m}$.

In future experiments we plan to examine to what extent the level of carbon after bombardwent is determined by (1) the presence of surface carbon, (2) the value of the initial bult carbon, or (3) the finite pressure of carbun-containing gases in the target chamber. Although the present data are consistent with (1) and (2), the significance of (3) has not yet been determined.

Table 4.4. Carbon Concentrations Found at a 0.7 fm Depth in Ion-Bombarded Alloys

\begin{tabular}{ccccc}
\hline \multirow{2}{*}{ Alloy } & \multicolumn{4}{c}{ Carbon Concentration, at, ppm, at Each Dose Level } \\
\cline { 2 - 5 } & Unbombarded & $1 \mathrm{dpa}$ & $70 \mathrm{dpa}$ & $100 \mathrm{dpa}$ \\
\hline 316 stalnless & $500 \pm 100$ & $1100 \pm 200$ & $2600 \pm 500$ & \\
N1-25\% Mo & $60 \pm 20$ & $70 \pm 20$ & & $600 \pm 100$ \\
\hline
\end{tabular}




\subsubsection{Bean Shitters and Computer ñutonation of Target Chamber ileasurewents - M. B. Lewis and R. A. Buh?}

Shutter systems have been developed to interrupt bot the nickel and helium ion beams synchronously during dual-ion bombardments, so as to provide an interaftent irradiation environment for planned swelling experiments. Presently available cycle tines range from tenths of seconds up to arbitarily long tines.

Computer control has been implemented for periodically inserting a nine-hole Faraday cup array to intercept the fon beans and to record the signils so as to provide information on beam uniformity during interrupted or steady bombardments. The system uses a Tennecomp TP-50 minfcomputer interfaced to an external current integrator and servodevice. The ion bean profile is measured in a $3 \times 3$ matrix. The computer also determines the correct fluence for the three possible fluences in a single bombardment. Work is in progress to interface specimen temperature and target chamber vacuum measurement to the computer. 


$$
204
$$




\section{ENGINEERINY MATERIALS}

\subsection{EROSION AND MEAR OF CERAMICS - C. S. Yust}

The characteristic process in erosion is impact of a solid surface by a streas of particulate atter, either liquid or solid. At each point of imact localized damage way be introduced into the solid surface. The eraston process itself is the curculative effect of any collisions of particles with the surface. This study has been concerned with local damage in ceranics as a result of particle impact. We have demonstrated by siagle-particle imact tests on alunina that very high-strain-rate shear processes ay occul at the specimen surface and that extensive plastic defornation wy occur beneath the impact site. We have devoted sone effort to analysis of anotier very high-strain-rate deformation process in alunina, explosive compaction, to extend our knowledge of high-strain-rate effects in this acerial. The sinflaricy in appearance between dislocation arrays at some single particle impact sites ah.d in the explosive!y compacted alumina suggested that this comparison could be useful. The analysis of the explosively compacted alunina is now complete and has resulted in publications describing various aspects of the damage introduced under such conditions.

In general, the explosfve compaction of alumina yields a lattice filled with slightly aisoriented layers of mertal. The regions of msorientation are bounded by dislocation arrays lying on the basal plane of the hexagonal alunina lattice, spaced irregularly at distances in the range from 0.2 to $0.4 \mathrm{~m}$. In wany cases the dislocations are present as a network. Basal plane twinning is also comeon, and wost of the twin boundarfes contain dislocations. The mechaniss of dislocation generation under the shock conditions experienced in explosive conpaction are not well understood, but theories of dislocation generation under such conditions have been proposed. The dislocation arrays observed in this work have some features suggestive of the operation of the shock generation theories and some indicative of dislocation generation by wore convent fonit : ans. 
Sore of the dislocation damage at particle inpact sites in alunina is in the form of networks siallar in appearance to those introduced into a lumin- during explosive compaction. In both instances, the dislocations have Burgers vectors of the type (1/3) $11 \overline{2} 0$, the comor Burgers vector for basal plane glide. Further det lls are prisented in the papers abstracted below.

\subsubsection{High-Strain-Rate Deformation}
5.1.1.1 Explosive Compaction and Microstructural Analysis of AlN, $A$ rorphous $\mathrm{Si}_{3} \mathrm{H}_{4}$, Boron, and $\mathrm{Al}_{2} \mathrm{O}_{3}$ Ceramics 1 - C. L. Hoenig ${ }^{2}$ and C. S. Yust

Ceranic powders were explosively compacted to high density at pressures up to $7 \mathrm{CPa}$. Microstructures of tire compacted and annealed ceramics were exanined by transaission and scanning electron microscopy and wcrohardness techriques. Lattice damage is evident in the form of dislocations and planar faults. Interparticle bonding and melting are a lso apparent.

\subsubsection{Observation of Dislocations and Twins in Explosively Conpacted Alumina ${ }^{3}$ - C. S. Yust and L. A. Harrís}

The microstructure at the half-radius position of a polycrystaline a lumina rod formed by explosive compaction has been studied by cransmission election microscopy. The as-compacted lattice is composed of ulsoriented bands aligned predominantly in one direction. Such bands way correspond to frequently observed shock lamellae. The land edges are defined by dislocation arrays lying on the basal planes of the hexagonal

\footnotetext{
I Subattced to Joumal of the American Ceramic Sosiety.

2Lawrence Iivernore Laboratory.

${ }^{3}$ Subuitted for Inclusion in the International conference on the Metallurgical Effects of High Strain-Rate Deformation and Pabrication, Albuquerque, New Hexico, June 22-26, 1980.
} 
alumina lattice. The dislocations have Burgers vectors of the types (1120) and $(10: 0)$, which are the Eurgers vectors of slip dislocations in the hasal plane. Basal plane twinning is also observed, and the twin boundartes contain interfa :1al dislocatiuns. While dislocation generation occurs primarily on basa 1 planes, sjee dislocation activicy is also noted on prisa, $\{1 \overline{1} 00\}$, an $j$ on thombohedral, $\{\overline{1} 01\}$, planes. Nonbasal twinning, however, has not been detacted. The lattice damage is discussad in terus of possible dislocation and twituing mechanisus.

\subsubsection{Errsion of Aluaina - C. S. Yust}

Iavestigation of single , jarticle impact camage in single-crystal alumina is continuing. In these experiments, limited numbers of particles of SiC are accelerated in an air pressure gun onto small alumina single-crystal samples. Tt? alumina sample is then thinned for cransmission electron microscopy (TEM) by removal of material from the beck surface. The TEM investigation permits the study of subsurface damage assoclated with the incividual impact sites. In alumina the damage has been found to include both plastfc deforsation and fracture. The plastic deformation accurs orincipally on basal planes and involves dislocations having a Burgers vector of $(1 / 3)(11 \overline{2} 0)$. A series of experiments is currenty in progress to assess the variation of the damage with erosion conditions. The test matix is outlined in Table 5.1. To date, tests have been performed at room temperature at a $20^{\circ}$ angle of impingement and $90 \mathrm{~m} / \mathrm{s}$ particle velocity, wh particles 100 and $240 \mathrm{~mm}$ in diameter. The damage introducei by these tests is under study.

\subsection{FUNDAMEiTtals OF WELding AND JOINING - S. A. David and J. M. Vitek}

The purpose of this program is to understand the development of the structure, stability, and properties of austentic stainless steel weld metal. The program has two mafor parts relating to the study of (1) weld pool solidification and (2) phase stability.

The weld pool solidification study is directed toward an understanding and modeling of the basic solldification ctaracteristics 
Table 5.1 Test Matrix for Alumina Bingle-Parícle Impact Tests

\begin{tabular}{|c|c|c|c|c|c|c|c|}
\hline \multirow{3}{*}{$\begin{array}{l}\text { Part icle } \\
\text { D'aneter } \\
\quad(\boldsymbol{\mu} \text { ) }\end{array}$} & \multirow{3}{*}{$\begin{array}{c}\text { Particle } \\
\text { Velocity } \\
\text { (r./s) }\end{array}$} & \multicolumn{6}{|c|}{$\begin{array}{l}\text { Tests for Each Temperature } \\
\text { and Impingement Angle }\end{array}$} \\
\hline & & \multicolumn{2}{|c|}{ Room Temp } & \multicolumn{2}{|c|}{$500^{\circ} \mathrm{C}$} & \multicolumn{2}{|c|}{$1000^{\circ} \mathrm{C}$} \\
\hline & & $20^{\circ}$ & $90^{\circ}$ & $20^{\circ}$ & $90^{\circ}$ & $20^{\circ}$ & $90^{\circ}$ \\
\hline \multirow[t]{2}{*}{240} & 65 & & & $x$ & & $\mathbf{x}$ & \\
\hline & 90 & $\begin{array}{l}\text { ER-113 } \\
\text { ER-116 }\end{array}$ & $x$ & ER-114 & $x$ & $x$ & $\mathbf{x}$ \\
\hline \multirow[t]{2}{*}{100} & 65 & & & $x$ & & $x$ & \\
\hline & 90 & ER-115 & $x$ & $x$ & & $x$ & $x$ \\
\hline \multirow[t]{2}{*}{35} & 65 & & & $x$ & & & \\
\hline & 90 & & & $x$ & & & \\
\hline
\end{tabular}

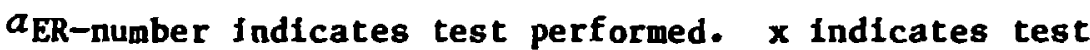
condit:on presently planned as an experiment.

of austeritfic etainless steel weld metal orer the normal range of welding conditions for a ressonatle variation in alloy content and toward forming a base for developing weld metal structure with desirable properties.

The phase stability study is ifrected toward, an understanding of the stability of ferrite, austenite, and second phases and to characterize and mojel the sequences of precification in the weld metal. Significant chan'scs occur on agfing at elevated temperatures. Ferrite transforms to 81 gma, carbides, nitrides, and other interwetallic phases.

The program described as above should lead to the following: better Insignt into the fundamentals of ferrite formation and its statility and control, better understanding of the role of ferrite in preventing hot cracking during welding, and finally a better correlation between weld metal structure and properties. 


\subsubsection{A Study of Ferrite Morpholngy in Austenitic Stainless Steel Welds - S. A. David}

A certain asount of ferrite $(\delta)$ is present in austenitic stainless steel welds to prevent hot cracking. This ferrite bas been found to influence in various ways the strength and corrosion behavisr of welds. In particular, the $r-\delta$ interfacial area and, hence, the morphology of ferrite has been found to be a critical factor in the sensitization behavior of austenitic stainless steel welds containing duplex structures. Ferrite ay be present in various amounts and in different morpholngies within the weld wetal depending on the welding process and welding parameters.

An investigation to identify and classify distinct ferrite worphologies into varfous $L$ 'pes has enabled us to identify four distinct types of ferrite wrphology if type 308 stainless steel weld metal. They are: (1) vermicular, (2) lacy, (3) acicular, and (4) globular and are shown in Fig. 5.1. For the various observed morphologies, the ferrile number varied from 5 to 15. Factors such as composition, solute segragation, and thermal history have been found to Influence the ferrite morphology. An earlier stuay showed that most of the ferrite observed in duplex stainless steel welds may be identified as the following:

1. residual primary ferrite resulting from incomplete $\delta+\gamma$ transformation during solidiflcation or

2. residual ferrite after Widmanstäten austenite precipitation in primary ferrite.

These modes of ferrite formation can be used to explain the abovedescribed ferrite morphologies in austenitic stainless steel welds.

\subsubsection{Ferrite Content Variations in Austenit 1c Stainless Steel Mult1pass Welds - S. A. David}

Variations in ferrite content within a wultipass weld are commonly observed A.l austentic stainless steel welds. Such variations are bound 

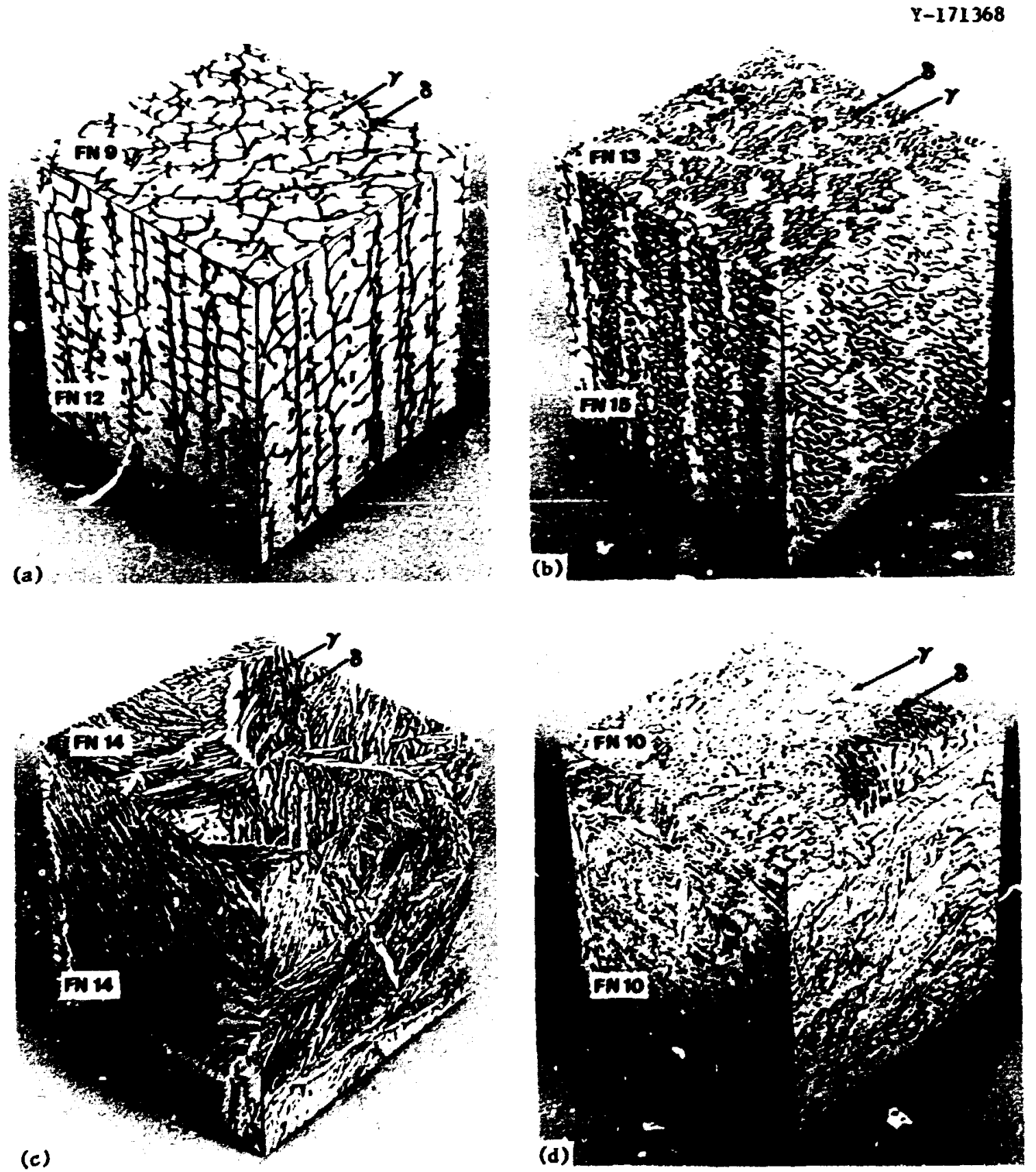

F1g. 5.1. Three-Dimensional Composite Photomicrographs of Various Perrite Morphologles in a Type 308 Stainless Steel Multipass Weld. (a) Type I, vermIcular. (b) Type II, lacy. (c) Type III, actcular. (d) Type IV, globular. 
to influence the mechanical and corrosion behavior of veld metal. The variation in ferrite content has often been attributed to the inadequacies of the present ferrite masuring devices. In addition to the problens assoctated with the accuracy of ferrit. masurement techniques, a muber of other factors that contibute to the observed variations in ferrite content within the weld etal have been identifted. They are (1) composition, (2) ferrite orphology, (3) dissolution and transformcion of ferrite due to thenal cycles, and (4) cooling rates. The extent of their influence m ferrite content within the weld metal is being investigated in great detail.

\subsubsection{Structure of Austenitic Stainless Steel Laser Melds - S. A. David}

During a recent investigation on austenitic stainless steel weld metal conducted at ORML, various factors were found to influence the amount of ferrite in duplex austenitic stainless steel weld metal. They are (1) composition, (2) ferrite morphology, (3) dissolution and transformation of ferrite due to theraal cycles, and (4) cooling rates.

The influence of one of the above factors, namely weld metal cooling rates, on the ferrite content and weldability was investigated by making autogenous bead-on-plate welds at 13,25 , and $63 \mathrm{ma} / \mathrm{s}$ on a type 308 stainless steel weld metal pad with approximately 10 vel I ferrite. The welds were made by using a wltikilowatt high-power laser system. Microstructural analyzes of these welds showed a wide variecy of features. The weld made at $13 \mathrm{~mm} / \mathrm{s}$ contained microstructures ranging from nearly $100 \%$ austenitic at the root of the weld to ferrite plus austenite duplex structure at the crown of the weld. However, nearly $100 \%$ austenitic weld metal structures were obtained in the welds made at 25 and $63 \mathrm{~mm} / \mathrm{s}$. In spite of the very low level of ferrite in the weld metal, no weld metal cracking was observed in any of these welds. The fully austenitic welds contained an excessive number of microtwins. 
Further nicrostructural analyses by transuission and scanning trans-ission electron wiczoscopy are under way to characterize and understand the origin of the above microstructures and their stability.

5.? STUdies In NONDESTRUCT IVE Evaluation - W. A. Simpson and C. v. Dodd

Elastic waves have often ben used to investigate nondestructively the internal structure of materials. Because of the lack of understanding of the basic phenomena involved, however, the results of such studies have often been qualitative and highly subjective. This is particularly true of the case in which the werial under investigation is composed of two dissinilar, possibly anisotropic components hiving a well-defined Interface across which the interrogating energy wst propagate. Therefore, we are studying such a systen to deternine that effect the interface has on the characterization of flaws in eicher component.

We previously obtained the solution for propagation between two dissimilar isotropic media in contact. A computer progran was written to allow several binary systems of interest to be studied. The solution was then extended to the case of an isotropic material in contact with an arbitrary anisotropic one. The anisotropic component principal axis my have an arbitrary orientation with respect to the interface. A computta program is being witten te päuvide quantitative results for several systems of interest.

A diffusion-bonded sample containing two dissimilar wetals has been obtained for concurrent experimental studies. Unfertunately, for such 8 amples the choice of possible components is extremely limited; the present sample is composed of titantus bonded to a carbon steel, neither of which is macroscopically anisotropic. Although the sample will be very useful for studying the effects of propagation across an interface on flaw characterization, efforts are continilng to obtain a sample containing an anisotroplc component.

Analytical studles were begun on scattering of elastic waves frow selected flaw shapes. Of principal interest is the crack or cracklike scatterer, since such shapes are most likely to prejudice the use of the 
host aterial. A computer progran is being developed for the analytical solution obtained by Mave 4 for diffraction of elastic waves by a half plane. An atcenpt wil be ade to extend the solution to anisotropic nedia.

In wany materials electrical condu ttivity measurewents can be used to deternine other ateria! properties such as tiveral conductivity, alloy centent, state of heat treatments, and hardness. This electrical conductivity can be easily masured by eldy-curtent techniques but until now had to be referted back to dc condustivity standards to obtain an absolute masurement.

By using our eddy-current theory 5 and computer prograns, 6 we have analyzed the errors present in the ac measurement to reduce thew tn a minimu. The eddy-current syst 2 used consisted of a driving coll that transitted an alternating signal through a flat conducting plate to a detector coll. The magnitude and phase of the signal is a function of the dimensions of the coll and conductor, the driving frequency, and the conductivity of the plate. By accurate'y controlling these dimensions we have been able to make an accurate absolute ac conductivity measurement. Measurements have been made from a set of plates whose resistivities were compared with secondary standards, as shown in Table 5.2.

The secondary dc standards were only specified to within 17 accuracy, and all ac measurements were within this lint, with an average absolute error of $0.46 z$.

The error is being reduced further by small improvements in the exptrimental setup, and a set of secondary dc standards that can be measured directly has been ordered.

4A. W. Maue, "The Diffraction of Elastic Haves at the Half Plane," 2. congew. Math. Mech. 33: 1-10 (1953).

${ }^{5}$ C. V. Dodd, W. E. Deeds, J. W. Luquire, and W. G. Spoeri, Some RddyCument Problems and Their Integral Solutions, ORNL-4384 (April 1969).

6W. E. Deeds, C. V. Dodd, and G. W. Scott, Computem-Aided Design of Layered Conductors with Multiple Property Variations, ORNL/TM-6856 (October 1979) 
Table 5.2 Prelininary Heasurements of $A C$ Electrical Resistivity of Sanples

Compared with Secundary

DC Standards

\begin{tabular}{ccc}
\hline $\begin{array}{c}\text { Sample } \\
\text { Thickness } \\
\text { (nom) }\end{array}$ & $\begin{array}{c}\text { Absolute AC } \\
\text { Resistivity } \\
\text { (mo m) }\end{array}$ & $\begin{array}{c}\text { Error Relative } \\
\text { to DC Standards } \\
(7)\end{array}$ \\
\hline 3.063 & 60.24 & -0.10 \\
3.173 & 39.11 & 0.78 \\
3.414 & 50.25 & -0.09 \\
3.115 & 50.35 & -0.52 \\
3.139 & 60.67 & -0.85 \\
4.205 & 38.15 & -0.14 \\
4.334 & 37.84 & 0.38 \\
3.051 & 39.13 & 0.81 \\
\hline
\end{tabular}




\section{THE HIGH TEMPERTURE MTERIALS LABORATORY}

\section{V. Cathcart}

We have wintinued our efforts to establish a High Temperature Materials Laboratory (HML). This action is wotivated by the recognition that high-terperature aterials problems serfously linit the efficiency, rellabilicy, and, In sone instances, the feastblltcy of advanced energy generating systews. The revere corrosion problems being encountered in certain coal-conversion systems and the need for better hard and corrosion-resistant valve-liner aterials in chese systens are examples of some of the sorts of problews that aust be solved.

High-temperature phenomena of this kind are inherently complex and are wost efficiently resolved by a wutidisciplinary staff working cooperatively in a centralized facility. Consequently, we have proposed that the Office of Basic Energy Sclences of DOE fund the construction of an HTM at Oak Ridge. Because of budgetary constraints we plan a reduction In size of the HIML from about 7000 to about $4700 \mathrm{~m}^{2}(80,000$ to $\left.50,000 \mathrm{ft}^{2}\right)$. The total staff size ( -75 professionals) will remain unchanged, although some zesearch efforts will have to be housed in an adjacent building. As before, the staff expertise will encompass six functlonal re.earch areas: Environmental Interactions, High-Temperature Chewistry, Physical Properties, Mechanical Behavior, Structural Characterization, and Materials Synthests and Preparation. Assuming funding in FY 1982, the HTML should ie ready for occupancy in late 1985.

In anticipation of the construction of the HTML, we have established a High Temperature Materials Program, and the selection of a director for the HMI is in progress. The Initial staff, whlch was recrulted from existing groups in the Metals and Cerazics, Solid State, Chemistry, and Chemlcal Technology DIvisions, consists of about 55 full-t Ime employees, the large maftey of whom are professionals. The Initial program conslsts of both applied and basic research projects, reflecting our tellef that interaction between baslc and applied workers is essential in the HML. Applied projects Include an Investigation of corrosion In a fluldized bed combustor for coal and studies dealing with the evaluation 
and developaent of structual ceranics (principally silicon carbide and $\mathrm{Al}_{2} \mathbf{O}_{3}$ ) for use in heat exihangers. Basic studies are perforwed in all six of the functional research areas mentioned above, and some of these investigations (e.g., studies of sulfidation kinetics of iron and transport processes in FeS) are specifically designed to parallel the applied efforts.

We consider interaction with the university and industrial research comunity to be an essential feature of the effective operation of the HML; when fully staffed, we anticipate an active users' progran with 10 to 15 full-tine equivalent participants per year. He have now initiated such a progran, with personnel from the University of virginia and Vanderblit Unfuersity spending time at ORM to perform research utilizing the HML's I-MV electron afcroscope and our electron aicroscopy facilities as a part of the SHaRE progran. 


\section{USERS GROUPS}

\section{J. Mchargue}

Interactions with thr: scientific comanity in the United States and abroad have always been an essential part of our p ogran. In recent years users groups have been formed to ensure that the unique facilities of the Materials Science Program are freely available to scientists from universities and other research laboratories.

\section{I SHARED RESEARCH EQUIPMENT PROGRAM (SHaRE) - R. W. Catpenter}

The last year was a productive period for the SHaRE program. It began in December 1978 as a collaborative research venture between the research staff of the Materials Sclence Section of the Metals and Ceramics Division and staff memers of several southeastern universities and their students. The progran facilitates research in areas pertinent to the DOE mission and gives SHaRE members external to ORNL access to research equipment, especially electron microscope equipment, much wore sophisticated than that available at their home laboratories. Research involving Auger surface analysis, Ion Implantation, and nuclear microanalysis is also part of the SHaRE program.

The inftial expenses of the SHaRE program were borne by the Materials Sclence Section, and the assistance required for fanillarization of SHaRE visitors with ORNL equipment was furnished by ORNL research staff memers. During FY 1980 the Division of Materials Sciences, Office of Basic Energy Sclences, provided funds through the Cak Ridge Assoctated Untversities (ORAU) to support the SHaRE activity directly. Progras funds are used for travel grants and local living expenses of SHaRE program members while at ORNL. SHaRe program pollcy is defined by a steering comblttee, whose current wembership 18:

Willam Peiling, Assistant Director, ORAU

R. W. Carpenter, ORNL

C. L. White, ORNL 
J. J. Wert, Professor and Chairman, Department of Mechanical and Materials Engineering, Vanderbilt liniversity, Nashville, Tennessee

E. A. Starke, Professor and Director, School of Chemistry and Metallurgy, Ceorgia Institste of Technology, At lanta, Georgia

An electron microscope engineer, G. L. Lehman, became a mber of the SHaRE prograw staff this year. His responsibility is to familiarize SHaRE wembers with the electron microscope and computer equipment a vailable to the SHaRE program and to participate in SHaRE research when the required microscope or computer operations make this appropriate.

Eight research projects were active during the first year of the prograw. The 13 research programs active at present are listed below:

B. R. Livesay, Georgia Institute of Technology, with E. A. Kenik: Hydrogen Storage Alloy Investigations.

K. R. Lawless, Unitersity of Virginia, with E. A. Kenik and R. W. Carpenter: HVEM Imaging: In Situ Oxidation of Vanadium, Vanadium-Tftaníum.

R. B. Benson, Jr., North Carolina State, with J. Bentley and R. W. Carpenter: Defect Analysis in Ion Implanted CaAs.

P. J. Reucroft, University of Kentucky, with J. Bentley and E. A. Kenik: Chemical and Physical Characterization of Dispersed Metal Particles in Porous :Ledia.

J. J. Wert, Vanderbilt University, with R. W. Carpenter: The Role of Structure in the Wear Process.

R. Sisson, VPI and State University, with M. B. Lewis: Nuclear Microanalysis of Hydrogen in Oxides Formed by Steam Oxidacion.

E. Schulson, Dartmouth University, with C. T. Liu and C. L. White: Collaborative Experiments on the Brittle to Ductile Transicion in Polycrystalline $\mathrm{Ni}_{3} \mathrm{Al}$.

T. H. Sanders, Jr., Georgia Institute of Technology with C. L. White: Scanning Auger Analysis of Al-Li Alloys.

D. R. Clarke, Rockwell International, Thousand Daks, Callfornia, with R. W. Carpenter: Elemental Microana?ysis of the Intergranular Phase in Silicon Nitride Alloys. 
H. Anderson, University of Missouri-Rolla, with R. W. Carpenter and J. Bentley: Lattice Inaging Studies of Donor Doped Transition Metal Oxides.

D. Northwood, University of Windsor, Canada, with E. A. Kenik: HVEM Studies of Hydrogen and Hydrides in Zirconium and Its Alloys.

A. Rrawitz, University of Missouri-Columbia, with E. A. Renik: Deforeation Substructures in Cemented Carbide Drill Bits.

J. J. Hren, University of Florida, with J. Bentley, K. Farrel, and R. W. Carpenter: High-Resolution Studies in Radiation Effects, Image Similat fon Calculations.

During the last year the SHaRE progran was extended to include industrial participation and participation of universities and laboratorfes beyond the Southeast.

Current results from research on some of the programs listed above a re described in Sect. 1.7 of this report.

Guests outside the ShaRE progran who have conducted research on this equipment during 1979-1980 include:

J. B. Clark, University of Missouri-Rolla

R. J. Bayuzick, Vanderbilt University

D. J. Bradley, Montana College of Mineral Science and Technology

H. C. Eaton, Tennessee Technological Unf versity

S. Mehta, Lowa State University

M. J. Coringe, Oxford University

L. L. Horton, University of Virginia

\subsection{SMULL-ANGLE SCATTERING RESEARCH - R. W. Hendricks}

In January 1978 a progran devoted to users was inftlated under an Interagency agreement between DOE and NSF. A Natlonal Small-Angle Scattering Research center was established, and construction of a new sall-angle neutron scattering facility at HFIR was started. As a part of this effort $30 \%$ of the bean time of the Small-Angle $X$-hay Scattering Pacilfty was reserved for users in this program. Ocher users or collaborators cone from the Materials Sclence Program at ORNL or other Inetallations. 
Users during 1979-1980 who were not NSF Center guests were:

S. Suehiro, University of Massachusetts and Kyoto University

P. Young, University of Massachusetts

J. H. Schultz, Unf versity of Delaware

K. M. Cupte, University of Deiaware

G. L. Lehaan, Universicy of Florida

P. D. LaBarbe, Uni versity of Montpellier (France)

J. Petermann, Universicy of Saarlandes, Saarbracken, FKG

\section{T.3 ORML-ORA' SYNCHROTRON LIGHT SOURCE USERS GROUP - C. J. Sparks, JT.}

The $x$-ray studies contained in the Macerials Science Progran as well as other prograes at ORN have ade a jor comitment to the use of synchrotron $x$-ray sources. Our curzent research, which uses the Stanford Synchrotron, is described in Sezt. 1.6 of this report.

Gak Ridge National Laboratory has continued work coward the design and construction of the egufpment needed to instrument one of the beam lines that will be available once the kactonal Synchrotron Light Source (NSLS) is completed at Brookhaven National Laboratory. In connection with this activity, G. E. Ice was added to our staff.

To involve the university community in planning the facility as well as its use, a users group has been iormed. It consists of

C. J. Sparks, Metals and Ceramics Division, ORNL, Chairman;

B. C. Larson, Solid State Division, ORNL;

A. H. Narten, Chemistry Division, ORNL;

S. C. Moss, University of Houston;

R. A. Young, Ceorgia Institute of Technology; and

R. J. DeAngelis, University of Kentucky.

Thirteen university scientists and six ORNL staff members (frow three divisions) met in November 1979 to develop research plans for using the NSLS. Another workling-planning meeting will be held in the sumer of 1980.

During FY 1980, the Division of Materials Sciences, Office of Basic Energy Sclences, provided funds through Oak Ridge Associated 
Universi-ies (ORAU) to support the users' participation. With this support, A. Habenschuss was added to che staff to act as an interface betweel, the university comanity and ORNI.

The current embers of :he ORiil. Synchrotror: X-Ray Source Users Group and their fields of interesi are listed below.

R. A. Young, Georgia Institute of Technology, School of Physics and Engineering - Phase Transformations, Structures of Small Crystals, X-Ray Topography.

R. Raplow, Massachusetts Institute of Technology, Vepartment of Materials Science and Engineering - Glass to Crystalline i-ansforations, Amorphous Materials, Physics of Surfaces.

B. S. Borie, ORN, Metals and Ceranics Division - Diffuse Scattering f roe Defect Structires, Extinction.

A. Habenschuss, CRNL, Metals and Ceranics Division - Structure of Liquid and Norcrystalline Materials.

G. S. Ice, ORNL, Metals and Ceramics Division - X-Ray Scattering, $X$-Ray Spectroscopy, X-Ray OpLics.

C. J. Sparks, Jr., ORNL, Metals and Ceramics Division - Jcattering

from Imperfect Structure, Anoma lous Scattering, Order-Disorder.

H. L. Yakel, ORNL, Metals and Ceramics Division - St ructure of Intermetallic Compounds.

A. H. Narten, ORNL, Chemistry Division - Structure of Amorphous Solids and Liquids.

B. C. Larson, ORil, Solid State Division - Crystal Defects, Strain Fields, Alloying Ef fects.

E. K. Ryba, Pennsylvania State University, Department of Materials Science - Structure of C'stering, Precipitation, and Imperfections in MaLerials.

A. Angell, Purdue Univerilty, Department of Chemistry - Structure of Amorphou - Materials.

H. Huang, Rice University, Department of Physics - EXAFS, Absorption F.dge Spectroscopy, Near-Edge Pine Structure.

S. Moss, Unfversity of Houston, Physics Department - Interstitials in Metals, Amorphous Materials, Intercalation Structures. 
R. J. DeA ugelis, University of Kentucky, Department of Metallurgical Engineering and Materials Science - Heterogeneous Catalysts and Their Deactivation Processes.

A. Krawitz, University of Missouri, Department of Mechanical and Aerospace Engi neering - Structure and Properties of Cemented C:rbides, Boron Fibers, Ordering.

L. Blum, University of Puerto Rico, Physics Department - Theory and Structure of Amorphous Materials.

M. I. Kay, University of Puerto Rico, Center for Energy and Environment Research - Time Resolved Studies of Ferroelectrics, Scatiering and iAfS of Liquid and Solid Interfaces under Electric Fields.

N. C. Halder, Univers $\$$ ty of Southern Fiorida, Physics Department Stricture of Amorphous Materials.

J. E. Spruiell, University of Tennessee, Department of Chemical, Metaliurgical, and Polymer Engineering - Defect Structures, Polymers.

H. Steinfink, University of Texas at Austin, Chemical Engineering Derargent - Fast Phase Transformations, Metal Surface Structures.

J. G. Byme, University of Utah, College of Engineering - Phase Transforma"ions and Cyclic Deformation.

K. Lawless, University of Virginia, Department of Materials Science - Structure of Thin Films, Corrosion Products.

C. R. Hcuska, Virginia Polytechnic Institute and State University, Depa-'ment of Materials Engineering - Metallic Interfaces, Diffusion, Surț :e rilms. 


\section{APPENDLX \\ 1. STAFF CHANGES AND GUEST ASSIGNMENTS}

From Materials Science Program

B. S. Borie from X-Ray Scat iering Research to Unf versity of California, Berkeley, April-June 1980.

P. T. Carlson from Kinetics and Pirchanisas of Surface and Solid State Reactions to Conservation Program, Engineering Coordination and Evaluation Group.

G. R. Gessel from Radiation Effects to University of Arkansas.

J. M. Leitnaker from Fundamentals of Welding to Oak Ridge Gaseous Diffusion Plant.

J. P. Moore frum Physical Properties Research to Institute für Technische Physik, Kerforschungszentrum, Karlsruhe, FRG, September 1978Aug ist 1979.

T. C. Refley from Radiation Effects to Institute für Festkörperforschung, Kernforschungsanlage, Julich, FRG, June 1979-June 1980.

R. A. Vandermeer from Physical Metallurgy to Illinois Institute of Technology, January-May 1980.

H. L. Yakel from X-Ray Scattering Research to Stanford Synchrotron Radiation Laboratory, October 1978-September 1979.

N. J. Zaluzec from AEM-HVEM to Argonne National Laborat Jry.

\section{To Materisls Science Program}

(See Chap. 7 for visits by members of users groups.)

B. J. Anderson, Augeburg College, to Metastable Materíals, Summer 1980 .

F. W. Averill, Judson College, to Theory Group, JynuaryDecember 1980.

R. J. Bayuzick, Vanderbilt University, to AEM-HVEM, May-August 1980. 
T. P. Beaulac, State University of New York-Stony Brook, to Theory Group, February-July 1980.

P. L. Becher from Naval Research Laboratory to Structural Ceranics.

R. B. Benson, North Carolina State University, to AFM-HVEM, Summer 1980.

R. Bullough, Theoretical Physics Division, AERE Harwell, England, to Radiation Effects, July 1979. 1980.

J. B. Clark, University of Missouri-Rolla, to AEM-HVEM, May-July

R. J. DeAngelis, University of Kentucky, to X-Ray Research Using Syachrotron Sources, Sumer 1979, Sumer 1980.

A. T. Fromhold, Auburn University, to Theory Group, JanuarySeptember 1980 .

M. J. Goringe, Oxford University, to AEM-HVEM, Sunmer 1980.

K. M. Gupte, Undversity of Delaware, to Sual1-Angle X-Ray Scattering, $1979-1980$.

B. Györffy, Unlversity of Bristol, to Theory Group, AugustSeptember 1979.

R.0.A. Hall, Chemistry Division, AERE, Hacmill, England, to Physical Properties Research, September 1978-April 1980.

J. E. Harris, Central Electricity Generating Board, Berkeley, England, to Deformation Studies, June-September 1979.

J. F. Harris, Institut für Festkörperforschung, Kernforschungsanlage, Jülich, PRG, to Theory Group, June 1978-September 1979.

A. Habenschuss from Chemistry Division, ORNL, to ORNL-ORAU Synchrotron Users Group.

M. R. Hayns, Theoretical Physics Division, AERE, Harwell, England, to Radiation Zffects, January 1979 -April 1980.

L. L. Horton, University of Virginia, to Radiation Effects, JanuaryDecember 1980.

G. E. Ice from Stanford Synchrotron Radiation Laboratory to X-Ray Research Using Synchrotron Sources.

W. Kesternich, Institute fur Festköperforschung, Kerforschungsanlage, Júl1ch, FRG, to Radiation EffectB, January 1979-January 1980. 
P. D. LaBarbe, University of Hontpellier, France, to Sall-Angle X-Ray Scattering, March-Decenber 1980.

G. L. Lehaan fron University of Florida, to ORNL-ORAU SHaRE Progran.

F. R. Lawless, University of Virginia, to AEM-HVEM, May-June 1980.

P. E. Mackie, Georgia Institute of Technology, to X-Ray Research Using Synchrotron Sources, Iuly-September 1979.

R. L. Mills, Ohio State University, to Theory Group, Sunez 1979, Sumer 1980.

J. Petermann, University of Saarlandes, Saarbrücken, FRG, to SaallAngle X-Ray Scattering, $1979-80$.

F. J. Pinski, State University of New York-Stony Brook, to Theory Group, September 1979-August 1980.

J. M. Schultz, University of Delaware, to Small-Angle X-Ray Scattering, January-May 1980.

S. L. Somers, Virginia Polytechnic Institute, to Structural Ceranics, June-September 1980.

W. Specking, Institute für Technische Physik, Kernforschungzentrux, Karlsruhe, FRG, to Metastable Materials, June 1978-September 1979.

S. Suehiro, University of Massachusetts and Kyoto University, to Small-Angle X-Ray Scattering, April 1979-May 1980.

V. J. Tennery from Ceranics Technology to Structural Ceranics.

J. M. Vitek from Olins Corporattion to Fundamentals of Helding •

R. C. Wasielewsk1, Virginia Polytechnic Institute, to Structural Ceramics, June-September 1979.

P. Young, University of Massachusetts, to Small-Angle X-Ray Scatter1ng, September 1979-May 1990.

\section{UNIVERSITY APPOINTMENTS POR ACADEMIC YEAR 1979-80}

B. S. Borle, Professor, Metallurgical Engineering, University of Tennessee; Visiting Professor, University of Callfornia, Berkeley, April-June 1980.

R. W. Carpenter, Adfunct Professor, Materials Sclence and Engineering, Vanderbilt University. 
S. A. David, Adjunct Professor, Metallurgy and liaterfals Engineering, University of Pittsburgh.

A. DasGupta, Adjunct Professor, Department of Hetallurgy and Materials Engineering, Lehigh University.

L. A. Harris, Ad funct Assistant Professor, Department of Geoiogical Sclences, University of Teñnessee.

S. H. Jury, Professor, Chenical Engineering, University of Tennessee. Part-tine Physical Properties Group.

0. C. Kopp, Professor, Ceological Sciences, University of Tennessee. Part-tine Preparation of High-Tenperature Materials.

C. J. Mchargue, Professor, Metallurgical Engineering, University of Tennessee.

J. E. Spruiell, Professor, Hetallurgical Engineering, University of Tennessee. Part-tine Radiation Effects Progran.

R. A. Vanderweer, Professor, Metallurgical Engineering, University of Tennessee; Visiting Professor, Illinois Institute of Technology, January-June 1980 .

C. L. White, Adfunct Professor, Materials Sclence and Engineering, Vanderbilt Unirersity.

D. W. Yatbrough, Professor, Chemical Englneering, Tennessee Technologiral University. Physical Properties Group.

\section{SCIENTIFIC AND PROFESSIONAL ACTIVITIES}

J. Bentley:

B. S. Borie:

D. N. Braski:

R. W. Carpenter:
ORAU Traveling Lecture Progran.

Professor, Departwent of Chemical, Metallurgical, and Polywer Engineering, University of Tennessee; Visiting Professor, Department of Materials Science, University of California (Berkeley).

ASTM Technical Comnittee E. 10.04;

1979 McKay-lielm Award fron American Welding Society.

ORAU Traveling Lecture Program;

Adfunct Professor, Materials Sclence and Englneering,

Vanderbilt Und verelty;

TMS-AIHR Physical Metallurgy Committee;

TMS-AIME Non-Ferrous ketals Comittee; 
Chairuan, Organizing Comitcee for Horkshop on Analytical Electron Microscopy, SEM, Inc., Chicago, I11., 1980;

Chairnan, Steering Comitcee ORNL/ORaU SHaRe Progran; Director, Electron Microscopy Soclety of American.

J. V. Cathcart: TMS-AIME Corrosion Resistant Hetals Comittee;

Workshop Solar Materials-DOE.

H. A. Coghlan: THS-AIME Hechanical Metallurgy Comittee;

ORdL Ph.D. Rectuiting Program.

A. DasGupta: Th-AIME Physics and Chemistry of Metals Comitcee;

Adfunct Professor, Department of Metallurgy and

Katerials Engineering, Lehigh University.

S. A. David: THS-AIHE Solidification Comittee;

ASH Jolning Council Hember;

Adjunct Professor, Department of Metallurgy, University of Pitcsburgh;

1979 HeKay-Heln Arard from smerican Velding Society.

D. S. Easton: TMS-AIME Hechanical Properties Comittee;

Task Group, ASTM Physical/Mechanical Properties of

Superconductors:

THS-AIME Composites Comittee.

K. Farrell: ASTM Technical Comittee E. 10.08;

Consultants Symposium, ALKE Harwell, England;

Workshop on Hydrogen in S-irling Engines, DOE;

Task Force for Materials Selection for INTOR.

L. A. Hairis:

BD- AIME Ad Poc Comittee on Quantitative Process Mineralogy;

Adfunct Assistant Professor, Department of Geological Sclences, University of Tennesses;

Co-organizer, Workshop on Structure of Coal.

R. W. Hendricks: Associate Director, National Center for Saall-Angle Scattering;

Solid State Sciences Panel, National Academy of Sclences;

Comission on Crystallographic Apparatus, Internationa! Union of Crystallography;

Apparatur and Standards Comittee, American Crystallographic Assoclation;

Membership Comittee, Division of High Polymer Physics, Awertcan Physical Socity;

TMS-AIME Chemisty and Physics of Metals Comittee.

E. A. Kenik: ASTM Technical Comittee E. 10.06, Task Group 4. 
C. C. Koch: TMS-AIME Alloy Phases Committee;

TMS-AIME Non-Ferrous Hetals Con'ttee;

Organizer, Surface Alloying of Refractory Metals for

AIME Annual Meeting;

Organizer, Rapidly Solidified Nonferrous Metals for TMS-AIME Fall Meeting;

Fellow, American Association for the idvancesent of Science.

0. C. Kopp:

Professor, Department of Geological Sciences, University of Tennessee;

Abstractor for Mineralogical ibstracts.

D. L. McElroy: ASTM Technical Committee C-16;

Secretary of ASTM Subcomittee C. 16.30;

Nat Ional Laboratory Accreditation Criteria Comatree (Department of Commerce);

Board of Governors, International Theral Conductivity Conferences;

Board of Governors, Symposium on Expansion of Sollds;

Vice-President, Energy Conservation Society;

Editorial Board, Intermational Joumal of Thermophysics.

C. J. Nchargue: Professor, Department of Chemical, Metallurgical, and Polymer Engineering, University of Tennessee;

Secretary, ASM - TMS-AIME Nuclear Metallurgy Comelttee;

Visiting Commitzee, Department of Materials Science and Engineering, University of Kentucky;

International Metals Review Commit.tee, ASM;

Co-organizer, Workshop on Structure of Coal.

R. A. McKee: Consultant Symposium, AERE Harwell, England.

L. K. Mansur: ASTM Technical Committee E. 10.08;

ORAU Traveling Lecture Program.

J. P. Moore: Secretary, ASTM Technical Committee E. 37.05;

Guest Scientist, Institut für Technische Physik, Kernf orschungszent rum, Kärlsruhe, FRG;

Thermal Conductivity Award, 1979.

N. H. Packan: ASTM Technical Committee E. 10.08 .

T. C. Relley: ASTM Technical Committee E. 10.08;

Program Committee, ANS-MSTD;

ORNL Ph.D. Recruiting Program;

Guest Scientist, Institute für Restköperforschung, Kernf orschungsanlage, Jüllch, FRG.

C. J. Sparks: Applied Crystallography Speclal Interest Group, American Crystallographic Association; 
National Symchrotron Light Source idvisory Comittee of Users, DOE Brookhaven National Laboratory;

National Synchrotron Light Source $X$-Ray Bean Line Comictee, DOE and Biz;

Science Polfcy Board, Stanford Synchrotron Radiation Laboratories:

Steering Comittee, ORAL-ORAU Synchrotron Users Group.

J. O. Stfegler: ASTM Technical Comittee E. 10.

Fellow, American Society for Hetals.

R. A. Vanderweer: Professor, Department of Chealcal, Metallurgical, and

Polyner Engineering, University of Tennessee;

Oanl Graduate Fellow Selection Panel;

ThS-ADE Physical Hetallurgy Comitcee;

Visiting Professor, Illinois Institute of Technology.

C. L. Whice:

Ad funct Professor, Vanderbilt University;

THS-AIIE Heat Treating Conittee;

THS-AIME Hechanical Ketallurgy Comitcee;

ASH-HSD Progran Comittee;

DOE-BES Workshop on Time-Dependent Deformation;

Steering Comitcee ORNL-ORAU SHaRE Program.

H. L. Yakel:

Cuest Scientist, Stanford Synchrotron Radiation

Laboratories;

Fellow, herican Association for Avancement of Science;

Coeditor Joumal of Applied Crystallography.

D. U. Yarbrough: ASTM Technical Comittee C. 16;

Professor, Chenical Engineering, Tennessee

Technological Unive:sity.

M. H. Yoo:

Publication Comicte.. MS-AIME, Metallungical

Trarsactions A;

TMS-AIME Mechanical Metallurgy Comitcee;

TMS-AIME Physical Metallurgy Comitcee;

C. S. Yust: Progran Comittee, merican Ceranics Society;

ASn Technical Comitctee G. 2;

NACE Technical Practices Comittee T-12A;

National Macerial Advisory Board Comaitcee on Dynanic

Compaction of Ceranic Pouders. 


\section{PRESENTATIONS AT TECHNICAL METINCS}

Gordon Conference on Corrosion, New London, New Hanpshire, July 6-11, 1979.

R. A. McKee, * -Defect Kinetics and the Oxidation of Metals.-

US/USSR Brceder Reactor Core Materials Inforwation Exchange Heeting, Hanford Engineering Development Laboratory, Richland, Washington, July 30-31, 1979.

A. F. Rowcliffe, * E. H. Lee, and P. S. Sklad, Charged Particle Irradiatiun in the United States Breeder Reactor Progran."

Aeerican Crystallographic Association Heeting, Boston, Massachusetts, August 12-17, 1979.

J. E. Epperson, * J. Faber, R. H. Hendricks, and J. S. Lin, "Spall Angle Scatcering Observations of a Decomposing Ni-Al Alloy."

R. H. Hendricks, J. M. Schultz, J. S. Lin, * J. Peterman, and R. M. Gohil, Annealing of Polypropylene Filus Crystallized From a Highly Extended Melt."

R. W. Hendricks, J. S. Lin,* J. M. Schultz, and R. G. Nepler, "Temperature-Dependent Small-Angle $X$-Ray Scattering from Poly(Vinylidene Fluoride)."

C. J. Sparks, Jr.,* "Applications of Solid State Detectors to X-Ray Scattering Measurements: Background Reduction and Unique Information."

R. H. Hendricks, * "Small-Angle Scattering Observations of a Decomposing Ni-Al Alloy."

37th Annual Heeting of the Electron Mfcroscopy Soclety of America (EMSA), San Ant snio, Texas, August 13-17, 1979.

J. Bentley* and R. W. Carpenter, "The Dependence of Secondary Electron Image Contrast of Periodic Objects Upon Probe Diameter."

D. N. BraskI and J. T. Houston, * "Improved Transwission Electron Microscope Specimen for Semlautomatic Jet Polishing."

R. W. Carpenter* and E. A. Kenik, "The Effect of Displacement Cascades on Chemical Order in $\mathrm{Ni}_{4} \mathrm{Mo}$."

E. A. Kenik,* B. R. LIvesay, and R. H. Carpenter, "High Voltage Electron Microscopy Studies of Hydrogen Storage Materials."

«Speaker 
E. A. Kenik, * K. R. Lawless, and R. W. Carpenter, "High Voltage Electron Microscopy In-Situ Oxidation Research on Vanadium and Vanadium-Titanium.-

D. N. Braski, * R. W. Carpenter, and E. A. Kenik, "Discont inuous Precipitation in Ordered $(\mathrm{Fe}, \mathrm{Co})_{3} \mathrm{~V}$ Alloys."

Seminar, AERE, Harwell, England, August 16, 1979.

M. H. Yoo,* "The Role of Divacancies in Loop Growth and Vofd Swelling."

International Cryogenic Materials Conference, Madison, Wisconsin, August $21-24,1979$.

D. S. Easton, W. Specking,* and P. A. Sanger, "Stress Ef fects in an Nb3 3 Conductor 1 -oposed for use in the Magnetic Fusion Energy Program.:

Fifth International Conference wistrength of Metals and Alloys, Aachen, West Germany, August 27-31, 1979.

M. H. Yoo,* "A Dislocation Model for Twinning and Fracture and Its Application to H.C.P. Metals."

KFA, Jülich, West Germany, September 3, 1979.

M. H. Yoo,* "A Generallized Rate Theory Model of Void Swelling."

Centre D'Études Nucléaires de Saclay, France, September 6, 1979.

M. H. Yoo,* "Growth Kinetic of Dislocation Loops and Voir's."

University of Paris-Sud, Centre D'Orsay, France, September 7, 1979.

M. H. Yoo,* "Slip, Twinning, and Fracture in H.C.P. Metals."

Symposium on Rare Gases in Metals and Ionic Solfds, AERE, Harwell, England, September 10-14, 1979.

K. Farrel1,* "Experimental Observations of Effects of Inert Gases on Cavity Formation."

American Society for Metals, Bluegrass Chapter, Lexington, Ky., September 12, 1979.

S. A. David,* "Solidification Behavior of Austenitic Stainless Steel Filler Metals."

*Speaker 
AIME Fall Meeting, Milwaukee, Wisconsin, September 16-20, 1979.

J. D. Holder* and G. W. Clark, "Synthesis of Oxide-Metal Eutectic Composites by Improved Internal Zone Growth and Sknll-Melting Techniques."

M. H. Yoo,* "The Competitive Role of Defornation Twinning Against Cleavage Fracture."

J. M. Leftnaker, J. Bent ley * and Said Izadi, "Comparative Rates of Prectpitation in Cast and Wrought Structures."

D. S. Easton* and $W$. Specking, The Effect of Copper Stabilization on the Strain Behavior of Nb3Sn Multifflanentary Conductors."

D. M. Kroeger, * D. S. Easton, A. DasGupta, J. O. Scarbrough, and C. C. Koch, The Effect of Stress upon the Scaling Law for Flux Pinning in Bronze Process $\mathrm{Nb}_{3} \mathrm{Sa}_{\text {." }}$

C. C. Koch, A. DasGupta, * D. M. Kroeger, J. O. Scarbrough, "The Peak Effect, Summation Problea, and Magnetic History in a Superconducting Nb-38 at. 7 Hf Alloy."

A. DasGupta,* "Flux Pinning by Grain and Phase Boundaries."

M. B. Lewis, * "Nondestructive Techniques for the Measurement of Oxygen and Hydrogen Profiles Near Metal Surfaces."

Third Europhysics Topical Conference on Lattice Defects in Ionic Crystals, Canterbury, England, September 17-21, 1979.

R. A. McKee* and A. B. Lidiard, "Kinetics and Thermodynamics of the Migration of Interstitial Defects."

Meeting with USSR Delegation on Inelastic Scattering Research, Oak RIdge National Laboratcry, September 19-20, 1979.

L. K. Mansur, * "Summary of Theoretical and Experimental Work at ORNL on Irradiation Creep."

Seminar at Lawrence Livermore Laboratory, Livermore, Callfornla, on September 20-21, 1979.

R. A. Vandermeer, * "A Report on Recent Studies of Phase Transformations and Shape Memory Effects (SME) in Uranium-Niobium Alloys."

Seminar for Department of Metallurgy, University of Connecticut, Storrs, Connect 1cut, September 26, 1979.

A. DasGupta, * "Some Aspects of Flux Pínning by Grain Boundaries and Precipitates in Superconductors." 
Midwest Solid State Theory Conference, Columbus, Ohio, October 8-9, 1979.

J. S. Faulkner * "Calculating Properties Uith the Coherent Potentlal Approximation.-

Poster Session, American Physical Society, Columbus, Ohio, October 8-9, 1979.

F. J. Pinski, * P. B. Allen, U. H. Butler, and J. S. Faulkner, -Electrical and Thermal Reststivities: Solutions to the Boltzmann Equation for Electrons in Metals.-

American Ceranic Society Fall Meeting, New Orleans, Loulstana, October 14-17, 1979.

P. Angelini, * R. W. Carpenter, and D. P. Stinton, "High Resolution Analytical Electron Microscopic Analysis of Synroc Muclear Waste Storage Material."

C. L. Hoenig* and C. S. Yust, Explosive Compaction and Microstructural Analysis of $\mathrm{AIN}$, Amorphous $\mathrm{Si}_{3} \mathrm{~N}_{4}$, Boron, and $\mathrm{Al}_{2} \mathrm{O}_{3}$ Ceranics.-

Appalachian Regional Electron Microscopy Society Fall Meeting, East Tennessee State University, Johnson City, October 19, 1979.

J. Bentley,* "Analytical Electron Microscopy."

University of Tennessee, Knoxville, October 23, 1979.

W. A. Coghlan, "A Collection of Technical Highlights from Visits to Laboratories in France, Germany, and Poland."

Seminar at College of Engineering, Vanderbilt University, Nashville, Tennessee, October 24, 1979.

R. W. Carpenter, * "Analytical Electron Microscopy and Modern Materials Sclence Research."

Geologlcal Society of America National Meeting, San Diego, Calffornla, November 5-8, 1979.

H. E. Barrett, O. C. Kopp,* and L. A. Harris, "A Study of Elemental and Maceral Distribution in Coals of Different Palepenvironments."

16th International Thereal Conductivity Conference, Chicago, Illinols, November 7-9, 1979.

R. S. Graves, R. K. Will1ams, and J. P. Moore, * "The Thermal Conductivity, Electrical Resistivity and Seebeck Coefficlent of Standard Reference Material 735."

*Speaker 
D. L. McElroy, * R. K. Hilliams, F. J. Keaver, and R. S. Graves, The Physical Properties of $\mathrm{V}(\mathrm{Fe}, \mathrm{Co}, \mathrm{Ni})_{3}$ All,ys from 300 to $1000 \mathrm{~K}$."

D. W. Yarbrough, * R. K. Hilliams, and R. S. Graves, -Transport Properties of Concentrated Ag-Pd and $\mathrm{Cu}-\mathrm{ili}$ Alloys from 300 to $1000 \mathrm{~K}$.American Nuclear Society linter Yeeting, San Francisco, November $11-19$, 1979.

N. H. Packan* and K. Farrell, On the Valfitty of Helium Preinjection in Radiation Damage Simulation."

24th Annual Conference on Magnetism and Magnet ic Macerials, Sleveland, Ohio, November 14-18, 1979.

W. C. Koehler and R. W. Hendricks, * "The United States National SimallAngle Neutron Scattering Facility."

Materials Engineering Graduate Seminar, VP 1, Blacksburg, Virgínia, November $15,1979$.

J. D. Holder,* "Preparation of High-Temperature Oxide-Metal Eutectic Compositas: A Review."

ORAU Visiting Lecture Program, North Carolina State University, November $20,1979$.

J. Bentley, * Analytical Electron Microscopy."

Colloquium Series, Case Western Reserve Univeisity, Cleveland, Ohio, November $20,1979$.

R. W. Carpenter, * “Convergent Beam Diffraction: Applications and Inst rumentation."

Second Japanese Institute of Metals International Symposium on Hydrogen in Meta1s, Minakaml Spa, Japan, November 26-29, 1979.

E. A. Kenik* and B. R. Livesay, "In-Situ Hydriding of Hydrogen Storage Mater s."

Materlals Research Soclety Meeting, Boston, Massachusetts, November 26-30, 1979.

L. A. Boatner,* G. W. Bea11, M. M. Abraham, C. B. Finch, P. G. Huray, and M. Rappaz, "Monazite and Other Lanthanide Orthophosphates as Alternate Actinide Waste Forms."

L. A. Harris and C. S. Yust, * "Transwission Electron Microscoplc Characterization of Cosls." 
D. M. Kroeger, * C. C. Koch, D. S. Easton, and J. O. Scarbrough, -A Study of Arc-Hamer Speeds and Critical Conling Rates in Arorphous Transition Metal Alloys."

C. C. Koch, * B. C. Giessen, D. M. Kroeger, and J. O. Scarbrough, -Superconductivity in Amorphous Equi-Electronic Transition Hetal Alloys."

Seminar at Stanford ial versity, Stanford, Callfornia, November 28, 1979.

W. A. Coghlan, "Growth of Interstitial Loops Under HVEA Irradiatiun.-

Seninar at Vanderbilt University, Nashville, Tennessee, December 5, 1979.

J. Bentley,* Electron Diffraction Techniques in an Analytical Electron Micro:cope."

ORAU Visiting Lecture Program, University of Kentucky, January 16, 1980.

J. Bentley, * Analytica.. Electron Microscopy.-

ASM Seminar, Oak Ridge, Tennessee, January 1?. 1980.

R. W. Carpenter, * "Analytical Electron Microscopy Techniques and Developments."

Centro Informazion Studi Experienze (CISE), Milan, Italy, January 2!, I 980 and JRC-Ispra, Verese, Itaky, January 23, 1980.

T. C. Reiley, * "Irradiatic. Creep Using Light Ions - Experimental Proceoures and Mechanistic Studies."

Seminar, Rockwell Sclence Center, Thousand Oaks, Callfornla, February 18, 1980.

R. W. Carpenter, * "Analytical Electron Hicroscopy: Electron Energy Loss Spectroscopy and Convergent Beam Diffraction for Phase Ident if ication."

AIME Annual Meeting, Las Vegas, Nevada, February 24-28, 1980.

L. A. Harris* and C. S. Yust, "A Review of Advanced Coal Petrographic Methods in Characterizing and Assessing Coals for Utilization."

W. A. Coghlan,* "T ie Effect of Applied Stress on the Sink Efficiency of Pinite Brank Loof:."

R. A. Vanderweer* and J. C. Ogle, "The Kinetics of Vold Annealing in Neutron Irradiated Aluminum." 
R. W. Carpenter, * "Applications of Microdiffraction to Phase Transformation Research and Lattice Defect Identification in Solids."

N. J. Zaluzec* and R. W. Carpenter, "Light Element Analysis in Structural Alloys and Ceramics by Electron Energy Loss Spectroscopv."

S. A. David* and D. N. Briski, "Solidification Behavior of Austenit ic Stainless Steel Filler Metal."

J. Bentley,* "Analytical Electron Microscopy IIsing a Field Emission Gun."

J. S. Lin,* R. W. Hendricks, J. Bentley, and F. W. Wiffen, "Small-Angle $X$-Ray Scattering Study on Neutron-Irradiation Effects in Moly Jdenum and Molybdenum Alloys."

G. R. Gessel* and C. L. White, "Use of Auger Electron Spectros:opy and Residual Gas Anaiysis to Study Neutron-Irradiation-Enhancec Segregation to Internal Surfaces."

E. W. Hendricks,* "The Use of Small-Angle X-Ray and Neutron Scattering fur Characterizing Vofds in Neutron-Irradiatfd Metals and Alluys."

M. B. Lewis* and K. Farrell, "Nuclear Microanalysis as a Probe of Impurity-Defect Interactions."

E. A. Kenik,* K. A awless, and R. W. Carpenter, "Low . ressule in Sifu Oxidation of Vanadium and $\mathrm{V}-20 \% \mathrm{Ti}$."

DOE Workshop on Heat Transfer Propertic a for General Purpose Heat Source Dealgn, Germantown, Maryland, March 5, 1380.

R. K. Williams* and R. S. Graves, "Vacuum Corsact Conductance Measurements on Interfaces Between Fine-Weave ilerced Fabric" (a graphite fiber composite).

Metallurgical and Materlals IngIneering Department, Illinols Institute of Technology, Sem1:at:, Chicago, Illinois, March 6, 1980.

R. A. Vendermeer, "The Kinetics of Vold Annea'ing in NeutronIrrad'ate. Alumd.num."

Semirar University of Virginia, Charlottesville, Virginia, March 17, 1930.

R. W. Carpsenter, * "High-Resolution Electron Diffraction Methode 'n Analytica: Electron Microscopy."

*Speakor 
Aberican Crystallographic Association Hinter Meeting, Gulf Shores, Alabama, March 17-21, 1980.

R. W. Hendricks* and W. C. Koehler, The Nat Ional Center for SmallAngle Scattering Research."

American Physical Soclety, New York, March 24-28, 1980.

A Goris and G. M. Stocks, * Total and Component Densities of States in the KKR-CPAt and Average t-Matrix Approximation."

G. M. Stocks* and B. L. Györffy, Momentum Distribution of Electrons In Random Alloys: The Fermi Surface of $\mathrm{AB}_{c} \mathrm{Pd}(1-c)$ Alloys."

J. S. Faulkner* and G. M. Stocks, "New Formulas for Calculating Properties with the KKR-C?AT: Algebraical."

G. M. Stocks* and J. S. Faulkner, "New Formulas for Calculating Propertles with the KKR-CPAt: Numerical."

L. A. Boatner, * C. W. Beall, M. M. Abraham, C. B. Finch, P. G. Huray, and M. Rappaz, "The Growth and Characterization of Act Inide-Doped Lanthanide Orthophosphate Single Crystals."

S. Suehiro* and R. W. Hendricks, "Dynamic Deformation Device for Small-Angle X-Ray and Neutron Scattering."

R. W. Hendricks and W. C. Koehler,* "The National Center for SmallAngle Scattering Research - A Progress Report."

R. A. McKee, * "Phenomenological Coefficients for Interstitial Diffusion in a Dilute, Two-Component System."

D. M. Kroeger,* D. S. Easton, C. C. Koch, A. DasGupta, and J. 0. Scarbrough, "Evidence for Microstructural Changes Under Strain in Bronze Process Nbjsn."

F. J. Pinski,* "Solutions to the Boltzmann Equation for Electrons in a Metal: Energy Dependence."

T. P. Beaulac,* P. B. Allen, and F. J. Pinski, "Calculation of the Low-Fiej+ Ho11 Coefficlent in $\mathrm{Cu}$ and $\mathrm{Nb}$."

F. J. Pinsk1, Y. S. Kahn, and W. H. Butler,* "Calculation of the Anlsotroplc Electron-Phonon Mass Enhancement in $\mathrm{Cu}$ and Nb."

W. H. Butler, * "Upper Critical Field of Pure Nb: Calculated Temperature Dependence and An1Botropy."

tKorringa-Kohn-Rostoker coherent-potential approximation. 
G. M. Stocks* and W. H. Butler, "Residual Resistivity of AgPd Alloys."

A. DasGupta, * D. M. Kroeger, C. C. Koch, and Y. T. Chou, "Flux Pinning by Grain Boundaries in Niobium Bicrystals can be Treated by the First Order Perturbation of Ginzburg-Landau Free Energy."

J. M. Schultr, * J. S. LIn, R. W. Hendricks, J. Petermann, and R. M. Gohil, "Annealing of Polypropylene Filus Crystallized from a Highly Extended Melt."

Geological Society of America, Southeastern Division Conference, Birmingham, Alabama, March 27-29, 1980.

0. C. Kopp* and C. B. Finch, "Crystal Growth and Stability of Fayalite $\left(\mathrm{Fe}_{2} \mathrm{SiO}_{4}\right)$ Under Controlled $\mathrm{f}\left(\mathrm{O}_{2}\right)$ Conditions."

BES/DMS (DOE) Meeting on Coal Structures and Properties, Gatlinburg, Tennessee, April 8-10, 198 .

L. A. Harris and C. S. Yust*, Transmission Electron Microscopy of Coal."

Seminar, College of Engineerinr. University of Houston, Houston, Texas, Apr: $110,1980$.

R. W. McClung,* "Current Activities in Nondestructive Testing at ORNL."

Invited talk, American Physical Society, Cornell University, Ithaca, New York, Apri1 11-12, 1980.

C. J. Sparks, Jr., * "Synchrotron Radfation Sources: Novel Optirs and Changed Research Style."

Dynamic Compaction of Metal and Ceramic Powders Commitcee Meering, Washington, D.C., Apri1 14, 1980.

C. S. Yust* and L. A. Harris, "Electron Microscope Observations of Explosively Compacted Ceramics."

American Welding Society Annual Meeting, Los Angeles, California, April $14-18,1980$.

L. B. Splegel and S. A. David,* Microstructural Study of Laser Beam Welds in Single-Phase Alloys."

Seminar at Max-Planck Inst1tute, Stuttgart, West Germany, .1pri1 21, 1980.

J. D. Holder,* "Synthesis of Oxide-Metal Eutectic Composites."

* Speaker 
Seninars at Degussa Institute, Frankfurt, West Germany, April 22, 1980; Siemens Research Institute, Erlangen, West Gerwany, April 23, 1980; and Flesserel, West Gemany, April 25, 1980.

J. D. Holder, * -Synthesis and Electronic Applications of Oxide-Hetal Eutect Ic Composites."

Seninar at Laboratory for Physical Cheaistry, Eindhoven University, Netherlands, April 28, 1980.

J. D. Holder, * "Synthesis of Oxide-Hetal Eutectic Composites." Amertcan Ceramic Soclety, Chicago, Illinols, April 28-30, 1980.

C. S. Yust* and L. A. Harris. Transmission Electron Microscopic Analysis of Explosively Conpacted Alunina."

P. S. Sklad, * R. W. Carpenter, N. J. Zaluzec, and J. E. Selle, Phase Identiffcation in $\mathrm{Si}_{3} \mathrm{~N}_{4} / \mathrm{MgO}$ and $\mathrm{Si}_{3} \mathrm{H}_{4} / \mathrm{Y}_{2} \mathrm{O}_{3}$ Compacts by ConvergentBeam Diffraction and Energy Loss Spectroscopy."

P. Angelini, D. P. Stinton, R. H. Carpenter, J. S. Vavruska, and H. J. Lackey, * "Phase Identification and Partitioning of Elements in Sol-Gel-Derived Synroc."

KFK-Karlsruhe, West Gerwany, April 29, 1980.

T. C. Reiley,* "Recent Experiments in Irradiation Creep Using Light Ions."

Seminar at Michigan Technological University, Houghton, Michigan, May 2-6, 1980.

C. L. White,* "Grain Boundary Segregation and Fracture in Noble Metal Alloys."

Electrochemical Society, St. Louis, Missourt, May 11-16, 1980.

R. E. Pawe1* and J. J. Campbe11, "Some Experiments and Calculations Regarding the Effect of Specimen Dimensions and Oxygen Solubility on Oxidation Kinetics."

Impromptu presentation at meet Ing of USA-INTOR Group, University of Wisconsin, May 13, 1980 (INTOR = Internat Lonal Tokamak Reactor).

K. Farrell, "Neutron Damage Response of Aluminum Alloys in INTOR."

First International A1-LI Conference, Stone Mountain, Georgla, May 19-21, 1980.

C. L. White, "Graln Boundary Segregation and Intergranular Pallure." 
International Cryogenics Materials Conference, Brookhaven National Laboratory, May 28-29, 1980.

D. S. Easton,* D. M. Kroeger, and C. C. Koch, -Superconducting and Mechanical Properties of $\mathrm{Mb}_{3} \mathrm{Sa}$ Conductors Under Tensile Stress."

D. M. Kroeger, * D. S. Easton, C. C. Koch, and A. DasGupta, "Evidence for Microstructural Change Under Strain in Bronze-Process Mb3Sn.-

International Synposium on Managenent of Alpha-Contaninated Uastes, Vienna, Austria, June 2-6, 1980, sponsored by International Atomic Energy Agency.

L. A. Boatner, * G. W. Beall, M. M. Abre an, C. B. Finch, P. G. Huray, and M. Rappaz, "Lanthanide Orthopnosphates for the Priaary Imoobilization of Actinide Wastes."

Tenth International Symposiun on Ef fects of Radiation in Materials (ASTM), Savannah, Georgia, June 3-5, 1980.

K. Farrell, * Microstructure and Tensile Properties of Heavily Irradiated 5052-0 Aluminum Alloy."

M. R. Hayns and L. K. Mansur, * "Applifcations of the Theory of Cavity Growth to Dual-Ion Swelling Experiments."

Sixth International Conference on Vacuum U1traviolet Spectroscopy, University of Virginia, Char lottesville, Virginia, June 4, 1980.

T. A. Callcott, * J. A. Tagle, E. T. Arakawa, and G. M. Stocks, "Soft $\mathrm{X}$-Ray Emission from $\mathrm{LA}-\mathrm{Mg}_{\mathrm{g}}$ and Li-Al Alloys and Comparisons with KKR-CPAt Calculations."

Second International Symposium on U1trasonic Materials Characterization, Nat Ional Bureau of Standards, Gaithersburg, Maryland, June 4-6, 1980.

S. Golan, L. Adler, K. V. Cook, * and D. Chwirut, "Uitrasonic

Diff raction Technique for Characterization of Fatigue Cracks."

AERE, Harwe11, Abingdon, England, June 5, 1980.

T. C. Relley, "Irradiation Creep Using Light Ions."

National Synchrotron Light Source User's Meeting, Brookhaven National Laboratory, Upton, New York, June 9, 1980.

C. J. SparkB, Jr.,* "Oak RIdge Synchrotron Consortlum of Radiation Experiments - X Rays." 
C. J. Sparks, Jr., * "Some Things About X-ray Optics for Synchrotron Radiation: August 1979 Report."

BES Wrkshop on Nondestructive Evaluation, Los Mlanos Scientific Laboratory, June 17-20, 1980.

C. V. Dodd, * "Long-Range Research Needs for Eddy-Current Testing-"

International Conference on Hetallurgical Effects of High Strain-Rate Deforeation and Fabrication, Albuquerque, Mew Mexico, June 22-26, 1980.

C. S. Yust* and L. A. Harris, "Observation of Dislocations and Twins In Explosively Compacted Alumina."

International Conference on Dislocation Hodeling of Physical Systens, Gainesville, Florida, June 22-27, 1980.

H. A. Coghlan* and M. H. Yoo, Applications of Theoretical Point Defect-Dislocation Interactions to Physical Problems.-

Seventh European Therwophysical Properties Conference, Antwerp, Belgiua, June $30-$ July 4, 1980.

J. P. Hoore, * R. S. Graves, and R. K. Hillians, -thermal Transport Properties of NLoblun and Sone Niobiun Base Alloys from 80 to $1600 \mathrm{~K}$."

«Speaker 


\section{PUBLICATIONS}

J. Bentley, "Advantages of a Field Erission Cun for a Combined Analytical and High Resolution Transmission Electron Microscope," Pp. 72-73 in 38th Annu. Proc. Blectron bicroscopy Soc. Am., ed. by G. H. Bailey, Claitor's Publishing Division, Baton Rouge, Louisiana, 1980.

J. Bentley and R. W. Carpenter, "The Dependence of Secondary Electron Image Contrast of Periodic objects Upon Probe Diameter," pp. 566-67 in 37th Annu. Proc. Electron Microscopy Soc. Am., ed. by G. H. Bailey, Claitor's Publishing Division, Baton Rouge, Louisiana, 1979.

J. Bentley and J. M. Leitnaker, "Stable Phases in Aged Type 321 Stainless Steel," pp. 70-91 in The Metal Science of Stairless Steel, ed. by E. W. Collins and H. W. King, The Metallurgy Soctety of AIME, New York, 1979.

J. Bentley, L. L. Horton, and K. Farrell, -Defect Structures in Neutron-Irradiated Iron," pp. 390-91 in 38th Annu. Proc. Electron Microscopy Soc. Am., ed. by G. W. Bailey, Claitor's Publishing Division, Baton Rouge, Loufstana, 1980.

D. N. Braskf, H. Schroeder, and H. Ul lmaler, "The Ef fect of Tensile Stress on the Growth of Helium Bubbles in an Austenitic Stainless Steel," J. Nucl. Mater. 83(L): 265-77 (September 1979).

R. W. Carpenter and J. Bentley "On the Performance of a Field Emission Gun TEM/STEM," pp. 153-60 in Proc. Scanning Electron Vicroscopy, Washington, D.C., April 16-20, 1979, Scanning Electron Microscopy, Inc., AMF O'Hare, Illinols, 1979.

R. W. Carpenter and D. N. Brasixi, "Heterogeneous Precipltation of MC 'Carbides' on Extrinsic Stacking Faults in V-Co-Fe Ordered Alloys," pp. 648-49 in 37th Annu. Proc. Flectron Microscopy Soc. Am., ed. by G. W. Bailey, Claitor's Publishing Division, Baton Rouge, Louisiana, 1979.

R. W. Carpenter and E. A. Kenik, "In-Situ Radiation Response of Nickel-Molybdenum Al loys in an HVEM," PP. 577-80 in High Voltage Electron Microscopy 1977, Vo1. 22, ed. by T. Imura and H. P. Hashimoto, Japanese Soclety of Electron Microscopy, Kyoto, Lapan, 1977.

R. W. Carpenter and E. A. Kenik, "The Effect of Displacement Cascades on Chemical Order in $\mathrm{Ni}_{4} \mathrm{Mo}, " \mathrm{Pp}$. 654-55 in 37th Annu. Proc. Electron Microscopy Soc. Am., ed. by S. W. Balley, Claltor's Publishing Division, Baton Rouge, Loulsiana, 1979.

R. W. Carpenter, J. J. Wert, and S. G. Caldwell, "Metal Surface Deformation and Subsurface Defect Structure: A Microscopy Correlation Study," pp. 140-41 in 38th Annu. Proc. Electron Microscopy Soc. Am., ed. by G. W. Balley, Claltor's Publishing Division, Baton Rouge, Loulsiana, 1980. 
J. V. Cathcart, R. A. Perkins, J. B. Bates, and L C Manley, Tritium Diffusion in Rutile $\left(\mathrm{THO}_{2}\right),-J$. Appl. D.ys. 50(6): $\$ 110-19$ (June 1979).

J. V. Cathcart and R. E. Pavel, The Hechanical Behavior of Oxide Scales," Pp. 300-29 in Proc. Corros./Erosion Coal Convers. Syst. Hater. Conf., ed. by A. V. Levy, Mational Assoclation of Corrosion Engineers, Houston, Texas, 1979.

S. A. David and G. M. Cooduin, "Solidification Behavior of Type 308 Stainless Steel Filler Metal,- pp. 19-28 in Weldments: Fhysical Yetallurgy and Pailure Ehenomena, ed. by R. J. Christoffel, E. F. Nippes, and H. D. Soloeon, Ceneral Electric Conpany, Schenectady, New York, 1979.

S. A. David, G. M. Coodwin, and D. N. Braski, Solidification Behavior of Austenitic Stxinless steel Filler :̊sals, ORuL/TH-7116 (February 1980).

S. A. David, G. M. Cooduin, and D. M. Braski, "Solidification Behavior of Austenitic Stainless Steel Filler Metals," NeLd. J. (Miomi) S9(11): 330-s-336-s (Noveaber 1979).

P. J. Durhan, D. Chaleb, B. L. Gyorffy, C. F. Hague, J-H. Martot, G. M. Stocks, and W. M. Temerman, "Soft X-Ray Enission and the Local Densitses of States in Cu-Ni Aloys, $J$. Phys. P.: Metal Phys. 9(8): 1719-30 (August 1979).

D. S. Easton, D. H. Kroeger, W. Specking, and C. C. Koch, TA Prediction of the Stress State in $\mathrm{Nb}_{3} \mathrm{Sn}$ Superconducting Composites, $J$. Appl. Phy 8. 51(5): 2748-57 (May 1980).

K. Farrell, Experimental Obsemations of Effects of Inert sas on Cavity Pomation During Irradiation, ORNL/TIT-7193 (April 1980).

K. Farrell and J. T. Houston, "Suppression of Radiation Damage Microstructure in Aluminum by Trace Inpurities," $J$. Mucl. Mater. 83(1): 57-66 (August 1979).

R. Farrell and R. T. KIng, "Tensile Properties of Neutron-Irradiated 6061 Aluminum Alloy in Annealed and Precipitation-Hardened Conditions," PP. $440-49$ in Zffects of Aadiation on Structural Yaterials, ASTM Spec. Tech. Publ. 683, J. A. Sprague and D. Kraner, eds., Auerican Society for Testing and Materials, Philadelphia, 1979.

K. Farrell and N. H. Packan, "A Helium-Induced Shift in the Temperature Dependence of Swelling," $J$. Mucl. Mater. $85 \& 86$ (II,B): 683-87 (December 1979).

K. Farrell and A. E. Richt, Microstructure and Tensile Properties of Heavily Ir radiated 1100-0 Aluminum," Pp. 427-39 in Effects of nadiation on Structural Matemlals, ASTM Spec. Tech. Publ. 683, J. A. Sprague and D. Kramer, eds., Merican Soctety for Testing and Materials, Philadelphta, 1979. 
J. S. Faulkner, Tultiple-Scattering Approach to Band Theory, " Dhys. Rev. B 19(12): 6186-6206 (June 1979).

J. S. Faulkner and G. M. Stocks, "Calculating Properties with the Coherent-Potential Approxfmation," Phys. Rev. 3 21(8): 3222-44 (April 1980).

C. B. Finch, G. U. Clark, and 0. C. Kopp, "Czochralski Growth of Single-Crystal Fayalite Under Controlled Oxygen Fugacity Conditions," Am. Mineral. 65(3-4): 381-89 (March-April 1980).

R. H. Gilbert, R. Farrell, and C. E. Coleman, Damage Structure in Zirconium Alloys Irradiated at 573 to $923 \mathrm{~K},{ }^{-J}$. Hucl. Mater. 84(I): 137-48 (October 1979).

B. L. Gyorffy and G. M. Stocks, "First Principles Band Theory for Randow Metallic Alloys,- pp. 89-192 in ELectrons in Disondered Metals and at Metallic Surfaces, ed. by P. Phariseau, B. L. Gyorify, and L. Schelre, Plenum Press, New York, 1979.

H. R. Haines, R.O.A. Hall, J. A. Lee, M. J. Mortimer, and D. L. McElroy, "The Low Temperature Specific Heats of Three Plutonium Carbides," J. MucZ. Mater. 88(2\&3): 261-64 (February 1980).

J. Harris, "The Role of Occupation Numbers in HKS-Theory," Int. $J$. vuantum Chem. Quantum Chem. Symp. 13: 189-93 (1979).

L. A. Harris, O. B. Cavin, R. S. Crouse, and C. S. Yust, "Scanning Electron Microscopical Observations and Energy Dispersive X-Ray Analysis of Secondary Mineralization In a Bituminous Coal, Micros. Acta 82(4): $343-49$ (January 1980).

L. A. Harris and C. S. Yust, "Transmission IR Microscopy (750-1200 $\mathrm{nm}$ ) of Semicoke," Carbon 17(3): 307 (1979,.

R. W. Hendricks, The ORNL 10-m Small-Angle X-Ray seattering Camera, 1. Overview, ORNL/TM-6342 (December 1979).

R. W. Hendricks, P. A. Seeger, J. W. Scheer, and S. Suehiro, The LASLORNL Rast Digital Data Acquisition System, ORNL/TM-7325, LASL-8260-MS (June (980).

J. D. Holder and G. W. Clark, "New Developments in the IZG of Metal Oxide-Hetal Eutectic, Composites," Pp. 195-207 in Conference on In Situ Compositeo-III, ed. by J. L. Halter, M. F. Gigllotti, B. F. Oliver, and H. Bibring, Ginn Custom Publishing, Lexington, Massachusetts, 1979.

J. D. Holder, C. W. Clark, and B. F. Oliver, "Oxygen Partlal Pressure: A Key to Alloying and Discovery In Metal Oxide-Metal Eutectic Systems," PP. 35L-56 in Conference on In Situ Compositee-III, ed. by J. L. Walter, M. F. Gigllotti, B. F. Oliver, and H. Bibring, Ginn Custom Publishing, Lexington, Mas8., 1979. 
A. Jostsons, P. M. Kelly, R. G. Blake, and K. Farrell, Neutron Irradiation-Induced Defect Structures in Zircontum," pp. 46-61 in Effects of Radiation on St ructural Mterials, ASTM Spec. Tech. Publ. 683, J. A. Sprague and D. Kramer, eds., American Society for Testing and Materials, Philadelphia, 1979.

E. A. Kenik, "The Influence of thel fum on Microstructural Evolution in an Ion-Irradiated Low-Swelling Stainless Steel, $J$. Mrol. Mater. 85 \& 86(II, B): 659-63 (December 1979).

E. A. Kenik, K. R. Lawless, and R. H. Carpenter, "High V.sltage Electron Micr-scope In-Situ Oxidation Research on Vanadium and VanadiumTitanium," pp. 420-i2? in 37th Annu. Proc. Blectron Vicroscrpy Soc. Am., ed. by G. W. Bafley, Claz-or's Publishing Division, Baton Fouge, Louistana, 1979.

E. A. Kenik, B. R. Livesay, and R. H. Carpenter, "High Voltage Electron Microscope Studies of 'ydrogen Storage Materials," Pp. 430-31 in 37th Ann. Proc. Electron Microscopy Soc. Am., ed. by G. H. Bailey, Clattor's Publishing Division, Baton Rouge, Lolistana., 1979.

E. A. Kenik, J. Mullins, S. Spooner, and B. R. Livesay, "HVEM In Situ Hydriding of Hydrogen Storage Materials," Tran6. Jpn. Inst. Met. Suppl. 21: 321-24 (1980).

C. C. Koch, "Technetium," PP. 804-06 in Metals Handbook, Ninth Edition, Volume 2, Properties and Selection: Nonferrous Alloys and Pure Metals, American Soclety for Metals, Metals Park, Ohfo, 1979.

C. C. Koch, A. DasGupta, D. M. Kroeger, and J. O. Scárbrough, "The Peak Effect, Summation Problem, and Magnetic History in a Superconducting Nb-38 at. 7 Hf Alloy," Philos. Mag. s 40(5): 361-87 (Nowerber 1979).

D. M. Kroeger, D. S. Easton, A. DasGupta, C. C. Koch, and J. 0. Scarbrough, "The Effect of Striin Upon the Scaling Law for Flux Pinning in Bronze Process $\mathrm{Nb}_{3} \mathrm{Sn}, " J$. Appl. Phys. 51(4): 2184-92 (April 1980).

E. H. Lee, L. K. Manstr, and M. H. Yoo, "Spatial Variation in Void Volume During Charged Parti.:le Bosbardment - The Effects of Injected Interstitials," J. Mucl. Mater. $85 \& 86($ II,A): 577-81 (December 1979).

E. H. Lee, A. F. Rowcliffe, and E. A. Kenik, "Effects of Silicon and TItanium on Swelling of AISI 315 Stalnless Steel," J. Mucl. Mater. 83(1): $79-89$ (Auguse 1979).

M. B. Lewis, "A Method for Simulating Fusion Reactor Radiation Damage Using Triple Ion Beams," IEEE Trans. Mucl. Sci. 26(1): 1320-22 (February 1979).

M. B. Lewis, "Deuterium Migration and Trapping in Uranlum and Uranfum Dioxide During $D^{+}$Implantat Ion," J. Mucl. Mater, 88(1): 23-30 (1980). 
Y. B. Lewis and K. Farrell, "An Ion Beam Technique for the Measurement of Deuterium Diffusion Coefficients," Appl. Phys. Lett. 36(10): $819-21$ (May 1980).

M. B. Lewis, N. H. Packan, G. F. Hells, and R. A. Buhl, "Improved Techniques for Heavy-Ion Simulation of Neutron Radiation Damage," Nucl. Inst mom. Methods 167(2): 233-47 (December 1979).

M. B. Lewis and R. A. Perkins, "The Use of Nuclear Reactions to Trace the Source of Oxygen in Anodization,- IEEE Thans. Nuci. Sei. 26(1): 1818-20 (February 1979).

E. L. Long, Jr., P. Krautwasser, R. L. Reatty, M. J. Kania, r. S. Morgan, Jr., and C. S. Yust, Chamatemization and Irradiation 'erformance of HTGR Biso-ioated Pertile Particles in HFIR Experiments 4T-28, -29, and -30, ORNL/TM-7298 (July 1980).

L. K. Mansur, W. A. Coghlan, and A. D. Brailsford, "Swelling with Inhomogeneous Point Defect Production - A Cascade Diffusion Theory," $J$. Nucl. Mater. 85\& 86(II,A): 591-95 (December 1979).

L. K. Mansur, Effects of Point Defect Trapping and Solute Segrega$t$ ion on Iiradiation-Induced Swelling and Creep," $J$. Mucl. Mater. 83(1): 109-27 (Augrust 1979).

L. K. Mansur, Effective Diffusion Coefficients of Point Defects in Impure Materials, ORNL/TM-7247 (March 1980).

L. K. Mansur and W. G. Wolfer, "Reduction of Irradiation-Induced Creep by Point-Defect Trapping," l'p. 624-39 in Effects of Radiation on Stmuctural Materials, ASTM Spec. Trch. PubZ. 683, J. A. Sprague and D. Kramer, eds., American Society for Testing and Materials, Philadelphia, 1979.

L. K. Mansur and M. H. Yoo, "Advances in the Theory of Swelling in Irradiated Metals and Alloys," $J$. Mucl. Mater. $85 \& 86($ II,A): 523-32 (December 1979).

P. J. Mazlasz and K. Farrell, "The Tensile Properties of High Oxide SAP Containing Heltum and Tritium," $J$. Mucl. Mater. $85 \& 86(I 1, B): 913-17$ (December 1979).

P. J. Mazlasz and R. W. Carpenter, MC Precipitate Characterization In Austenitic Stainless Steel," Pp. $384-85$ in $38 t h$ Annu. Proc. Electron Microscopy Soc. Am., ed. by C. W. Balley, Claitor's Publishing Division, Baton Rouge, Loulsiana, 1980.

M. J. McCready, J. M. Schultz, J. S. LIri, and R. W. Hendricks, "Effect of Crystalization Time on the Properties of Melt-Crystallized Linear Polyethylene," J. Polym. Sci.: Polym. Phys. Ed. 17: 725_40 (1979). 
D. L. McElroy, "Insulation," pp. 230-31 in World Book Encyclopedin, Vol. 10, World Book-Childcraft International, Chicago, 1974.

C. J. Mchargue, Metals ond Cemamice Division Materials Seience Erogram Ann. Prog. Rep. For Period Ending e'une 30, 1979, ORNL-5589.

J. P. Moore, D. L. McElroy, and S. H. Jury, A Technique for ronsuring the Apparent Themal conductivity of Flat Ins alations, ORNL/TM-6494 (October 1979).

J. P. Moore and R. S. Graves, "The Ettingshausen-Nernst Coefficient and Transport Properties of Alumel from 200 to $473 \mathrm{k}, " J$. Phys. Chem. Solids 41(2): $129-33$ (1980).

C. H. Nestor, Jr., C. V. Dodd, and H. E. Deeds, Analygis and Computer Programs for Eddy current Coils Concentric with Multiple Cylindrical conductors, ORNL-5220 (July 1979).

A. L. 01 ins, E. Wilkinson-Singley, J. Bentley, D. E. ol ins, "StereoElectron Microscopy and Energy-Dispersive X-Ray Analys is of Avian Reticulocytes," Eur. J. Cell Biol. 19: $239-49$ (1979).

N. H. Packan and K. Farrell, "Simulation of First Wall Damage: Effects of the Method of Gas Implantation," J. Nucl. Mater. $85 \& 86($ II, B): $677-81$ (December 1979).

N. H. Packan and R. A. Buhl, A Multispecimen Duai-Beam Irradiation Damage Thamber, ORNL/TM-7276 (June 1980).

R. E. Pawel, "Oxygen Diffusion in the Oxide and Alpha Phases During Reaction of Zircaloy-4 with Steam from 1000 to $1500^{\circ} \mathrm{C}$, J. Flectrochem. Soc. 126(7): 1111-18 (July 1979).

R. E. Pawe 1, J. V. Cathcart, and R. A. McKee, "'Anomalous' Oxide Growth During Transient-Temperature Oxidation of Zircaloy-4," Oxit. Met. $14(1): 1-13(1980)$.

R. E. Pawel, J. V. Cathcart, and R. A. Mckee, "The Kinet lcs of Oxidation of Zircaloy-4 in Steam at High Temperatures," J. Flectrochem. Soc. 126(7): 1105-11 (July 1979).

F. J. Pinski and W. H. Butler, "Calculated Electron-Phonon Contributions to Phonon Linewidths and to the Electronic Mass Enhancement of Pd," Phys. Rev. B 19(12): 6010-15 (June 1979).

D. W. Schaefer and R. W. Hendricks, "Static Correlations in Semidilute Polymer Solutions," Polym. Prepr. Amer. Chem. Soc. Div. Polym. Chem. 20: 891 (1979).

P. S. Sklad, "Observations of Cas Bubbles in an Austenttlc Stainless Steel Charged with ${ }^{\mathrm{H}, "}$ PP. 388-89 in 38th Annu. Proc. Blectron Microscopy Soc. Am., ed. by G. W. Balley, Clattor's Publishing Diviston, Baton Rouge, Loulsiana, 1980. 
T. 0. Stiegler and L. K. Mansur, "Radiat fon Ef fects in Structural Materials," pp. 405-53 in Annual Review of Materials Seience, Vol. 9, ed. by R. A. Huggins, R. H. Bube, and D. A. Vermilyea, Annual Reviews Inc., Palo Alto, California, 1979.

R. H. Stinson, M. H. Bartlett, Teorin Kurg, P. R. Sweeny, and R. W. Hendricks, "Experimental Confirmation of Calculated Phases and Electron Density Profile for Wet Native Collagen," Biophys. J. 26: 209-22 (May 1979).

G. M. Stocks, W. M. Temreman, and B. L. Gyorffy, "Aspects of the Numerical Solution of the KGR-CPA Equations," PP. 193-221 in Electrons in Disordered Metals and at Hetallic Surfaces, ed. by P. Ptariseau, B. L. Gyorffy, and L. Scheire, Plen'm Press, New York, 1979.

G. W. Turner and R. W. Hendricks, An Intelligent CAMAC $1 / O$ Module Based on the Signetics 8X300 Microcontroller, ORNL/TM-6922 (September 1979).

G. W. Turner and R. W. Hendricks, "An Intelligent CAMAC I/O Module Based on the Signetics $8 \times 300$ Microcontroller," Nucl. Instrum. Methods 169(3): 373-80 (March 1980).

R. A. Vandermeer, "Phase Transformations in a Uranium +14 at. 7 Niobiuk Alloy," Acta Metall. 28(3): 383-93 (March 1980).

R. A. Vandermeer and W. B. Snyder, Jr., "Recovery and Recrystallization it. Rolled Tantalum Single Crystals," Metall. Trans. 10A(8): 1031-44 (August 1979).

R. A. Vandermeer and J. C. Ogle, "The Kinetics of Vold Annealing in Neutron Irradiated Aluminum," Acta Metall. 28(2): 151-61 (1980).

W. G. Wolfer and L. K. Mansur, The Capture Efficiency of coated Voids, University of Wisconsin Report UNFDM-329 (November 1979).

C. F. Yen, C. S. Yust, and G. W. Clark, "The Enhancement of Mechan 1cal Strength in Hot-Pressed $\mathrm{THB}_{2}$ Composites by the Addition of Fe and $\mathrm{Ni}, "$ pp. 317-30 in New Developments and Applications in Comosites, ed. by D. Kuhlmann-Wilsdorf and W. C. Harrigan, Jr., The Metallurgical Society of A MEE, Warrendale, Pennsylvania, 1979.

M. H. Yoo, "A Dislocation Model for Twinning and Fracture and Its Application to H.C.P. Metals," pp. 825-30 in Strengti of Metals and Alloys, Pergamon Pres8, Oxford and New York, 1979.

M. H. Yoo, "Growth KInetics of Dislocation Loops and Volds - the Role of Divacancies," Philos. Mag. A 40(2): 193-2ll (August 1979).

M. H. Yoo and L. K. Mansur, "The Inclusion of Mobile Helium in a Rate Theory Model of Vold Swelling," J. Mucl. Mater. 85 \& 86(II,A): 571-75 (December 1979). 
M. H. Yoo, "The Role of Divacancies in Void Swelling," Ser. Metall. 13(7): 635-39 (July !979).

c. S. Yust, "Unifying Factors in Eroston and the Wear of Machine Elements," pp. 543-53 in Fundamentals of Pribology, Massachusetts Institute of Technology Press, Cambridge, 1980.

N. J. Zaluzec, "Quantitative X-Ray Microanalysiz in an AEY: Instrumental Considerations and Applications to Materials Science," pp. 121-67 in Introduction to Analytical Electron ficroscopy, ed. by J. J. Hren, J. I. Goldstein, and D. C. Joy, Plenum Publishiug Corporation, New York, 1979. 

A. DasGupta, D. M. Kroeger, C. C. Koch, and Y. T. Chou, "Flux Pinning by Small Perturbations of the Order Parameter in Type II Superconductors," accepted by Philosophical Magazine.

K. Farrel1, "Experimental viservations of Ef fects of Inert Cases on Cavicy Formation," to be published as a Harwell report.

K. Farrell, Microstructure anil Te:isile Propertles of Heavily Irradiated 5052-0 Aluminum Alloy," submlitis.t i.) Joumal of Muclear Materiala.

$\therefore$ S. Faulkner, "Electronic States in Disordered Solids." To be publ:sied in the bulletin of the Seventh Annual International Symposium on Electronic Structure of Metals and Alloys, Gaubig, East Germany, April iö-22, 1977.

C. B. Finch, F. L. Ball, and J. B. Bates, "Czochralski Growth of Single-Crystal Gehlenite $\left(\mathrm{Ca}_{2}{ }^{\wedge}{ }_{2}, \mathrm{~S}\left({ }_{0}\right)_{7}\right), "$ to be published th the proceedings of the International Conference on Crystal Growth VI, Moscow, USSR, September 10-16, 1980.

R. S. Graves, R. K. Will lams, and J. P. Moore, "The Thermal Conductivity, Electrical Resistivity and Seebeck Coefficient of SRY-735." To be published in the proceedings of the 16th International Thermal Conductivity Conference, Chicago, Illinols, November 7-9, 1979.

J. Harris and G. S. rinter, "A Localized Muffin-Tin Orbital Basis for Atomic Cluster Cals! ". "ns Within the Local Density Formal ism," accepted by Physical $R_{k}:$ b. $^{\prime}$

i. A. Harris and C. S. Yust, "Transmitted Infrared Light Microscopy: an Improved Method for Viewing Coal Thin Sections," submitted to Joumal of Microsc.spy.

L. A. Harris and C. S, Yust, "The Ultrafine Structure of Coal Determined by Electron Microscopy," to be published as chapter of book, Coal Stmucture, part of Advances in Chemistry Series.

M. R. Hayns, "A Composite Numerical Scheme for the Nucleation of Secondary Defect Aggregates," to be published as an AERE report.

M. R. Hayns and L. K. Mansur, "Applications of the Theory nf Cavity Growth to Dual Ion Swelling Experiments," to be published in the pioceedings of the ASTM Tcnth International Symposium on Ef fects of Radiation on Materials, June 3-5, 1980, Savannah, Ceorgia.

C. L. Hoentg and C. S. Yust, "Expiosive Compaction and Microstr'ccural Analysts of AlN, Amorphous $\mathrm{Si}_{3} \mathrm{~N}_{4}$, Boron, and $\mathrm{Al}_{2} \mathrm{O}_{3}$ Ceramics," submitted to Joumal of the American Ceramic Soctety. 
J. D. Holder, R. A. Hartzell, and G. W. Clark, "Eutertics of $\mathrm{LaCrO}_{3}$ and $\mathrm{YCrO}_{3}$ with $\mathrm{H}$, Mo, and $\mathrm{Cr}$, " submitted to Joumal of the American Cemamic Society.

J. D. Holder, "Preparation of High-Temperature Oxide-Metal Eutectic Composites: A Review," to be published in Advanced Pibers and Their Composites for Application at Fievated Tempermitures, AIME.

J. D. Holder, "Soret-Modified Eutectic Constitutinnal Supercooling Criterinn," submitted to Metallurgical Transactions.

J. D. Holder, "Synthesis and Electronic Applications of Oxtde-Metal Eutectic Composites," to be published in the proceedings of "Verbundwerkst of fe 1980," Konstanz, West Cermany, April 17-18, 1980, Deutsche Gesellschaft fur Meta'lkunde.

P. H. Karr, P. Predecki, R. H. Hendricks, and J. S. Lin, "Kinetics of Lamellar Thickenfing During Isothermal Crystallization of Polyoxymethylene fro:n the Melt," submitted to Journal of Macromolecular Science - Physics.

C. C. Koch, D. M. Kroeger, J. O. Scarbrough, and B. C. Giessen, "Superconductivity in Amorphous ' $T_{5} T_{9}$ ' Transition Metal Alloys $\left(T_{5}=\mathrm{Nb}\right.$, Ta; $T_{9}=R h$, Ir)," submittef to Physical Review $B$.

C. C. Koch, J. D. Scarbrough, D. M. Kroeger, and A. DasGupta, "The Effects of asld Rolling on Fluxofd Pinning in a Supecconducting Metallic Glass," submitted to Applied Physics Letters.

M. B. Lewis and K. Farrell, "Nuclear Microanalysis as a Probe of Impurity-Defect Interactions," 109th AIMF. Annual Meeting, February 24-28, 1980, to be published in the AIME symposium volume on Advanced Techniques for Microstructural Analysis.

L. K. Mansur and J. O. St legler, "Radiation Effects In Metal and Al Loys," submitted to La Recherche.

L. K. Mansur, "Ef fective Diffusion Coefflripnts of Point Defects in Impure Materials," submitted to Acta Metallurgica.

L. K. Mansur, contribution to "Correlation and Interpretation," to be Issued as draft of ASTM Recommended Practice.

L. K. Mansur and M. H. Yoo, "Toward a Comprehensive Theory of Radiation-Induced Swelling and Creep - The Point Defect Concentrations," paper presented at and to be published in a supplement to the proceedings of the Conference on Irradiation Behavior of Metallic Materlals for Past Core Components, Corsica, France, June 5-8, 1979. 
L. K. Mansur and T. C. Reiley, "Irradiation Creep by Dislocarin:2 Gl Ide Enabled by Preferred Absorption of Point Defects - Theory and Expertinent, paper to be published in the proceedings of the International Conference on Fundamental Mecianisus of Radiation-Induced Creep and Growth, Chalk River, Ontario, Sanada, May 8-10, 1979.

D. L. McElroy, R. K. Williams, F. J. Weaver, and R. S. Graves, The Physical Properties of V(Fe, Co, NI) 3 Alloys from 300 to $1000 \mathrm{~K}$," to be published in the proceedings of the 16th International Themal Conductivi: $\therefore$ If speli:e, Chicago, November 7-9, 1979.

C. J. Mcllargue, Annealing of Defects Produced by Neutron Irradiation," subritted to Intemational Metals Review.

R. A. HcKee, "Stte Blocking and Correlated Defect Hotion in Tracer and Chemical Diffusion," submitted to Physical Review Section B: Solid state.

R. A. McKee, MThermodynamics and Kinetics of Interstitial Diffusion In a Two-Component System," submirte.1 to Physical Review Section B: Solid State.

R. A. Hckee, "Diffusion in a Pure, High Vacancy Concent Crysi.⿲l," submitted to Physical Review Section B: Solid state.

F. A. Modine, E. Sonder, H. P. Unruck, C. B. Finch, and F. D. Westlusi, "Phase Transitions in RbCaF $3, "$ submitted to Physical Review Section B: solid state.

J. P. Moore, "Analysts of Apparatus with Radial Symmetry for Steady Measurements of Thermal Conductivity," submitced for publication in book titled The Compendiun on Thermcphysical Property Measurements Methods.

J. P. Hoore, R. S. Graves, and R. K. Williams, "Thermal. Transport Properties of Niobium and Some Niobium-Base Alloys from 80 to 1600 K," subaitted to High Temperatures - High Pressures.

R. E. Pawel and J. J. Campbel1, "The Interaction of Stress and Mechanical Property Effects During Oxidation of Tantalum-Base Alloys," submitted to Joumal of the Electrochemical society.

R. E. Pawel and J. I. Campbell, "The Observation of Effects of Finite Specimen Geometry on the nxi! 71 i.in Kinetics of Zircaloy-4," submitted to Joumal of the Electrochemical society.

R. E. Pawel and J. I. Camphel.I, "A Comparison of the High Temperature Oxidation Behavior of 7ircaloy-4 and Pure Z1rconium," to be published in the proceedings of the Plfth International Conference on Zirconium in the Nisclear Indust:y, Boston, August 4-7, 1980. 
J. Yetermann, R. M. Gohil, J. H. Schultz, R. H. Hendricks, and J. S. Lin, "Swall-Angle X-Ray Scattering from Polybutene-1 Filns Crystallized from a Highly Extended Melt," subaltted to Joumal of Matemials Science.

A. J. P1ndor, W. M. Temernan, B. L. Gyorffy, and G. M. Stocks, “On the Flectronic Structure of $A_{C} \mathrm{Pd}(1-C)$ Alloys," accepted by Joumal of Phy6ics P: Netal Physics.

F. J. Pinski, "Solutions to the Boltzmann Equation for Electrons in a Metal: Energy Dependence," accepted by Physical Review Section B: Solid State.

F. J. Pinsk1, P. B. Allen, and H. H. Butler, "Exotfc Pairing in Metals: Formalism and Application to $\mathrm{Vb}$ and Pd.- To be published in the proceedings of the International Conference on Superconductivity in $d$ - and f-Band Hetals, San Diego, Caïifornia, June 21-23, 1979.

F. J. PInski, W. H. Butler, and P. B. Allen, "Ideal Theral Conductivity cf $\mathrm{Pd}$ and $\mathrm{Mb}$, - to be published in the proceedings of the 16th International Thermal Conductivity Conference, Chicago, November 7-9, 1979.

T. C. Reiley, R. L. Auble, and R. H. Shannon, "Irradlation Creep Under $60 \mathrm{MeV}$ Alpha Irradiation," submitted to Journal of Muclear Materials.

J. M. Schultz, J. S. Lin, R. W. Hendricks, J. Petermann, and R. M. Coliil, "Annealing of Polypropylene Films Crystallized from a Highly Extended Melt," submitted to Joumal of Polymer Science, Polymer Physics Edition.

J. M. Schultz, J. S. Lin, R. W. Hendricks, R. R. Lagasse, and R. G. Kepler, "Temperature-Dependent Saall-Angle X-Ray Scattering from Poly (Vinylidene Fluoride)," submitted to Joumal of Applied Phyoics.

C. J. Sparks, Jr., B. S Borle, and J. B. Hastings, "X-Ray Monochromator Ceometry for Focusing $S$, nchrotron Radiation Above $10 \mathrm{keV}$," substited to Nuclear Instruments and Methods.

C. I. Spark8, Jr., "X-Ray Fluorescence MIcroprohe for Chemlcal Analys18," to be published as chapter for a book on Synchrotron Radiatinn, Ples un Publishing Corporation.

W. Specking, D. S. Easton, D. M. Kroeger, and P. A. Sanger, "Stress Ef fects In an $\mathrm{Nb}_{3} \mathrm{Sn}$ Conductor Proposed for use in the Magnet1c Fuston Energy Prugram," submitted to Advances in Cryogenio Engineering, to be published with proceedings of the International Cryogenic Materials Conference, Mad1son, Wisconsin, August 21-24, 1979. 
G. H. Stocks and B. L. Györffy, Momentum Distribution of Electrons in Concentrated Randon Alloys," to be published in Joumat of Physics $F$ : Metal Physics.

R. A. Vandermeer, J. C. Ogle, and W. G. Northcutt, Jr., "A Phenonenological Study of Shape Hewry Effect (SFE) in Polycrystaliline UraniunNiobiun Alloys," subelted to Metcllurgical Transactions A.

L. R. West, P. L. Walne, and J. Bentley, Trachelnonas Hispida Var. Coronata (Eugleno-Phyceae): III. Envelope Elemental Composition and Mine ralization," subnitted to Journal of Phycology.

C. L. White and C. T. Liu, Outward Diffusion, and External Oxidation of Thoriun in Iridiun Alloys," subeited to Acta Metallurgica.

C. L. Thite, T. R. Odon, and R. E. Clausing, "A Study of Grain Boundary Enbrittlement In Cu-3AI-1 SI Using AES, subeitted to Microstructural Seience, Vol. 8, Aerican Elsevier.

R. R. Hillians and U. D. Philbrook, The Soret Effect in Holten Ag-Te Solutions," subitted to Joumal of the Electrochemical Society.

R. K. Willians, D. H. Yarbrough, J. H. Masey, T. K. Holder, and R. S. Graves, "Experimental Detereination of the Phonon and Electron Components of the Thermal Conductivity of BCC Iron," subaitted to Journal of Applied Physics.

H. L. Yakel, "Deteraination of the Cation Site-Occupation Paraneter In a Cobalt Ferrite from Synchrotron-Radiation Diffraction Data," subitted to Joumal of Physics and Chemistry of Solids.

D. H. Yarbrough, R. K. Willians, and R. S. Graves, Transport Properties of Concentrated $\mathrm{Ag}-\mathrm{Pd}$ and $\mathrm{Cu}-\mathrm{N1}$ Alloys from 300 to $1000 \mathrm{~K}$, - to be published in proceedings of 16th Incernational Therwal Conductivity Conference, Chicago, Novenber 7-9, 1979.

C. F. Yen, H. L. Fuller, and H. K. Bowen, "Electrical Conductivity in the $\mathrm{PeO}-\mathrm{Fe}_{2} \mathrm{O}_{3}-\mathrm{Al}_{2} \mathrm{O}_{3}-\mathrm{SiO}_{2}$ System - Part I. Correlation with Phase Equilibrium in A1r," and "Part II. Electrical Condutivity of Iron Aluninosil1cate Metals," osbatted to Joumal of the Amerisan Ceramic Society.

M. H. Yos, "Slip, Twinning, and Fracture in Hexagonal Close-Packed Metals," subalted to Metal'irgical Transactions $A$. 


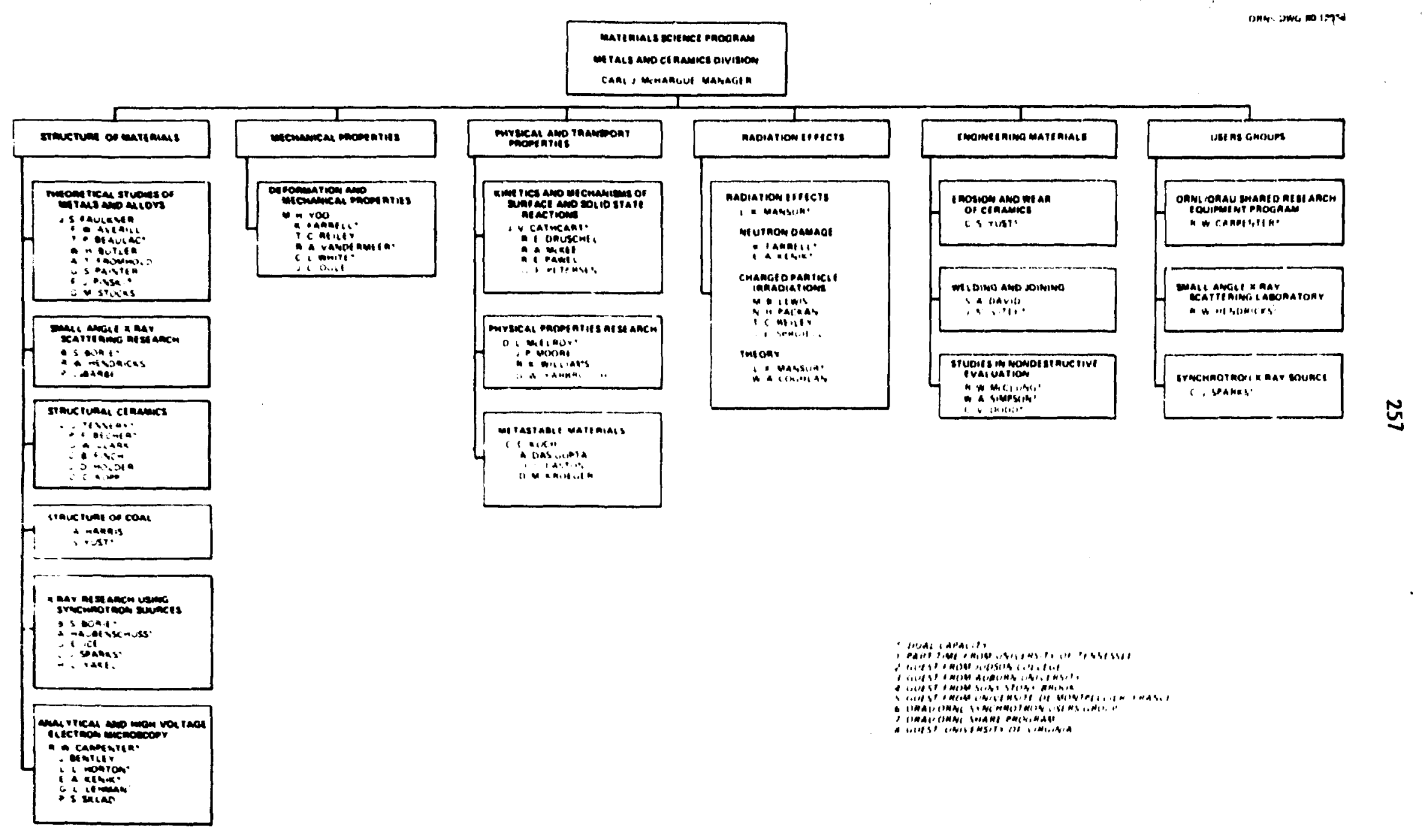

